\title{
Effect of Welding Conditions on Transformation and Properties of Heat-Affected Zones in LWR Vessel Steels
}

Manuscript Completed: November 1989

Date Published: Novemter 1990

Prepared by

C. D. Lundin, S. Mohammed

The University of Tennessec

Kroxville, TN 37916

Under Contract to:

Oak Ridge National Laboratory

Operated by Martin Marietta Energy Systems, Inc.

Oak Ridge National Laboratory

Oak Ridge, TN 37831

Prepared for

Division of Engineering

Office of Nuclear Regulatory Research

U.S. Nuclear Regulatory Commission

Washington, DC 20555

NRC FIN B0103

Under Contract No. DE-AC05-84OR21400

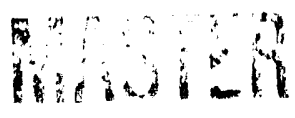


TABLE OF CONTENTS

1.IST OF TABLES

LIST OF FIGURES

$v$

ABSTRAC'T

INTRODUCTION

HISTORICAL REVIEW

EFFECTS OF HEAT TREATMENT ON WELD HEAT-AFFECTED ZONE . . . . . . . 5

WELD HEAT-AFFECTED ZONE AND ITS TOUGHNESS . . . . . . . . . . . . 7

TRANSFORMATION PRODUCTS IN WELD HEAT-AFFECTED ZONE . . . . . . . . 10

STRESS -RELIEF CRACKING OF WELD HEAT-AFFECTED ZONE . . . . . . . . 14

HYDROGEN EMBRITTLEMENT . . . . . . . . . . . . . . . . . . . . . . 17

HYDROGEN-ASSIS'TED CRACKING . . . . . . . . . . . . . . . . . . . 18

Theory of Hydrogen-Assisted Cracking . . . . . . . . . . . . 21

Prevention of Hydrogen-Assisted Cracking . . . . . . . . . . 22

Microstructural Effects on Hydrogen-Assisted Cracking . . . . 23

TRANSFORMATION BEHAVIOR . . . . . . . . . . . . . . . . . . . . 24

EXPERIMENTAL PROCEDURES . . . . . . . . . . . . . . . . . . . . . . . . 24

MATERIALS . . . . . . . . . . . . . . . . . . . . . . . . . . 24

ISOTHERMAL TRANSFORMATION BEHAVIOR . . . . . . . . . . . . . . . . 25

CONTINUOUS-COOLING TRANSFORMATION REHAVIOR . . . . . . . . . . . . . 26

Continuous - Cooling Transformation Obtained by Resistivity

Measurements . . . . . . . . . . . . . . . . . 26

Continuous-Cooling Transformation Behavior Obtained

Dilatometrically . . . . . . . . . . . . . . . . . . . 29

COLID CRACKING TESTS . . . . . . . . . . . . . . . . . . . . 32

STRESS-RELIEF CRACKING . . . . . . . . . . . . . . . . . . . . . . 35

CHARPY IMPACT TOUGHNESS OF HAZ . . . . . . . . . . . . . . . . . . 36

RESULTS AND DISCUSSION . . . . . . . . . . . . . . . . . . . . . . . . 38

ISOTHERMAL TRANSFORMATION BEHAVIOR . . . . . . . . . . . . . . . . 38

CONTINUOUS-COOLING TRANSFORMATION BEHAVIOR . . . . . . . . . . . . 45

Continuous-Cooling Transformation Behavior Obtained by

Resistivity Measurements . . . . . . . . . . . . . . . . . 48

Continuous-Cooling Transformation Behavior for the Heat-

Affected Zone Exposure Obtained by the Gleeble

Dilatometric Method . . . . . . . . . . . . . . . . . . 58

HARDENABILITY OF SA-533, GRADE B, CLASS 1, AND SA-508, CLASS 2,

STEELS . . . . . . . . . . . . . . . . . . . . . . . 72

COLI CRACKING TESTS . . . . . . . . . . . . . . . . . . . . . . . 81

Battelle Underbead Cracking Test . . . . . . . . . . . . . . 81

Results of Hydrogen Susceptibility Testing . . . . . . . . . 82

STRESS-RELIEF CRACKING . . . . . . . . . . . . . . . . . . . . . . . . . . . . . . 84

CHARPY $V$-NOTCH TOUGHNESS OF SIMULATED HEAT-AFFECTED ZONE

MICROSTRUCTURES . . . . . . . . . . . . . . . . . 92

SA-533, Grade B, Class 1.............. . . 93

SA-508, Class 2.................... 102

ENUMERATED RESULTS . . . . . . . . . . . . . . . . . . . . . . . . 111

CONCLUSIONS . . . . . . . . . . . . . . . . . . . . . . . . . . . . . . 112

ACKNOWLEDGMENTS . . . . . . . . . . . . . . . . . . . . . . 114

REFERENCES . . . . . . . . . . . . . . . . . . . . . . . 114

SELECTEL BIBLIOGRAPHY . . . . . . . . . . . . . . . . . . . . . . . . . 117 
Appendix A. HEAT TREATMENT SCHEDULES, CHARPY TOUGHNESS DATA, AND REHEAT CRACKING DATA . . . . . . . . . . . . . . . 119

Appendix B. COMPARISON OF LATERAL EXPANSIONS IN CHARPY TESTS . . . . 125

Appendix C. SI EQUIVALENTS OF UNITS USED IN THIS REPORT . . . . . . . 129 
Table 1. Chemical compositions of the materials . . . . . . . . . 5

Table 2. Minimum tensile properties of the materials at room temperature. . . . . . . . . . . . . . . . . . . . . . . . . 5

Table 3. Percentage compositions of materials SA-533, grade B, class 1 , and $\mathrm{SA}-508$, class 2. . . . . . . . . . . . . . . . 23

Table 4. Cooling rates of mácerial SA-533, grade B, class 1 , from curves a to 1 of Fig. 35 . . . . . . . . . . . . . . . . . . . . . . 50

Table 5. Cooling rates of material SA-508, class 2 , from curves a to $p$ of Fig. 39. . . . . . . . . . . . . . . . . . . . . . . . . . . . . 54

Table 6. Results of Battelle underbead cracking tests . . . . . . 82

Table 7. Results of University of Tennessee hydrogen susceptibility tests. . . . . . . . . . . . . . . . . . . . . . . . . 84

Table 8. Values obtained in stress-relief cracking test for

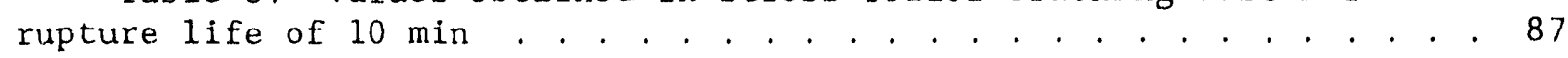

Table A.1. Schedule of salt bath heat treatment of SA-533 (3T) and SA-508 (8M) specimens. . . . . . . . . . . . . . . . . . . . . . 121

Table A.2. Thermal treatments and stresses employed in stress relief cracking test . . . . . . . . . . . . . . . . . . . . . . 121

Table A.3. Thermal treatments employed in Charpy V-notch test . . 122

Table A.4. Energy inputs as a function of plate thickness for SMAW process . . . . . . . . . . . . . . . . . . . . . . . . . 122

Table A.5. Data obtained by stress-relief cracking test . . . . 123

Table A.6. Charpy test data for SA-533 steel tested at $-25^{\circ} \mathrm{F} \cdot .123$

Table A.7. Charpy test data for SA-508 steel tested at $72^{\circ} \mathrm{F} . .124$ 


\section{LIST OF FIGURES}

Fig. 1. Schematic view of a typical large pressure vessel. . . . . 3

Fig. 2. Submerged-arc weldment hardness traverse at quarterthickness location. The region of the HAZ that is most sensitive to reheat cracks exhibits the highest hardness. . . . . . . . . . . . . . 8

Fig. 3. Charpy V-notch impact properties of alloy steel (125-ksi tensile strength) with different structures... . . . . . . . . . . . . 9

Fig. 4. Charpy V-notch impact test results for specimens from three levels in an SA-533, grade B, class 1, plate $305 \mathrm{~mm}$ (12 in.) thick. Closed dot, surface in longitudinal direction; open triangle, $1 / 4 T$ in longitudinal direction; closed diamond, $1 / 2 \mathrm{~T}$ in longitudinal direction. . . . . . . . . . . . . . . . . . . . 10

Fig. 5. Isothermal transformation diagram for A 302, grade C, steel. (The actual cooling data are superimposed on the diagram.) . . 12

Fig. 6. CCT diagram of steel "B." Composition: C 0.178, Si $0.268, \mathrm{Mn} 0.848, \mathrm{P} 0.058, \mathrm{~S} 0.068, \mathrm{Cr} 0.48, \mathrm{Ni} 0.848$, Mo 0.628 . . . 13

Fig. 7. Comparison of grain sizes in simulated (for a peak temperature of $1350^{\circ} \mathrm{C}$ ) and real heat-affected zones for the indicated cooling tines between 800 and $500^{\circ} \mathrm{C}$

Fig. 8. Partial continuous cooling transformation diagram of SA-533 steel . . . . . . . . . . . . . . . . . . . 15

Fig. 9. Hydrogen-induced cracks in HAZs of (a) fillet weld and (b) butt weld

Fi.g. 10. Solubility of hydrogen in weld metal . . . . . . . . . . 20

Fig. 11. Diffusion rate of hydrogen through ferritic steel . . . 21

Fig. 12. Isothermal transformation diagram for ASTM A 302, grade $C$, steel. (The analysis of $A 302$, grade $C$, is identical with that of A 533, grade B.) The rapid coolirg rate ru 3 r the fusion line in combination with the coarse austenite grains results in a microstructure that is predominantly martensitic . . . . . . . . . . . . . . 26

Fig. 13. Schematic representation of resistivity measurement at room temperature . . . . . . . . . . . . . . . . . . . . . . . . . . 28

Fig. 14. Schematic representation of resistivity vs temperature curves

Fig. 15. High-speed dilatometer . . . . . . . . . . . . . . 31 
Fig. 16. Schematic representation of dilation vs temperature curves

Fig. 17. Underbead cracking test specimen . . . . . . . . . . . 33

Fig. 18. Hydrogen susceptibility test specimen . . . . . . . . . 34

Fig. 19. Schematic representation of apparatus used to strain specimen . . . . . . . . . . . . . . . . . . . . . . 34

Fig. 20. Stress-relief cracking specimen used in the Gleeble. . 35

Fig. 21. Schematic representation of reheat cracking studies . . 36

Fig. 22. Details of Charpy specimen preparation . . . . . . . . 37

Fig. 23. Isothermal transformation diagram for SA-533, grade B, class 1, steel . . . . . . . . . . . . . . . . . . . . . 38

Fig. 24. Isothermal transformation diagram for SA-508, class 2, stee 1

Fig. 25. Specimen 3TOA of SA-533, grade B, class 1, stee1 (held for $1 \mathrm{~s}$ at $550^{\circ} \mathrm{F}$ ) shows fully martensitic structure. HRC 50. Super picral etch

Fig. 26. Specimen 3T1B of SA-533, grade B, class 1, steel (held for $10 \mathrm{~s}$ at $800^{\circ} \mathrm{F}$ ) shows bainitic-martensitic structure. HRC 44 . Super picral etch

Fig. 27. Specimen 3T3E of SA-533, grade B, class 1, steel (held for $1000 \mathrm{~s}$ at $1250^{\circ} \mathrm{F}$ ) shows ferritic-martensitic structure. HRC 44. Super picral etch

Fig. 28. Specimen 8MOA of SA-508, class 2, steel (held for $1 \mathrm{~s}$ at $550^{\circ} \mathrm{F}$ ) shows fully martensitic structure. HRC 52. Super picral etch

Fig. 29. Specimen $8 \mathrm{M} 2 \mathrm{~B}$ of SA-508, class 2, steel (held for $100 \mathrm{~s}$ at $800^{\circ} \mathrm{F}$ ) shows bainitic-martensitic structure. HRC 33. Super picral. etch

Fig. 30. Specimen 8M3E of SA-508, class 2, steel (held for $1000 \mathrm{~s}$ at $1250^{\circ} \mathrm{F}$ ) shows ferritic-martensitic structure. HRC 49. Super picral etch

Fig. 31. Specimen 8M4E of SA-508, class 2, steel (held for $10,000 \mathrm{~s}$ at $1250^{\circ} \mathrm{F}$ ) shows ferritic-pearlitic-martensitic structure. HRC 34. Super picral etch 
Fig. 32. Pearlitic-ferritic structure of specimen 8M4E of SA-508, class 2 , steel (held for $10,000 \mathrm{~s}$ at $1250^{\circ} \mathrm{F}$ ). Super picral etch.

Fig. 33. Comparison of isothermal transformation behavior for SA-533, grade B, class 1, steel with that for SA-508, class 2, stee1. 46

Fig. 34. Isothermal transformation diagrams for SA-533, grade B, class 1 , steel and SA-302, grade C, steel

Fig. 35. Continuous cooling transformation diagram of SA-533, grade B, class 1 , stee 1

Fig. 36. Fully martensitic structure of SA-533, grade B, class 1, steel representing curve a of Fig. 35. Cooling rate $167^{\circ} \mathrm{F} / \mathrm{s}$ at $1300^{\circ} \mathrm{F}$. Super picral etch

Fig. 37. Bainitic structure of SA-533, grade B, class 1, steel representing curve $g$ of Fig. 35. Cooling rate $4.5^{\circ} \mathrm{F} / \mathrm{s}$ at $1300^{\circ} \mathrm{F}$. Super picral etch

Fig. 38. Microstructures of SA-533, grade B, class 1, steel representing curve $k$ of Fig. 35. Cooling rate $0.09^{\circ} \mathrm{F} / \mathrm{s}$ at $1300^{\circ} \mathrm{F}$. Super picral etch. Ferritic-bainitic-pearlitic structure. (a) Optical micrograph. (b) Scanning electron micrograph . . . . . . . . . . . . 52

Fig. 39. Continuous-cooling transformation diagram of SA-508, class 2, steel . . . . . . . . . . . . . . . . . . . . . .

Fig. 40. Fully martensitic structure of SA-508, class 2, steel representing curve a of Fig. 39. Cooling rate $198^{\circ} \mathrm{F} / \mathrm{s}$ at $1300^{\circ} \mathrm{F}$.

Fig. 41. Bainitic structure of SA-508, class 2, steel representing curve $i$ of Fig. 39. Cooling rate $6^{\circ} \mathrm{F} / \mathrm{s}$ at $1300^{\circ} \mathrm{F}$. Super picral etch . . . . . . . . . . . . . . . . . . . . . 55

Fig. 42. Microstructures of SA-508, class 2, steel representing curve $p$ of Fig. 39. Cooling rate $0.018^{\circ} \mathrm{F} / \mathrm{s}$ at $1300^{\circ} \mathrm{F}$. Super picral. etch. Bainitic-pearlitic structure. (a) Optical micrograph. (b) Scanning electron micrograph

Fig. 43. Comparison of CCT behaviors for SA-533, grade B, class 1 , and SA-508, class 2, steels

Fig. 44. Continuous cooling transformation diagram of SA-533, grade $B$, class 1 , steel for a peak temperature of $1650^{\circ} \mathrm{F}$

Fig. 45. Microstructure of SA-533, grade B, class 1, stee1 corresponding to energy input of $20 \mathrm{~kJ} / \mathrm{in} ., 1650^{\circ} \mathrm{F}$ peak temperature. HRC 48. Super picral etch 
Fig. 46. Microstructure of SA-533, grade B, class 1, steel corresponding to energy input of $136 \mathrm{~kJ} / \mathrm{in} ., 500^{\circ} \mathrm{F}$ preheat, $1650^{\circ} \mathrm{F}$ peak temperature. HRC 21. Super picral etch . . . . . . . . . . . . . . . 60

Fig. 47. Continuous-cooling transformation diagram of SA-533, grade B, class 1 , steel for a peak temperature of $2400^{\circ} \mathrm{F}$. . . . . . . 61

Fig. 48. Microstructure of SA-533, grade B, class 1, steel corresponding to energy input of $50 \mathrm{~kJ} / \mathrm{in} ., 2400^{\circ} \mathrm{F}$ peak temperature.

HRC 44. Super picral etch . . . . . . . . . . . . . . . . . . . 62

Fig. 49. Microstructure of SA-533, grade B, class 1, steel corresponding to energy input of $136 \mathrm{~kJ} / \mathrm{in} ., 500^{\circ} \mathrm{F}$ preheat, $2400^{\circ} \mathrm{F}$ peak temperature. HRC 25. Super picral etch . . . . . . . . . . . . . . . 62

Fig. 50. Effect of peak temperature on continuous-cooling trans formation behavior of SA-533, grade B, class 1 , steel . . . . . . . 63

Fig. 51. Continuous-cooling transformation diagram of SA-508, class 2, steel for a peak temperature of $1650^{\circ} \mathrm{F}$. . . . . . . . . . . 64

Fig. 52. Microstructure of SA-508, class 2, steel corresponding to energy input of $32 \mathrm{~kJ} / \mathrm{in},, 1650^{\circ} \mathrm{F}$ peak temperature. HRC 44 . Super picral etch

Fig. 53. Microstructure of SA-508, class 2, steel corresponding to energy input of $136 \mathrm{~kJ} / \mathrm{in} ., 500^{\circ} \mathrm{F}$ preheat, $1650^{\circ} \mathrm{F}$ peak temperature. HRC 25. Super picral etch . . . . . . . . . . . . . . . . . . 65

Fig. 54. Continuous-cooling transformation diagram of SA-508, class 2, steel for a peak temperature of $2400^{\circ} \mathrm{F}$. . . . . . . . . . . 66

Fig. 55. Microstructure of SA-508, class 2, steel corresponding to energy input of $50 \mathrm{~kJ} / \mathrm{in} ., 2400^{\circ} \mathrm{F}$ peak temperature. HRC 47 . Super picral etch

Fig. 56. Microstructure of SA-508, class 2, steel corresponding to energy input of $136 \mathrm{~kJ} / \mathrm{in} ., 500^{\circ} \mathrm{F}$ preheat, $2400^{\circ} \mathrm{F}$ peak temperature. HRC 27. Super picral etch . . . . . . . . . . . . . . . . . 67

Fig. 57. Effect of peak temperature on continuous-cooling transformation behavior of SA-508, class 2, steel........... . 68

Fig. 58. Comparison of continuous-cooling transformation behavior of SA-533, grade B, class 1 , and SA-508, class 2, stee1s for a peak temperature of $2400^{\circ} \mathrm{F}$. . . . . . . . . . . . . . . . . . . . . . . . . . 69

Fig. 59. Comparison of continuous-cooling transformation behavior of steel "B" with that of SA-508, class 2, steel . . . . . . . . . 71 
Fig. 60. Energy input vs cooling rates for steel plates welded by the SMAW process . . . . . . . . . . . . . . . . . . . . . . . . . .

Fig. 61. Continuous-cooling transformation behavior of SA-533, grade $B$, class 1 , steel for a peak temperature of $1650^{\circ} \mathrm{F}$ (energy inputs correspond to 2 -in. steel plate)

Fig. 62. Continuous-cooling transformation behavior of SA-533, grade B, class 1 , steel for a peak temperature of $1650^{\circ} \mathrm{F}$ (energy inputs correspond to 3 -in. steel plate) . . . . . . . . . . . . . . . . . .

Fig. 63. Continuous-cooling transformation behavior of SA-533, grade $B$, class 1 , steel for a peak temperature of $2400^{\circ} \mathrm{F}$ (energy inputs correspond to 2 -in. steel plate)

Fig. 64. Continuous-cooling transformation behavior of SA-533, grade $B$, class 1 , steel for a peak temperature of $2400^{\circ} \mathrm{F}$ (energy inputs correspond to 3 -in. steel plate)

Fig. 65. Continuous-cooling transformation behavior of SA-508, class 2 , steel for a peak temperature of $1650^{\circ} \mathrm{F}$ (energy inputs correspond to 2 -in. steel plate)

Fig. 66. Continuous-cooling transformation behavior of SA-508, class 2 , steel for a peak temperature of $1650^{\circ} \mathrm{F}$ (energy inputs correspond to 3 -in. steel plate)

Fig. 67. Continuous-cooling transformation behavior of SA-508, class 2 , steel for a peak temperature of $2400^{\circ} \mathrm{F}$ (energy inputs correspond to 2 -in. steel plate)

Fig. 68. Continuous-cooling transframation behavior of SA-508, class 2, steel for a peak temperature of $2400^{\circ} \mathrm{F}$ (energy inputs correspond to 3 -in. steel plate) . . . . . . . . . . . . . . . . . . . . . 76

Fig. 69. Hardenalility curves for SA-508, class 2, and SA-533, grade B, class 1, steels . . . . . . . . . . . . . . . . . . . 7

Fig. 70. Correlation of continuous-cooling transformation and hardenability curves of SA-533, grade B, class 1 , stee $1 . . .7 . .78$

Fig. 71. Correlation of continuous-cooling transformation and hardenability curves of SA-508, class 2 , steel . . . . . . . . . . . 79

Fig. 72. Hardenability curves for SA-508, class 2, and SA-533, grade B, class 1, steels, austenitized at $2200^{\circ} \mathrm{F}$. . . . . . . . . . . 80

Fig. 73. Microstructures show underbead cracks for specimens welded at $32^{\circ} \mathrm{F}$. The top section of each micrograph is weld metal. Super picral etch. (a) SA-533, grade B, class 1, steel, (b) SA-508, class 2, steel 
Fig. 74. Macrographs of cracks observed in University of Tennessee hydrogen susceptibility test specimens. (a) SA-533 steel, (b) SA-508 steel

Fig. 75. Stress-rupture properties at $1150^{\circ} \mathrm{F}$ of simulated graincoarsened weld heat-affected zone of SA-508, class 2, and SA-533, grade B, class 1, steels . . . . . . . . . . . . . . . .

Fig. 76. Intergranular fracture behavior in stress-relief cracking test 3 , of SA-533, gxade B, class 1, steel (martensitic structure). (a) Scanning electron micrograph. (b) Metallographic section of (a) revaaling grain boundary cracks, super picral etch

Fig. 77. Intergranular fracture behavior in stress-relief cracking test 7, of SA-533, grade B, class 1, steel (bainitic structure). (a) Scanning electron mi:ro-graph. (b) Metallographic section revealing grain boundary secondary cracks below the main rupture-surface of $(a)$, super picral etch . . . . . . . . . . . . . .

Fig. 78. Intergranular fracture behavior in stress-relief cracking test 3 of SA-508, class 2 (martensitic structure).

(a) Scanning electron micrograph. (b) Metallographic section revealing grain boundary secondary cracks below the main rurture surface of (a), super picral etch. (c) Microductility observed in (a) . . . . . . . . 90

Fig. 79. Intergranular fracture behavior in stress-relief cracking test 7 of SA-508, class 2 (bainitic structure). (a) Scanning electron micrograph. (b) Metallographic section revealing grain boundary secondary cracks below the main rupture surface of (a), super picral etch

Fig. 80. Charpy $V$-notch toughness as related to different heataffected zone thermal cycles for SA-533, grade B, class 1, stee1 . . 93

Fig. 81. Microstructural behavior in SA-533, grade B, class 1, steel for Cycle II, $2400^{\circ} \mathrm{F}$ peak temperature. Super picral etch. (a) Martensitic structure, HRC 42. (b) Postweld heat treated, tempered martensitic structure, HRC 1

Fig. 82. Microstructural behavior in SA-533, grade B, class 1 , steel for Cycle VI, $2400^{\circ} \mathrm{F}$ ptak temperature. Super picral etch. (a) Bainitic structure, HRC 21. (b) Postweld heat treated, tempered bainitic structure, $\mathrm{HRB} 82$. . . . . . . . . . . . . . . . . . . .

Fig. 83. Microstructural behavior in SA-533, grade B, class 1 , steel for multiple cycles: Cycle II with $2400^{\circ} \mathrm{F}$ peak temperature fol. lowed by Cycle II with $1650^{\circ} \mathrm{F}$ peak temperature. Super picral etch. (a) Mixture of coarse and fine martensite, HRC 42. (b) Postweld heat treated, tempered martensite structure, HRC 3 
Fig. 84. Microstructural behavior in SA-533, grade B, class 1 , steel for multiple cycles: Cycle VI with $2400^{\circ} \mathrm{C}$ peak temperature followed by Cycle VI with $1650^{\circ} \mathrm{F}$ peak temperature. Super picral etch. (a) Fine bainitic structure, HRC 5. (b) Postweld heat treated, tempered bainitic structure, HRB 82 . . . . . . . . . . . . . . . . . .

Fig. 85. Microstructural behavior in SA-533, grade B, class 1 , steel for Cycle II with $2400^{\circ} \mathrm{F}$ peak temperature and 2 -h hold at $600^{\circ} \mathrm{F}$. Super picral etch. (a) Martensitic structure, HRC 39. (b) Postweld heat treated, tempered martensitic structure, HRC 6 . . . . . . . .

Fig. 86. Microstructural behavior in SA-533, grade B, class 1 , steel for Cycle VI with $2400^{\circ} \mathrm{F}$ peak temperature and $2-\mathrm{h}$ hold at $600^{\circ} \mathrm{F}$. Super picral etch. (a) Tempered bainitic structure, HRC 19. (b) Postweld heat treated, tempered bainitic structure, HRC 5

Fig. 87. Microstructural behavior in SA-533, grade B, class 1 , steel for Cycle VI with $2400^{\circ} \mathrm{F}$ peak temperature and 2 -h hold at $300^{\circ} \mathrm{F}$. Super picral etch. (a) Tempered bainitic structure, HRC 21 . (b) Postweld heat treated, tempered bainitic structure, HRC 10 . . . . . . . . 101

Fig. 88. Charpy V-notch toughness as related to different heataffected zone thermal cycles for SA-508, class 2, stee1 . . . . . . . 102

Fig. 89. Microstructural behavior in SA-508, class 2, steel for Cycle II with $2400^{\circ} \mathrm{C}$ peak temperature. Super picral etch. (a) Martensitic structure, HRC 46. (b) Postweld heat treated, tempered martensitic structure, HRC 28

Fig. 90. Microstructural behavior in SA-508, class 2, steel for Cycle VI with $2400^{\circ} \mathrm{F}$ peak temperature. Super picral etch. (a) Bainitic structure, HRC 28. (b) Postweld heat treated, tempered bainitic structure, HRC 18

Fig. 91. Microstructure behavior in SA-508, class 2, steel for multiple cycles: Cycle II with $2400^{\circ} \mathrm{F}$ peak temperature and Cycle II with $1650^{\circ} \mathrm{F}$ peak temperature. Super picral etch. (a) Mixture of coarse and fine-grained martensite, HRC 48. (b) Postweld heat treated, tempered martensitic structure, HRC 20 . . . . . . . . . . . . . . . 106

Fig. 92. Microstructural behavior in SA-508, class 2, steel for multiple cycles: Cycle VI with $2400^{\circ} \mathrm{F}$ peak temperature and Cycle VI with $1650^{\circ} \mathrm{F}$ peak temperature. Super picral etch. (a) Fine bainitic structure, HRC 26. (b) Postweld heat treated, tempered bainitic structure, HRC 13 . . . . . . . . . . . . . . . . . . 107

Fig. 93. Microstructural behavior in SA-508, class 2, steel for Cycle II with $2400^{\circ} \mathrm{F}$ peak temperature and 2 -h hold at $600^{\circ} \mathrm{F}$. Super picral etch. (a) Tempered martensitic structure, HRC 38. (b) Postweld heat treated, tempered martensitic structure, HRC 12 . . . . . . . 108 
Fig. 94. Microstructural behavior in SA-508, class 2, steel for Cycle VI with $2400^{\circ} \mathrm{F}$ peak temperature and $2-\mathrm{h}$ hold at $600^{\circ} \mathrm{F}$. Super picral etch. (a) Tempered bainitic structure, HRC 26. (b) Postweld heat treated, tempered bainitic structure, $\mathrm{HRC} 9$. . . . . . . . . . . 109

Fig. 95. Microstructural tehavior j.n SA-508, class 2, steel for Cycle II with $2400^{\circ} \mathrm{F}$ peak temperature and 2 -h hold at $300^{\circ} \mathrm{F}$. Postweld heat treated. Super picral etch. Tempercd martensitic structure, HRC 12 . . . . . . . . . . . . . . . . . . . . . 110

Fig. 96. Microstructural behavior in SA-533, grade B, class 1 , steel for Cycle VI with $2400^{\circ} \mathrm{F}$ peak temperature and $2-h$ hold at $300^{\circ} \mathrm{F}$. Postweld heat treated. Super picral etch. Tempered bainitic structure, HRC 11 . . . . . . . . . . . . . . . . . . . . . . . . . 110

Fig. B.1. Lateral expansion values for Charpy specimens of SA-533, grade B, class 1, exposed to difierent heat-affected zone thermal cycles . . . . . . . . . . . . . . . . . . . . . . . 127

Fig. B.2. Lateral expansion values for Charpy specimens of SA-508, class 2, exposed to different heat-affected zone thermal cycles . . . . . . . . . . . . . . . . . . . . . 128 


\title{
EFFECT OF WELDING CONDITIONS ON THE LOW-TEMPERATURE TRANSFORMATION AND PROPERTIES OF THE WELD HEAT-AFFECTED ZONE OF LOW-ALLOY STEELS FOR USE IN LIGHT-WATER REACTORS
}

Carl D. Lundint and Sher Mohammed

\begin{abstract}
The continuous cooling cransformation behavior (CCT) and isothermal transformation (IT) beha ior were determined for SA-508 and SA-533 materials for coiditions pertaining to standard heat treatment and for the coarse-grained region of the heataffected zone (HAZ). The resulting diagrams help to select welding conditions that produce the most favorable microconstituent for the development of optimum postweld heat treatment (PWHT) toughness levels. In the case of SA-508 and SA-533, martensite responds more favorably to PWHT than does bainite. Bainite is to be avoicled for the optimum ioughness characteristics of the HAZ. For an untempered martensitic structure, a postweld hold at ${ }^{\circ} \mathrm{C}$ $\left(600^{\circ} \mathrm{F}\right.$ ) was inj-rious to the as-welded HAZ toughness, but superior toughiness could be achieved by PWHT. Grain rerining thermal cycles do not improve toughness per se if the transformation product is untumpered bainite. The heat flow associated with and peair temperatures reached by additional passes are considered necessary for optimum HAZ toughness.
\end{abstract}

We recommend thai weld energy inut be controlled during welding of $S A-533$ and $S A-508$ to obtain a cooling rate faster than the critical cooling rate for bairite, thus forming a primarily martensitic structure. We recommend PWHT of this structure after welding to temper the martensite and optimize the HAZ behavior.

The reheat cracking tendency for both steels was evaluated by metallographic studies of simulated HAZ structures subjected to PWHT cycles and simultaneous restraint. Both SA-533, grade B, class 1, and SA-508, class 2, cracked intergranularly. The stress rupture parameter (the product of the stress for a rupture life of $10 \mathrm{~min}$ and the corresponding reduction of area) calculated for both steels showed that SA-508, class?, was more susceptible to reheat cracking than SA-533, grade $B$, class 1.

\footnotetext{
${ }^{*}$ Research sponsored by the office of Nuclear Regulatory Research, Division of Engineering Technology, U.S. Nuclear Regulatory Commission, under Interagency Agreement. DOE 1886-8010-3B with the U.S. Department of Energy under Contract DE-AC05-840R21400 with Martin Marietta Energy Systems, Irc.

tWelding Research and Ergineering, University of Tennessee, Knoxville, TN 37916.
} 
Cold cracking tests (Battelle Test and University of Tennessee modified hydrogen susceptibility test) indicated that a higher preheat temperature is required for SA-508, class 2, to avoid cracking than is required for $S A-533$, grade $B$, class 1 . Further, the Hydrogen Susceptibility Test showed that SA-508, class 2, is more susceptible to hydrogen embrittlement than is SA-533, grade B, class 1 .

\section{INTRODUCTION}

The pressure vessels used as the primary containment for light-water nuclear power plants are fabricated from thick-walled plate or forgings by welding. ${ }^{1}$ Figure 1 indicates the various components that are joined together to produce a large pressure vessel. The main course sections in Fig. 1 are constructed from plate o: forgings.

The pressure vessels used as the primary containment for light-water ruclear power plants in the United States are fabricated primarily from only two base metal compositions. Those steels are identified as SA-533, grade B, class 1 , and SA-508, class 2. (SA-503 class 1 is also employed to avoid reheat cracking.) The SA before the specification number indicates that the material has been accepted for use by the American Society of Mechanical Engineers Boiler and Pressure Vessel Code (ASME Code). A steel that is employed in the fabrication of a nuclear pressure vessel must satisfy the requirements of the SA specification, which indicate the limits on chemical composition, permissible melting and processing practices, and minimum mechanical properties, as well as other criteria that are established by the ASME Code, the Federal Register, and Nuclear Regulatory Commission (NRC) guides.

The purpose of the research reported here was to investigate the weldability of the above materials, which constitute a significant fraction of the low-alloy steels employed for heavy-section light-water-reactor fabrication. In the fabrication of the low-alloy steels used in 1 ight. water-reactor construction, control of welding energy input, preheat for welding, and, in some instances, maintenance of preheat after welding are employed to avoid some fabrication problems. Preheat is employed primarily to eliminate cold cracking in the heat-affected zone (HAZ), especially in the coarse-grained region adjacent to the weld fusion line. The weld metal is not inmune to cracking problems but, since the carbon content is low, the problem is rarely encountered.

Normally, HAZ crazking is attributed to two causes:

1. cold cracking due to hydrogen in the HAZ (picked up from the weld metal in most instances), the low-temperature transformation of austenite to martensite, and the restraint and residual stresses; and

2. reheat cracking occurring during postweld heat treatment (PWHT) for stress relief in the grain-coarsened HAZ as a result of strain accumulation and rupture of the prior austenite grain boundaries, the 


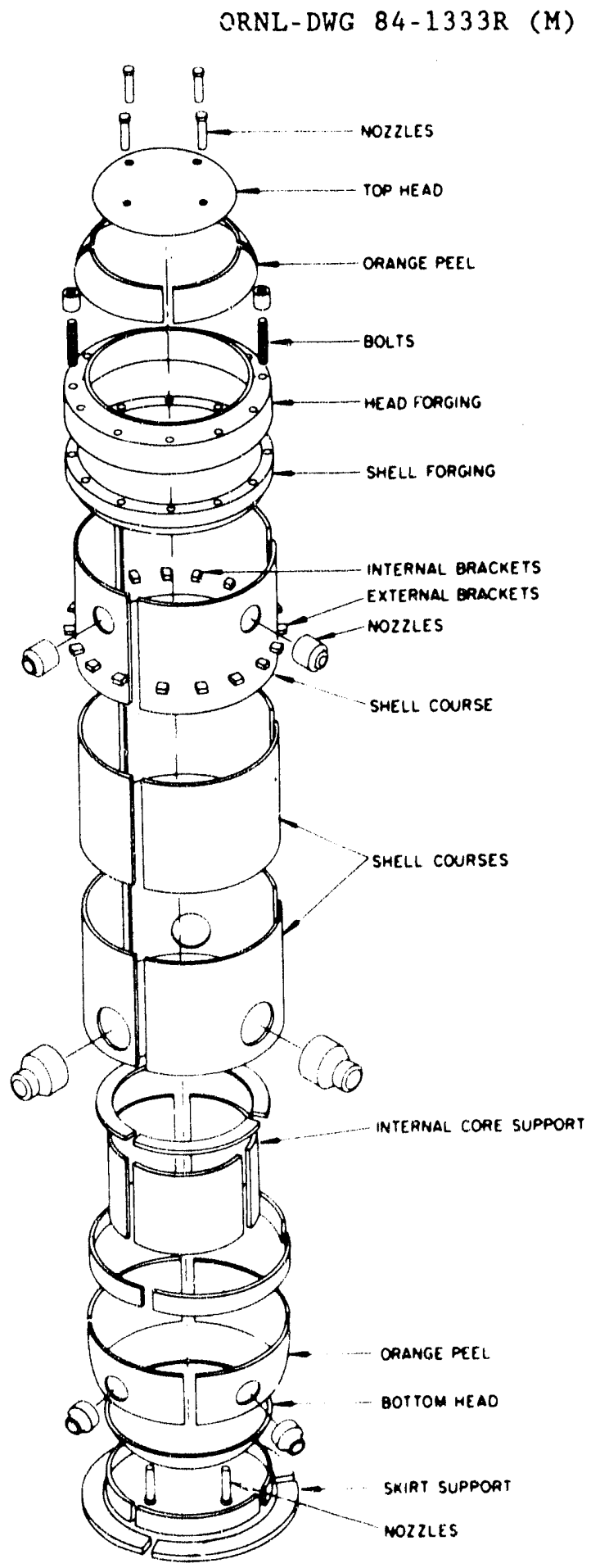

Fig. 1. Schematic view of a typical large pressure vessel. 
occurrence of which is strongly influenced by minor or residual element distribution produced at these boundaries during welding.

Development of residual stresses in heavy-section welding can be minimized only to a limited extent, so most preventive measures for cold cracking revolve around elimination of hydrogen and control of the trans. formation of austenite to martensite. To those ends, low-hydrogen welding procedures are employed. Preheating and maintenance of heating throughout welding are used to retard cooling, thus modifying the martensite transformation and permitting hydrogen to escape before transformation takes place. Those procedures are very effective, but they are costly. To conserve energy it would be desirable to minimize preheating and holding at preheat temperatures for long times, without adversely affecting product fabricability or performance. However, we do not have sufficient knowledge of the metallurgical response in the $\mathrm{HAZ}$ to determine the required procedures scientifically. The research reported here is directed toward obtaining that knowledge.

The reheat cracking tendency of a particular naterial must be addressed in terms of chemistry control or the minimization of residual stresses during welding, as PWHT must be employed to ensure HAZ toughness after welding. The application of PWHT also reduces the final stress distribution and thus is important from a fracture initiation standpoint. The occurrence of reheat cracking has been noted with the SA-508, class 2, material; the newer composition in the class 3 specifin 2 tions has less reheat cracking tendency. Susceptibility to reheat cracking can be readily determined with the Gleeble "simulated HAZ technique."

Knowledge of the transformation behavior of the HAZ is necessary to the understanding of most metallurgically related welding problems. The HAZ experiences a spectrum of temperatures from preheat to the melting temperature and, depending on the welding conditions, a conling rate, which, together with the peak temperature, controls the metallurgical. transformations. The development of the appropriate HAZ continuous-cooling transformation (CCT) diagrams has generally been neglected. However, when available, these diagrams can be utilized to choose welding condicions that will produce the desired $\mathrm{HAZ}$ microstructures and thus the appropriate properties. Development of the HAZ CCT diagrams for the two principal materials, SA-533 and SA-508, by two independent procedures is warranted.

By integrating the information on material behavior, the influence of welding preheat and transformation on the toughness of the HAZ can be as sessed. The proper preheat for elimination of cold cracking can be defined, and the potential for reheat cracking determined, by simple test procedures.

\section{HISTORICAL REVIEW}

The light-water nuclear reactor (LWR) pressure vessels have been fabricated from primarily two low-alloy, high-strength : teels. The 
quenched-and-tempered alloys are identified as SA-533, grade B, class 1 , and SA-508, class 2, in the ASME Code. The range of chemical compositions of both alloys is given in Table $1 .{ }^{2}$ Note that SA-508, class 2, has higher $\mathrm{C}, \mathrm{Ni}$, and Mo contents and also has some $\mathrm{Cr}$ and $\mathrm{V}$, whereas SA 533, grade $B$, class 1 , is higher in $\mathrm{Mn}$ content and contains no $\mathrm{Cr}$ or $\mathrm{V}$. The minimum room-temperature tensile property requirements for the SA specification of both materials are given in Table $2 .^{2}$ Both materials tend to have similar mechanical properties, except that SA-508, class 2, has a higher allowable upper limit on tensile strength and a lower minimum percentage reduction in area compared with SA-533, grade B, class 1 .

Table 1. Chemical compositions of the materials

\begin{tabular}{|c|c|c|c|c|c|c|c|}
\hline \multirow{2}{*}{ Materials } & \multicolumn{7}{|c|}{ Composition ( $(x)$} \\
\hline & $\mathrm{C}$ & $\mathrm{Mn}$ & N1 & Mo & $\mathrm{Cr}$ & S1 & $\mathrm{v}$ \\
\hline $\begin{aligned} \text { SA- } 533, \text { grade } B \\
\text { class }\end{aligned}$ & $0.25 \max$ & $1.15-1.50$ & $0.4-0.7$ & $0.45-0.60$ & - & $0.15-0.30$ & - \\
\hline SA-508, class 2 & $0.27 \max$ & $0.5-1.0$ & $0.5-1.0$ & $0.55-0.70$ & $0.25-0.45$ & $0.15-0.40$ & 0.05 \\
\hline
\end{tabular}

Table 2. Minimum tensile properties of the materials at room temperature

\begin{tabular}{lcc}
\hline & $\begin{array}{c}\text { SA-533, grade B, } \\
\text { class } 1\end{array}$ & SA-508, class 2 \\
\hline Tensile strength & $550-690$ & $550-725$ \\
MPa & $80-100$ & $80-105$ \\
ksi & & \\
Yield strength & 345 & 345 \\
MPa & 50 & 50 \\
ksi & 18 & 18 \\
Elongation, \& & 62 & 38 \\
Reduction of area, \& & & \\
\hline
\end{tabular}

EFFECTS OF HEAT TREATMENT ON WELD HEAT-AFFECTED ZONE

Most pressure vessels are made in the United States by forming flat plate into cylindrical shapes, pressing spherical heads, joining those parts by fusion welding, and incorporating forged components such as nozzles and ring forgings to produce the vessel. Several disadvantages are associated with these welding operations. ${ }^{3}$ First, the high residual stresses that develop in thick-walled vessels are undesirable from the fabrication and the service behavior standpoints. Second, local high 
hardness values and associated embrittlement in the HAZs are of concern from the corrosion standpoint and because of the risk of hydrogen cracking. The most common method of reducing these reildual stresses and high hardness levels is to carry out a heat treatment below the lower critical temperature of the material to induce piastic flow sufficient to reduce the stresses to an acceptable level and distrinution. In addition, this treatment has the metaliurgical effect of tempering the material, resulting in recovery of ductility and decreasing hardness.

In general, it has been recognized for a long time that material strengths are degraded by exposure to elevated temperatures, and consideration has been given to quantifying these effects in pressure vessel materials that undergo PWHT. This is an area many design codes tend to neglect. The advent of large nuclear-reactor and petrochemical pressure vessels has increased wall thickness and complexity, requiring the fabri. cator to adopt multiple PWHTs that often total 20 to $40 \mathrm{~h}$ or more. The requirements dictating long-time PWHT are

1. thickness of the vessels,

2. highly restrained welds at nozzles,

3. long manufacturing cycles making it unwise to leave component parts of the vessel in the as-welded condition for extended periods,

4. increased use of more complex low-alloy steels, and

5. multiple repair cycles for welds.

Because a nuclear vessel. is fabricated by welding, the entire vessel is given a final minimum PWHT for $1 \mathrm{~h}$ per inch* of thickness up to 2 in., and 15 additional minutes for each additional inch. Usually the PWHT temperature is between 595 and $620^{\circ} \mathrm{C}\left(1100\right.$ and $\left.1150^{\circ} \mathrm{F}\right)$. During fabrication, vessel components are given short-time intermediate PWHTs, and total PWHT time for some weldments may exceed $40 \mathrm{~h}$.

For low-alloy steels, even long periods of PWHS are normally beneficial to HAZ cleavage resistance in situations where precipitation hardening effects are small (e.g., with Ni-Mo, Ni-Cr-Mo, and Mn-Cr-Mo-V steels). ${ }^{3,4}$ Steels with high vanadium and copper contents, however, can give secondary hardening in the HAZ, particularly at high carbon levels, and some embrittlement may result unless the PWHT temperature is carefully chosen. ${ }^{5}$ The maximum levels of vanadium and copper that can be tolerated from the HAZ. toughness viewpoint will depend on other alloying elements present, and each steel type must be considered separately. Where secondary hardening is likely, PWHT conditions that cause overaging in the HAZ. are normally chosen to develop maximum toughness, although under-aging of high-vanadium steels at approximately $520^{\circ} \mathrm{C}\left(968^{\circ} \mathrm{F}\right)$ is occasionally practiced in Germany. Dolby concluded that PNHT generally improves HAZ

*Although the policy of the Oak Ridge National Laboratory is to report its work in SI units, customary units are used in this report, because it was written before this policy became effective. Some SI conversions are included in the text. Other SI equivalents of units used in this report are 1 isted in Appendix $C$. 
toughness of all grades unless they contain high levels of elements that are capable of causing secondary hardening. ${ }^{6}$ Even if the toughness is reduced on PWHT, critical defect sizes may be increased by the reduction of the residual stress level.

In addition to PWHT, the effect of preheat and postweld holds must be considered. Both SA-533, grade B, class 1, and SA-508, class 2, materials are designated by Section IX of the ASME Code and are treated similarly when preheat is employed for welding. Althougn preheat is not mandatory under ASME Section III, Appendix D of the code suggests $250^{\circ} \mathrm{F}$ for P3 materials over $5 / 8$ in. thick. Most fabricators find that, for material 4 to $6 \mathrm{in}$. thick and greater, $250^{\circ} \mathrm{F}$ preheat and interpass temperature is not sufficient to prevent fabrication problems; they use higher temperatures and, on occasion, maintain those temperatures throughout welding and then hold at temperature for various times after welding. In the case of nozzles (severe restraint), some fabricators customarily hold preheat until PWHT is performed (often an inordinately long time). The carbon equivalent calculations used to predict preheat requirements for SA-508, c1rss 2, and SA-533. grade B, class 1, yield approximately 0.70 (for the rich analysis), suggesting a preheat in the range of $400-700^{\circ} \mathrm{F}$.

WELD HEAT-AFFECTED ZONE AND :TS TOUGHNESS

The HAZs of welded components have long been considered of most concern for potential crack initiation and failure because many of the early failures were associated with HAZ cracks. Heat-affected zones exhibit high hardness in the low-alloy steels and, as hardness is increased, the toughness generally decreases. What is important from a structural viewpoint is not the hardness per se but the fracture toughness of the HAZ relative to that of the adjacent base material. It can be shown that this concern of HAZ brittleness is not warranted if the toughness of the HAZ is greater at any given temperature than the toughness of the base material.

Maximum embrittlement (low toughness) in the transformed HAZ is normally found in the grain-coarsened region, where peak temperatures exceed about $1200^{\circ} \mathrm{C}\left(2192^{\circ} \mathrm{F}\right)$, whereas the fine-grained transformed HAZ usually shows the highest toughness of any HAZ region. The toughness of multipass welds depends on the proportion of HAZ that is refined by successive weld passes, so it is a function of weld procedure. Dolby notes that singlepass reheated $\mathrm{HAZ}$ regions normally show lower toughness than do multipass HAZs because of the increased proportion of grain-refined structure sampled by the test specimen in the multipass case. ${ }^{6}$

The transformation in the HAZ of a low-alloy steel is determined by the maximum temperature reached and the cooling rate. ${ }^{8}$ The resultant structures have properties depending on the transformation products. The maximum value of the hardness occurs in the martensitic-bainitic microstructure of the coarse-grained region in the vicinity of the fusion boundary. A hardness traverse (Fig. 2) across an SA weldment made betwcen two 30.5-cm-thick (12-in.) plates of SA-533, grade B, class 1 , stee ${ }^{9}$ shows that the highest hardness is found in the HAZ. 


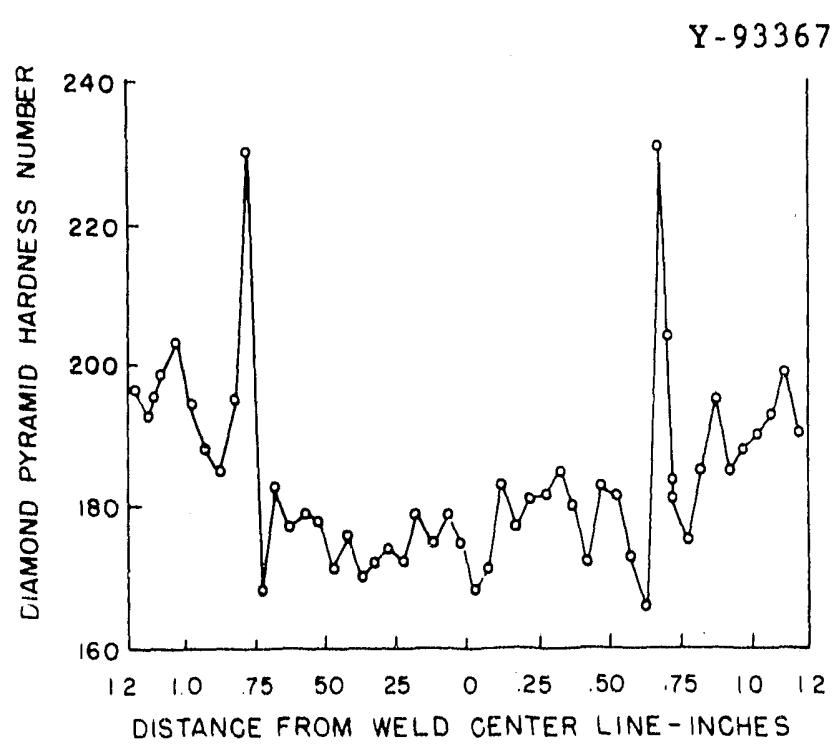

Fig. 2. Submerged-arc weldment hardness traverse at quarter-thickness location. The region of the heat-affected zone that is most sensitive to reheat cracks exhibits the highest hardness.

The HAZ of welds can possess superior tensile and toughness properties compared with their chemically equivalent base metal. ${ }^{1}$ This is particularly true for low-alloy high-strength steels that are correctly postweld heat treated. (Untempered martensite has poor toughness, but martensite that is correctly postweld heat treated has superior properties.) Figure 3 shows an example of the influence of the microstructure on the Charpy toughness of low-alloy high-strength steel. ${ }^{10}$ (This figure does not represent the microstructures in SA-533, grade B, class 1 , or SA-508, class 2, steel; it is used only to illustrate the influence of microstructure on toughness.) The structure with the best toughness is tempered martensite; the martensite plus bainite structures are less tough but still quite acceptable. The most rapid cooling rate occurs in conjunction with the coarse-grained region of the HAZ, so that this region has the lowest temperature transformation product possible for the SA-508, class 2, and SA-533, grade B, class 1, steels. Therefore, if correctly tempered, the coarse-grained region of the HAZ can indeed be superior to the remainder of the structure. If incorrectly tempered, it can have the poorer toughness. The correct tempering temperature for these steels ranges from about 621 to $677^{\circ} \mathrm{C}$ (about 1150 to $1250^{\circ} \mathrm{F}$ ).

In a similar manner, enhancement of the surface properties for thicks plates has been observed in Charpy V-notch tests. ${ }^{11,12}$ Figure 4 shows the Charpy energy curves obtained for material representing the surface, $1 / 4$ thickness $(1 / 4 \mathrm{~T})$, and midthickness locations. (The ASME Code considers only $1 / 4 \mathrm{~T}$ properties when assessing the toughness of a nuclear pressure vessel.) The superior strength and toughness properties of the surface layers are attributed to the lower temperature microstructural constituents. ${ }^{13}$ The SA-533, grade B, class 1 , steel transforms throughout its 12-in. thickness to bainite; however, the surface cools faster and 


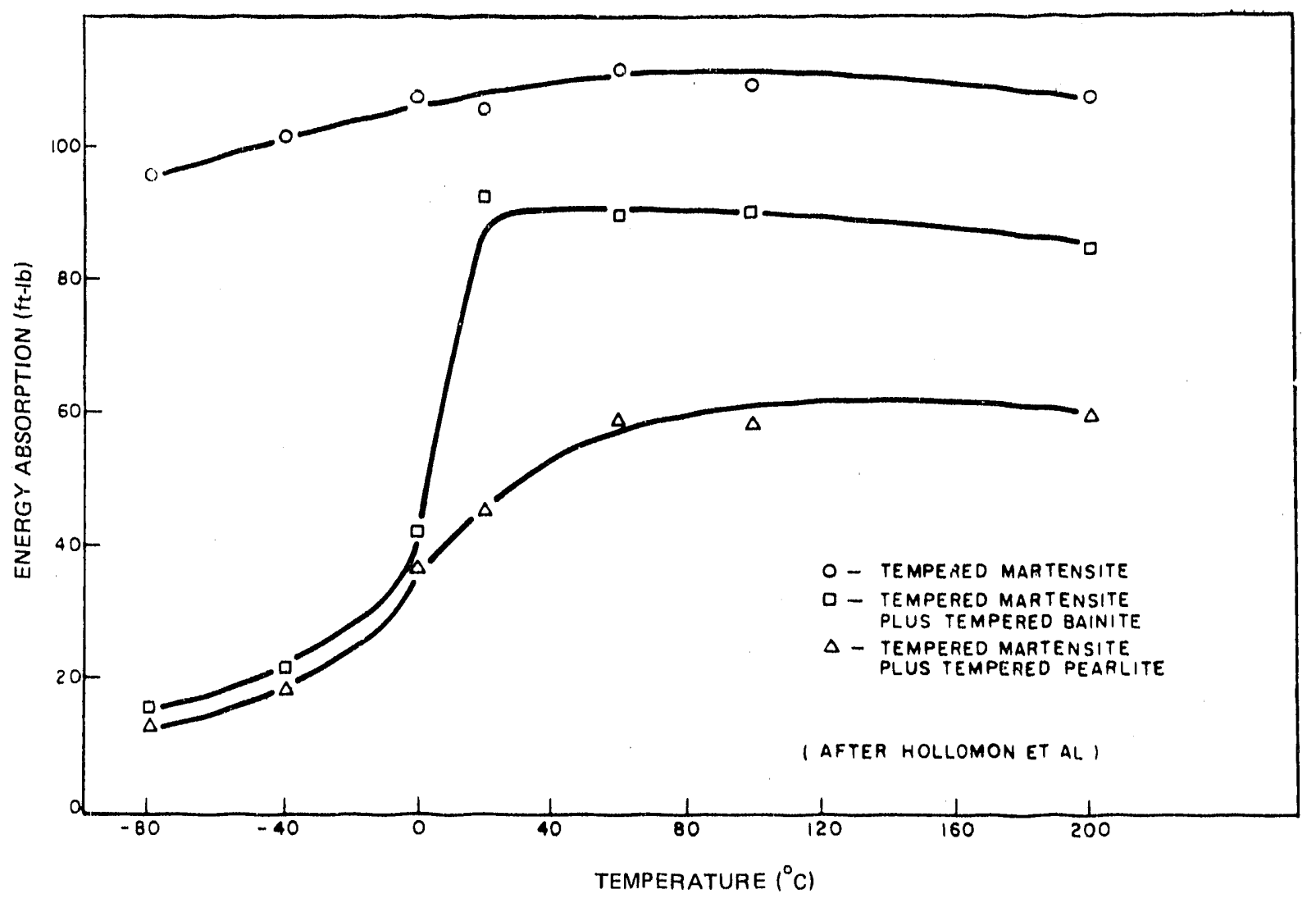

Fig. 3. Charpy V-notch impact properties of alloy steel (125-ksi tensile strength) with different structures. Source: Transactions of the ASM , 38, 839 (1947).

transforms to lower bainite. Experiments determined that the surface ccols ten times faster than the midthickness location and about eight times faster than the $1 / 4 T$ location. ${ }^{12}$ Measured values were about $2.8,0.33$, and $0.25^{\circ} \mathrm{C} / \mathrm{s}\left(5,0.6\right.$, and $\left.0.45^{\circ} \mathrm{F} / \mathrm{s}\right)$ for these locations.

Recently, Grotke et al. have simulated the HAZ microstructure of SA-508, class 2, stee1 weldments using thermal cycles representative of commercial practice [about $3.78 \mathrm{MJ} / \mathrm{m}(96 \mathrm{~J} / \mathrm{in}).] .^{14}$ They found that specimens heated to $1343^{\circ} \mathrm{C}\left(2450^{\circ} \mathrm{F}\right)$ and not tempered (postweld heat treated) had room-temperature Charpy energy values less than those of the quenched and tempered base metal. However, in all tests in which the specimens were given a multicycle thermal excursion representative of a multipass welding procedure, the Charpy toughness of the HAZ microstructure was superior to that of the base metal.

The specimen blanks obtained from the weld thermal cycle simulations were also used for precracked Charpy tests to obtain dynamic fracture toughness data for the simulated HAZ microstructure. The room-temperature dynamic fracture toughness of specimens heated to the peak temperature $1343^{\circ} \mathrm{C}\left(2475^{\circ} \mathrm{F}\right)$ was about $30 \%$ lower than that of the base metal. When the 


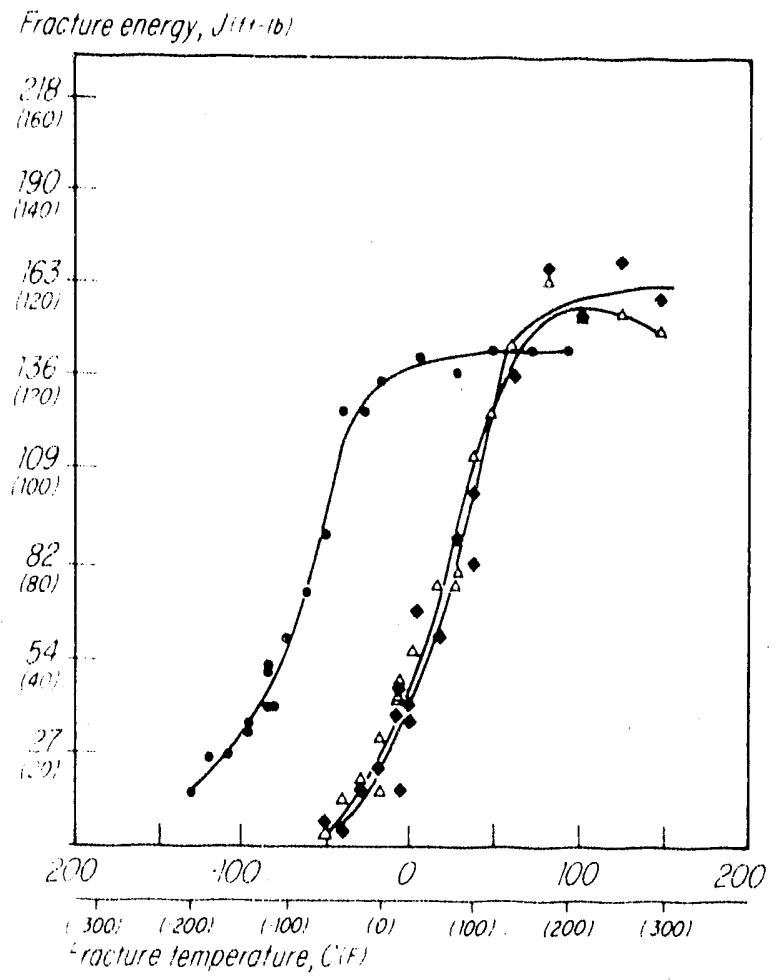

Fig. 4. Charpy V-notch impact test results for specimens fxom three levels in an SA-533, grade B, class 1, plate $305 \mathrm{~mm}$ (12 in.) thick. Closed dot, surface in longltudinal direction; open triangle, $1 / 4 T$ in longitudinal direction; closed diamond, $1 / 2 T$ in longitudinal direction. Source: D. A. Janonico, "Heavy Section Steel Technology Program (HSST)," Met. Prog. 116(2), 37-40 (July 1979).

specimens were subjected to a thermal excursion simulating that of a multi. pass welding procedure, the HAZ toughness was superior to that of the base metal. Glover mentioned in his literature survey that low toughness is found when the microconstituent exists as large blocky particles of lath martensite associated with bainitic carbides in segregated pools. ${ }^{15}$ Toughness was enhanced if the particles were fine, uniformly distributed, and in the form of higher carbon twinned martensite. Thus, in addition to the grain size, the fine microstructure effects also are important.

\section{TRANSFORMATION PRODUCTS IN WELD HEAT-AFFECTED ZONE}

To understand the transformation in the weld HAZ, it would be beneficial to correlate the transformation phenomena occurring during continuous 
cooling with isothermal data. The fundamental character of the isothermal diagram and its importance in understanding the heat treatment of steel are fully recognized. This diagram can, however, be quantitatively applied only when austenite is made to transform at substantially constant temperature. Davenport ${ }^{16}$ has pointed out the need for correlating the transformation phenomena during continuous cooling with isothermal data and has outlined the principles of a "cooling transformation diagram."

The isothermal diagram shows the fundamental transformation behavior of austenite at constart temperature; however, most actual heat treatments involve transformation as it occurs during cooling through a range of temperatures. The isothermal diagram is not, therefore, directly applicable to cooling transformation, but it can be used if the relationship between the two types of transformation can be established.

A cooling transformation diagram analogous to the isothermal diagram can be derived from isothermal data or determined experimentally. ${ }^{17}$ It lies below and to the right of the corresponding isothermal diagram. The amount of the displacement, in general, increases with more rapid cooling up tc the rate that just produces, on cooling to room temperature, a fully martensitic structure.

The derived relationship ${ }^{17}$ between transformation on cooling and isothermal transformation may be employed to advantage in actual heat treatments provided the cooling history is known; it may also be used for determining the rate of cooling necessary to achieve a desired final transforllation product and combination of mechanical properties. The transformation during hardening, welding, or heat treating by any method of controlled cooling can be predicted from the isothermal and the continuous cooling diagrams, which aid in understanding and designing such heat treatments.

The properties of welds in low-alloy high-strength steels depend on the microstructures and compositions of the welds. Therefore, the rate at which welds cool and transform from austenite after freezing exerts a strong influence on their properties. Since the cooling rates depend on the conditions of welding, an understanding of the interaction of welding, parameters on the cooling characteristics of weld metal is essential if reliable weldments are to be produced. ${ }^{18}$

An isothermal transformation (IT) diagram ${ }^{12}$ representative of SA-533, grade $B$, class 1 , steel is shown in Fig. 5. Lukens Steel Company provided this diagram of A 302, grade C, steel, which is quite similar to SA-533, grade $B$, steel. The diagram contains a bainitic shelf, and the proeutectoid ferrite transformation is retarded.

The cooling rates superimposed (for approximation only) on the IT diagram imply that, at the surface and $1 / 12 \mathrm{~T}$ locations, the structure does not contain any proeutectoid ferrite. The $1 / 4 T$ and $1 / 2 T$ locations may contain approximately 15 and 258 primary ferrite, respectively. However, it must be noted that ASTM A 533, grade B, is enriched in C, Mn, Mo, and $\mathrm{Ni}$ as compared with $\mathrm{A} 302$, grade $\mathrm{C}$. If those factors (i.e., an I'l' diagram instead of a CCT diagam and an enriched chemical analysis) were 


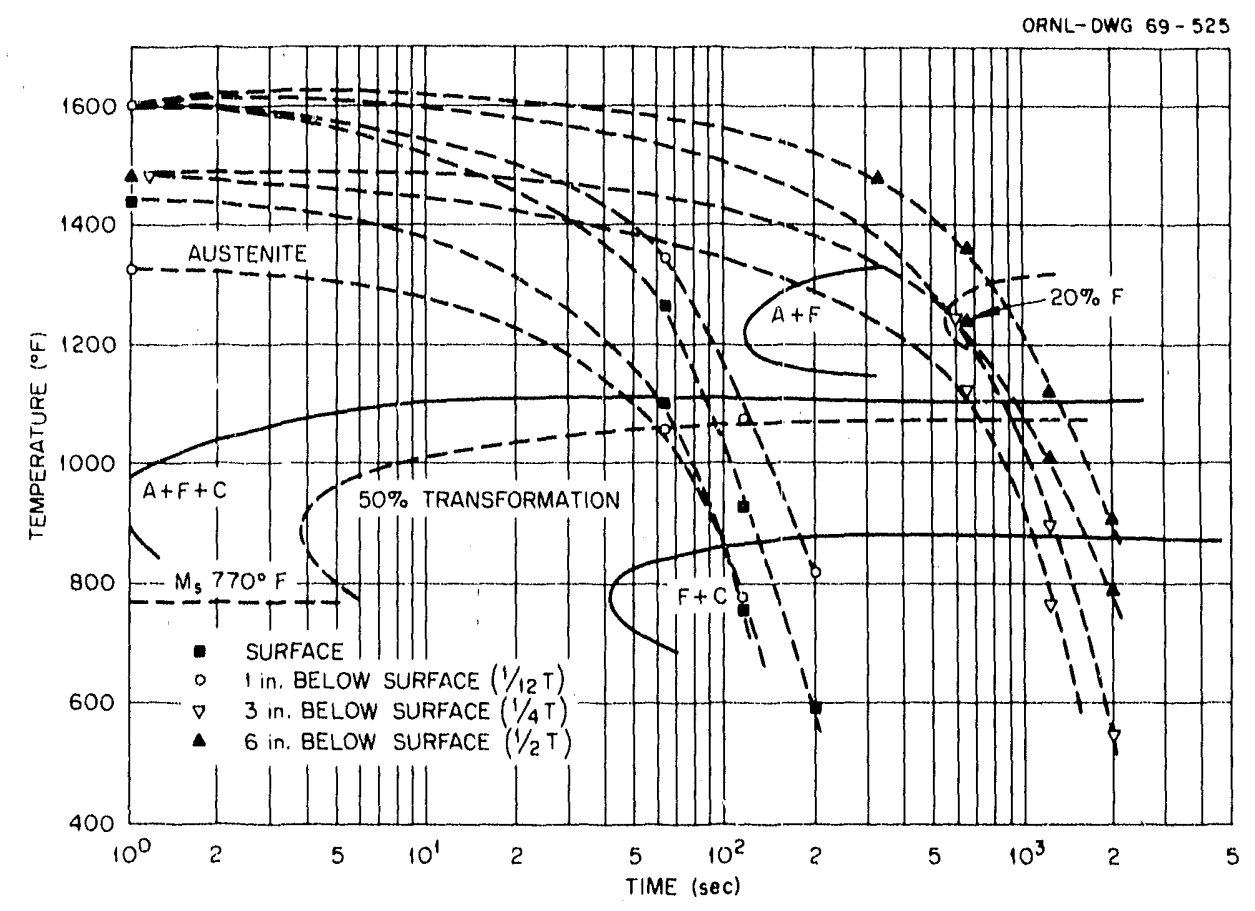

Fig. 5. Isothermal transformation diagram for A 302 , grade $C$, steel.. (The actual cooling data are superimposed on the diagram.)

taken into consideration, the IT diagram in Fig. 5 would be expected to be transposed to the right and downward. Hence, the absence of proeutectoid ferrite in 12-in.-thick SA-533, grade B, can be explained.

A CCT diagram by Fuji Maki ${ }^{19}$ for a steel "B" is shown in Fig. 6. This steel is similar in compositions to SA-508, class 2, steel except that it is lower in carbon. The critical cooling rate for martensite formation is approximately $74^{\circ} \mathrm{C} / \mathrm{s}$, and the critical cooling rate for bainite formation without ferrite decomposition (bainite + martensite) is $11^{\circ} \mathrm{C} / \mathrm{s}$. All the steels tested by Fuji Maki showed bainitic structures accompanied by proeutectoid ferrite for the range of practical cooling rates, ${ }^{19}$ and, therefore, it was reasoned that it would be very difficult to generate martensite in any conmercial treatment.

Klumpes discussed the peak temperature cooling time (PTCT) diagrams of SA-508, class 2, and SA-533, grade B, class 1., and compared real and simulated HAZs. ${ }^{20}$ In order to construct the PTCT diagram for the steels, he performed several thermal cycles with peak temperatures of 1350,1250 , 1150,1050 , and $900^{\circ} \mathrm{C}$ and cooling times between 800 and $500^{\circ} \mathrm{C}$ of $5,12,24$, 48,96 , and $480 \mathrm{~s}$ (giving cooling rates of $60,25,12.5,6.25,3$, and $\left.0.62^{\circ} \mathrm{C} / \mathrm{s}\right)$.

The PTCT diagram for SA-508, class 2, showed that shielded metal arc welding (SMAW) with a cooling rate of about $50^{\circ} \mathrm{C} / \mathrm{s}$ yields a martensitic 


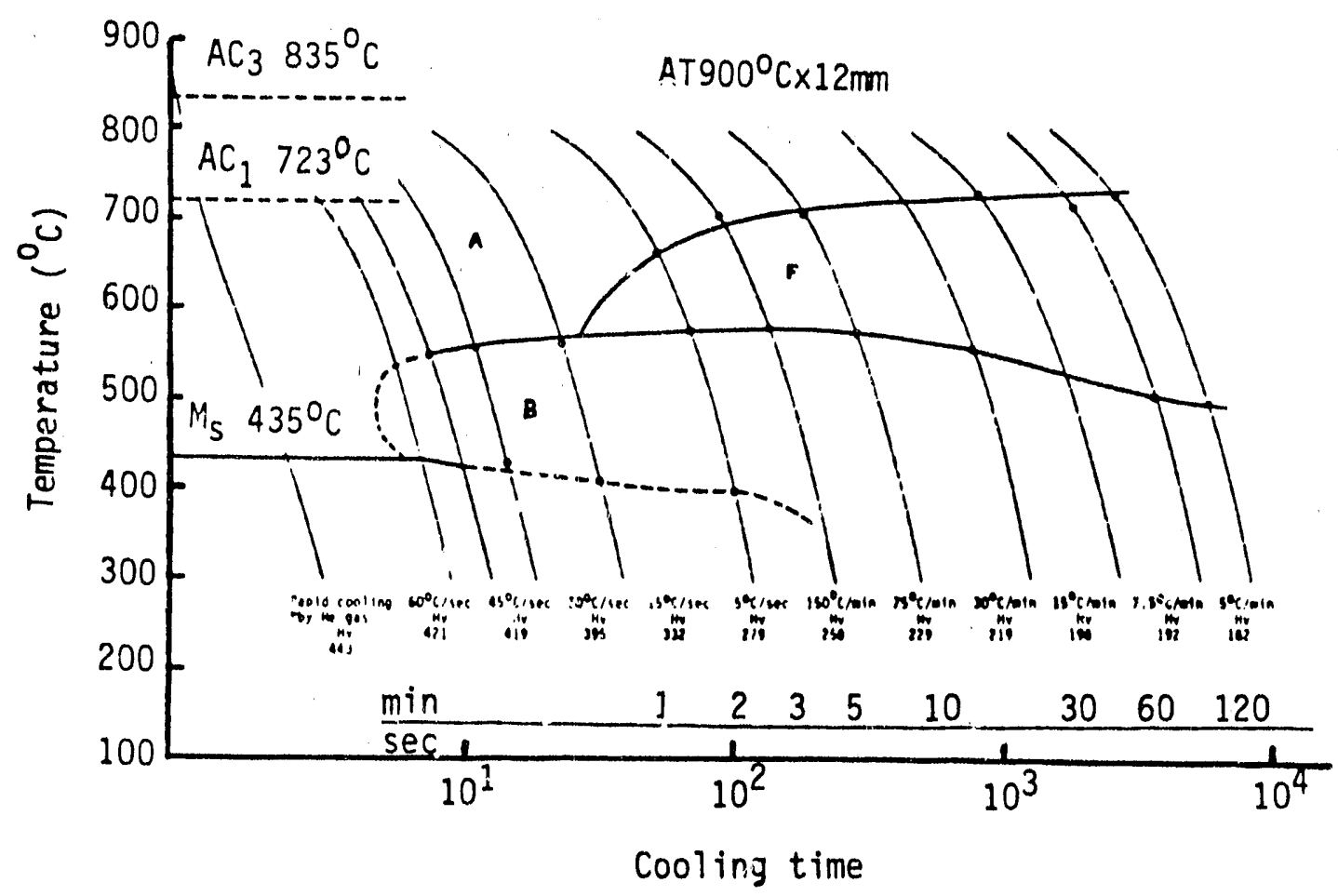

Fig. 6. CCT diagram of steel "B." Composition: C 0.178 , Si 0.268 , Mn $0.848, \mathrm{P} 0.058$, S 0.068 , Cr 0.48 , Ni 0.848 , Mo 0.628 . Source: H. Fuji Maki et al., "Development and Manufacturing of Steel Forgings of ASTM-A508 Class 2 for Nuclear-Reactor Pressure Vessels," pp. 21-35 in Nippon Steel Technical Report 7, November 1975.

structure in the HAZ with hardness between 450 and $500 \mathrm{HV} 30$. Submerged arc welding (SAW) with preheat, with a cooling rate of about $11^{\circ} \mathrm{C} / \mathrm{s}$, gives a martensitic-bainitic structure with hardnesses varying between 290 and $350 \mathrm{HV} 30$. Electroslag welding (cuoling rate about $0.6^{\circ} \mathrm{C} / \mathrm{s}$ ) gives a bainite-ferrite structure with a hardness of 225 HV 30.

Cooling time between 800 and $500^{\circ} \mathrm{C}$ of $12 \mathrm{~s}$ (i.e., cooling rate $25^{\circ} \mathrm{C} / \mathrm{s}$ ) gave the best toughness. Faster cooling rates deteriorated the coughness because of the increased amount of martensite in the structure. Slower cooling rates deteriorated the toughness because of grain growth. Afte PWHT, the toughness of test specimens subjected to thermal cycles with faster cooling rates (cooling time less than $12 \mathrm{~s}$ ) and peak temperature of $1350^{\circ} \mathrm{C}$ is deteriorated further. For the slower cooling rate, the same heat treatment gives a recovery of the toughness properties.

In the PTCT diagram of SA-533, grade B, class 1, for different cooling rates between 800 and $500^{\circ} \mathrm{C}$, the hardnesses obtained were somewhat higher than those of SA-508, class 2. The depth of hardening in SA-533, grade B, class 1, exceeds that in SA-508, class 2. 
In the as-welded condition, the Charpy- $V$ transition temperature for material subjected to thermal cycles with peak temperatures of $1350^{\circ} \mathrm{C}$ is the lowest for cooling rates faster than $60^{\circ} \mathrm{C} / \mathrm{s}$ (a ful' $\mathrm{y}$ martensitic structure). For these cooling rates, a heat treatment of $6 \mathrm{~h}$ at $610^{\circ} \mathrm{C}$ deteriorates the toughness. For a slower cooling rate, the same heat treatment has a very beneficial effect on the transition temperature, especially when compared with SA-j08, class 2.

For comparison of real and simulated HAZ microstructure, Klumpes considered grain dimensions and hardnesses. ${ }^{20}$ His comparison of grain sizes between real and simulated $\mathrm{HAZ}$ for peak temperature of $1350^{\circ} \mathrm{C}$ is given in Fig. 7(a) for SA-508, class 2, and in Fig. 7(b) for SA-533, grade B, class 1 . The major cause of the difference in grain sizes is the steep temperature gradient occurring in real HAZ, which hampers grain growth, whereas in simulated test specimens the grain growth is greater because of the relatively large volume of metal at the same temperature (i.e., less temperature gradient). The hardnesses in real HAZ appear to be 30 to 40 HV30 higher than in the simulated HAZ for steel SA-508, class 2 . Steel SA-533, grade B, class 1, gives a better agreement, but some hardnesses in the real HAZ are higher than in the simulated ones. The differences in hardness correlate with grain sizes.

Klumpes finally concluded that a PTCT diagram provides a good evaluation of HAZ, especially on predicting changes that occur by changing welding parameters. ${ }^{20}$

The effect of preheat on transformations other than the effect on cooling rate is not obvious from CCT diagrams, especially since only incomplete diagrams are available. The partial CCT diagram shown in Fig. 8 for SA-533 material does indicate that the transformations to bainite and martensite are the most important considerations, but the diagram does not extend to the faster cooling rate characteristic of weld HAZs in heavy plate. In this diagram, the bainite finish temperature agrees closely with a calculated Martensite start $\left(M_{S}\right)$ temperature of $680^{\circ} \mathrm{F}$, and the extension of this bainite finish 1 ine would be expected to be approximately $M_{S}$. A calculated value for the Martensite finish $\left(M_{f}\right)$ (908) would lie approximately $100^{\circ} \mathrm{F}$ below the $M_{S}$, and the $M_{f}(998)$ would be approximately $200^{\circ} \mathrm{F}$ below the $M_{S}$. From these values, one would predict that the transformation from austenite to bainite and/or martensite would be complete at the preheat temperatures, and the sole effect of preheat would be to drive off hydrogen. However, the coarse-grained HAZ may transform differently from what the continuous cooling curve suggests for lower austenitizing temperatures. Further, subsequent thermal cycles may reaustenitize the $\mathrm{HAZ}$ or cause any remaining austenite to transform at higher temperatures to bainite or, alternatively, may stabilize the austenite and retard its transformation even at preheat temperature.

\section{STRESS-RELIEF CRACKING OF WELD HEAT-AFFECTED ZONE}

The term stress-relief cracking is associated with the stress-relief heat treatment of welded components. Stress-relief heat treatment (PWHT) 


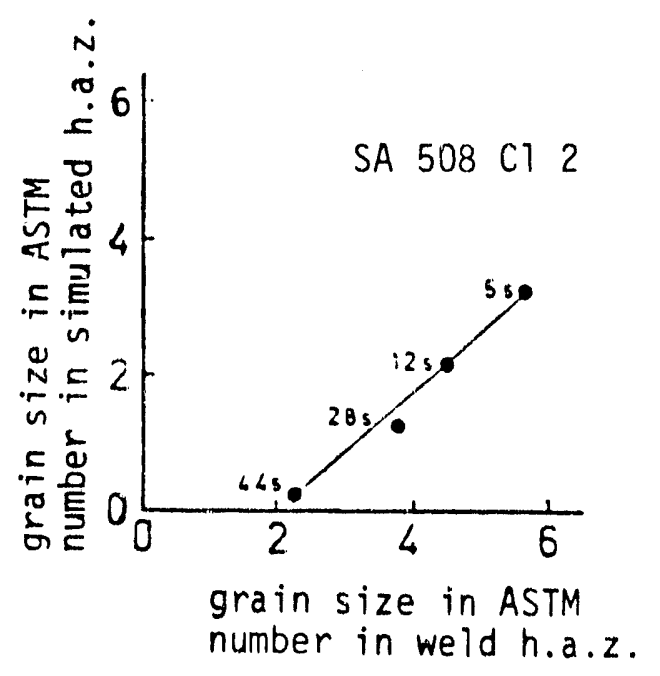

(a)

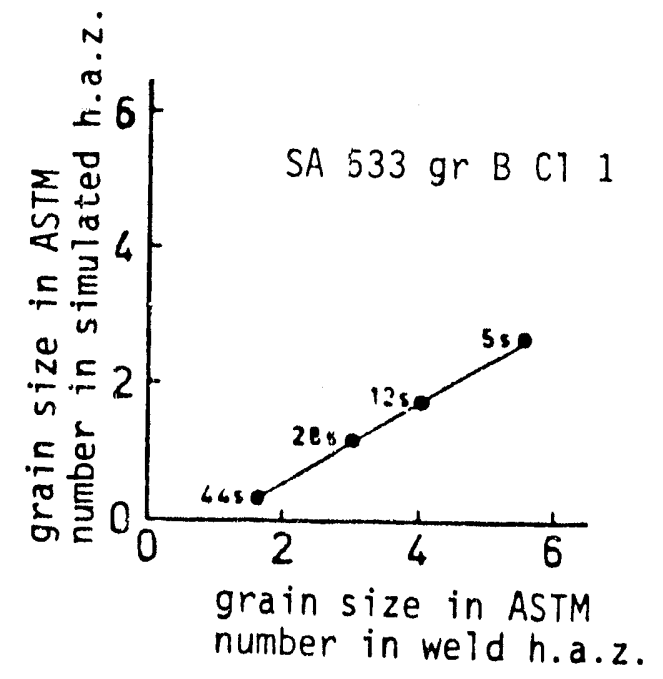

(b)

Fig. 7. Comparison of grain sizes in simulated (for a peak temperature of $1350^{\circ} \mathrm{C}$ ) and real heat-affected zones for the indicated cooling times between 800 and $500^{\circ} \mathrm{C}$. Source: H. Kiumps, "Peak Temperature Cooling Tiro Dlagram of Pressure Vessel Steels ASIIE SA 508 C1 2 and SA 533 Gr B C1 1," pp. 23-24 in tiDVS Berichie No. 32, Proceedings, 2nd International Colloquium on Welding in Nuclear Engineering, Dusseldorf, October 1974.

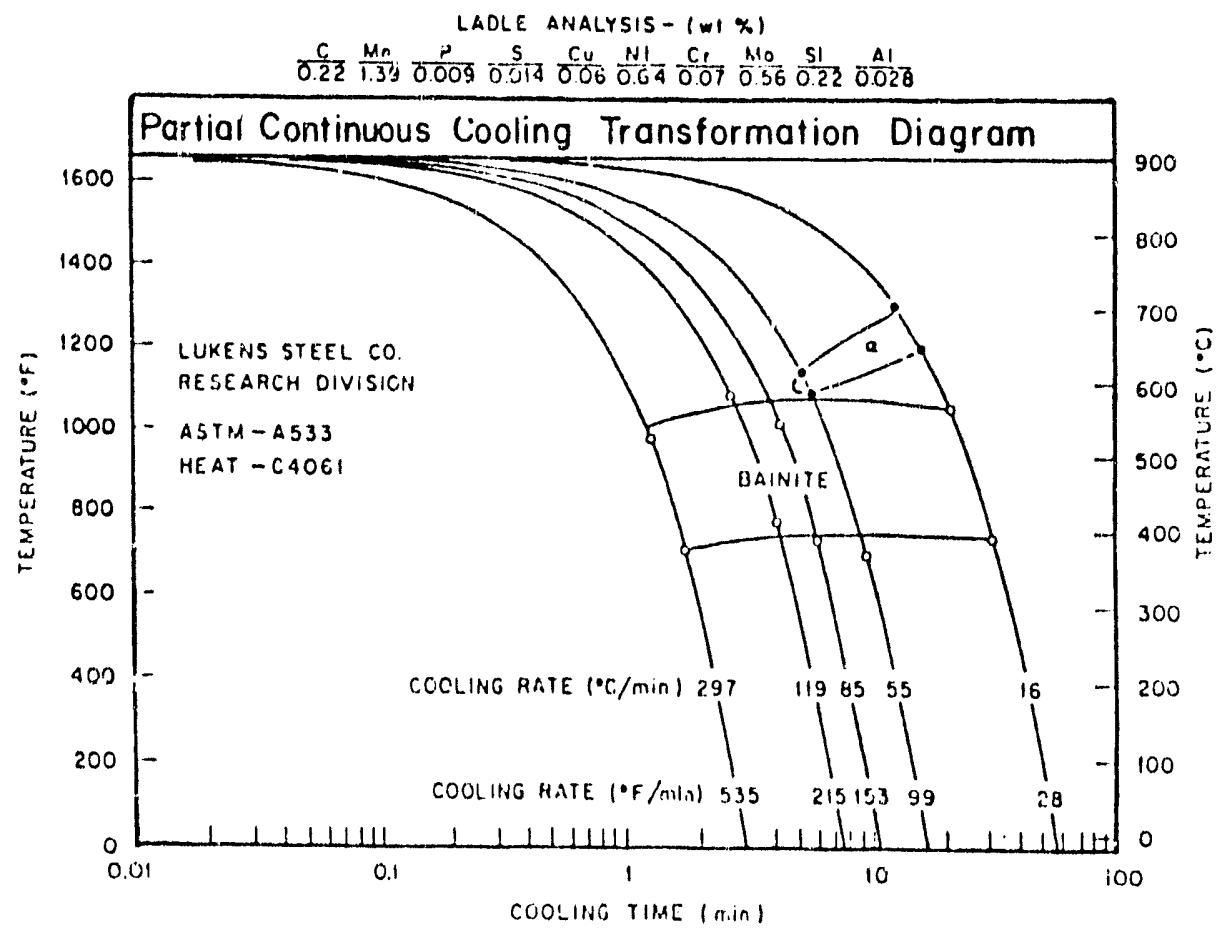

Fig. 8. Partial continuous-cooling transformation diagram of SA-533 steel. Source: University of Tennessee. 
is usually applied to the welded structure to reduce the residual stresses that formed in the weldment when it cooled to room temperature. The residual stresses are relieved by plastic flow and creep processes. ${ }^{21}$ Materials containing carbide-forming alloy elements often exhibit precipitation of the alloy carbides within the grains of the weld HAZ during stress-relief heat treatment (PWHT) and serve to strengthen the matrix relative to the grain boundary. The creep strain necessary to relieve the residual stresses is forced into the weakened grain boundary region, and, consequently, extensive grain boundary deformation may induce cracks in the HAZ. Thus, this type of cracking has often been called stress-relief cracking $(\mathrm{SRC})$.

Investigations ${ }^{22-24}$ have shown that the cracking is primarily intergranular in nature and confined to the grain-coarsened HAZ. The typical microstructural features that accompany and promote cracking are fine carbides precipitated within the grains of the HAZ in combination with a denuded or weakened grain boundary region. The creep strain normally accompany:ing thermal stress relief is forced into the weakened grain boundary region, and the resulting extensive grain boundary deformation, usually accommodated by grain boundary sliding, produces intergranular cracks. The presence of grain boundary carbides often observed in the susceptible steels further restricts the amount of grain boundary deformation that can be accommodated without cracking. The weld HAZ is particularly susceptible to cracking because it has undergone a hightemperature thermal cycle that serves to redissolve many carbides, and subsequent reprecipitation may occur during thermal stress relief.

Detert ${ }^{25}$ and Lorenz ${ }^{26}$ concluded that heating alloy steels to tenteratures above $1250^{\circ} \mathrm{C}\left(2300^{\circ} \mathrm{F}\right)$ brings the alloy carbides into solution so that enhanced grain growth occurs. After rapid cooling, the interior of the coarse austenitic grains transforms intc a hardened martensitic structure. During subsequent reheating, such as in a creep test or during a postweld treatment for stress relief, the carbide-forming elements such as $\mathrm{Cr}$, Mo, and $V$ precipitate in the form of submicroscopic alloy carbides that stabilize the hardened martensitic structure. Simultaneously, at the site of former austenitic grain boundaries, coarse precipitates are formed.

Bertram and Banga indicated that the extent of the low creep ductility of the coarse-grained structure of a HAZ varies from steel to steel. ${ }^{25}$ It depends on the amount of alloying and on the alloy elements. Creep ductility measured in the coarse-grained region of $\mathrm{SA}-533$ steel was at least 18 . Creep ductility of the same microstructure of SA-508, class 2, steel was neasured as low as a few tenths of a percent in certain heats. This may indeed be the reason why underclad cracking occurs more often in SA-508, class 2 , steel.

The tendency toward SRC increases with the degree of mechanical constraint imposed on the weld region, and it has recently been shown that the SRC tendency is related to the purity of the steel. ${ }^{27}$ In a study of the $\mathrm{Mn}-\mathrm{Mo}-\mathrm{Ni}$ pressure vessel steels of the SA-533, grade B, type, Brear and $\mathrm{King}^{2 B}$ showed that a high-purity heat (prepared by vacuum induction melting) was not susceptible to SRC. They reported that the cracking 
tendency increased with the value of the following impurity parameter (where the symbols in parentheses represent the weight percentages):

$$
0.20(\mathrm{Cu})+0.44(\mathrm{~S})+1.0(\mathrm{P})+1.8(\mathrm{As})+1.0(\mathrm{Sn})+2.7(\mathrm{Sb}) .
$$

This parameter was obtained from experiments on laboratory heats of fixed base composition in which the impurity contents were systematically varied.

H. Nakamura ${ }^{49}$ established an equation, based on extensive tests with low-alloy high-strength structural steels, that predicts crack sensitivity on the basis of the main alloying elements:

$$
\Delta G=8 \mathrm{Cr}+3.3(8 \mathrm{Mo})+8.1(8 \mathrm{~V})-2 .
$$

A positive $\Delta G$ value indicates that a steel is sensitive to reheat cracking. Another formula, ${ }^{27}$ which appears to be insufficiently rigorous for low vanadium contents $(0.058)$, is

$$
P_{S R}=(8 \mathrm{Cr})+2(8 \mathrm{Mo})+10(8 \mathrm{~V})+7(8 \mathrm{Nb})+(8 \mathrm{Ti})-2 .
$$

Both formulas, which were derived from an extensive series of welding tests, have the same limit value of 2.0 ; that is, they contain the severity of the testing procedure as a parameter. Nevertheless, the Nakamura formula has proven useful as a tool for selecting steels for welding.

Applying Nakamura's equation to nominal compositions for SA-533, grade $\mathrm{B}$, class 1 , steel $(0.218 \mathrm{C}, 0.178 \mathrm{Cr}, 0.478 \mathrm{Mo}, 0.488 \mathrm{Ni})$ and SA-508, class 2, steel $(0.268 \mathrm{C}, 0.758 \mathrm{Mn}, 0.458 \mathrm{Cr}, 0.618 \mathrm{Mo}, 0.818 \mathrm{Ni}$, and $0.058 \mathrm{~V}$ ) provides $\Delta G$ values of -0.27 and +0.86 , respectively, ${ }^{1}$ which agrees with the work of Lorenz ${ }^{26}$ and McMahon ${ }^{27}$ that SA-508, class 2, steel is considerably more sensitive to reheat cracking than is SA-533, grade B, class 1 .

Liljestrand and his colleagues ${ }^{29}$ extensively studied the formation of microcracks during stress-relief annealing of a weldment in SA-508, class 2. They concluded that the coarse-grained HAZ has very low ductili.ty at elevate ' temperatures and that cracks form in the primary grain boundaries at small strains. Also, there was nothing to indicate that the presence of impurities in the material is the primary cause of the low ductility. They also found that the high-temperature strength of the structure enables relaxation to occur to some extent by grain boundary sliding and, hence, crack formation.

\section{HYDROGEN EMBRITTLEMENT}

Hydrogen embrittlement is another phenomenon of possible concern in vessel steels. ${ }^{30}$ The potential source of hydrogen is release by a corrosion reaction in the water environment. A critical appraisal of the applicable information indicates that this is not a significant problem for low-alloy steel vessel materials. ${ }^{30}$ The maximum probable concentration 
of corrosion-produced hydrogen appears to be an order of magnitude less than that required to produce measurable embrittlement in these steels. It is known that cold working can increase sensitivity to hydrogen embrittlement, and this sensitivity would be of potential concern in the locally deformed region resilting from warm prestressing.

The literature review revealed that, although certain phenomena in regard to the weldability and HAZ cracking problems of SA-508 and SA-533 have been studied, the information is insufficient for prediction of the transformations and thus the properties of the HAZs and their response to welding-imposed residual stresses and to service stresses.

\section{HYDROGEN-ASSISTED CRACKING}

Hydrogen-assisted cracking is not confined to welding but may occur in steel during manufacturing, fabrication, or service. When cracking occurs as the result of welding, the cracks are situated in the HAZ, in the base metal, or in the weld metal itself. Cracks in the HAZ are usualiy situated at the weld toe, at the weld root, or in the underbead position, as showr schematically in Fig. 9 for fillet welds and butt welds. The HAZ cracks in fillet welds usually are oriented along the weld, but in butt welds subsurface cracks can be transverse to the weld. Intergranular, quasicleavage, and microvoid coalescence fracture modes all have been observed in hydrogen cracks. Beachem ${ }^{31}$ has shown that the operating fracture mode depends on microstructure, the crack-tip stress intensity, and the concentration of hydrogen.

As outlined by Coe, ${ }^{32}$ hydrogen-assisted cracking occurs when the following four conditions occur simultaneously:

1. Hydrogen is present.

2. Tensile stress is acting on the weld.

3. A susceptible HAZ microstructure is present.

4. A low temperature is reached.

Hydrogen is absorbed by the weld metal from the arc during welding. Although much of the hydrogen may escape during cooling, some may diffuse into the HAZ and the base metal. The amount diffused depends on the initial amount absorbed, size of the weld, and decreasing solubility (Fig. 10). Hydrogen is dissociated into atomic hydrogen $\left(\mathrm{H}^{+}\right)$in the weld arc and is dissolved in the metal as an interstitial constituent or as recombined hydrogen gas located in traps. The interstitial solubility of hydrogen in molten steel is governed by Sievert's Law ${ }^{33}$

$$
8 \mathrm{H}=K \quad P_{\mathrm{H}_{2}}
$$

where $8 \mathrm{H}$ is the percent of the hydrogen dissolved in the molten steel, $K$ is a constant, and $P_{\mathrm{H}_{2}}$ is the partial pressure of hydrogen in the atmosphere above the molten steel. In steel, hydrogen may also be trapped at grain 


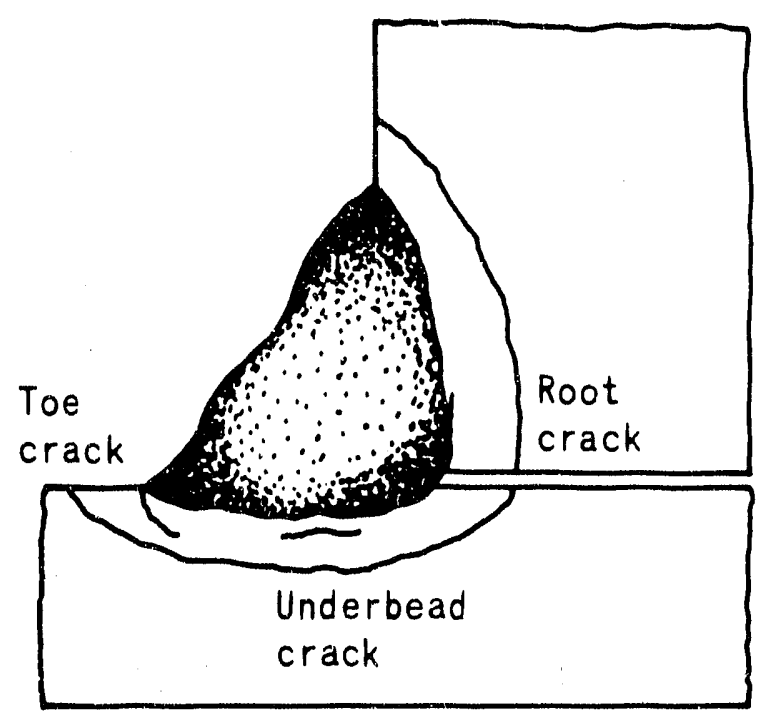

(a)

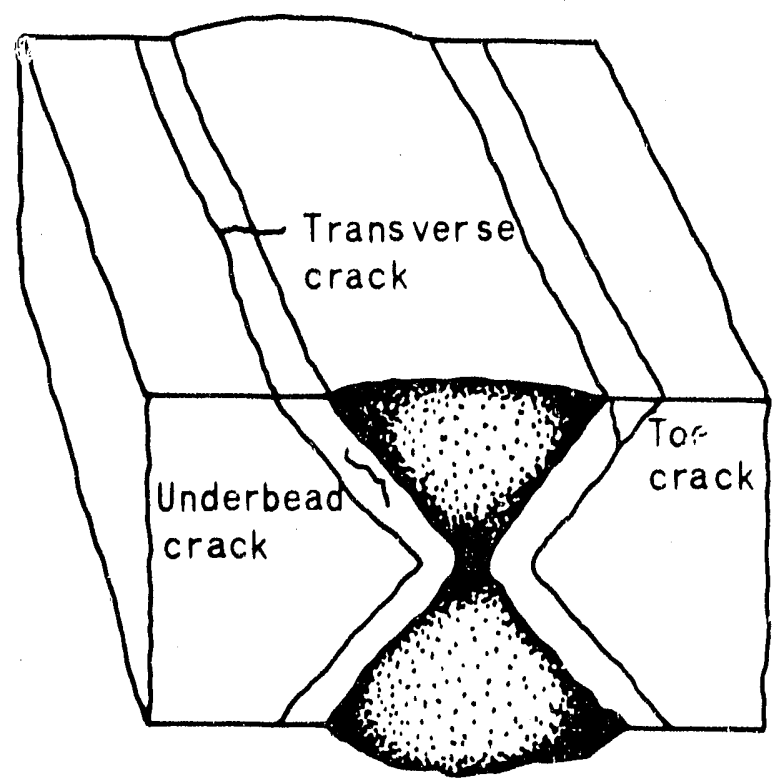

(b)

Fig. 9. Hydrogen-induced cracks in HAZs of (a) fillet weld and (b) butt weld. Source: F. R. Coe, Welding Steels Without Cracking, The Welding Institute, Cambridge, England, 1973.

boundaries, carbides, nonmetallic inclusions, dislocations, and microvoids. According to Lancaster, the total concentration of hydrogen in the traps may be up to $10^{4}$ times the interstitial value. ${ }^{34}$ The portion of hydrogen that diffuses out of the weld at room temperature is known as diffusible hydrogen and is expressed as milliliters per $100 \mathrm{~g}$ of deposited metal. Typical weld hydrogen levels range from $30 \mathrm{~mL} / 100 \mathrm{~g}$ of deposited metal in shielded metal arc covered-electrode welds to $2 \mathrm{~mL} / 100 \mathrm{~g}$ of deposited metal in gas-shielded metal arc welds.

Hydrogen is introduced into the arc atmosphere from the consumables or from the surfaces of materials to be welded. Coe ${ }^{32}$ described the principal sources of hydrogen in welding consumables as

1. moisture in electrode coatings or in the fluxes;

2. any hydrogeneous compound in the coating or flux; and

3. oil, dirt, and grease on the surface or trapped in welding wires and electrode wires.

Coe also described the principal sources of hydrogen from the material to be welded as

1. oil, grease, dirt, and paint on the weld surface; and

2. degreasing liquids employed to clean welding surfaces. 


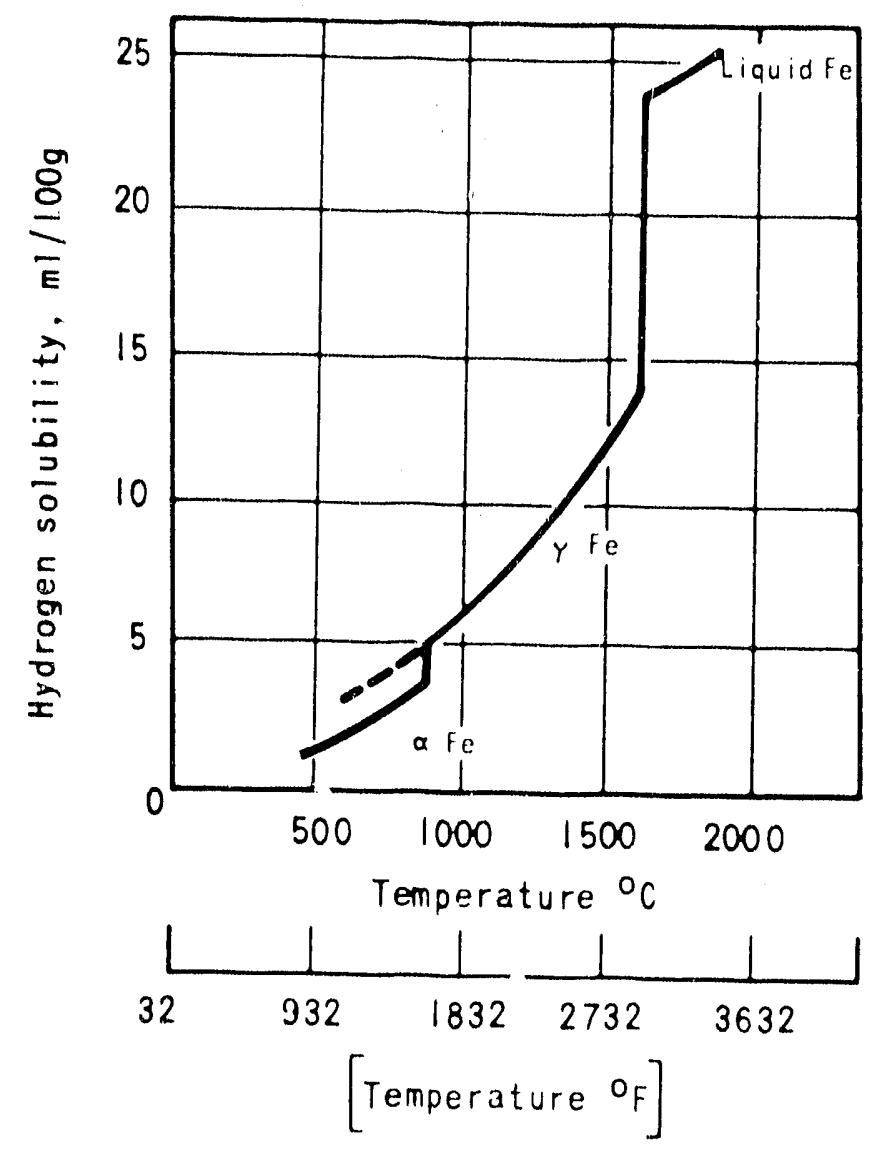

Fig. 10. Solubility of hydrogen in weld metal. Source: F. R. Coe, Welding Steels Without Cracking, The Welding Inst1tute, Cambridge, England, 1973.

As the weld cools, stresses developed as a result of thermal contraction must be accommodated as strain in the weld. The stresses tend to be concentrated at the toe and root of the weld and at inclusions or any other defect that acts as in notch. Hydrogen appears to lower the stress level at which cracking at the notch occurs.

The region of the HAZ adjacent to the fusion zone experiences a temperature sufficient to produce a coarsened grain size that is more hardenable and less ductile than regions farther from the fusion boundary. The greatest risk of cracking is therefore in the coarsened region.

As the temperature of the weld decreases after welding, the rate of diffusion of hydrogen decreases, thus reducing the amount of hydrogen removed from the weld. As shown in Fig. 11, this effect is particularly 


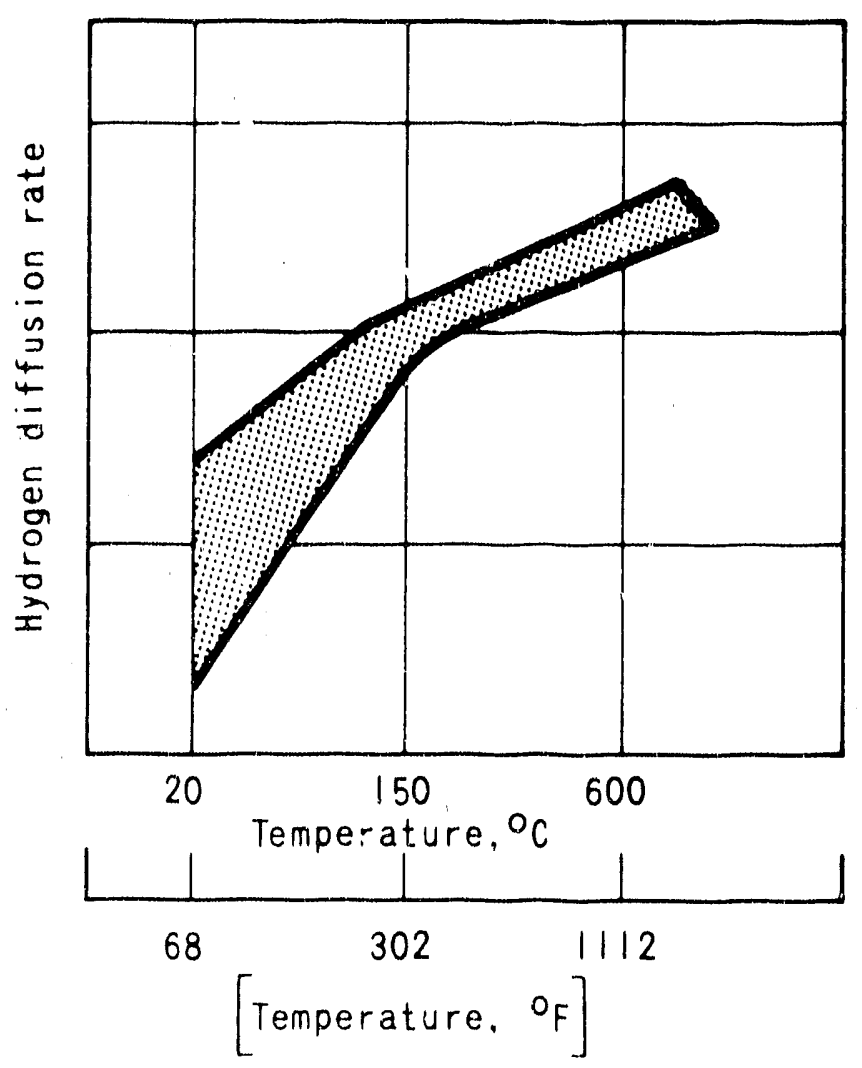

Fig. 11. Diffusion rate of hydrogen through ferritic steel. Source:

F. R. Coe, Welding Steeis Without

Cracking, The Welding Institute, Cambridge, England, 1973.

marked in the range of 20 to $150^{\circ} \mathrm{C}\left(68-300^{\circ} \mathrm{F}\right)$. Preheat slows down the cooling rate above $150^{\circ} \mathrm{C}\left(300^{\circ} \mathrm{F}\right)$ and allows more time for the escape of hydrogen.

\section{Theory of Hydrogen-Assisted Cracking}

Much research, time, and effort have been devoted to determine the exact cause and nature of hydrogen-assisted cracking in welding and other metallurgical operations, but still no unifying theory explains precisely how the presence of hydrogen within a metal structure leads to the formation of cracks under some circumstances and not in others. According to Bernstein, ${ }^{35}$ all the proposed theories of the role of hydrogen fall. into one or more of four general categories:

+ pressire

2. surfac adsorption,

3. binding energy, and

4. dislo ation mobility modification. 
The oldest and, until recently, the most popular of these theories has been the pressure theory first proposed by Zapffe and Sims. ${ }^{36}$ According to this theory, molecular hydrogen precipitates into preexisting mosaic rifts in the lattice, resulting in high internal pressures and subsequent failure along mosaic boundaries.

In the surface adsorption theory first proposed by Petch and Sables, hydrogen, on precipitation from the lattice, is adsorbed on the surface of the internal lattice imperfections and microcracks. ${ }^{37}$ According to this theory, the surface energy at the crack nucleus would be reduced and a lower stress could extend the submicroscopic rift into a catastrophic crack.

The pressure theory and the surface adsorption theory were advanced before the exact nature of hydrogen-assisted cracking was recognized. Both theories were inadequate in explaining many observed details of delayed brittle fracture. For example, in some cases the effects of hydrogen in steel can be completely removed by baking. ${ }^{38}$ If the embrittlement of the steel by hydrogen is the result of hydrogen trapped in the microscopic voids, it is difficult to explain how, at low baking temperatures, this mechanism could operate.

Troiano ${ }^{39}$ proposed a cracking theory based on the stress-induced diffusion of hydrogen in an effort to more fully explain observed cracking behavior. In this theory, hydrogen distributed in a matrix diffuses to the area of highest triaxial stress just ahead of a crack tip. When sufficient hydrogen is concentrated in this region, a crack is initiated. The hydrogen is thought to reduce the cohesive strength of the lattice by interacting with the electron structure to lower the binding energy of the base metal.

The dislocation mobility modification model proposed by Beachem ${ }^{31}$ unites parts of the previous cracking models to explain the observed decrease in microscopic plasticity and changes of fracture mode associated with some forms of hydrogen-assisted cracking. This model suggests that the presence of sufficiently concentrated dissolved hydrogen in the lattice just ahead of the crack tip unlocks dislocations, allowing them to multiply or to move at reduced stresses. This process aids whatever de. formation process the microstructure will permit (intergranular, quasicleavage, or microvoid coalescence) and thus explains various fracture features observed in hydrogen-assisted cracking.

\section{Prevention of Hydrogen-Assisted Cracking}

Cracking in low-alloy steels must be prevented by hydrogen control and temperature control. Low-hydrogen welding processes and procedures must be used in fabrication. Temperature control includes both preheat and postweld heating methods of preventing hydrogen-assisted cracking. The general effects of preheating have been summarized by $\mathrm{Coe}^{40}$ as follows: 
1. reduces cooling rate in the HAZ to produce softer and less susceptible microstructures,

2. allows "self" tempering of martensite, and

3. promotes diffusion of hydrogen away from the HAZ after welding.

Because of the hardenability of low-alloy steels, preheat has little effect on their HAZ microstructure and hardness. Apblett et al. ${ }^{41}$ showed that, in $2.25 \mathrm{Cr}-1 \mathrm{Mo}$ stee1, softer transformation products could not be produced by a practical preheat temperature. Preheats as high as $315^{\circ} \mathrm{C}$ $\left(600^{\circ} \mathrm{F}\right)$ resulted in only a minor decrease in the maximum HAZ hardness.

In low-alloy steels, preheat increases the rate of diffusion of hydrogen and thus accelerates its removal from the weld. Preheat requirements are related to chemical composition and thickness. As thickness and alloy content increase, the preheat temperatures to guard against cracking also increase. Carbon content is the most important factor in establishing preheat temperatures. The presence or absence of free ferrite in the structure is a secondary consideration. In addition to alloy content and material thickness, the mess of the joint and degree of restraint must also be considered when determining preheat temperatures.

When preheat cannot remove sufficient hydrogen to prevent cracking, a weld interpass temperature or postheating temperature high enough to avoid cracking must be held long enough to allow hydrogen to diffuse away before the weld cools. Any decision as to postheat temperature and time must be based on consideration of the hydrogen concentration at the end of welding and some critical concentration below which cracking will not occur when the weld cools to ambient temperature. There is yet little information on critical hydrogen concentrations for low-alloy steels, and postheating procedures are generally based on practical experience.

\section{Microstructural Effects on Hydrogen-Assisted Cracking}

The HAZ microstructure is one of the most important factors in determining the hydrogen-assisted cracking susceptibility of any steel. Linnert ${ }^{38}$ has 1 isted, in order of increasing propensity to hydrogenassisted cracking, six microstructures commonly found in the HAZ of steel welds :

1. ferrite and carbides (e.g., pearlite),

2. bainite,

3. bainite mixed with martensite,

4. martensite,

5. martensite with some ferrite, and

6. martensite with internal twinning.

The microstructure produced in any steel weld depends on the cooling rate through the transformation temperature range of the material and on its composition and hardenability. The cooling rate is governed by energy input, plate thickness, joint geometry, and preheat temperature. The hardenability of a steel is governed by its composition and grain size. 
In summary, review of the current literature reveals surprisingly little information on the relative hydrogen-assisted cracking sensitivities of SA-508 and SA-533 steels even though those steels have been fabricated by welding for a number of years. Most of the studies have concentrated on establishing the relative cracking sensitivities of only a few selected low-alloy materials, and little effort has been directed toward explaining the observed cracking behavior on the basis of compositional or microstructural differences. It is therefore apparent that a more broadly based investigation of the relative hydrogen-assisted cracking sensitivities of SA 508 and SA-533 materials is needed to address more adequately the effects of microstructure and composition on cracking sensitivity.

\section{TRANSFORMATION BEHAVIOR}

The transformation behavior for SA-508 and SA-533 steels has not been adequately documented for either isothermal or continuous cooling conditions. This is especially true for the high austenitizing temperature characteristics in the HAZ of welds. This transformation behavior must be adequately defined to permit prediction of HAZ properties in both the as welded and the PWHT condition.

\section{EXPERIMENTAL PROCEDURES}

\section{MATERIALS}

Oak Ridge National Laboratory (ORNL) purchased a 6-in.-thick SA-533, grade B, class 1, plate from Lukens Steel Company for its Heavy Section Steel Technology (HSST) Program. ${ }^{42}$ A portion of that material was used for this program. The order specified that the steel

1. meet the requirements of Sect. III of the ASME Code for Class-A nuclear vessels,

2. be vacuum degassed,

3. be made by the basic electric furnace process, and

4. have concentrations of phosphorous and sulfur as low as possible but restricted to 0.012 and 0.0158 maximum.

Heat treatment of the plate consisted of

1. austenitizing at $1675 \pm 25^{\circ} \mathrm{F}$ for a 6 -h hold period, followed by water quenching;

2. reaustenitizing at $1575 \pm 25^{\circ} \mathrm{F}$ for a 6 - h hold period, followed by water quenching;

3. tempering at $1225 \pm 25^{\circ} \mathrm{F}$ for a $6-\mathrm{h}$ hold period, followed by water quenching; and

4. stress relieving at $1125 \pm 25^{\circ} \mathrm{F}$ for a 1 -h hold period, followed by air cooling. ${ }^{42}$ 
The heat treatment for plate and forgings of SA-508, class 2, is similar - austenitizing at 870 to $900^{\circ} \mathrm{C}\left(1600\right.$ to $\left.1650^{\circ} \mathrm{F}\right)$, followed by a quench in highly agitated water or brine. The quenched steel is tempered, usually at 650 to $675^{\circ} \mathrm{C}\left(1200\right.$ to $\left.1250^{\circ} \mathrm{F}\right)$ for a minimum of $1 \mathrm{~h}$ per inch of thickness. ${ }^{9}$ The compositions of both steels examined in this study are shown in Table 3. Note that the SA-508, class 2, is higher in $\mathrm{C}, \mathrm{Ni}$, Mo, $\mathrm{Cr}$, and $\mathrm{Si}$ contents and contains some $\mathrm{V}$, whereas SA-533, grade B, class 1 , is higher in $M n$ and contains no $V$.

Table 3. Percentage compositions of materials SA-533, grade B, class 1 , and SA-508, class 2

\begin{tabular}{ccccccccccc} 
Material & C & Mn & N1 & Mo & Cr & S1 & P & S & Cu & $V$ \\
\hline $\begin{array}{l}\text { SA-533, grade } \\
\text { class } 1\end{array}$ & 0.21 & 1.38 & 0.48 & 0.47 & 0.17 & 0.18 & 0.010 & 0.014 & 0.12 \\
SA-508, class 2 & 0.26 & 0.75 & 0.81 & 0.61 & 0.45 & 0.26 & 0.010 & 0.014 & & 0.05 \\
\hline
\end{tabular}

The experiments conducted were to characterize and provide a thorough understanding of the transformation characteristics of SA-508 and SA-533 materials under the continuous cooling that occurs in the HAZ of welds and t.o study the isothermal transformation (IT) behavior of those materials at low temperature (within the preheat range and above). The transformation products were studied as to their morphologies and properties.

\section{ISOTHERMAL TRANSFORMATION BEHAVIOR}

The IT behavior of austenite can best be studied by determining the transformation behavior at a series of temperatures below $A_{1}$ (by quenchings sma11 samples to the desired temperature in a liquid bath, allowing them to transform isothermally) and following the progress of the transformation metallographically or dilatometrically. This procedure not only provides the rates of transformation at the various temperatures but also furnishes information as to the metallographic structures characteristic of the various temperatures of transformation and thus permits estimation of the properties of those microstructures.

Thus, to study the IT behavior, 25 specimens of each material were cut into 0.5-in. cubes and heated to $1700^{\circ} \mathrm{F}$, held for $1 \mathrm{~h}$, and then quenched in a salt bath. The specimens were held in salt bath for different time periods at five different temperatures. Lukens Steel Company provided an IT diagram for SA-302, grade C, steel, which is shown in Fig. 12. The composition of SA-533, grade B, class 1, is similar to that of SA-302, grade $C$, and therefore the transformation behavior of both steels should be similar. On the basis of that prediction, the hold times were selected to range from 1 to $10,000 \mathrm{~s}$, and temperatures were 550,800 , 950,1150 , and $1250^{\circ} \mathrm{F}$. A complete schedule for both steels is shown in 


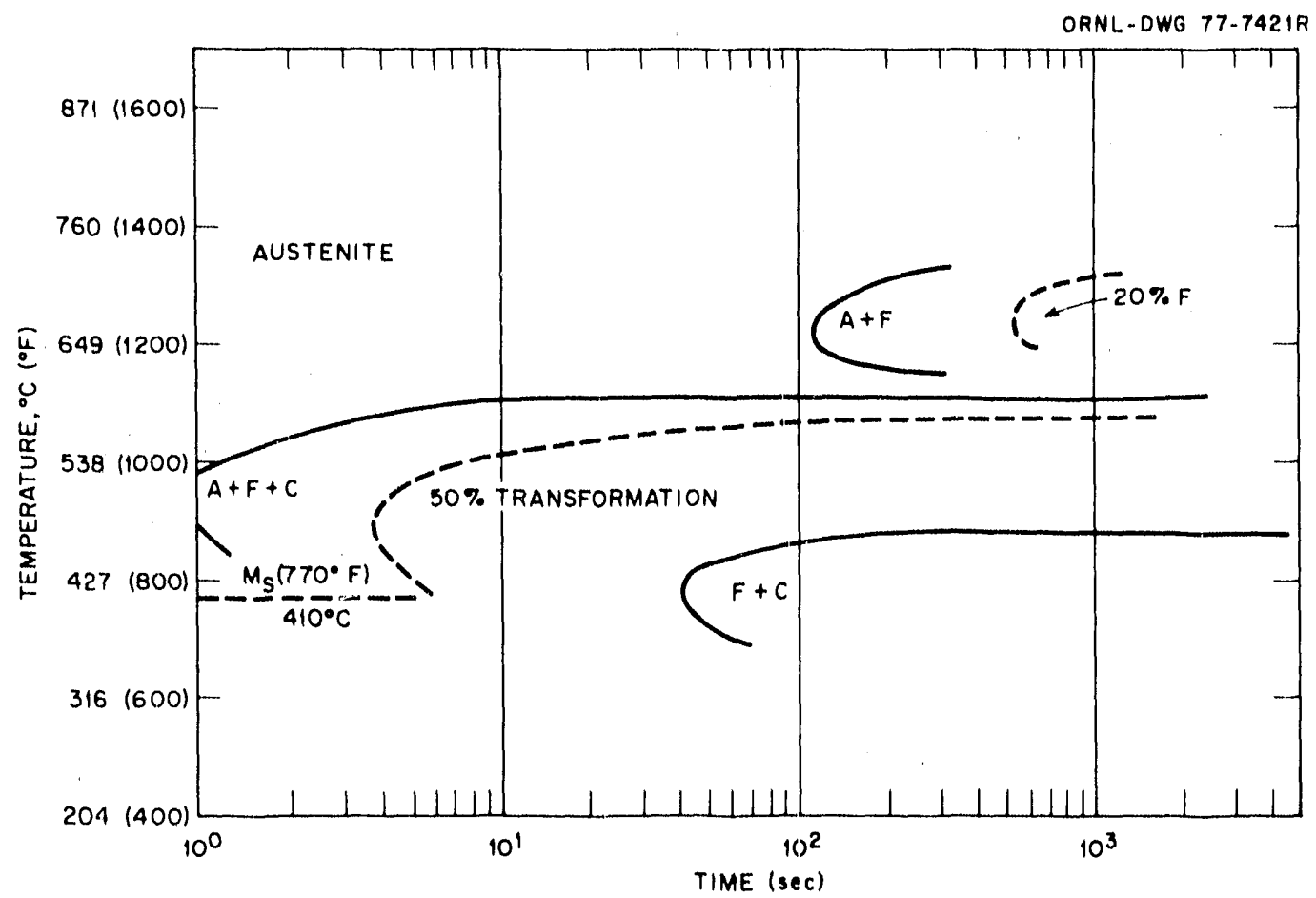

Fig. 12. Isothermal transformation diagram for ASTM A 302, grade C, steel. (The anilysis of A 302, grade C, is lidentical with that of A 533, grade B.) The rapid coolirig rate near the fusion line in combination with the coarse austenite grains results in a microstructure that is predominantly martensitic.

Table A.1 of Appendix A. After reaching the temperature of the molten bath, the samples were held for the required period of time, withdrawn, and quickly quenched in cold water to room temperature. The cubes were sec. tioned and examined microstructurally. As the temperature of the molten bath (and consequently the transformation temperature) changed, a series cif data points was obtained and used to construct the isothermal diagrams.

\section{CONTINUOUS-COOLING TRANSFORMATION BEHAVIOR}

\section{Continuous-Cooling Transformation Obtained by Resistivity Measurements}

Electrical resistivity measurement equipment was extensively used to study the behavior under CCT. This equipment was developed over several years at the University of Tennessee at Knoxville (UTK) ${ }^{4.3}$ and recently adapted for computer control. A description of the procedure involved in measuring resistivity follows.

Manual measurements at room temperature, The resistivity ( $\rho$ ) of a rod sample was calculated from

$$
\rho=0.7854 V D^{2} / I L
$$


where

$$
\begin{aligned}
& D=\text { diameter of a rod, } \\
& L=\text { sample length along axis } \\
& V=\text { voltage drop across length } \\
& I=\text { current passed through rod. }
\end{aligned}
$$

The diameters of rods were measured with a micrometer having a vernier scale of 0.001 -in. resolution. An average value for the diameter of each rod was obtained through multiple reading both along the rod axis and around the rod circumference.

The sample length $L$ was defined by the span between two knife edges glued to the cut ends of a quartz cylinder. The span was calibrated under a reflection optical microscope equipped with a precision traveling stage micrometer. A knife-edge standard of $25.438 \pm 0.005 \mathrm{~mm}$ was prepared.

The resistivity was measured by mechanically fixing the rod across the top of the knife edges and connecting the ends to a precisioncontrolled current source in serles with a calibrated standard resistor, as shown in Fig. 13. With a current passing, voltage drops were measured between the knife edges, designated as $V$, and between the terminals of the standard resistor. The voltage drop across the standard resistor was divided by the calibrated value of its resistance to provide an accurate value of the electrical current, $I$.

Vo1tage drops were read with a digital voltmeter (5 $1 / 2$ digit), Data Precision Corporation model 3500 with an accuracy of $\pm 4 \mu \mathrm{V}$ in the full scale $0.12 \mathrm{~V}$. Readings were taken with the current in forward and then in reverse direction and the values averaged to cancel thermal emf effects in the circuit. The reproducibility of the resistance measurements of a specimen with $0.02 \Omega$ was $\pm 6 \mu \Omega$ or $\pm 0.03 \%$. However, the absolute accuracy is limited by the accuracy of the diameter and the measurement uniformity of diameter of the rod, which is about \pm 0.58 . As a consequence, the absolute accuracy of the resistivity measurements was determined to be 0.58 .

Measurements at elevated temperatures under digital computer control. A PDP 15/35 digital minicomputer was adapted to measure the resistivity of samples over wide ranges of heating and cooling rates. The computer, equipped with analog-to-digital converters, digital-to-analog converters, and relay switching, allowed both resistivity measurements and temperature control to be programmed with great flexibility. FORTRAN IV language was used in programming.

The resistivity of the sample was first measured manually at room temperature. Two nickel wire probes, $0.020 \mathrm{in}$, in diameter were spotwelded about $7 \mathrm{~mm}$ apart near the center of the specimen. The actual distance was back calculated through the known resistivity and the voltage drop induced by a known current. Two Pt vs Pt-13\% Rh thermocouples were spot-welded onto the specimen in the vicinities of the nickel probes, as shown in Fig. 13. 


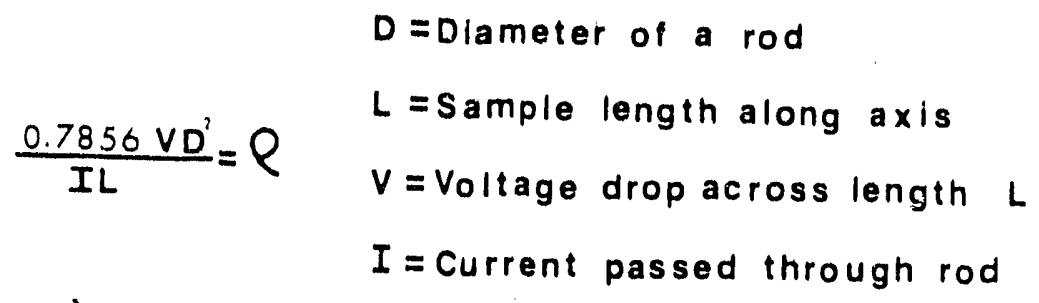

a)

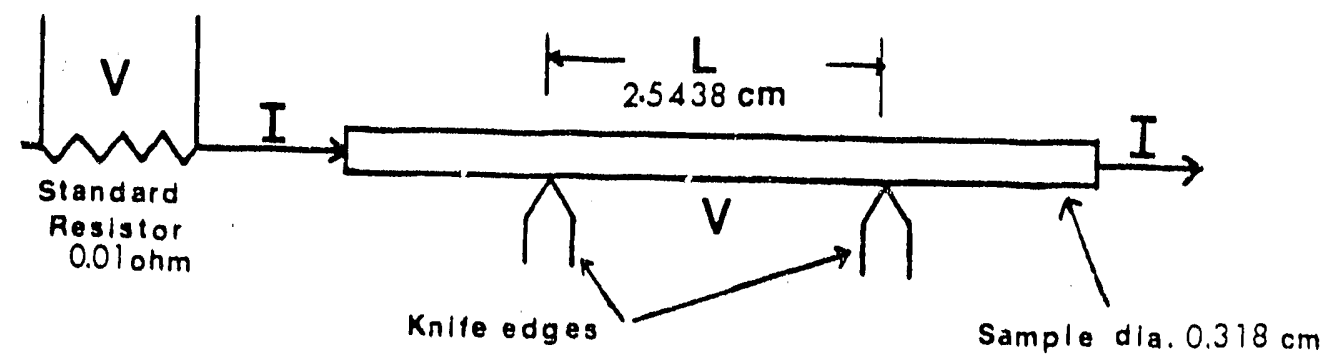

b)

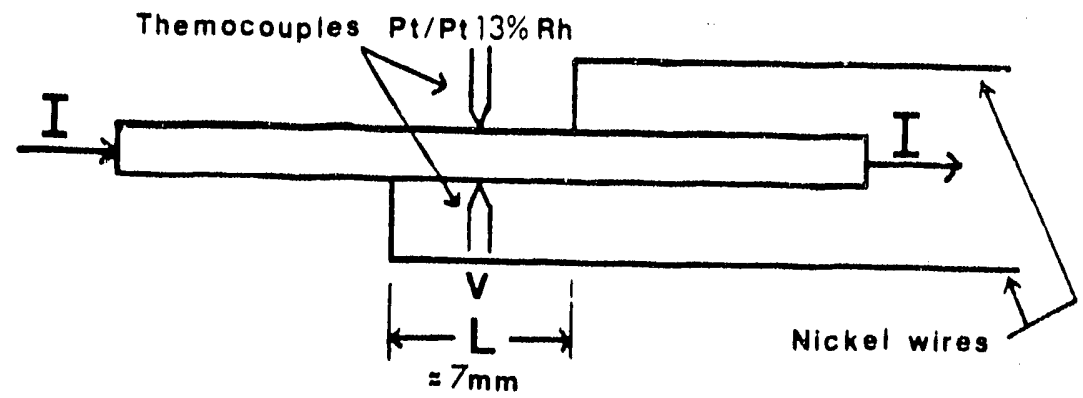

Fig. 13. Schematic representation of resistivity measurement at room temperature. Source: University of Tennessee.

The specimen was suspended vertically in a 2.5-in.-diam ceramic tube lined with 0.010 -in.-thick nickel foil as a reflector to decrease the heat lost. Direct current to heat the specimen was supplied by vertical 1/4-in.-diam graded copper and thin nickel rods. These rods along with ceramic tubes for thermocouple and voltage probe wires supported ten radiation shield disks, which, with a series of radiation shields below the specimen, provided acceptably low heat loss. All these leads passed through vacuum-tight seals in the wall of the specimen chamber, which was maintained at a vacuum of $5 \times 10^{-5}$ torr or lower.

Controlled cooling rates up to $0.5^{\circ} \mathrm{C} / \mathrm{min}$ can be programmed. Faster cooling rates were obtained by blowing helium gas on the specimen. The cooling curves were recorded on a strip chart recorder. Resistivity versus temperature curves are represented schematically in Fig. 14. The reactionstart and reaction-stop temperatures were determined by the change in slope. The strip chart recorder trace of temperature vs time was used to develop the time base. The transformation temperatures as previously determined were located on the temperature-time trace. Zero time was taken
at the peak temperature. 


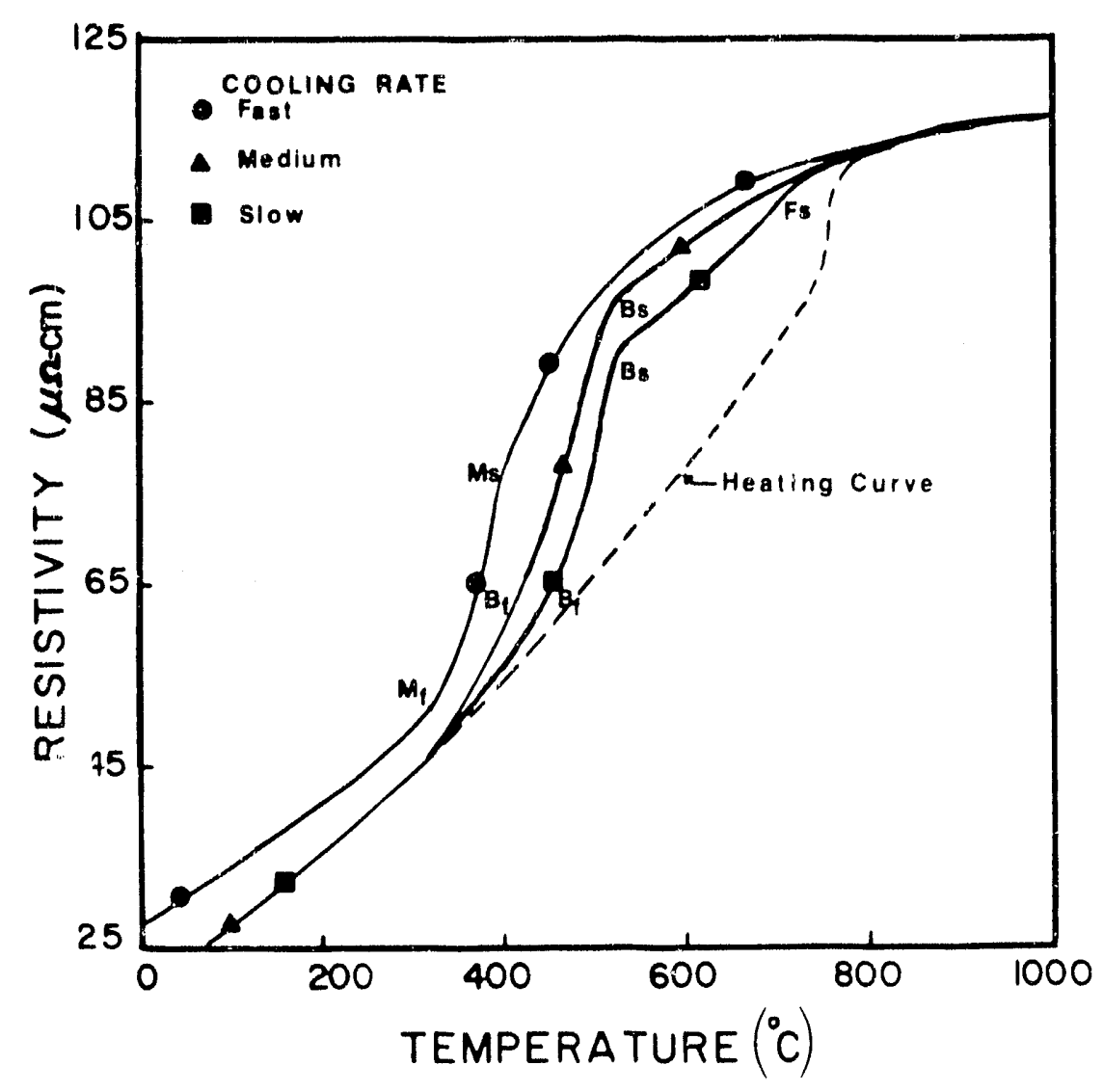

Fig. 14. Schematic representation of resistivity vs temperature curves. Source: University of Tennessee.

The pertinent times and temperatures for each of the transformations over a variety of cooling rates were then plotted on a temperature vs logtime scale to generate the continuous cooling transformation diagrams. The specimens with different cooling rates were saved for metallographic examination.

\section{Continuous-Cooling Transformation Behavior Obtained Dilatometrically}

The continuous-cooling characteristics of SA-533, grade B, class 1 , and SA-508, class 2, low-alloy steels were investigated dilatometrically with a high-speed time-temperature control device known as the "Gleeble." This evaluation is directly related in weld HAZ transformations.

Specimens (0.25 in. diam $\times 3$ in. long) of SA-533, grade B, class 1 , and SA-508, class 2, were subjected to different thermal cycles with peak temperatures of $2400^{\circ} \mathrm{F} \pm 40^{\circ} \mathrm{F}$ and $1650^{\circ} \mathrm{F} \pm 20^{\circ} \mathrm{F}$, followed by cooling rates appropriate to the energy input and preheat. The dilation of the specimens was monitored with a high-speed dilatometer to generate a CCT diagram based on thermal cycles that duplicate those experienced by the HAZ of arc weldr. 
The Gleeble. The device called the Gleeble, developed at Renssilaer Polytechnic Institute, reproduces a thermal cycle for a particular point of interest in the $\mathrm{HAZ}$ of an actual weld in a specimen of suitable size for testing. Thus the microstructure found at the point of interest in the weld HAZ is created in the test volume of the specimen experiencing the corresponding thermal cycle.

Briefly, the apparatus (Gleeble) consists of a proportional, variablerate, on-off, time-temperature controller that has the ability to duplicate, in a specimen of convenient size, the thermal conditions existing at any point in the HAZ of an arc weld. In operation, a specimen is clamped between twu water-cooled copper jaws, one fixed and one movable, which are connected to the secondary of a transformer. The specimen is thus heated by its resistance to the passage of an electric current and is cooled by extraction of heat longitudinally to the water-cooled jaws.

By use of a thermocouple welded to the specimen, the Gleeble compares a programmed reference signal with the specimen temperature 120 times a second and makes the necessary corrections. Any thermal cycle may be reproduced with heating rates up to $3000^{\circ} \mathrm{F} / \mathrm{s}$ and controlled cooling rates up to approximately $1000^{\circ} \mathrm{F} / \mathrm{s}$.

The dilatometer. To generate a continuous cooling transformation diagram, a high-speed dilatometer was used so that volume changes accompanying the various allotropic transformations could be monitored and recorded. The dilatometar, shown in Fig. 15, consists of a precision rectilinear transducer and solid-hinge mechanical linkage. Quartz rods are used to contact the specimen.

Volume changes in the specimen were transmitted through the hinge to the rectilinear potentiometer, which was in turn connected to a precision bridge circuit. The output of the bridge was connected to a channel in a recording oscillograph (Honeywel1 Visicorder M906 B) containing a galvanometer (M100-120) with a sensitivity of $11.0 \mu \mathrm{A} / \mathrm{in}$. In this manner, a continuous record of the dilational behavior of the specimen was produced.

The thermal cycles used in this investigation consisted of the weld thermal cycle corresponding to:

$\begin{array}{rrrr}\text { A } & 20 \mathrm{~kJ} / \text { in. } & \text { Preheat } & 80^{\circ} \mathrm{F} \\ \text { I } & 32 \mathrm{~kJ} / \text { in. } & \text { Preheat } & 80^{\circ} \mathrm{F} \\ \text { II } & 50 \mathrm{~kJ} / \text { in. } & \text { Preheat } & 80^{\circ} \mathrm{F} \\ \text { III } & 100 \mathrm{~kJ} / \text { in. } & \text { Preheat } & 80^{\circ} \mathrm{F} \\ \text { IV } & 136 \mathrm{~kJ} / \text { in. } & \text { Preheat } & 80^{\circ} \mathrm{F} \\ \text { V } & 136 \mathrm{~kJ} / \text { in. } & \text { Preheat } & 300^{\circ} \mathrm{F} \\ \text { VI } & 136 \mathrm{~kJ} / \text { in. } & \text { Preheat } & 500^{\circ} \mathrm{F}\end{array}$

Weld thermal cycles were calculated for 1 -in. steel plate for initial plate temperatures of 80,300 , and $500^{\circ} \mathrm{F}$. The CCT behavior studied was for the coarse-grained region next to the fusion zone with a peak temperature of $2400^{\circ} \mathrm{F}$ and the refined region with a peak temperature of $1650^{\circ} \mathrm{F}$. in the outer extremities of the HAZ. As the energy inputs and preheat 


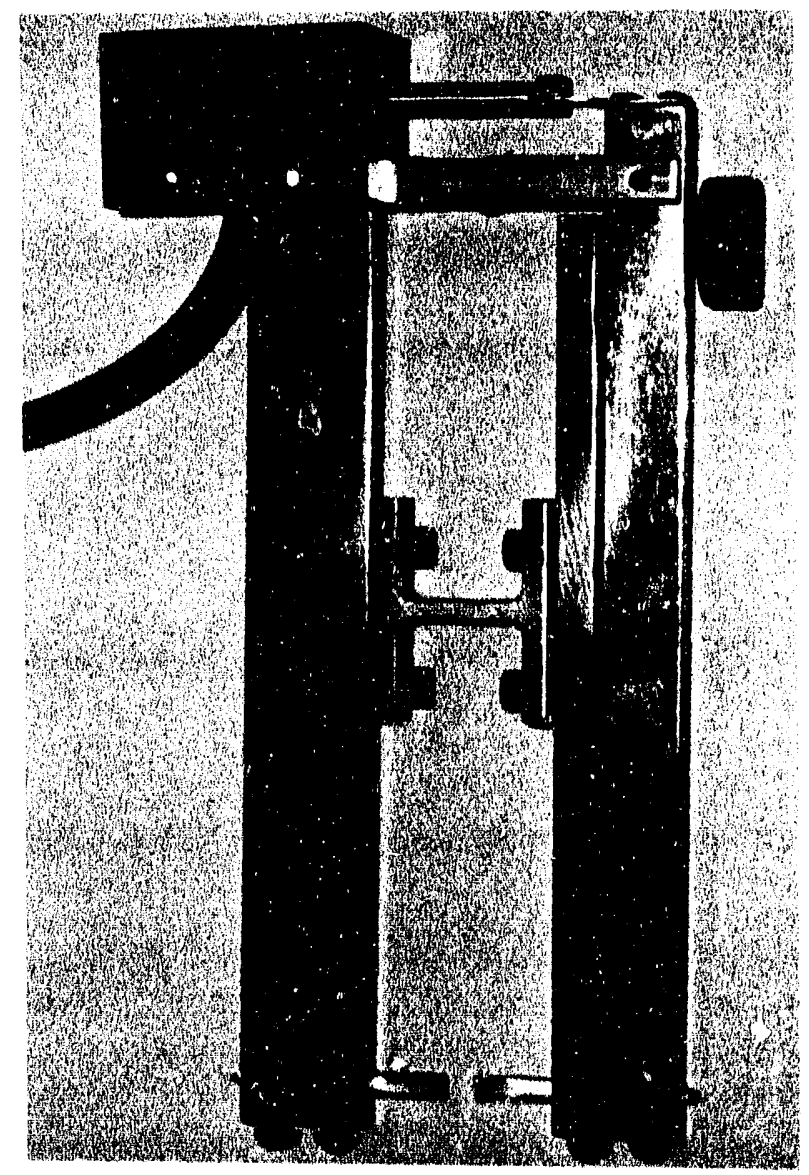

Fig. 15. High-speed dilatometer. Source: University of Tennessee.

increased, the integrated time at peak temperature increased and the cooling rates decreased. Multiple runs were made for each of the weld thermal cycles studied, using a new specimen for each run to ensure that the same initial microstructure was present.

On thermal cycling, two related traces were obtained: a dilation vs time and a temperature vs time. From those data, dilation was plotted against temperature, as shown schematically in Fig. 16. The reaction-start and the reaction-stop temperatures were chosen as the points where sensible departure from the smooth thermal contraction curve began. The transformation temperatures as previously determined were located on the temperature-time trace. Zero time for cooling was chosen at the peak: temperature. The minimum peak temperature used was $1650^{\circ} \mathrm{F}$. For the higher peak temperature, a time differential must be applied to evaluate the transformation equivalently (cooling tine from 2400 to $1650^{\circ} \mathrm{F} \approx 10 \mathrm{~s}$ ). The pertinent times and temperatures for each of the transformations over a variety of cooling rates were then plotted on a temperature vs log-time scale, thereby generating the CCT diagrams. The specimens with different thermal cycles were prepared for metallographic evaluation. 


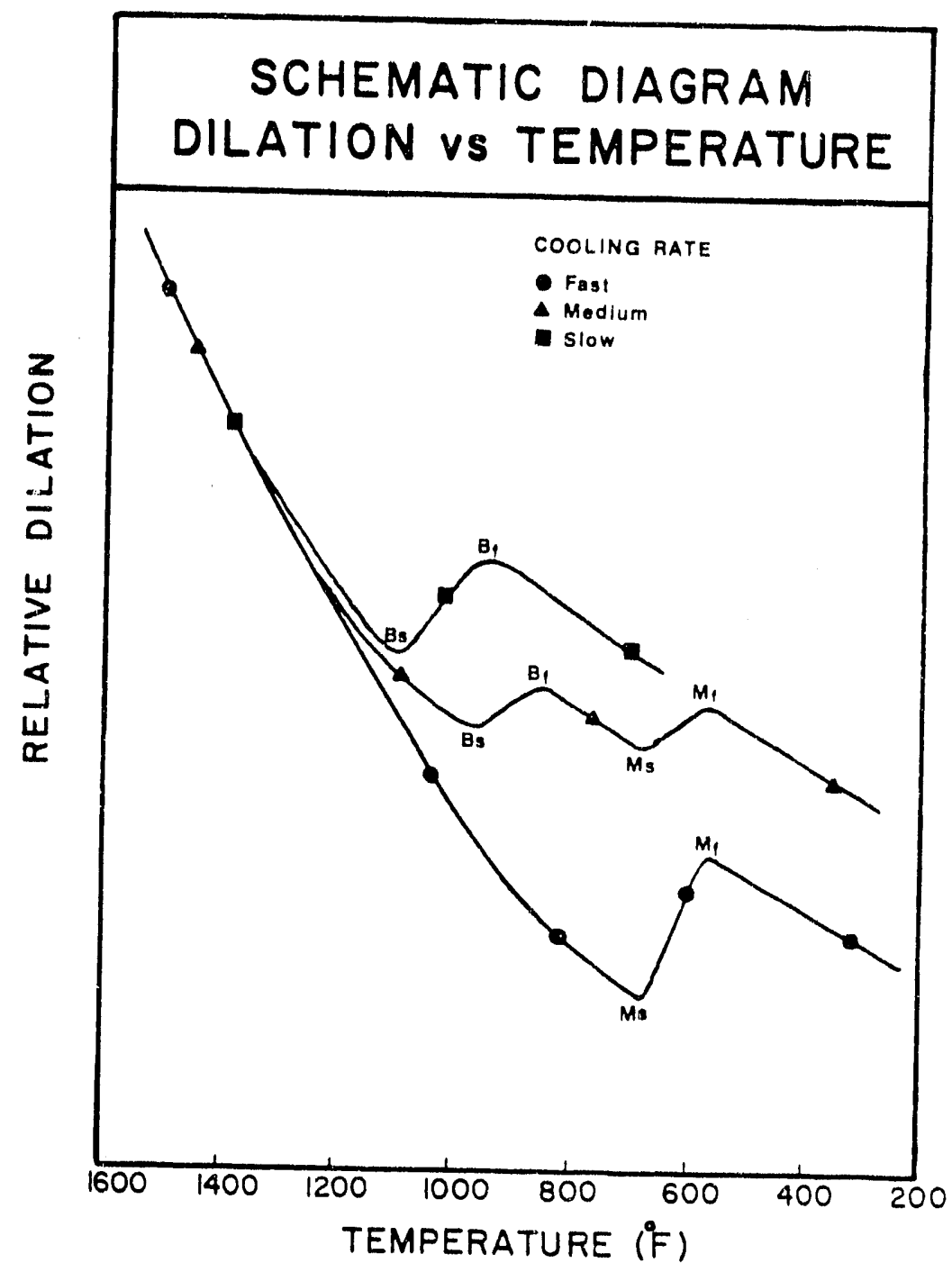

Fig. 16. Schematic representation of dilation vs temperature curves. Source: University of Tennessee.

COLD CRACKING TESTS

Cold cracks usually occur in the base metal HAZs at low temperature (usually below $200^{\circ} \mathrm{C}$ ). Cracking in this range is almost invariably associated with the presence of dissolved and diffusable hydrogen. To study the cold cracking behavior, two experimental methods were employed:

1. Underbead Crack Test - Battelle Memorial. Institute developed a test for determining the underbead crack sensitivity of steels. ${ }^{44}$ Battelle samples, 2 in. wide by 3 in. long in the direction of rolling, and was deposited were cut from the two steels. A weld bead $11 / 4 \mathrm{in}$. long electrode a check with a 1/8-in.-diam E6010 electrode, a current of $100 \mathrm{~A}$ at 24 to $26 \mathrm{~V}$, and travel speed of 
$10 \mathrm{in.} / \mathrm{min}$. The small blocks were precouled or preheated to one of several temperatures such as $32,85,200,300$, and $400^{\circ} \mathrm{F}$. Upon completion of weld, the samples were held $24 \mathrm{~h}$ at $60^{\circ} \mathrm{F}$ and then tempered to $1100^{\circ} \mathrm{F}$ for $1 \mathrm{~h}$. After PWHT, the samples were sectioned longitudinally (along the centerline of the weld bead) to examine the underbead crack metallographically. The Battelle test specimen and the parameters used for this test are shown schematically in Fig. 17.

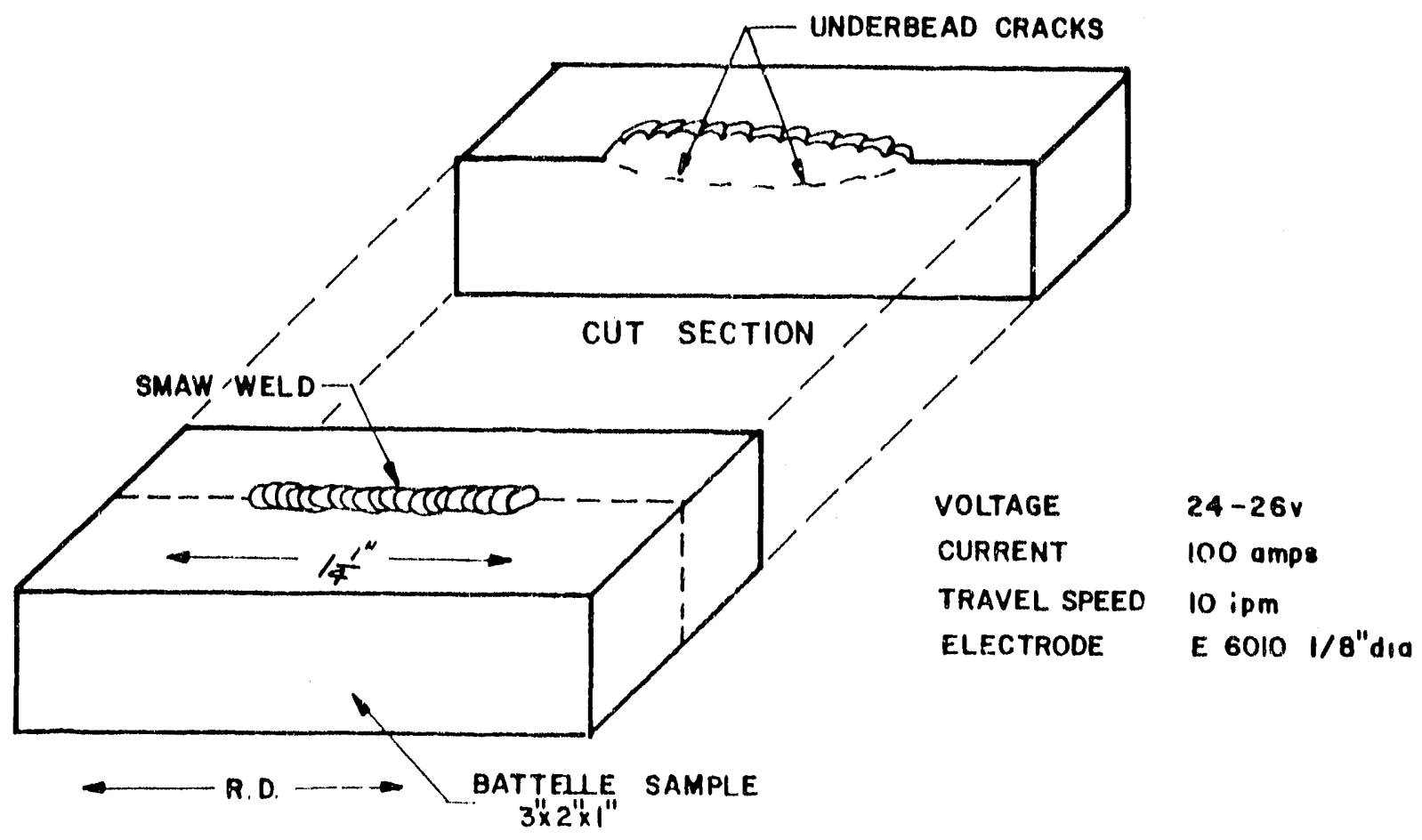

Fig. 17. Underbead cracking test specimen. Source: University of Tennessee.

2. Hydrogen Susceptibility Test (HST). A testing procedure, developed at the University of Tennessee, reproduces hydrogen-induced cracking in small laboratory-scale specimens and allows direct observation of both initiation and propagation of the cracking. The specimens were prepared $5 / 8$ in. wide $\times 1-5 / 8$ in. long $\times 1 / 8$ in. thick. Autogeneous GTA welds were made parallel to the rolling direction. During the deposition of the welds, hydrogen was added to the shielding gas to saturate the weld fusion zone with hydrogen. Figure 18 shows a schematic drawing of the specimen and gives the welding parameters.

The testing device shown in Fig. 19 imposes an augmented strain on the welded surface of the bead-on-plate weld. Five minutes after welding, the samples are strained in the device. The approximate value of the augmented strain on the top surface of the weld in the longitudinal direction can be calculated by the relationship

$$
E \approx t / 2 R
$$




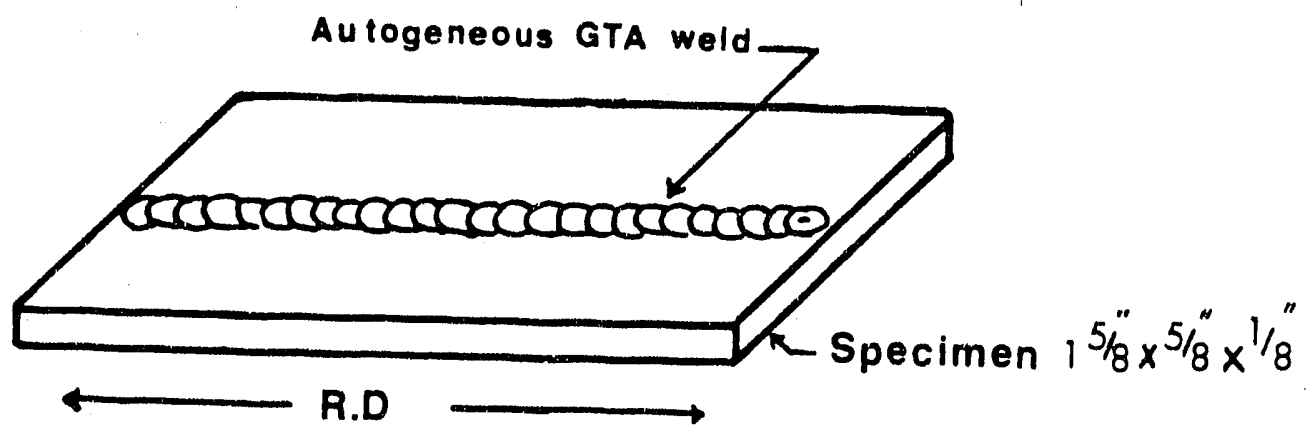

Current

Voltage

Travel Speed

Shielding gas

Electrode
$80-100$ amps

$10 v$

5 ipm

$5 \% \mathrm{H}_{2} 95 \%$ Ar,flow rate $30 \mathrm{CFH}$

$2 \%$ thoriated tungsten $1 / 16$ dia.

$w / 60^{\circ}$ included point

Fig. 18. Hydrogen susceptibility test specimen. Source: University of Tennessee.

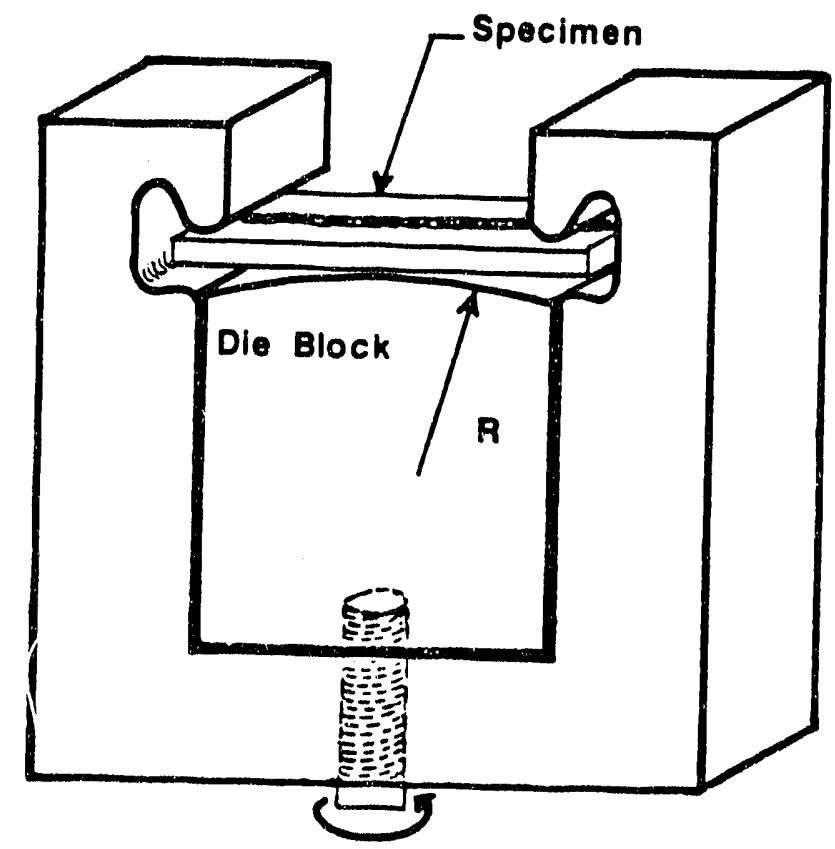

Fig. 19. Schematic representation of apparatus used to strain specimen. Source: W. F. Savage, E. F. Nippes, and E. S. Szekeres, "Hydrogen Induced Cold Cracking in a Low Alloy Steel," Weld. J. (Miami)
$57(9), 276-83-\mathrm{s}(1976)$. 
where
$E=$ augmented strain in the outer fibers,
$t=$ thickness of specimen,
$R=$ radius of curvature of the die block (where $R \gg t$ ).

Therefore, either by substituting a die block with the appropriate radius of curvature or by changing the thickness of the specimen, any desired augmented strain can be applied to the outer surface of the specimen. The augmented strain applied for both steels was 48 . This strain is sufficient to cause cracking in the specimens and provide a conservative assessment of cracking sensitivity. The cracking was tested as a function of preheat temperatures of $32,90,300,400,500$, and $600^{\circ} \mathrm{F}$.

\section{STRESS-RELIEF CRACKING}

Stress-relief or reheut cracking may occur in the HAZ of welds in alloy steel during PWHT or during service at elevated temperature. Cracking is due to the combined effects of embrittlement and stress relief.

To reveal information about the phenomenon of stress-relief cracking, HAZ structures were created by resistance heating and rapid cooling of base metal samples ( $0.25 \mathrm{in.} \mathrm{diam} \times 4.75 \mathrm{in.}$ long) in the Gleeble. The specimen shown in Fig. 20 was treated with different simulated welding cycles. The thermal treatment and stress applied are represented schematically in Fig. 21. After the desired HAZ thermal cycle, the sample is reheated to $1150^{\circ} \mathrm{F}$ with stress simultaneously applied. The basic thermal cycles employed for SRC tests were Cycle II (50 kJ/in.) and Cycle VI (136 kJ/in., $500^{\circ} \mathrm{F}$ preheat) to create martensitic and bainitic structures, respectively, in the simulated grain-coarsened region. The two transformation products were further tested with superimposed cycles (such as a hold at $600^{\circ} \mathrm{F}$ or multiple high-temperature cycles) and also as a function of stress. Table A.2 in Appendix A shows a complete schedule of the thermal and stress treatments employed in SRC testing.

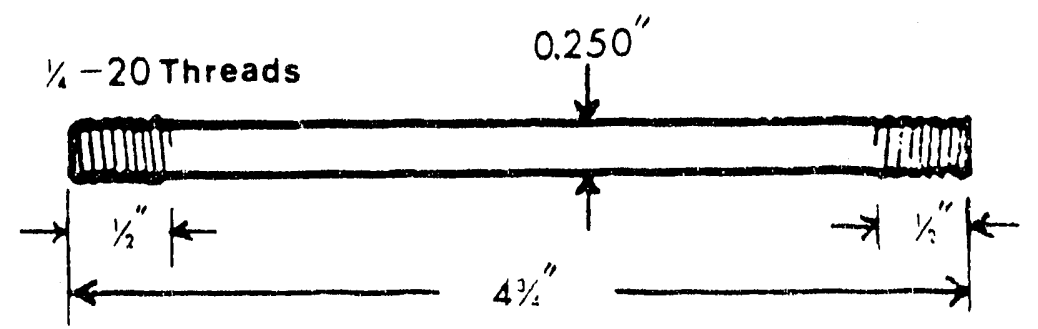

Fig. 20. Stress-relief cracking specimen used in the Gleeble. Source: University of Tennessee. 


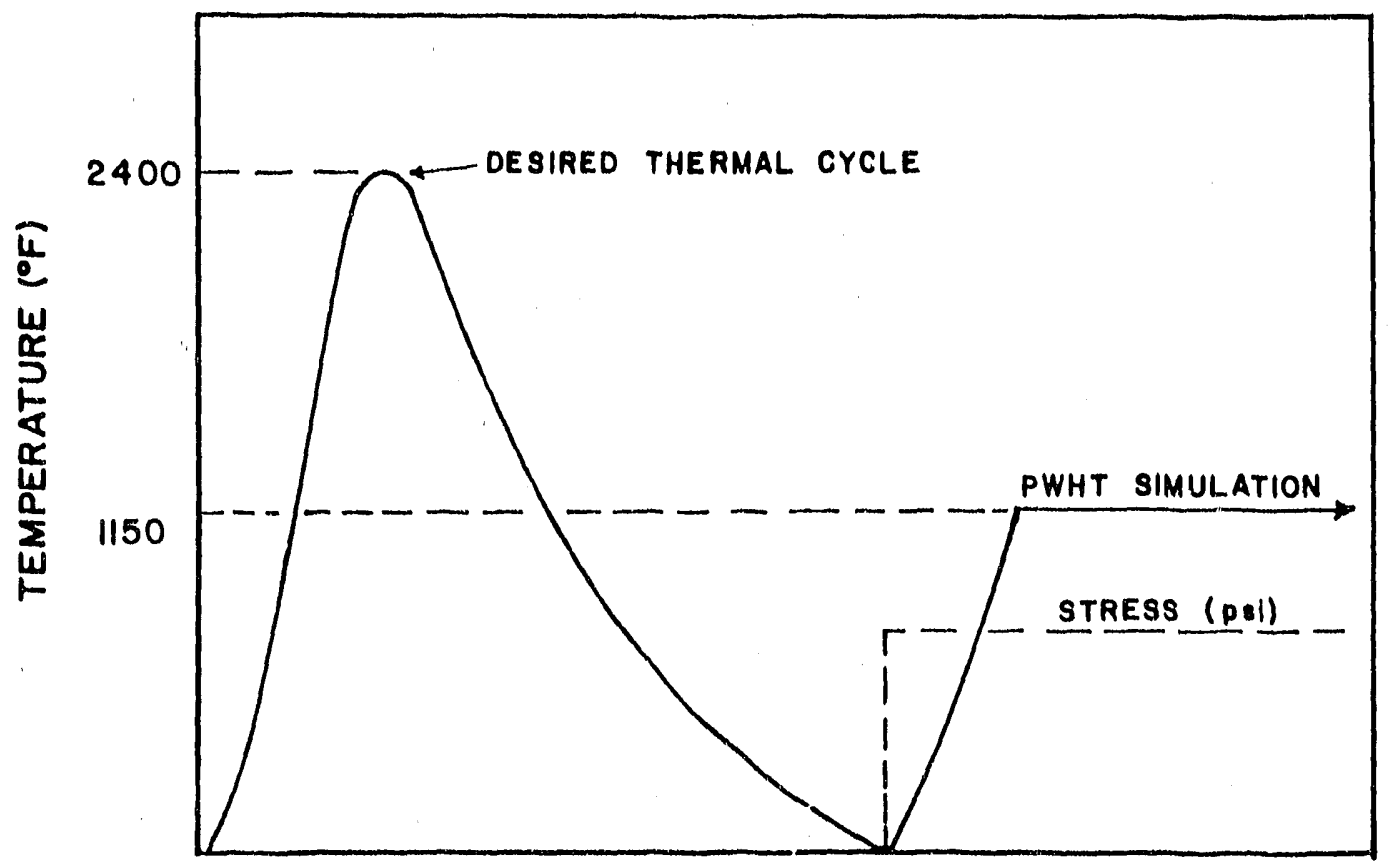

TIME

Fig. 21. Schematic representation of reheat cracking studies. Source: University of Tennessee.

The specimens with simulated grain-coarsened weld HAZ microstructures postweld heat treated at $1150^{\circ} \mathrm{F}$ usually failed within a stress-relieving time of $120 \mathrm{~min}$. If the specimen did not fail within $120 \mathrm{~min}$, the test was discontinued. The test data provided the reduction of area and time to failure for each specimen. The failed specimens were retained for metallographic and fractographic evaluations.

\section{CHARPY IMPACT TOUGHNESS OF HEAT-AFFECTED ZONE}

The Gleeble microstructure simulation technique for assessing the Charpy notch toughness of HAZ structures was used in this investigation. The procedure involves subjecting a number of specimens to one or more peak-temperature weld thermal cycles and testing in the as-welded or PWHT condition.

The material used for Charpy blanks was chosen from the $1 / 4 T$ and $3 / 4 T$ depths of 6 -in. plates of both steels. Charpy blanks were machined with a longitudinal orientation according to the dimensions shown in Fig. 22. The Charpy blanks were subjected to different thermal cycles and post treatments in the Gleeble. A complete schedule of thermal heat treatments is shown in Table A.3 of Appendix A. The thermal cycles selected were cycle II $(50 \mathrm{~kJ} / \mathrm{in}$.$) to obtain a fully martensitic structure$ 
ROLLING DIRECTION $\longrightarrow$

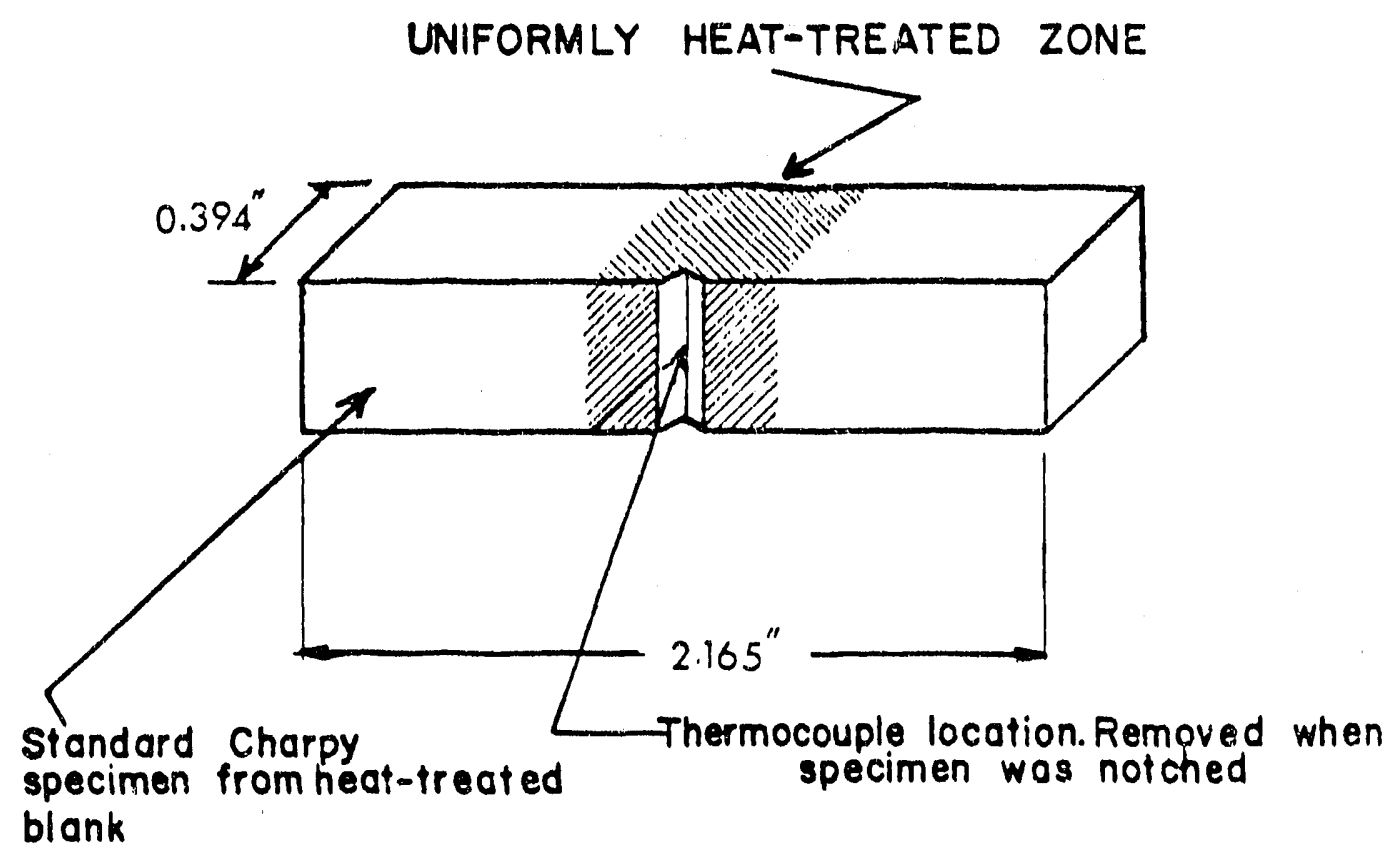

Fig. 22. Details of Charpy specimen preparation. Source: University of Tennessee.

and Cycle VI (136 kJ/in., $500^{\circ} \mathrm{F}$ preheat) to obtain a fully bainitic structure.

Each specimen $0.42 \times 0.42 \times 2.5$ in. long was clamped in water-cooled copper jaws of the Gleeble, and a fine wire thermocouple was percussion welded to the specimen surface. The reference generator was adjusted to provide the proper time-temperature program, and the specimen was subjected to the programmed thermal cycle. Each specimen was then removed from the apparatus, the thermocouple was clipped to a length of approximately $1 / 2$ in., and the specimens were stored at ambient temperature. The 1/2-in. length of the thermocouple was left attached to serve as an index of the center of the volume of metal subjected to the desired thermal cycle so that the $V$-notches could be located accurately when the final machining was accomplished.

We obtained 54 specimens for each material, of which 48 were subjected to the selected thermal cycles and heat treatments (Table A. 3 in Appendix A). The remainder were tested to obtain base-metal toughness. Of the 48 specimens, 24 were set aside for PWHT. For SA-533 the specimens were postweld heat treated at $1150 \pm 50^{\circ} \mathrm{F}$ for $40 \mathrm{~h}$, whereas for SA-508 the specimens were postweld heat treated at the same temperature for $24 \mathrm{~h}$. The time of PWHT is similar to that employed commercially.

After the final machining of Charpy blanks to the standard Charpy bars $0.394 \times 0.394 \times 2.165 \mathrm{in.}$, the temperatures for the impact test were 
selected as $-25^{\circ} \mathrm{F}$ for $\mathrm{S} \Lambda-533$ and $72^{\circ} \mathrm{F}$ for $\mathrm{SA}-508$. Those temperatures were based on the transition temperature for the base material. For each thermal treatment, three Charpy bars were tested. The averages of three values were used to construct the bar graphs, which represented energy absorbed and lateral expansion as functions of different thermal heat treatments. The broken bars were retained for metallographic and fractographic examinations.

\section{RESULTS AND DISGUSSION}

To achieve a better understanding of the weldability of the two steels, one should have available suitable diagrams for predicting the microstructure of the HAZ after heat treatment and after welding. To provide that fundamental information, we determined the isothermal and continuous-cooling transformation behavior for both steels and drew the appropriate diagrams.

\section{ISOTHERMAL TRANSFORMATION BEHAVIOR}

The isothermal transformation (IT) diagrams for SA-533, grade B, class 1, and SA-508, class 2, steels are shown in Figs. 23 and 24, respectively. These diagrams are based on microstructural observations and the hardnesses obtained for the microconstituents.

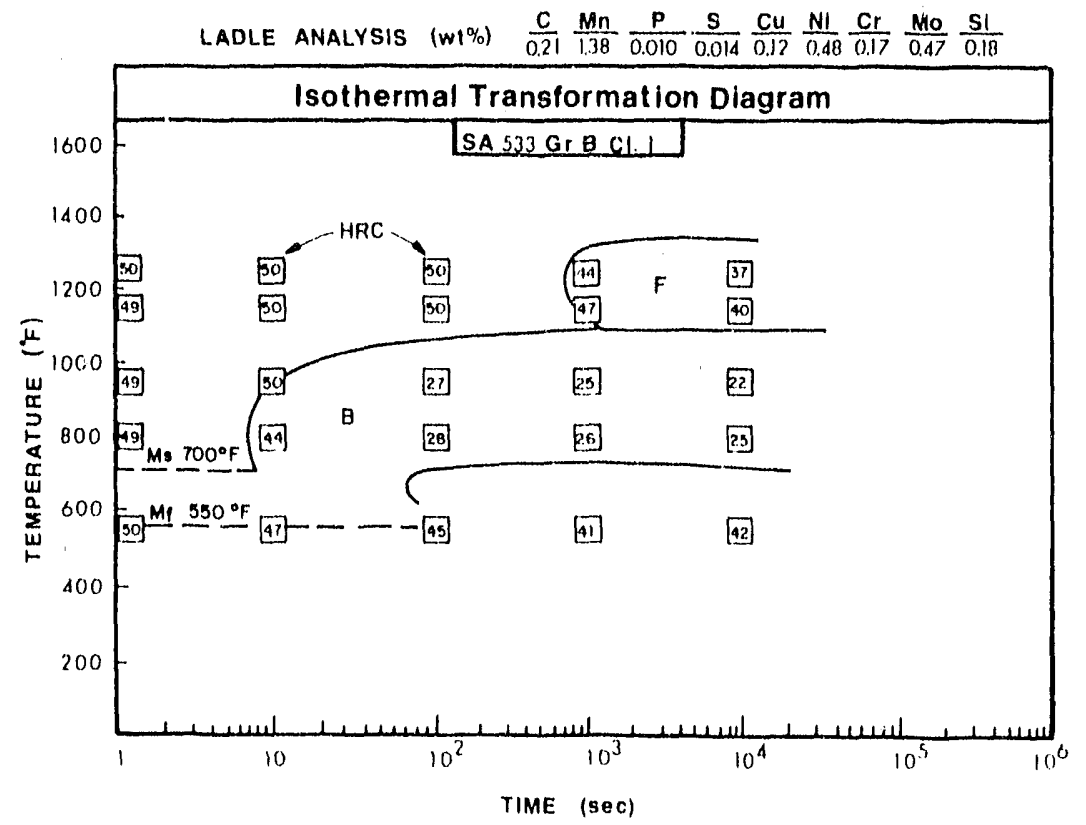

Fig. 23. Isothermal transformation diagram for SA-533, grade B, class 1, steel. Source: University of Tennessee. 


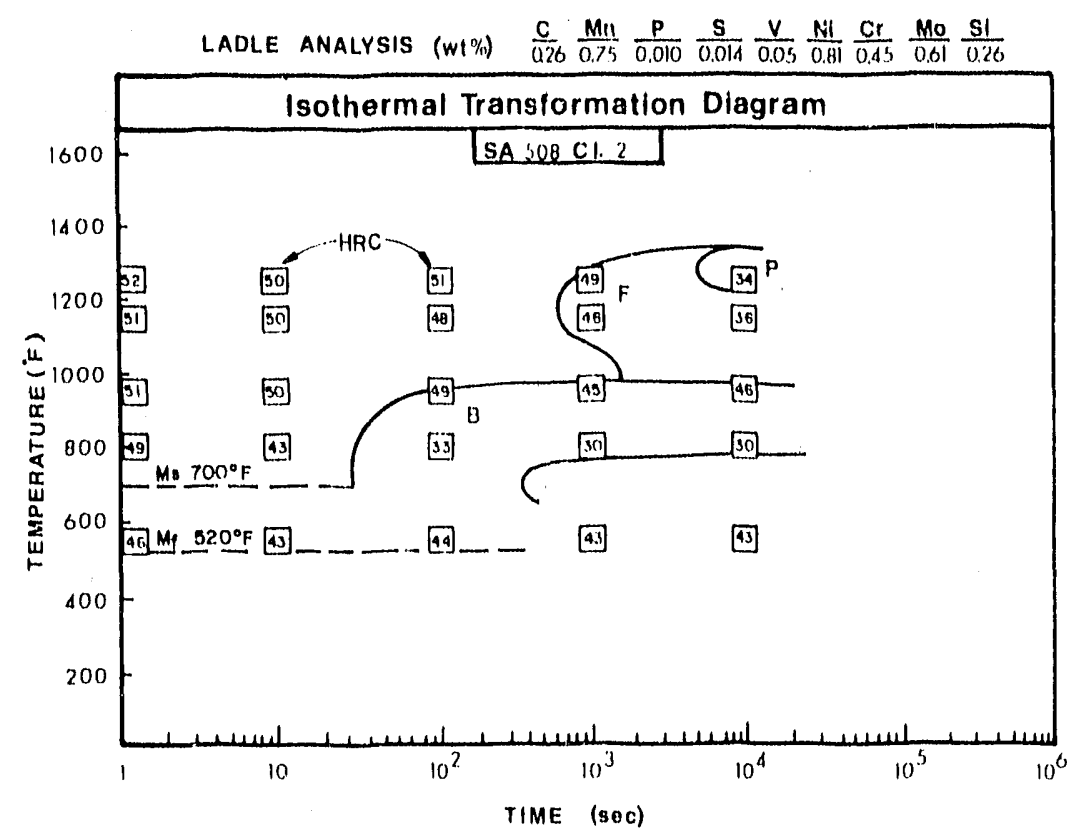

Fig. 24. Isothermal transformation diagram for SA-508, class 2, steel. Source: University of Tennessee.

At the austenitizing temperature, the steel is composed of a single constituent, austenite, which can exist as long as the temperature is maintained above a certain minimum temperature. When austenite is cooled below this critical temperature, it becomes unstable and transforms into a mixture of ferrite and carbide. For other than martensite, this change of austenite requires a certain incubation period before the transformation begins and then a certain amount of time to complete the transformation.

In the IT diagram in Fig. 23, representing the behavior of SA-533, grade $B$, class 1 , steel, the ferrite nose occurs at approximately $800 \mathrm{~s}$ and the bainite nose at approximately $7 \mathrm{~s}$. Transformation to martensite (which in this steel occurs at about $700^{\circ} \mathrm{F}$ ) differs from transformation of ferrite, pearlite, or bainite in that it is not diffusion-controlled (time-dependent) but occurs almost instantly upon cooling below the $M_{f}$, and the percentage of transformation depends only on the temperature to which it is cooled $\left(0-1008\right.$ from $M_{S}$ to $\left.M_{f}\right)$. Thus, in this steel, transformation to martensite starts on cooling at $700^{\circ} \mathrm{F}$ (designated as the $M_{S}$ temperature), is 908 complete on cooling at about $632^{\circ} \mathrm{F}$ (calculated value), and is essentially 1008 complete at about $550^{\circ} \mathrm{F}$. In Fig. 25, a fully martensitic structure is shown for a specimen quenched to $550^{\circ} \mathrm{F}$ from the austenitizing temperature.

Above $1100^{\circ} \mathrm{F}$, ferrite is the primary constituent forming with the onset of pearlite at longer times in this tempexature range. The constituent formed below $1100^{\circ} \mathrm{F}$ is bainite, which consists of a nonlamellar aggregate of ferrite and carbides. The morphology of bainite changes gradually with transformation temperature so that it is difficult to 


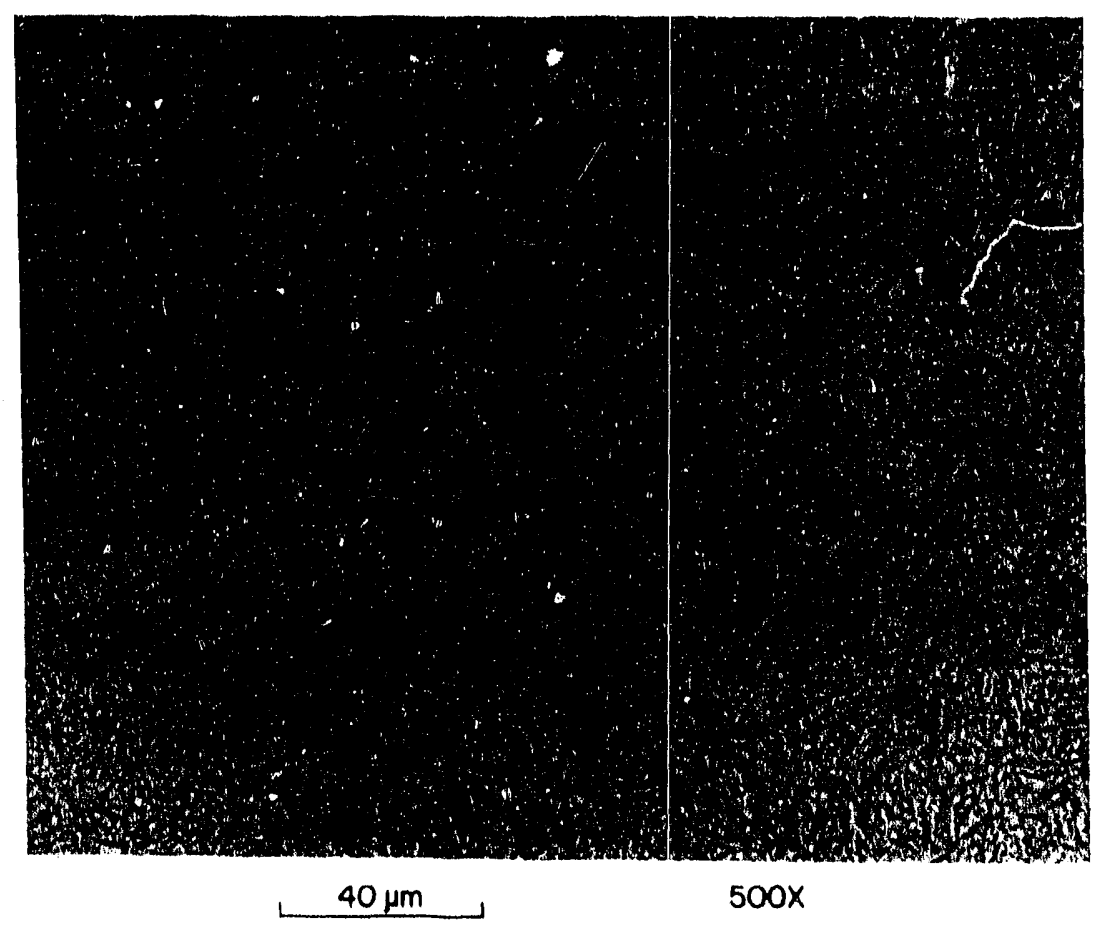

Fig. 25. Specimen 3TOA of SA-533, grade B, class 1 , steel (held for $1 \mathrm{~s}$ at $550^{\circ} \mathrm{F}$ ) shows fully martensitic structure. HRC 50. Super picral etch. Source: University of Tennessee.

uniquely define outstanding characteristics. In Fig. 26, the microstructure of the specimen, which was held at $800^{\circ} \mathrm{F}$ for $10 \mathrm{~s}$, shows martensite and bainite. On isothermal holding, the austenite begins to transform to bainite; the untransformed austenite remaining in the specimen at the instant it was quenched to room temperature appears in the final structure as martensite, which is a readily distinguishable transformation product. Similarly, in Fig. 27 a specimen held at $1250^{\circ} \mathrm{F}$ for $1000 \mathrm{~s}$, followed by quenching, shows a ferritic and martensitic structure.

The IT diagram in Fig. 24 for SA-508, class 2, represents isothermal transformation behavior similar to that observed for SA-533, grade B, class 1, steel. The ferrite nose has not changed position (start at $800 \mathrm{~s}$ ), but at longer times $(6000 \mathrm{~s}$ ) another micrconstituent, pearlite, is noted (the pearlite nose in SA-533, grade B, class 1, is apparently at times greater than $10,000 \mathrm{~s}$ ).

In SA-508, class 2, stecl the transformation to martensite occurs at approximately $700^{\circ} \mathrm{F}$; it is $90 \%$ complete (calculated value) on cooling at about $593^{\circ} \mathrm{F}$ and essentially 101$) 8$ complete at about $550^{\circ} \mathrm{F}$. In Fig. 28 , a fully martensitic structure is shown for a specimen quenched to $550^{\circ} \mathrm{F}$ from the austenitizing temperature of $1700^{\circ} \mathrm{F}$. 

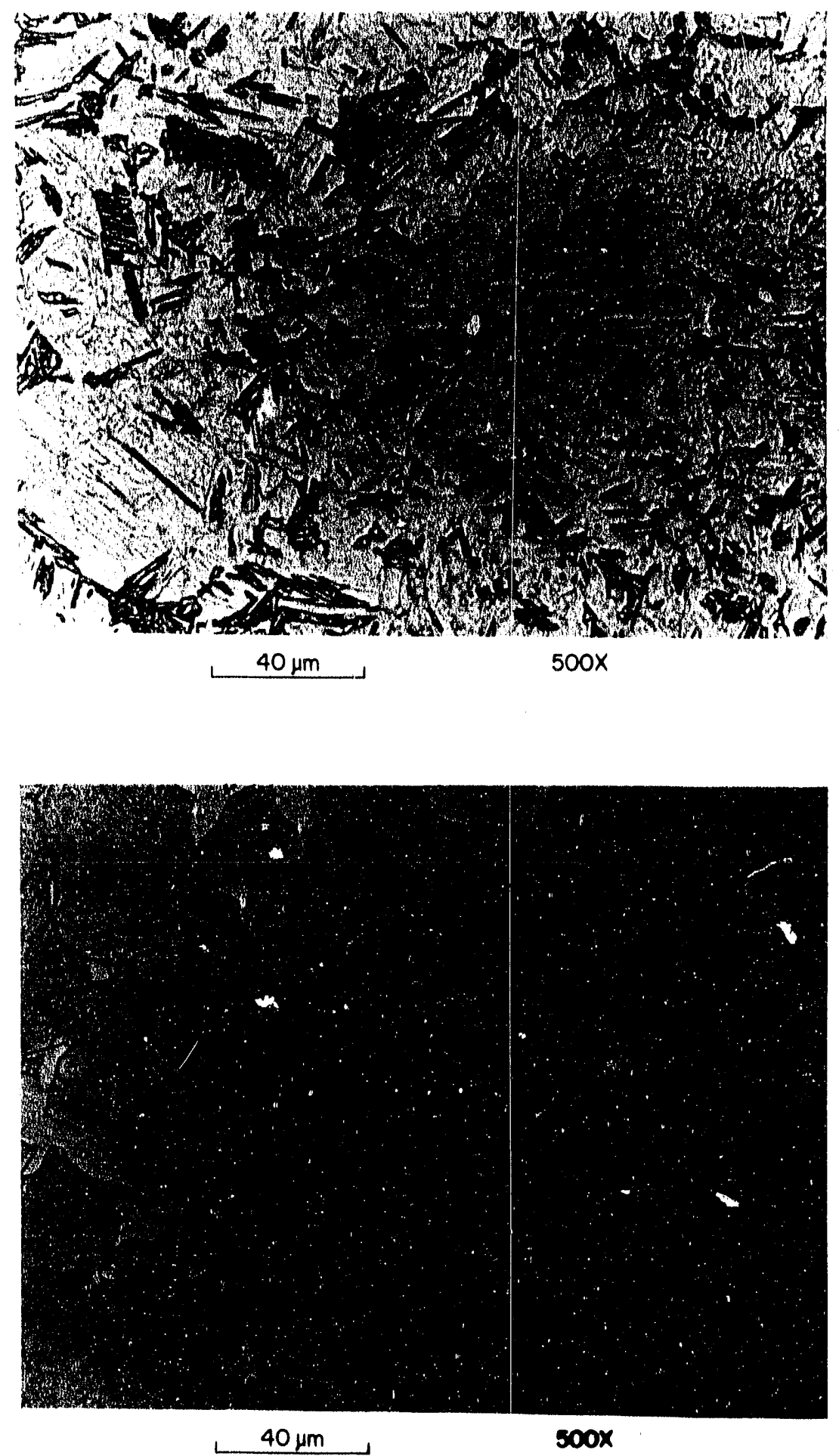

Fig. 26 .

Specimen $3 \mathrm{TLB}$ of SA-533, grade B, class 1, steel (held for $10 \mathrm{~s}$ at $800^{\circ} \mathrm{F}$ ) shows bainiticmartensitic structure. HRC 44. Super picral etch. Source: University of Tennessee.

F1g. 27.

Specimen $3 \mathrm{~T} 3 \mathrm{E}$ of SA-533, grade B, class 1, steel (held for $1000 \mathrm{~s}$ at $1250^{\circ} \mathrm{F}$ ) shows ferriticmartensitic structure. HRC 44. Super picral etch. Source: Un1versity of Tennessee. 


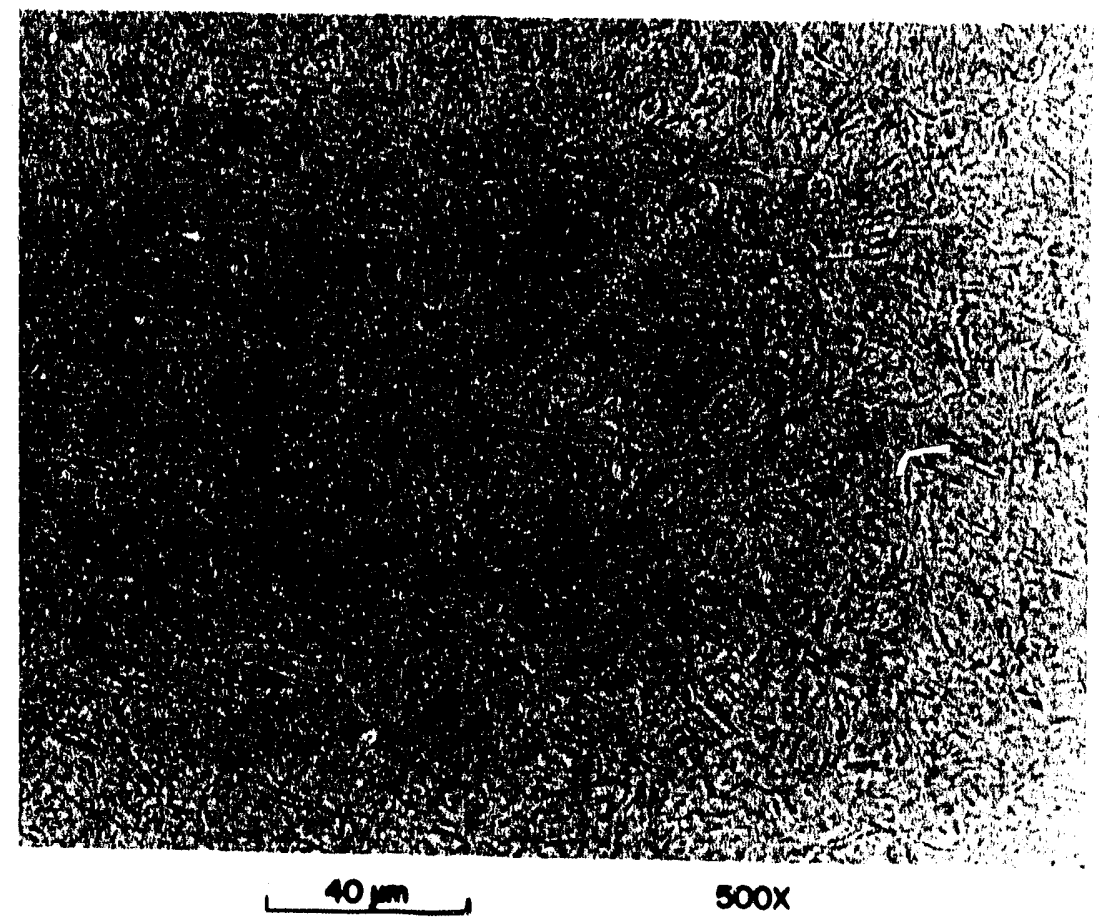

Fig. 28. Specimen $8 \mathrm{MOA}$ of SA-508, class 2, steel (held for $1 \mathrm{~s}$ at $550^{\circ} \mathrm{F}$ ) shows fully martensitic structure. HRC 52. Super picral etch. Source: Unlversity of Tennessee.

Figure 29, representing the specimen held at $800^{\circ} \mathrm{F}$ for $100 \mathrm{~s}$, shows that most of the austenite transformed to bainite; the untransformed austenite remaining in the specimen at the instant it was quenched to room temperature appears in the final structure as martensite. We concluded that austenite begins to transform to bainite at times less than $100 \mathrm{~s}$. Therefore, on the basis of microstructure and hardnesses, we estimated that the bainite nose occurs at approximately $35 \mathrm{~s}$.

The specimens held at $950^{\circ} \mathrm{F}$ appear to have less bainite than the samples held at $800^{\circ} \mathrm{F}$. The hardnesses correlated well with the microstructures because the hardness is higher for the specimens held at $950^{\circ} \mathrm{F}$ than for the specimens held at $800^{\circ} \mathrm{F}$. The observations suggest that the bainite start temperature for SA-508, class 2 , steel is lower than that observed in $\mathrm{SA}-533$, grade $B$, class 1 .

Transformation of austenite to ferrite is shown in Fig. 30 for the specimen held at $1250^{\circ} \mathrm{F}$ for $1000 \mathrm{~s}$. The untransformed austenite appears in the final structure as martensite, which was attained upon quenching. For the same holding temperature of $1250^{\circ} \mathrm{F}$ and longer time of $10,000 \mathrm{~s}$, a new microconstituent, pearlite, is formed (Fig. 31). This figure shows ferrite, martensite, and pearlite. The lamellar appearance of pearlite is not clearly visible at this magnification because of its fine structure. The scanning electro microscope (SEM) was used to achieve better 


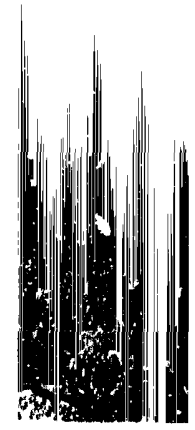

\section{$40 \mathrm{~mm} 500 x$}

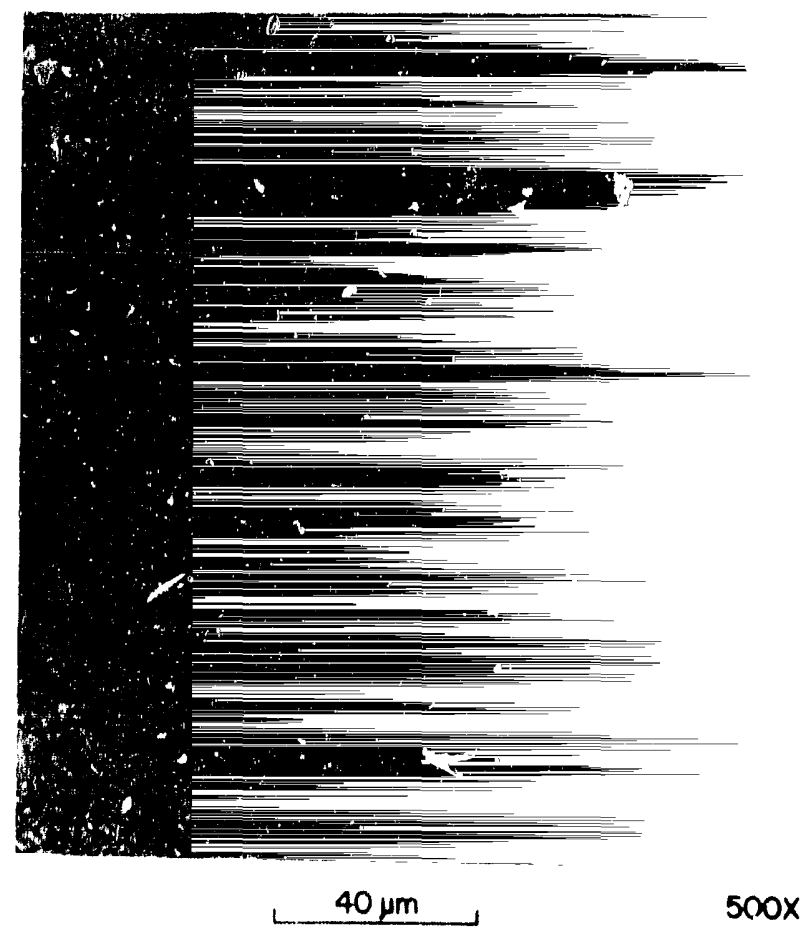




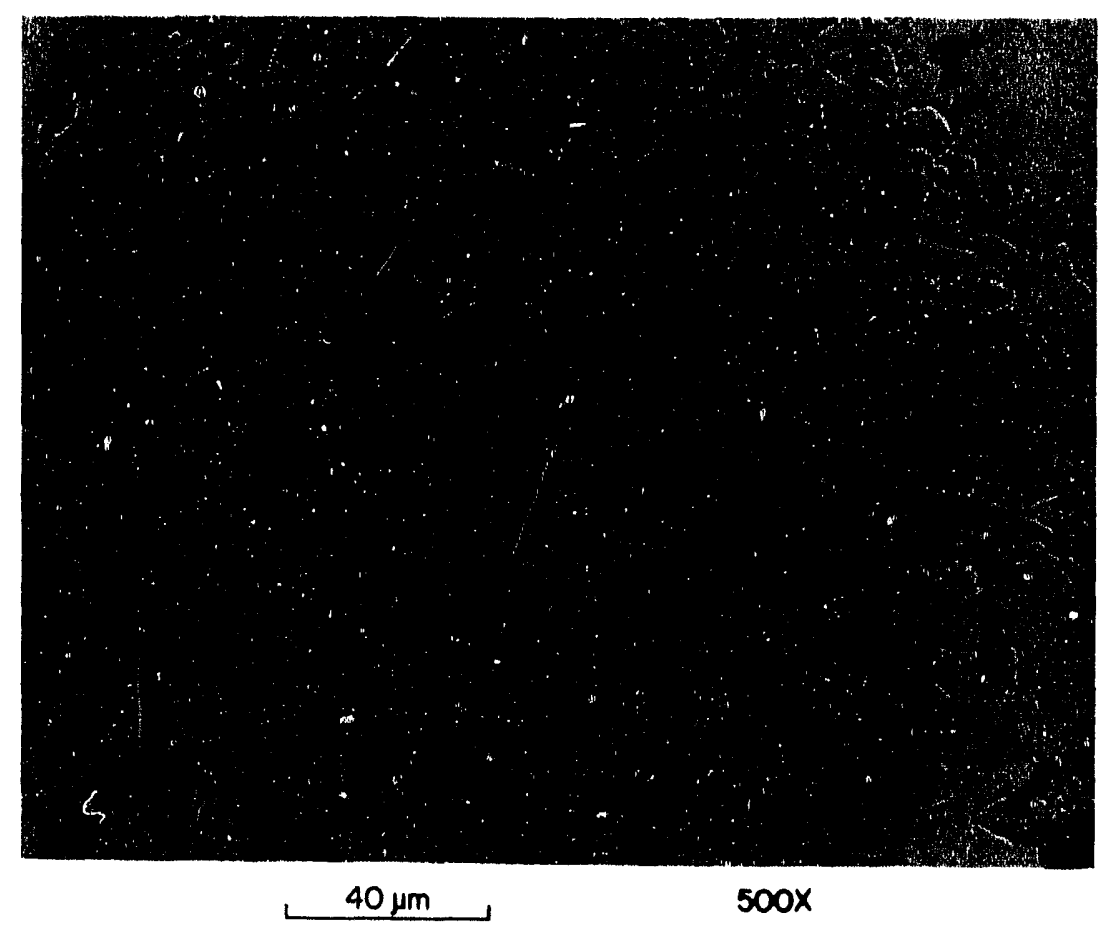

Fig. 31. Specimen 8M4E of SA-508, class 2, steel (held for $10,000 \mathrm{~s}$ at $1250^{\circ} \mathrm{F}$ ) shows ferriticpearlitic-martensitic structure. HRC 34. Super picral tech. Source: University of Tennessee.

resolution of the pearlite, and pearlite lamellae were clearly observed (Fig. 32).

Comparing the isothermal diagrams of SA-533, grade $B$, class 1 , and SA-508, class 2, steels shows that the bainite nose for SA-508, class 2, steel is shifted to larger times, approximately $30 \mathrm{~s}$ (Fig. 33). The bainite start temperature for SA-508, class 2, is lower than the bainite start temperature for SA-533, grade B, class 1. The ferrite nose for both steels is identical, located at approximately $800 \mathrm{~s}$. A pearlite nose for SA-508, class 2, is seen at approximately $6000 \mathrm{~s}$, whereas no pearlite was formed in SA-533, grade B, class 1., for holds up to $10,000 \mathrm{~s}$.

The $M_{S}$ values for both steels are approximately $700^{\circ} \mathrm{F}$, and the $M_{f}$ value for SA-533, grade B, class 1 , is estimated to be slightly higher than that for SA-508, class 2, steel. This estimation is based on the hardness values obtained at the hold temperature of $550^{\circ} \mathrm{F}$ for all times. We estimated that $M_{f}$ for SA-533, grade B, class 1 , is $550^{\circ} \mathrm{F}$, whereas $M_{f}$ for SA-508, class 2, steel is approximately $520^{\circ} \mathrm{F}$.

Lukens Steel Company ${ }^{12}$ indicates that because the analysis of SA-533, grade $B$, class 1 , steel is similar to that of $\mathrm{SA}-302$, grade $C$, steel, the transformation behavior of both steels should be nearly identical. To 


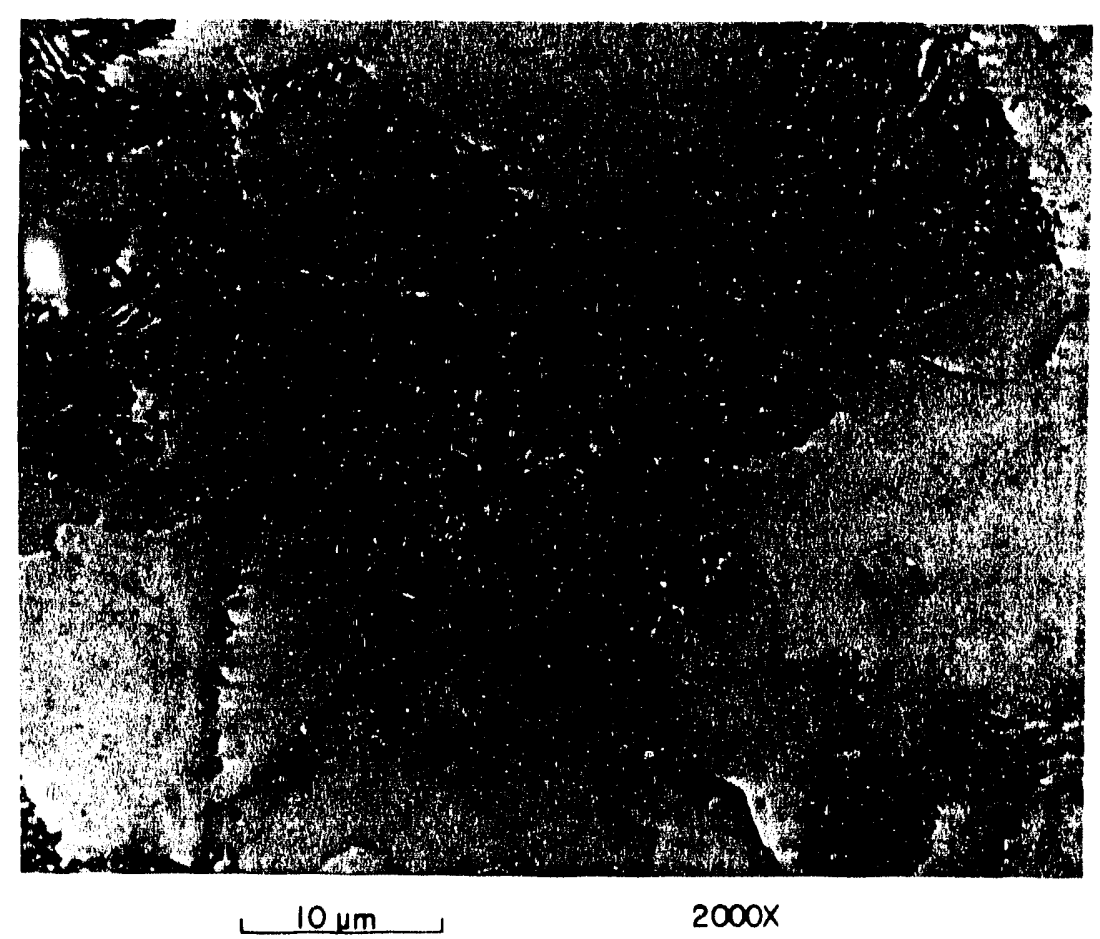

Fig. 32. Pearlitic-ferritic structure of specimen $8 \mathrm{M} 4 \mathrm{E}$ of SA-508, class 2, steel (held for $10,000 \mathrm{~s}$ at $1250^{\circ} \mathrm{F}$ ). Super picral etch. Scanning electron micrograph. Source: University of Tennessee.

verify that information, isothermal transformation diagrams for SA-533, grade $B$, class 1 , and $S A-302$, grade $C$, steels are compared in Fig. 34 . Transformation of the two steels is not identical; the transformation for the SA-533, grade B, class 1, begins at longer times than that for the SA-302, grade $C$, steel.

The isothermal diagrams show the fundamental transformation behavior of austenite at constant temperature; however, most actual heat treatinents involve transformation during cooling through a range of temperatures. The transformation that occurs during hardening, welding, or heat treating, by any method of controlled cooling can be approximated from the isothermal diagram, but continuous-cooling diagrans are more directly applicable. Therefore, continuous cooling transformation behavior for the weld HAZ of SA-533, grade B, class 1 , and SA-508, class 2 , steels has been documented.

CONTINUOUS-COOLING TRANSFURMATION BEHAVIOR

The problem of materials selection has become increasingly complex in recent years. No longer is it sufficient to choose materials for service on the basis of perfunctory examination. Many investigators have shown that materials that are to be weided must be carefilly examined as to changes brought by the heat of welding. 

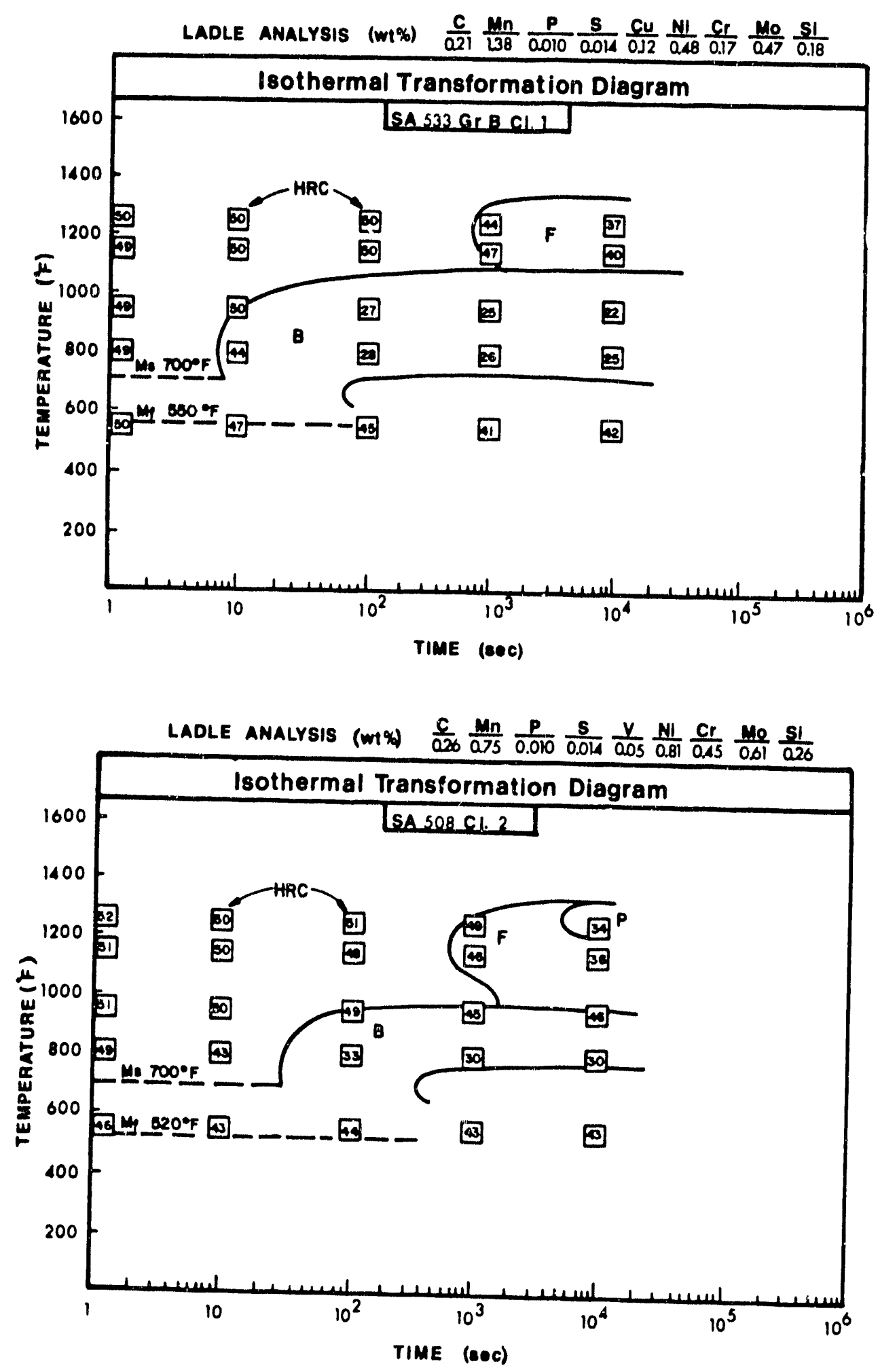

Fig. 33. Comparison of 1sothermal transformation behavior for SA-533, grade B, class 1, steel with that for SA-508, class 2, steel. Source: University of Tennessee. 

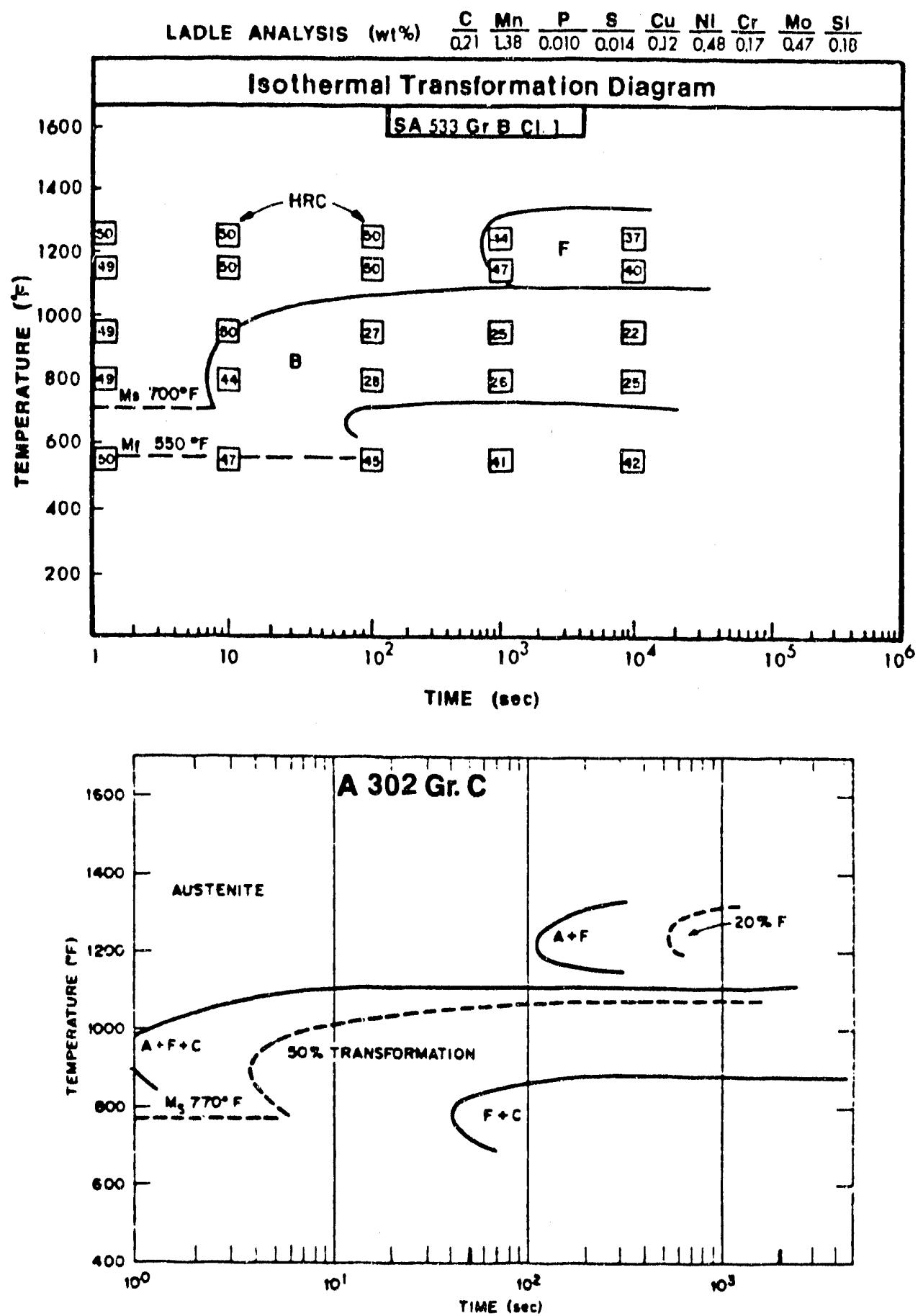

Fig. 34. Isothermal transformation diagrams for SA-533, grade B, class 1 , steel and SA-302, grade C, steel. Source: Lukens Steel Co., Coatesville, Penn. 
By careful evaluation, it has been possible to predict the weldability of many steels and to avoid welding conditions that would lead to poor properties. Metallography is one of the most powerful methods for evaluating weldability. It has long been known that, in steel, the microstructure of the HAZ frequently determines the overall performance of a weld. Thus it is very useful indeed to be able to predict accurately the microstructure in the HAZ of a weld knowing only the welding parameters and the CCT diagram.

Many CCT diagrams are available in the literature; however, few of them are directly applicable to weld HAZ problems. For the most part, the thermal cycles used to generate the diagrams are not similar to weld thermal cycles. Austenitization is usually accomplished at temperatures only high enough to produce complete austenitization. The extreme grain coarsening seen near the fusion zone in an arc weld is seldom duplicated by the thermal cycles used. The slow heating rates and extended periods at elevated temperatures used in previous investigations afford a degree of homogeneity and solution of carbides unattainable in the HAZ of an arc weld.

We decided, therefore, to determine CCT diagrams for SA-533, grade $B$, class 1, and SA-508, class 2, steels applicable to predicting inicrostructures in the HAZ. We employed two methods to study the behavior of CCT: (1) measuring the resistivity change of the material occurring on cooling and during transformation and (2) measuring the dilation of the material as the volume changes during the various transformations.

Continuous-Cooling Transformation Behavior Obtained by Resistivity Measurements

SA-533, grade $B$, class 1 . The CCT behavior for SA-533, grade $B$, class 1 , steel is shown in Fig. 35. The specimens were heated to the austenitizing temperature of $1650 \pm 20^{\circ} \mathrm{F}$, held for $10 \mathrm{~min}$, and then cooled in vacuum at a predetermined rate. Cooling curves from a to $\mathrm{g}$ were obtained by helium blast, whereas curves $h$ to $I$ were obtained in vacuum at programmed rates. The cooling rates obtained at $1300^{\circ} \mathrm{F}$ for curves $a$ to $g$ are shown at the end of each curve. Table 4 shows cooling rates obtained at $1300^{\circ} \mathrm{F}$ and $1000^{\circ} \mathrm{F}$ for curves a to $\mathrm{g}$ and the controlled linear cooling rates of curves from $h$ to 1 .

When the steel was cooled under conditions applicable to curves a and $b$, only martensite formed and two transformation temperatures were obtained, $M_{s}$ and $M_{f}$, whereas for curve $c$ three transformation temperatures were noticed, which indicates that the critical cooling rate for bainite is approximately $140^{\circ} \mathrm{F} / \mathrm{s}$ at $1300^{\circ} \mathrm{F}$. The calculated $M_{S}\left(700^{\circ} \mathrm{F}\right)$ and $M_{f}$ $\left(632^{\circ} \mathrm{F}\right)$ temperatures correlate well with the experimental transformation temperatures $\left[M_{S}\left(720^{\circ} \mathrm{F}\right), M_{f}\left(600^{\circ} \mathrm{F}\right)\right]$.

The bainite nose (Fig. 35) occurs at approximately $9 \mathrm{~s}$ and the ferrite nose at approximately $1500 \mathrm{~s}$. Cooling curves from $i$ to $I$ show the ferrite start $\left(F_{S}\right)$ and also show that the $F_{S}$ temperature decreases with increasing cooling rates. The critical cooling rate for ferrite is 


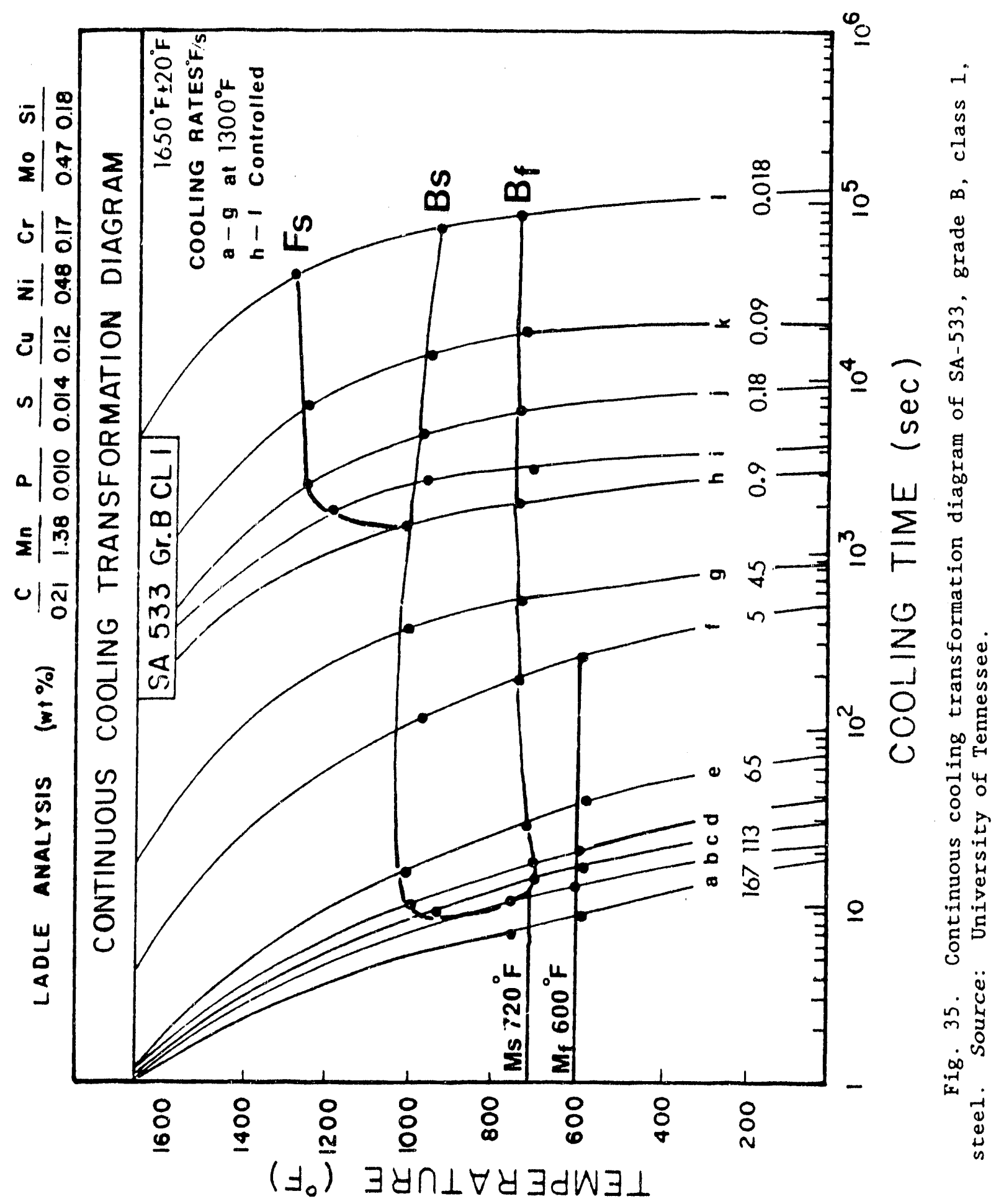


Table 4. Cooling rates of material SA-533, grade B, class 1 , from curves a to 1 of Fig. 35

\begin{tabular}{|c|c|c|c|c|c|}
\hline \multirow{3}{*}{$\begin{array}{l}\text { Cooling } \\
\text { curves }\end{array}$} & \multirow{3}{*}{$\begin{array}{l}\text { Helium blast } \\
\text { (psi) }\end{array}$} & \multicolumn{4}{|c|}{ Cooling rate } \\
\hline & & \multicolumn{2}{|c|}{$1300^{\circ} \mathrm{F}$} & \multicolumn{2}{|c|}{$1000^{\circ} \mathrm{F}$} \\
\hline & & $\left({ }^{\circ} \mathrm{C} / \mathrm{s}\right)$ & $\left({ }^{\circ} \mathrm{F} / \mathrm{s}\right)$ & $\left({ }^{\circ} \mathrm{C} / \mathrm{s}\right)$ & $\left({ }^{\circ} \mathrm{F} / \mathrm{s}\right)$ \\
\hline$a$ & 30 & 93 & 167 & 62 & 111 \\
\hline$b$ & 15 & 76 & 137 & 51 & 92 \\
\hline$c$ & 5 & 63 & 113 & 49 & 88 \\
\hline$d$ & 2 & 43 & 77 & 41 & 74 \\
\hline$e$ & 0.5 & 37 & 65 & 19 & 34 \\
\hline$f$ & $<0.25$ & 3 & 5 & 2 & 3.6 \\
\hline$g$ & No He used & 2.5 & 4.5 & 0.6 & 1.08 \\
\hline \multicolumn{6}{|c|}{ Controlled rate } \\
\hline$h$ & & 0.5 & 0.9 & 0.5 & 0.9 \\
\hline$i$ & & 0.3 & 0.54 & 0.3 & 0.54 \\
\hline$j$ & & 0.1 & 0.18 & 0.1 & 0.18 \\
\hline$k$ & & 0.05 & 0.09 & 0.05 & 0.09 \\
\hline 1 & & 0.010 & 0.018 & 0.010 & 0.018 \\
\hline
\end{tabular}

approximately $1^{\circ} \mathrm{F} / \mathrm{s}$ at $1300^{\circ} \mathrm{F}$. The $F_{S}$ transformation temperature was difficult to detect by the electrical resistivity measurement (ERM) method.

Selected samples were examined metallographically. The specimen experiencing a cooling rate of $167^{\circ} \mathrm{F} / \mathrm{s}$ (curve a) formed a fully martensitic structure, which is shown in Fig. 36 . The sample experiencing a cooling rate of $4.5^{\circ} \mathrm{F} / \mathrm{s}$ (curve $g$ ) resulted in a bainitic structure shown in Fig. 37. Finally, the specimen with the slowest cooling rate of $0.09^{\circ} \mathrm{F} / \mathrm{s}$ (curve $k$ ) showed a ferritic, bainitic, pearlitic structure as shown in Fig. 38. The onset of the pearlite reaction was not observed in the CCT diagrams obtained by ERM.

SA-508, class 2. The CCT diagram for SA-508, class 2, steel is shown in Fig. 39. The heating and cooling of the sample was identical to that described for the SA-533, grade B, class 1 , specimens. Table 5 shows the cooling rates obtained at $1300^{\circ} \mathrm{F}$ and $1000^{\circ} \mathrm{f}$ for curves a to $i$ and the controlled linear cooling rates for curves $j$ to $p$.

The cooling curves a through $f$ show only the martensite transformation, whereas curve $g$ exhibits three transformation reactions, indicating that critical cooling rate for the bainite start lies between curves $f$ and $g$ (approximately $50^{\circ} \mathrm{F} / \mathrm{s}$ at $1300^{\circ} \mathrm{F}$ ). The calculated $M_{S}\left(685^{\circ} \mathrm{F}\right.$ ) and $M_{f}$ $\left(593^{\circ} \mathrm{F}\right)$ temperatures agree with the experimental values $M_{S}\left(685^{\circ} \mathrm{F}\right)$ and $M_{f}$ $\left(500^{\circ} \mathrm{F}\right)$. 


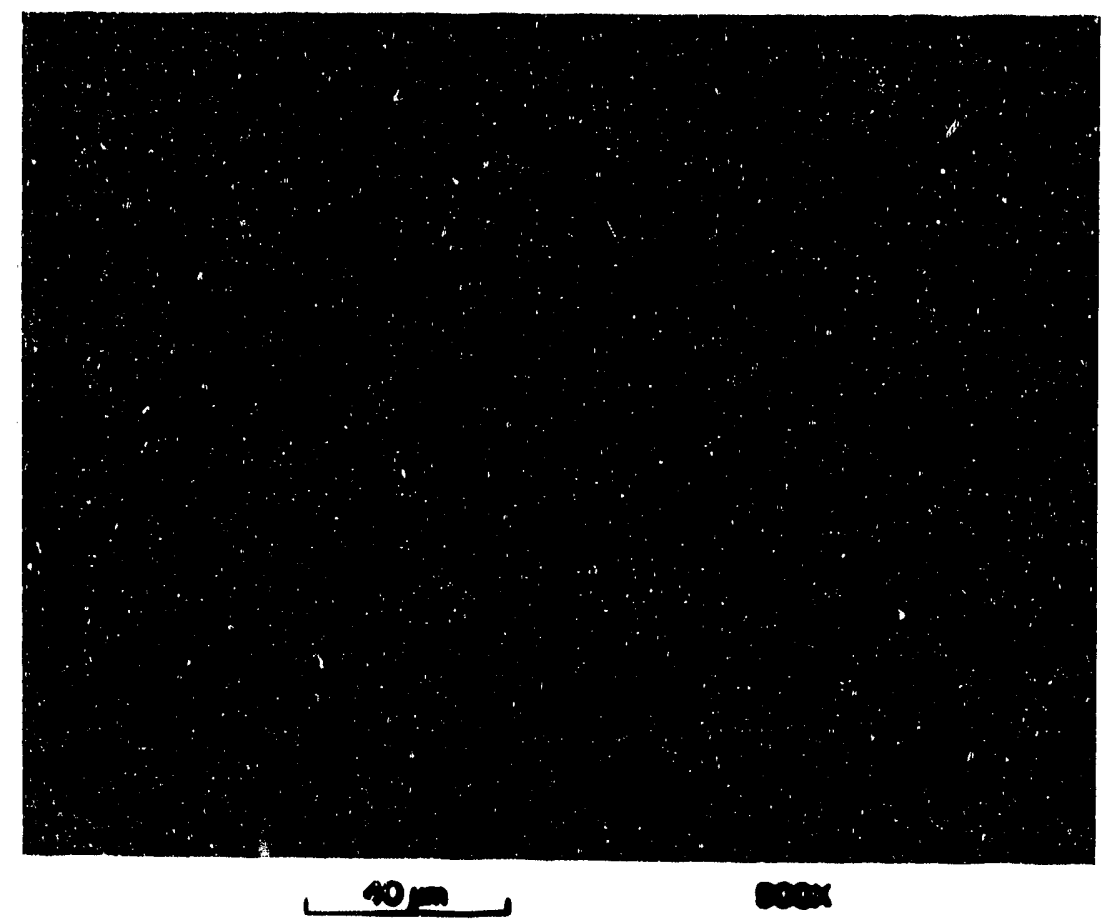

Fig. 36. Fully martensitic structure of SA-533, grade B, class 1, steel representing curve a of Fig. 35. Cooling rate $167^{\circ} \mathrm{F} / \mathrm{s}$ at $1300^{\circ} \mathrm{F}$. Super picral etch. Source: University of Tennessee.

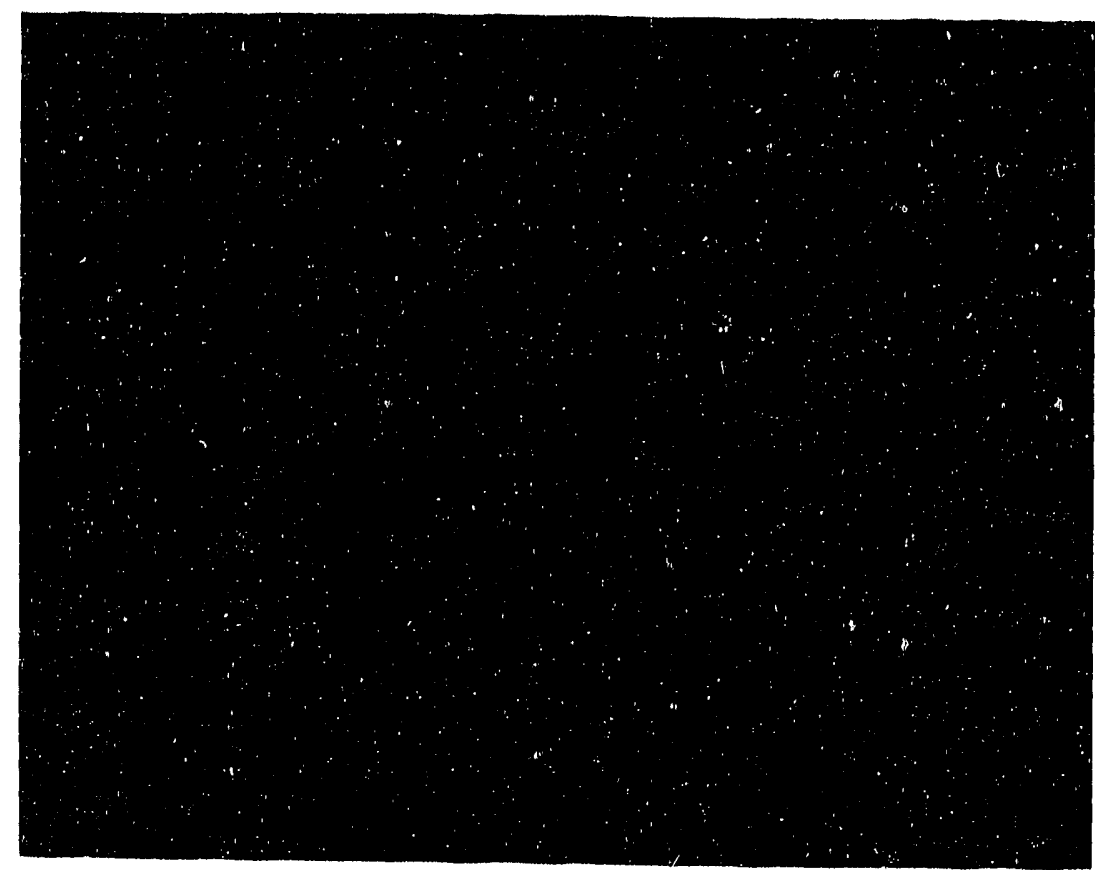

F1g. 37. Bainitic structure of SA-533, grade $B$, class 1 , steel representing curve $g$ of Fig. 35. Cooling rate $4.5^{\circ} \mathrm{F} / \mathrm{s}$ at $1300^{\circ} \mathrm{F}$. Super picral etch. Source: University of Tennessee. 

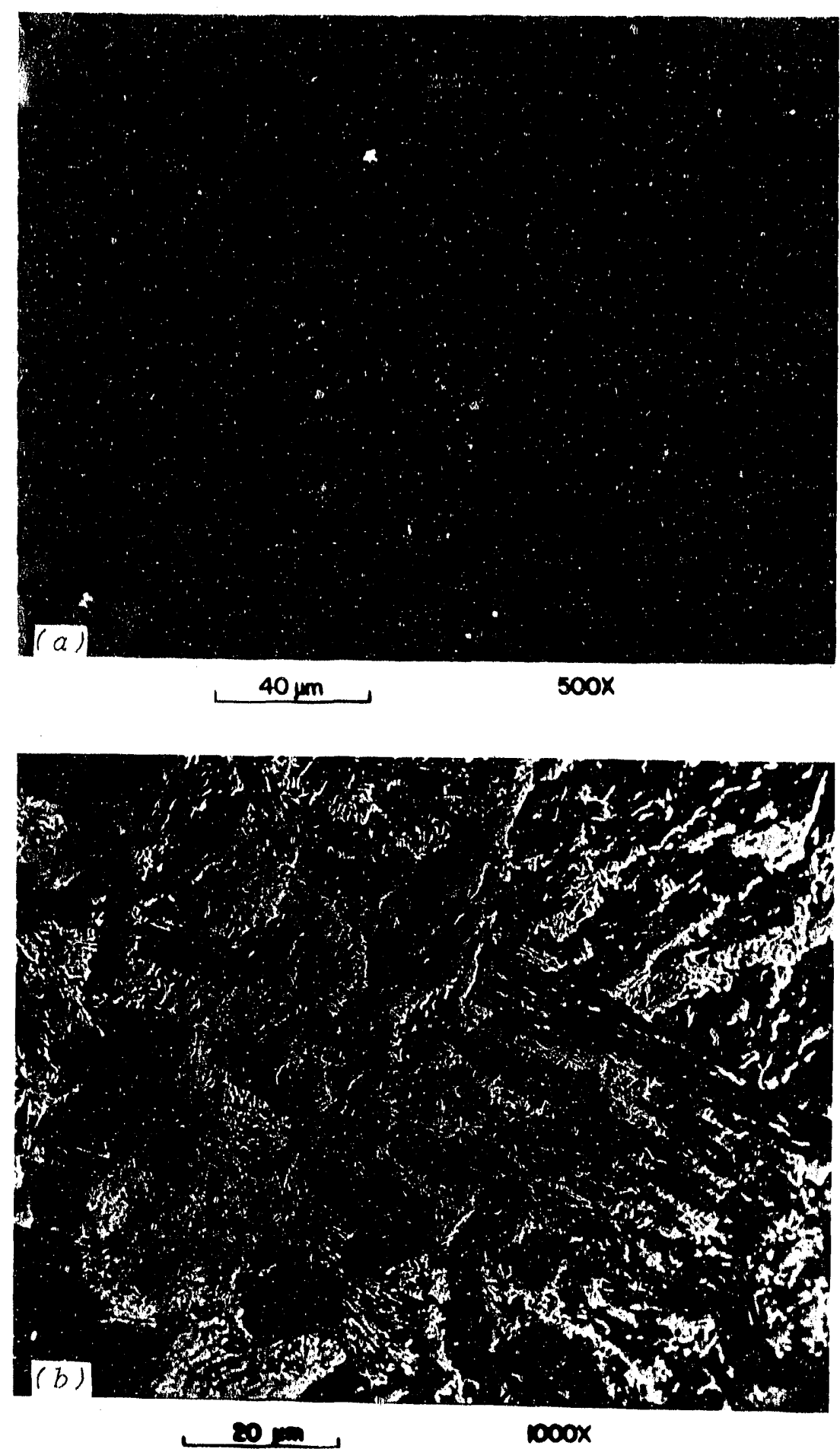

Fig. 38. Microstructures of SA-533, grade B, class 1, steel representing curve $k$ of Fig. 35 . Cooling rate $0.09^{\circ} \mathrm{F} / \mathrm{s}$ at $1300^{\circ} \mathrm{F}$. Super picral etch. Ferritic-bainitic-pearlitic structure. (a) Optical micrograph. (b) Scanning electron micrograph. Source: University of Tennessee. 


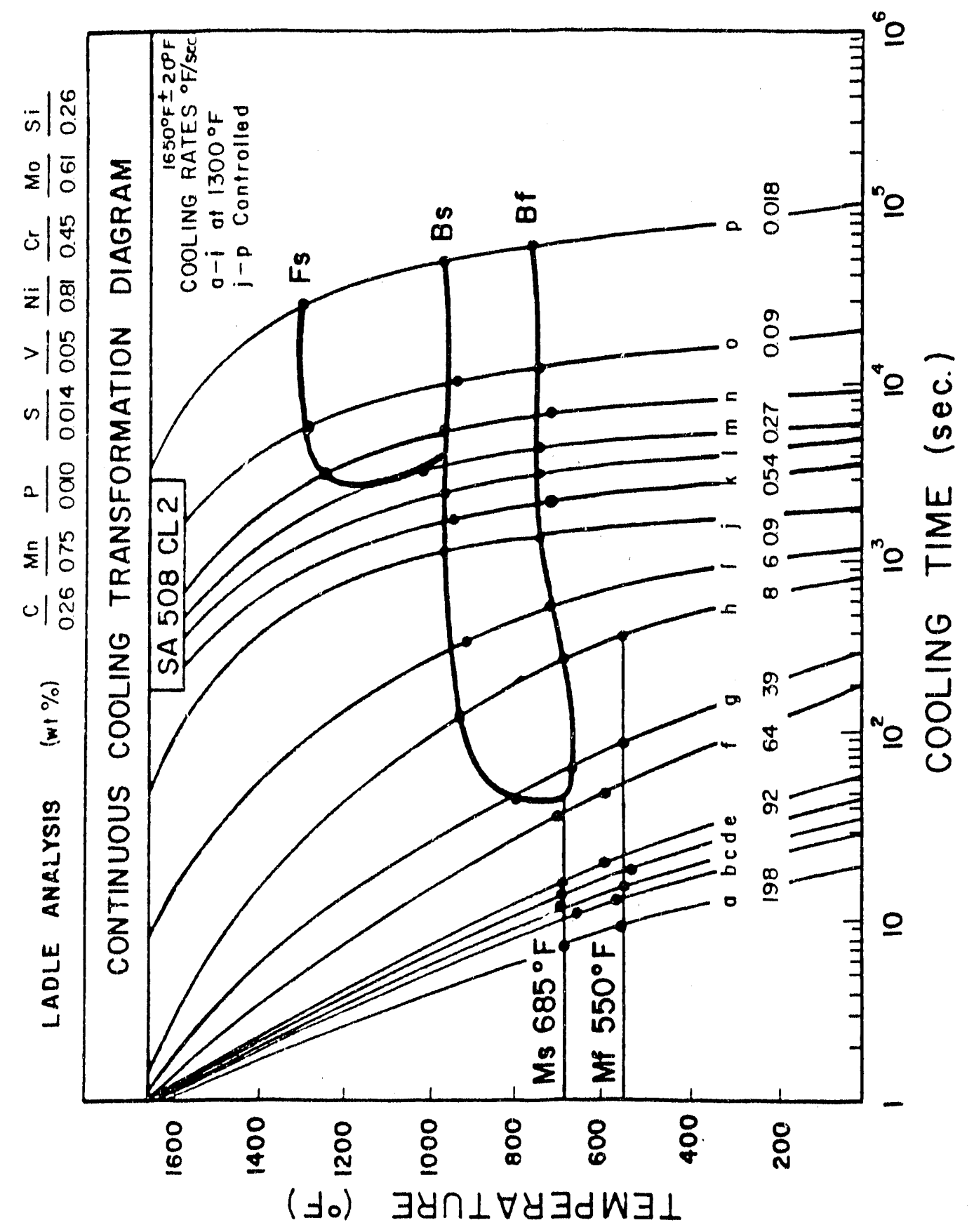

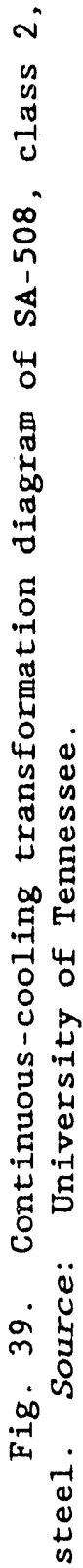


Table 5. Cooling rates of material SA-508, class 2, from curves a to $p$ of Fig. 39

\begin{tabular}{|c|c|c|c|c|c|}
\hline \multirow{3}{*}{$\begin{array}{l}\text { Cooling } \\
\text { curves }\end{array}$} & \multirow{3}{*}{$\begin{array}{l}\text { Helium blast } \\
\text { (psi) }\end{array}$} & \multicolumn{4}{|c|}{ Cooling rate } \\
\hline & & \multicolumn{2}{|c|}{$1300^{\circ} \mathrm{F}$} & \multicolumn{2}{|c|}{$1000^{\circ} \mathrm{F}$} \\
\hline & & $\left({ }^{\circ} \mathrm{C} / \mathrm{s}\right)$ & $\left({ }^{\circ} \mathrm{F} / \mathrm{s}\right)$ & $\left({ }^{\circ} \mathrm{C} / \mathrm{s}\right)$ & $\left({ }^{\circ} \mathrm{F} / \mathrm{s}\right)$ \\
\hline$a$ & 32 & 110 & 198 & 96 & 173 \\
\hline$b$ & 15 & 85.3 & 153 & 66 & 119 \\
\hline$c$ & 5 & 78 & 141 & 55.5 & 100 \\
\hline$d$ & 2 & 60 & 108 & 40 & 72 \\
\hline$e$ & 0.5 & 51 & 92 & 38.6 & 69 \\
\hline$f$ & $>0.25$ & 35.4 & 64 & 15.5 & 28 \\
\hline$g$ & 0.25 & 21.6 & 39 & 9.3 & 17 \\
\hline$h$ & $<0.25$ & 4.5 & 8 & 2.6 & 5 \\
\hline$i$ & No He used & 3.3 & 6 & 0.88 & 2 \\
\hline \multicolumn{6}{|c|}{ Controlled rate } \\
\hline j & & 0.5 & 0.9 & 0.5 & 0.9 \\
\hline$k$ & & 0.3 & 0.54 & 0.3 & 0.54 \\
\hline 1 & & 0.2 & 0.36 & 0.2 & 0.36 \\
\hline$m$ & & 0.15 & 0.27 & 0.15 & 0.27 \\
\hline$n$ & & 0.1 & 0.18 & 0.1 & 0.18 \\
\hline 0 & & 0.05 & 0.09 & 0.05 & 0.09 \\
\hline$p$ & & 0.010 & 0.018 & 0.010 & 0.018 \\
\hline
\end{tabular}

Figure 39 shows that the bainite nose lies at approximately $40 \mathrm{~s}$ and the ferrite nose at approximately $3000 \mathrm{~s}$, with the critical cooling rate for ferrite formation being approximately $0.25^{\circ} \mathrm{F} / \mathrm{s}$ at $1300^{\circ} \mathrm{F}$.

The samples exhibiting a cooling rate of $198^{\circ} \mathrm{F} / \mathrm{s}$ at $1300^{\circ} \mathrm{F}$ representing curve a show a fully martensitic structure (Fig. 40). Specimens with cooling rates of $6^{\circ} \mathrm{F} / \mathrm{s}$ at $1300^{\circ} \mathrm{F}$ (curve i) reveal a fully bainitic structure, which is shown in Fig. 41. The specimen with the slowest cooling rate of $0.018^{\circ} \mathrm{F} / \mathrm{s}$, representing curve $p$, formed ferrite and a bainite/pearlite microstructure as shown in Figs. 42(a) and 42(b). Again, the pearlite transformation was not uniquely revealed and may lie in the same range as bainite for very slow cooling.

CCT comparisons. The CCT diagrams for SA-533, grade B, class 1 , and SA-508, class 2, steels are compared in Fig. 43. The bainite nose of SA-508, class 2, is shifted farther to the right (approximately $30 \mathrm{~s}$ ) and has slower critical cooling rate than for $S A-533$, grade $B$, class 1 . The ferrite nose for SA-508, class 2, has also shifted farther to the right (approximately $1500 \mathrm{~s}$ ). A careful observation of the bainite start temperature for both steels shows that bainite start temperature for SA-508, class 2, is a little lower than that for SA-533, grade B, class 1. This observation also reflects the results of the isothermal transformation 


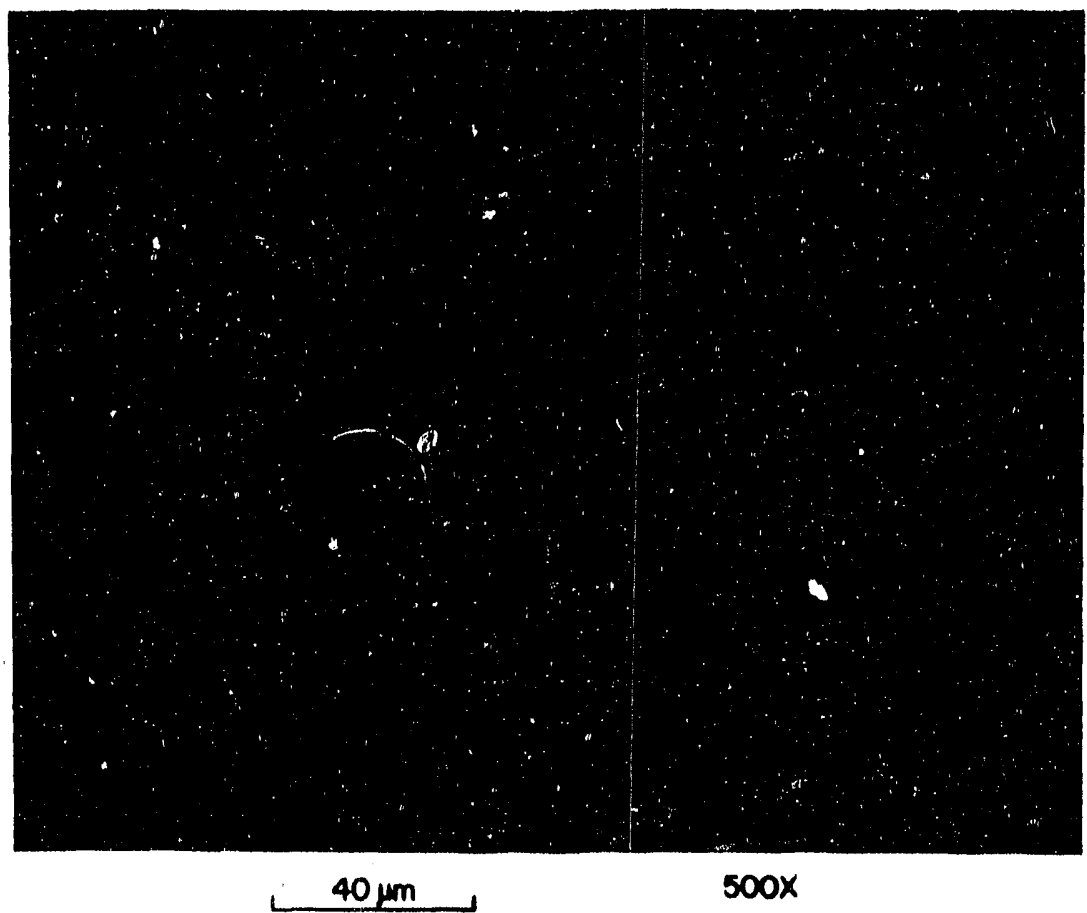

Fig. 40. Fully martensitic structure nf SA-508, class 2, steel representing curve $a$ of Fig. 39. Cooling rate $198^{\circ} \mathrm{F} / \mathrm{s}$ at $1300^{\circ} \mathrm{F}$. Super picral etch. Source: University of Tennessee.

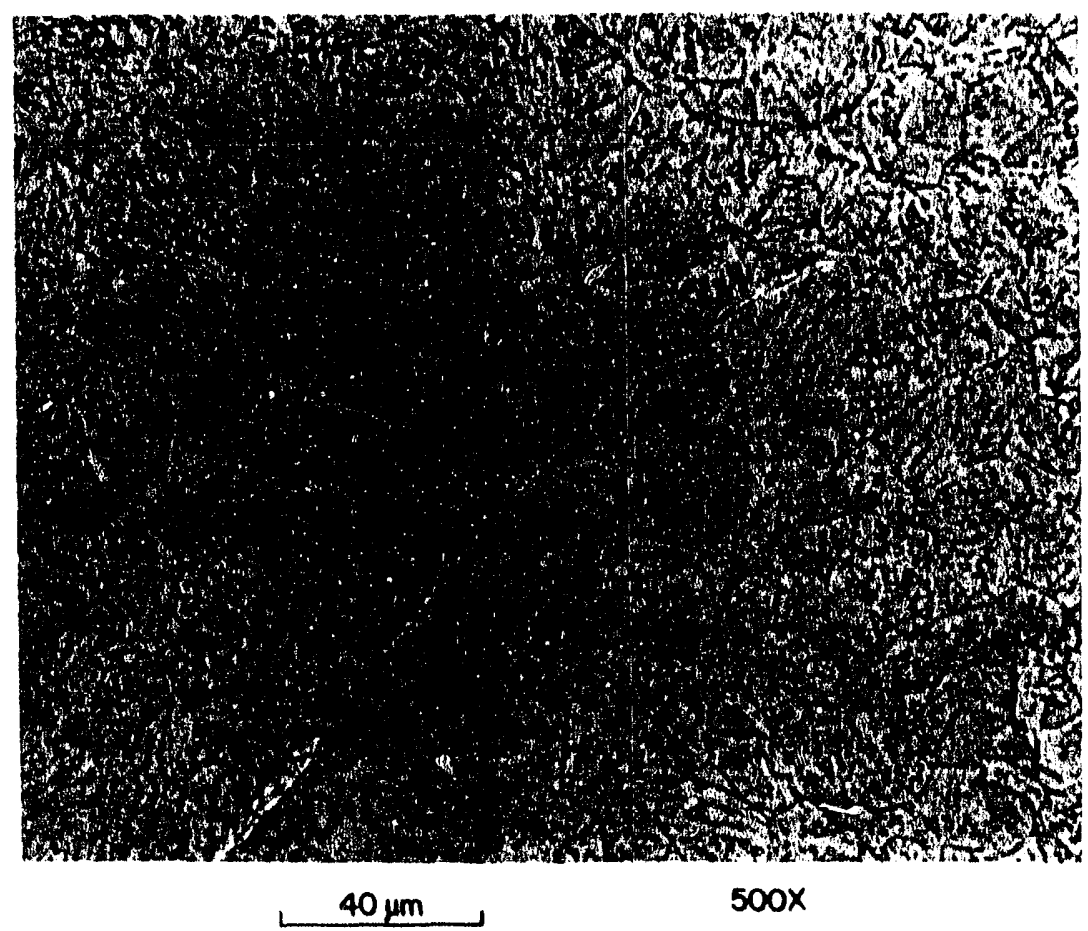

Fig. 41. Bainitic structure of SA-508, class 2, steel representing curve $i$ of Fig. 39. Cooling rate $6^{\circ} \mathrm{F} / \mathrm{s}$ at $1300^{\circ} \mathrm{F}$. Super picral etch. Source: University of Tennessee. 

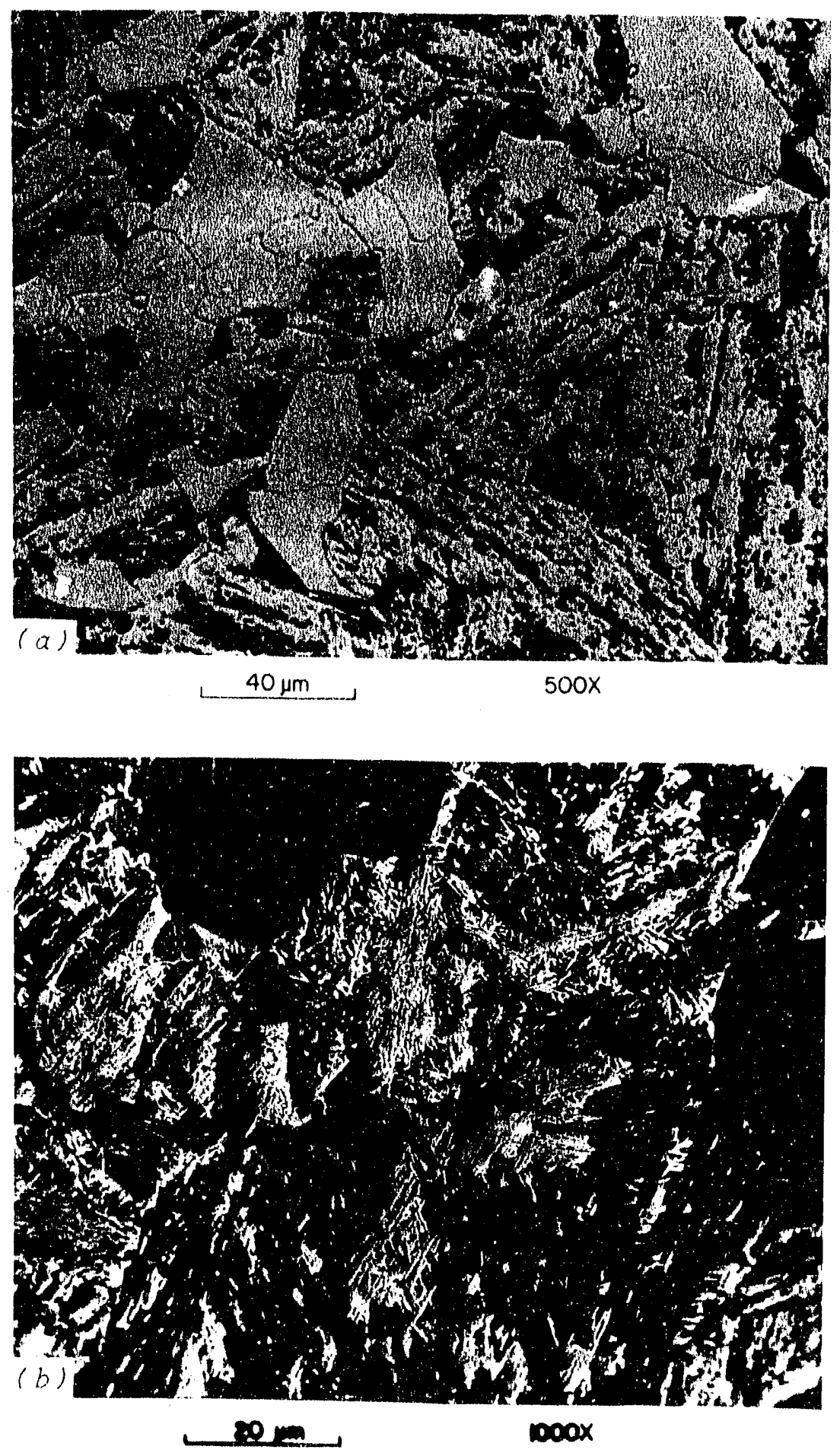

Fig. 42. Microstructures of SA-508, class 2, steel representing curve $p$ of Fig. 39. Cooling rate $0.018^{\circ} \mathrm{F} / \mathrm{s}$ at $1300^{\circ} \mathrm{F}$. Super picral etch. Bainitic-pearlitic structure. (a) Optical micrograpt. (b) Scanning electron micrograph. Source: University of Tennessee. 

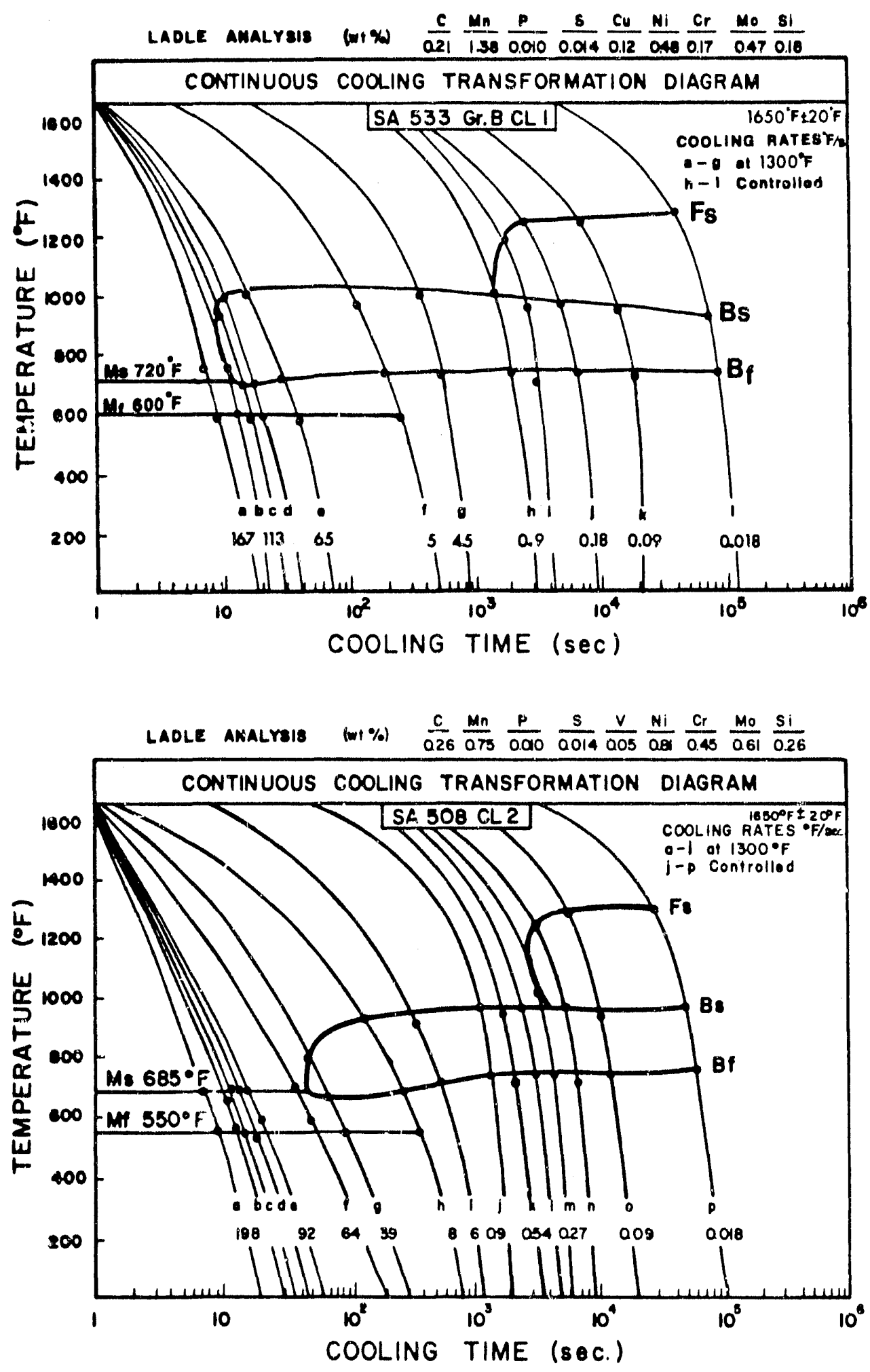

Fig. 43. Comparison of continuous-cooling transfor. mation behaviors for SA-533, grade B, class 1, and SA-508, class 2, steels. Source: University of Tennessee. 
studies. The $M_{S}$ and $M_{f}$ temperatures of SA-508, class 2, steel are lower than those of SA-533, grade B, class 1, steel.

The transformation behavior observed with the slowest cooling rates in both steels showed bainitic, pearlitic, and ferritic microconstituents. The transformation temperature for pearlite start $\left(P_{s}\right)$ could not be uniriuely detected. The transformation may be similar to the bainite transformation for very slow cooling occurring in the same temperature range.

Comparing the CCT behavior with the IT behavior shows that CCT transformation curves lie below and to the right of the corresponiing isothermal transformation curves, as expected from previous work. ${ }^{12}$

It is readily predicted from the CCT diagrams that SA-508, class 2, steel has higher hardenability than SA-533, grade B, class 1 , steel. Further, these CCT diagrams are not directly applicable to the wald HAZ because the thermal history of the material for these diagrams is not similar to weld HAZ thermal cycles and because the austenitizing temperature was only high enough to produce complete austenitization but not high enough to produce grain coarsening, which is usually noted near the fusion line in arc welds. Continuous cooling transformation diagrams were determined for both steels in a manner that renders them applicable to predicting transformations and microstructures in the weld HAZ.

Continuous Cooling Transformation Behavior for the Heat-Affected Zone Exposure Obtained by the Gleeble Dilatometric Method

We obtained CCT diagrams for two regions of the weld HAZ. The two peak temperatures chosen represent the coarse-grained region $\left(2400^{\circ} \mathrm{F}\right.$ peak) next to the fusion zone and the refined region $\left(1650^{\circ} \mathrm{F}\right.$ peak) in the outer extremities of the HAZ.

SA-533, grade B, class 1. We determined the behavior of $\mathrm{SA}-533$, grade $B$, class 1 , steel for a peak temperature of $1650^{\circ} \mathrm{F}$ (Fig. 44). Cooling curve a represents the most rapid cooling attainable in the Gleeble corresponding to approximately $20 \mathrm{~kJ} / \mathrm{in} .(1-i n$. plate). With this rapid cooling, all transformation was to martensite. Cooling conditions from I to VI all pass through the bainite region, ravealing the $B_{S}$ and $B_{f}$ transformation temperatures, and, at the rapid rates, they reveal mixed bainite-martensite transfornation. The ferrite region was not revealed because it would require slower cooling rates and thus welding energy inputs not characteristic of any reasonable welding process except, possibly, electroslag.

Note that SA-533, grade B, Class 1 , CCT behavior obtained by the Gleeble dilatometric technique (Fig. 44) correlates well with the CCT behavior obtained by ERM (Fig. 35) albeit with different times at $1650^{\circ} \mathrm{F}$. The gap between $B_{f}$ and $M_{S}$ lines shown in Fig. 44 is due to the ability of the Gleeble to clearly detect start and finish points, whereas ERM is not as sensitive in detecting the finish points. The Rockwell $C$ hardness 


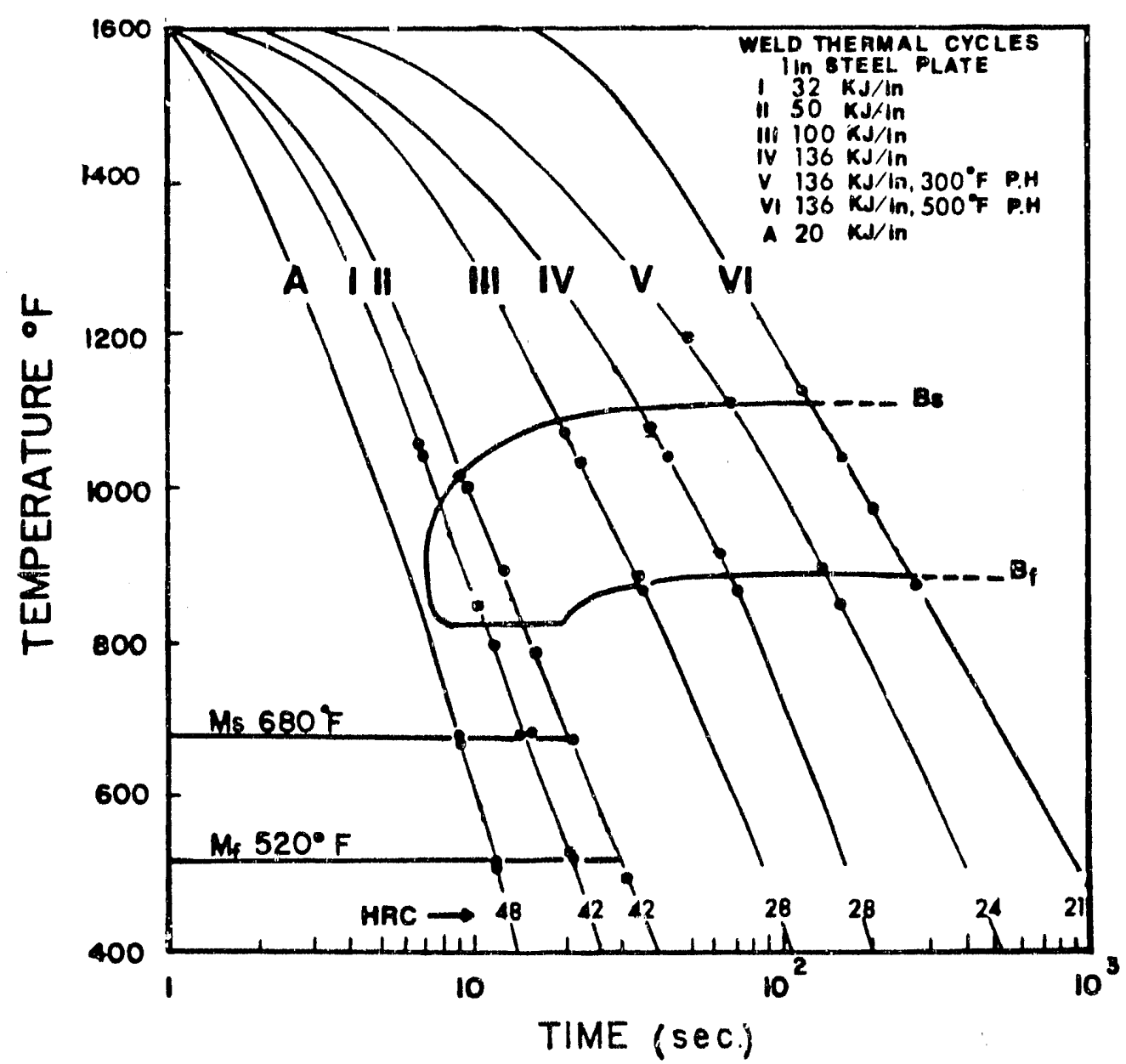

Fig. 44. Continuous-cooling transformation diagram of SA-533, grade B, class 1, steel for a peak temperature of $1650^{\circ} \mathrm{F}$. Source: University of Tennessee.

values are shown at the end of each cooling curve. The hardness values drup gradually as the microstructure changes from fully martensitic to fully bainitic.

The $M_{S}$ and $M_{f}$ were determined to be $680^{\circ} \mathrm{F}$ and $520^{\circ} \mathrm{F}$, respectively. The martensitic microstructure produced by the fastest thermal cycle (curve a) corresponding to energy input of $20 \mathrm{~kJ} / \mathrm{in} ., 80^{\circ} \mathrm{F}$ preheat (1-in. plate), is shown in Fig. 45. For the slowest thermal cycle (curve VI) corresponding to energy input of $136 \mathrm{~kJ} / \mathrm{in}$., $500^{\circ} \mathrm{F}$ preheat (1-in. place), a bainitic structure results and is shown in Fig. 46.

Simjlarly, thermal cycles with a $2400^{\circ} \mathrm{F}$ peak temperature were used to achieve a coarse-grained austenite with the maximum practical amount of the alloying elements present in solution and to effectively represent the HAZ near the fusion line. The CCT diagram for the $2400^{\circ} \mathrm{F}$ peak temperature cycle is shown in Fig. 47. As the energy input increases, the 


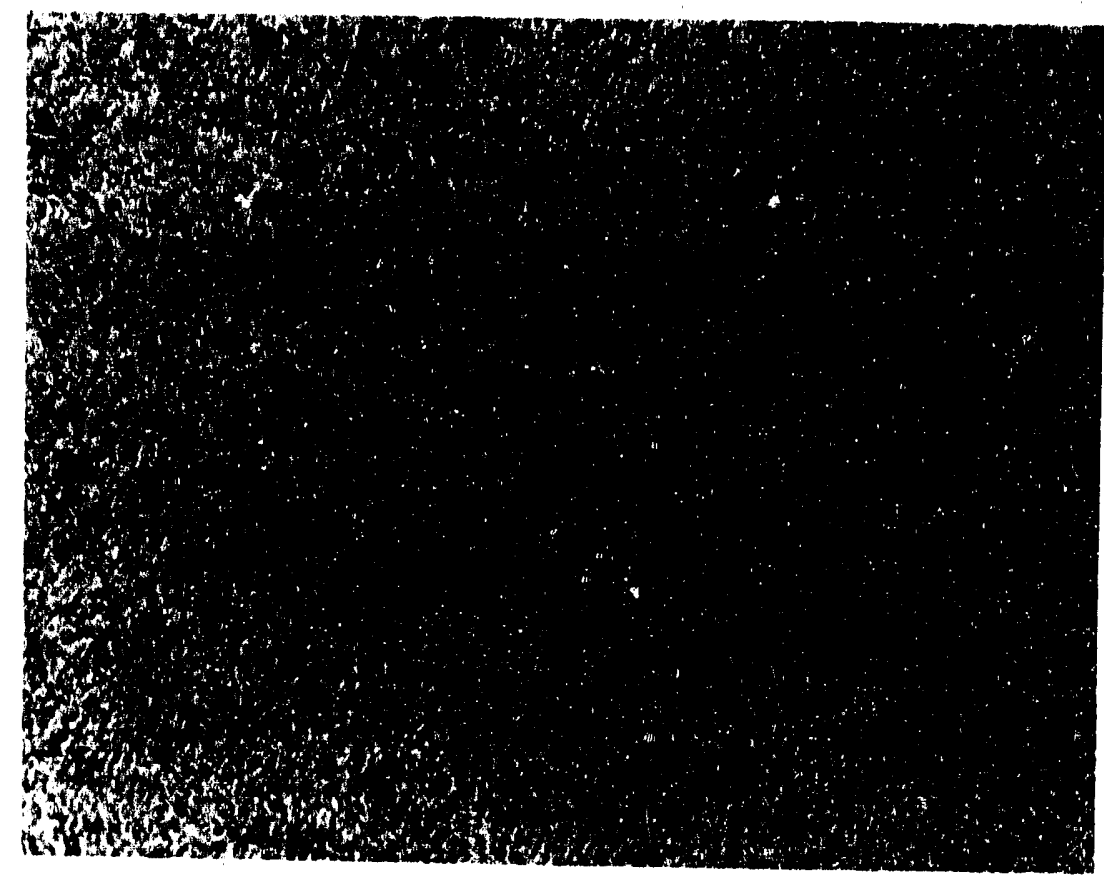

Fig. 45. Microstructure of SA-533, grade $B$, class 1 , steel corresponding to energy input of $20 \mathrm{~kJ} / \mathrm{in},{ }^{2} 1650^{\circ} \mathrm{F}$ peak temperature. HRC 48. Super picral etch. Source: University of

Tennessee.

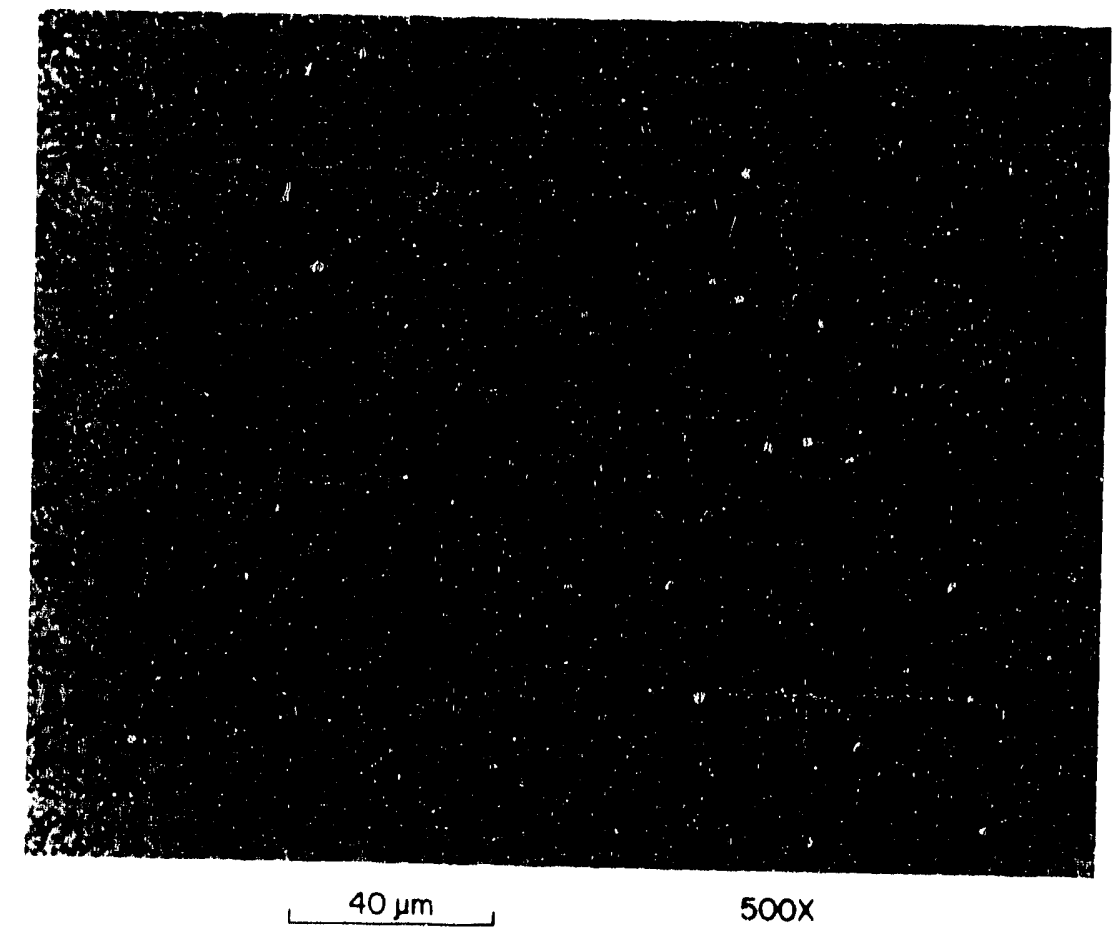

Fig. 46. Microstructure of SA-533, grade $B$, class 1 , steel corresponding to energy input of $136 \mathrm{~kJ} / \mathrm{in}$., $500^{\circ} \mathrm{F}$ preheat, $1650^{\circ} \mathrm{F}$ peak temperature. HRC 21. Super picral etch. Source: University of Tennessee. 


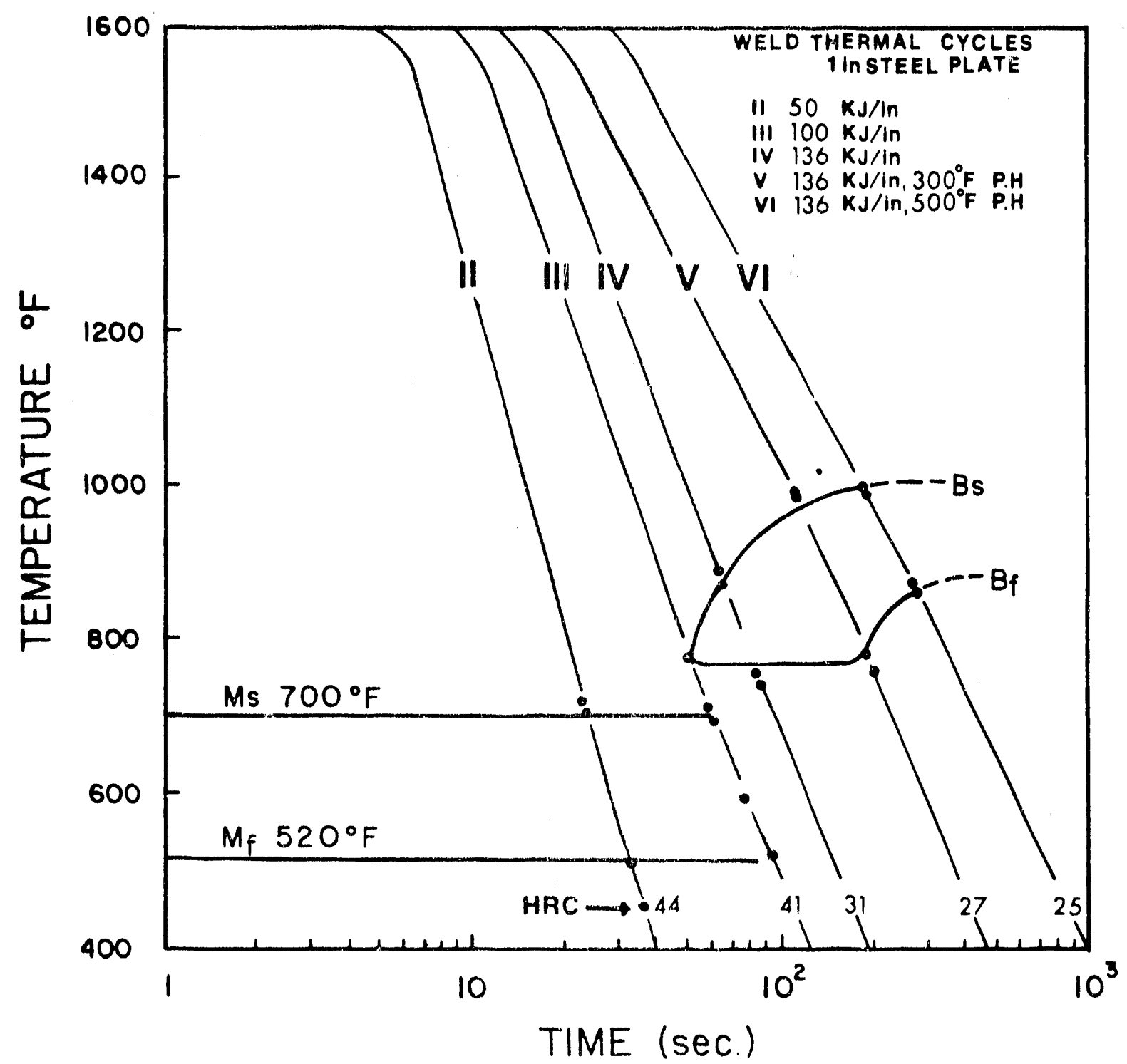

Fig, 47. Continuous-cooling transformation diagram of SA-533, grade B, class 1 , stee 1 for a peak temperature of $2400^{\circ} \mathrm{F}$. Source: University of Tennessee.

integrated time at peak temperature increases and the cooling rate decreases. Cooling conditions II and III pass; through the martensitic region, whereas cooling conditions IV, V, and VI pass through the bainitic region. The $M_{S}$ and $M_{f}$ in this case were $700^{\circ} \mathrm{F}$ and $520^{\circ} \mathrm{F}$. The microstructures produced by thermal cycle II $\left(50 \mathrm{~kJ} / \mathrm{in}, 80^{\circ} \mathrm{F}\right.$ preheat) and thermal cycle VI (136 kJ/in., $500^{\circ} \mathrm{F}$ preheat) are shown in Figs. 48 and 49 , respectively.

Comparing Figs. 45 and 46 with Figs. 48 and 49 shows that the grain size for $2400^{\circ} \mathrm{F}$ peak temperature is much laryer (approximately ASTM 2) than the grain size for the $1650^{\circ} \mathrm{F}$ peak temperature (approximately ASTM 13). 


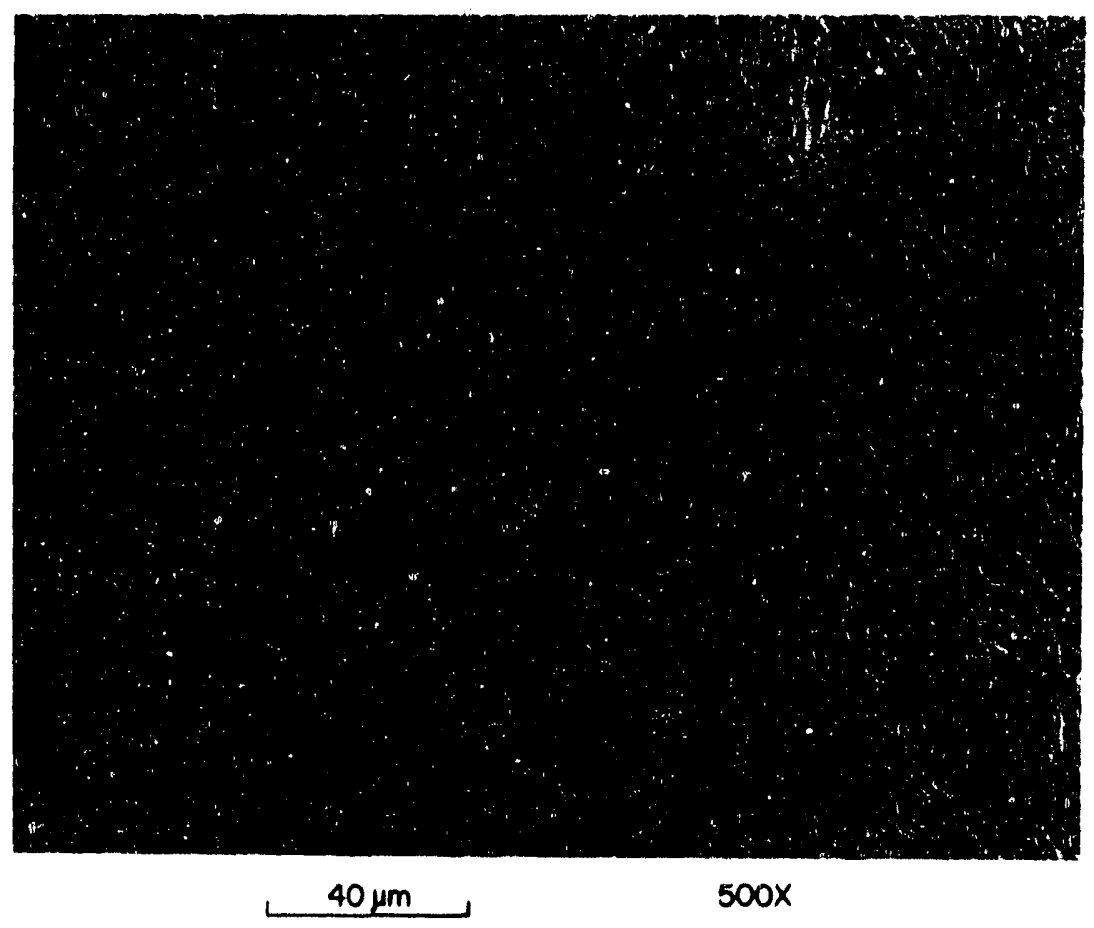

Fig. 48. Microstructure of SA-533, grade $B$, class 1 , steel corresponding to energy input of $50 \mathrm{~kJ} / \mathrm{in} ., 2400^{\circ} \mathrm{F}$ peak temperature. HRC 44. Super picral etch. Source: University of Tennes iee.

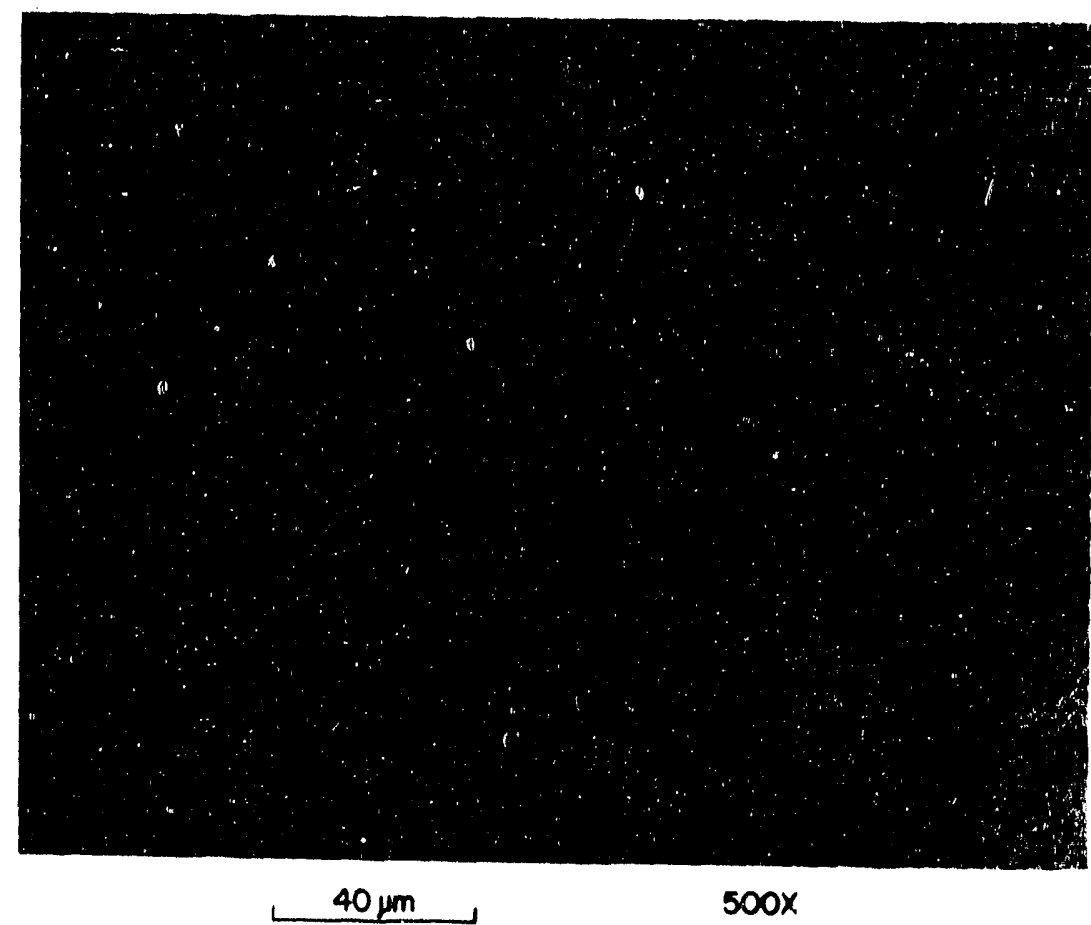

F1g. 49. Microstructure of SA-533, grade $B$, class 1 , steel corresponding to energy input of $136 \mathrm{~kJ} / \mathrm{in} ., 500^{\circ} \mathrm{F}$ preheat, $2400^{\circ} \mathrm{F}$ peak temperature. HRC 25. Super plcral etch. Source: University of Tennessee. 
To clearly define the effect of peak temperature on CCT behavior, the CCT diagram obtained for a peak temperature of $1650^{\circ} \mathrm{F}$ is superimposed on the CCT diagram for $2400^{\circ} \mathrm{F}$ peak temperature in Fig. 50. The higher peak temperature $\left(2400^{\circ} \mathrm{F}\right)$ caused the bainite nose to shift to the right and down, hence lowering the $B_{S}$ temperature. Taking into account the zero time difference, the nose has shifted approximately $40 \mathrm{~s}$ and decreased approximately $100^{\circ} \mathrm{F}$. The critical cooling rate shifts from $100^{\circ} \mathrm{F} / \mathrm{s}$ to approximately $40^{\circ} \mathrm{F} / \mathrm{s}$ at $1300^{\circ} \mathrm{F}$. The $M_{S}$ and $M_{f}$ transformation temperatures are not significantly affected by the different peak temperatures.

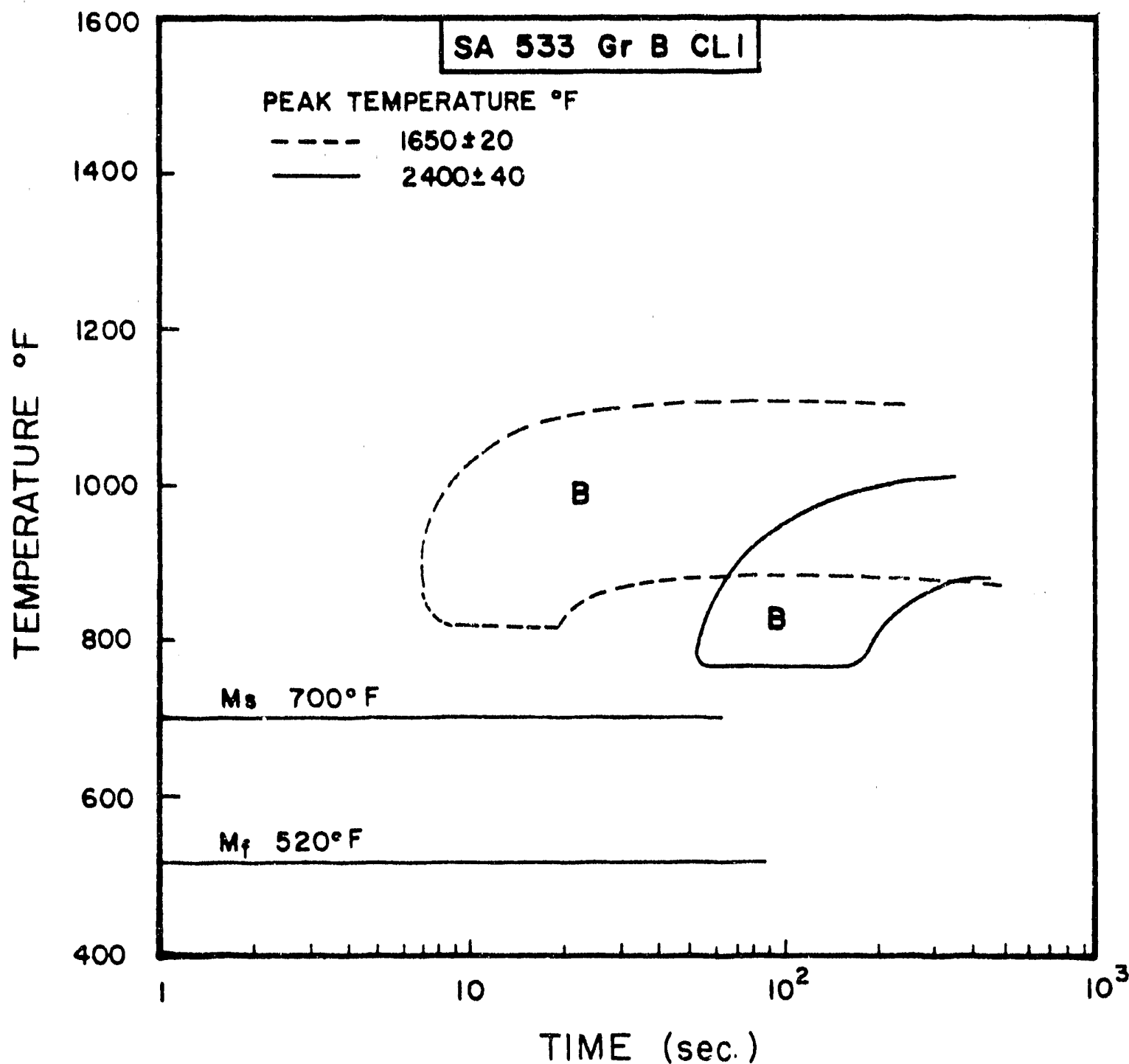

Fig. 50. Effect of peak temperature on continuous-cooling transformation behavior of SA-533, grade B, class 1, steel. Source: University of Tennessee. 
SA-508, class 2, The same thermal cycles used for determining CCT behavior for SA-533, grade B, class 1, steel were also used to determine CCT behavior for SA-508, class 2, steel. A CCT diagram for peak temperature of $1650^{\circ} \mathrm{F}$ is shown in Fig. 51. A thermal cycle of $50 \mathrm{~kJ} / \mathrm{in}$., $80^{\circ} \mathrm{F}$ preheat, yields a martensitic transformation, whereas in SA-533, grade $B$, class 1 , steel a more rapid thermal cycle of $32 \mathrm{~kJ} / \mathrm{in} ., 80^{\circ} \mathrm{F}$ preheat, did not give a martensitic transformation. This shows that the bainite nose for SA-508, class 2, steel is farther to the right than that for $\mathrm{SA}-533$, grade $B$, class 1 , and the critical cooling rate shifts accordingly from $100^{\circ} \mathrm{F} / \mathrm{s}$ to $60^{\circ} \mathrm{F} / \mathrm{s}$ (at $1300^{\circ} \mathrm{F}$ ). The ERiM results again correlate well with the CCT diagrams obtained in the Gleeble $\left(1650^{\circ} \mathrm{F}\right.$ for both). The $M_{S}$ and $M_{f}$ were determined to be $685^{\circ} \mathrm{F}$ and $540^{\circ} \mathrm{F}$, respectively. The microstructures produced by thermal cycle I (32 kJ/in., $80^{\circ} \mathrm{F}$ preheat) and ther. mal cycle VI $\left(132 \mathrm{~kJ} / \mathrm{in} ., 500^{\circ} \mathrm{F}\right.$ preheat) are shown in Figs. 52 and 53.

They are the martensitic and bainitic transformation products corresponding to SA-533, grade B, class 1, steel in Figs. 45 and 46, respectively.

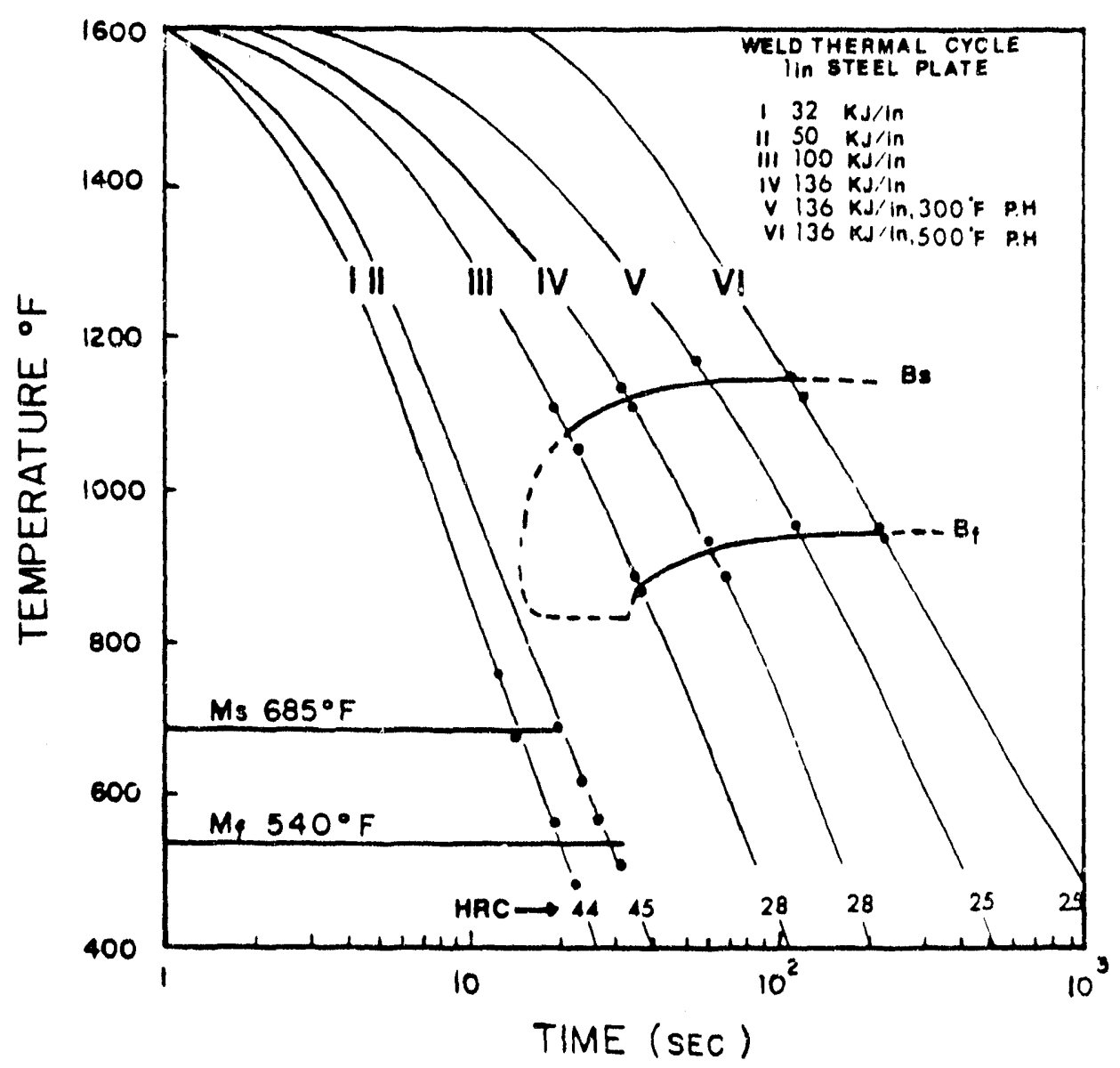

Fig. 51. Continuous-cooling transformation diagram of SA-508, class 2, steel for a peak temperature of $1650^{\circ} \mathrm{F}$. Source: University of Tennessee. 

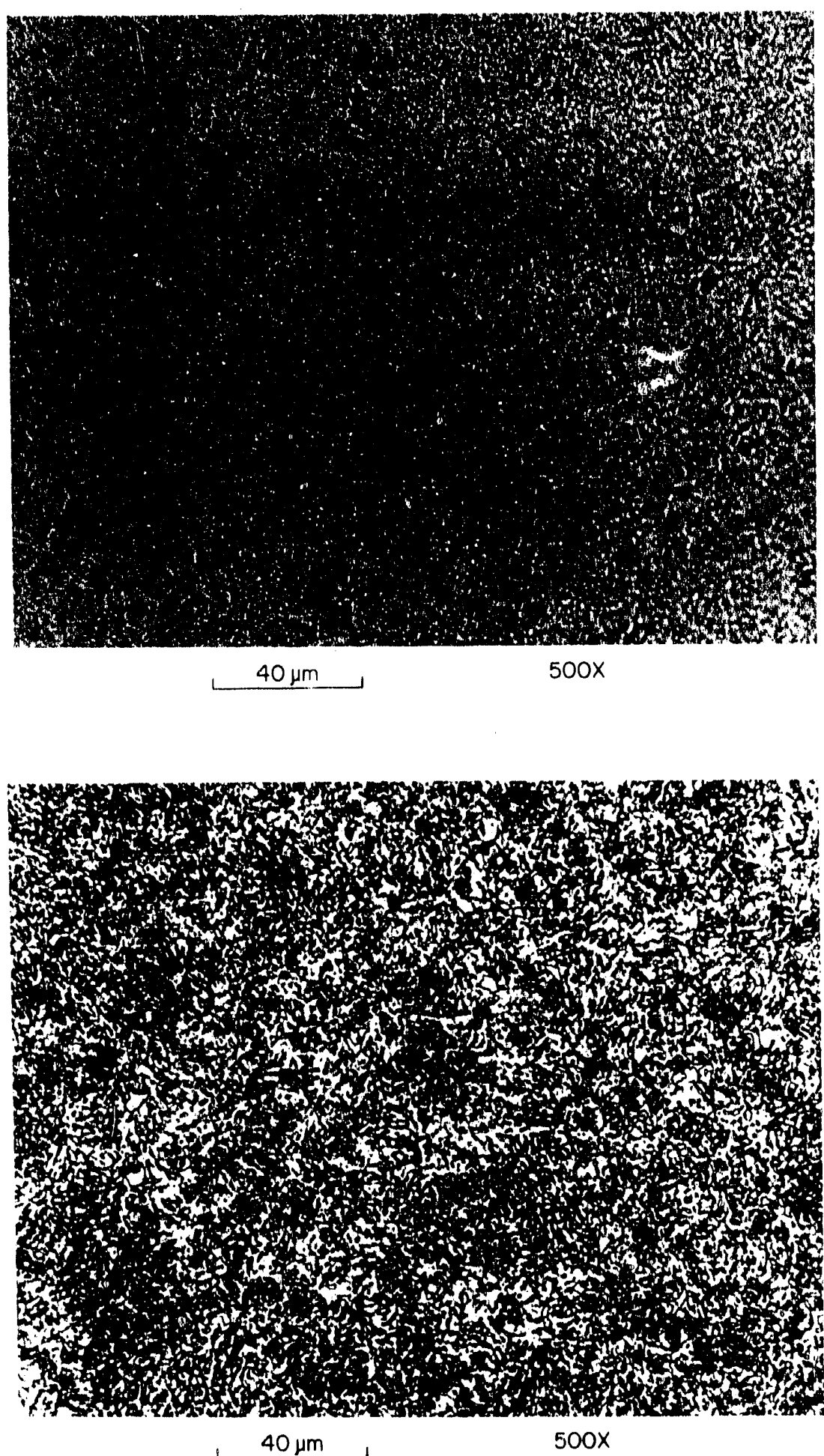

Fig. 52. Microstructure of SA-508, class 2, steel corresponding to energy input of $32 \mathrm{~kJ} / \mathrm{in}$., $1650^{\circ} \mathrm{F}$ peak tempera ture. HRC 44. Super picral etch. Source: University of

Tennessee.
Fig. 53. Microstructure of SA-508, class 2, steel corresponding to energy input of $136 \mathrm{~kJ} / \mathrm{in}$., $500^{\circ} \mathrm{F}$ preheat, $1650^{\circ} \mathrm{F}$ peak temperature. HRC 25. Super picral etch. Source: University of Tennessee. 
The CCT diagram for a higher peak temperature of $2400^{\circ} \mathrm{F}$ is shown in Fig. 54. The bainite start has shifted to longer times and lower temperatures. The $M_{S}$ and $M_{f}$ temperatures were determined to be 690 and $520^{\circ} \mathrm{F}$, respectively, very similar to the $1650^{\circ} \mathrm{F} M_{S}$ and $M_{f}$ temperatures. The microstructures produced by thermal cycle II $\left(50 \mathrm{~kJ} / \mathrm{in} ., 80^{\circ} \mathrm{F}\right.$ preheat) and thermal cycle VI $\left(136 \mathrm{~kJ} / \mathrm{in}, 5^{\circ} \mathrm{F}\right.$ preheat) are shown in Figs. 55 and 56. In the case of SA-508, class 2, the ASTM grain size observed for $2400^{\circ} \mathrm{F}$ peak temperature is approximately 2 ; for $1650^{\circ} \mathrm{F}$ peak temperature, it is approximately 13. The data for SA-533, grade B, class 1, show identical grain sizes.

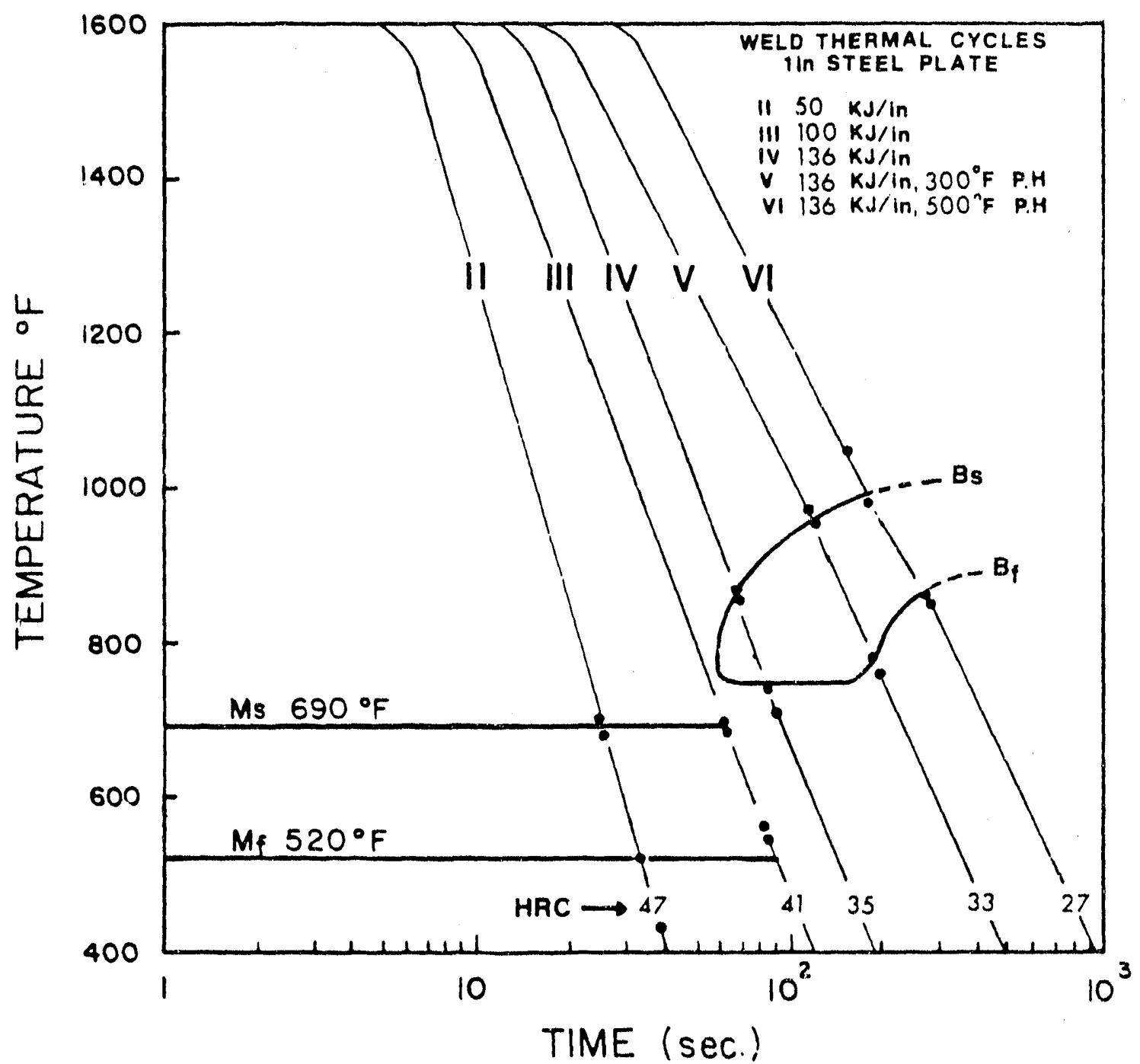

Fig. 54. Continuous-cooling transformation diagram of SA-508, class 2, steel for a peak tempernture of $2400^{\circ} \mathrm{F}$. Source: University of Tennessee. 


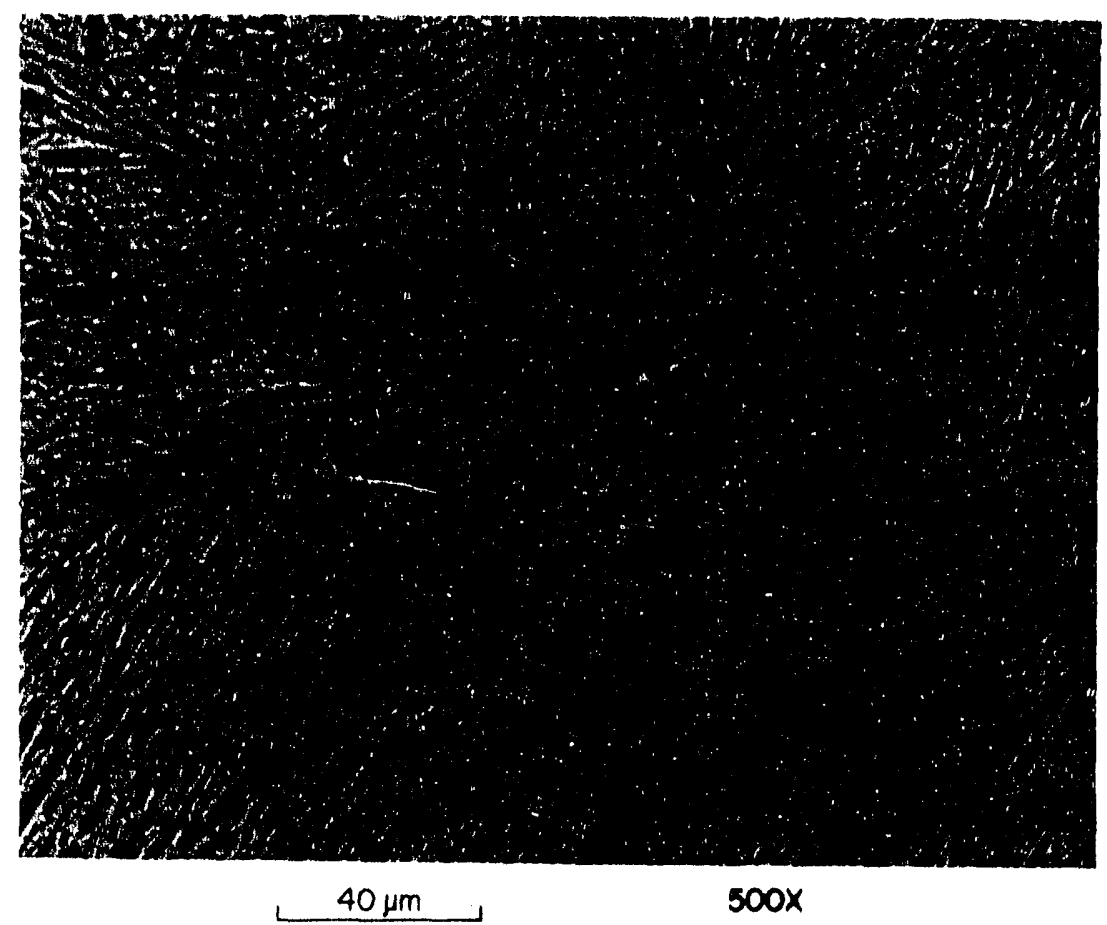

Fig. 55. Microstructure of SA-508, class 2, steel corresponding to energy input of $50 \mathrm{~kJ} / \mathrm{in}$. $2400^{\circ} \mathrm{F}$ peak temperature. HRC 47. Super picral etch. Source: University of Tennessee.

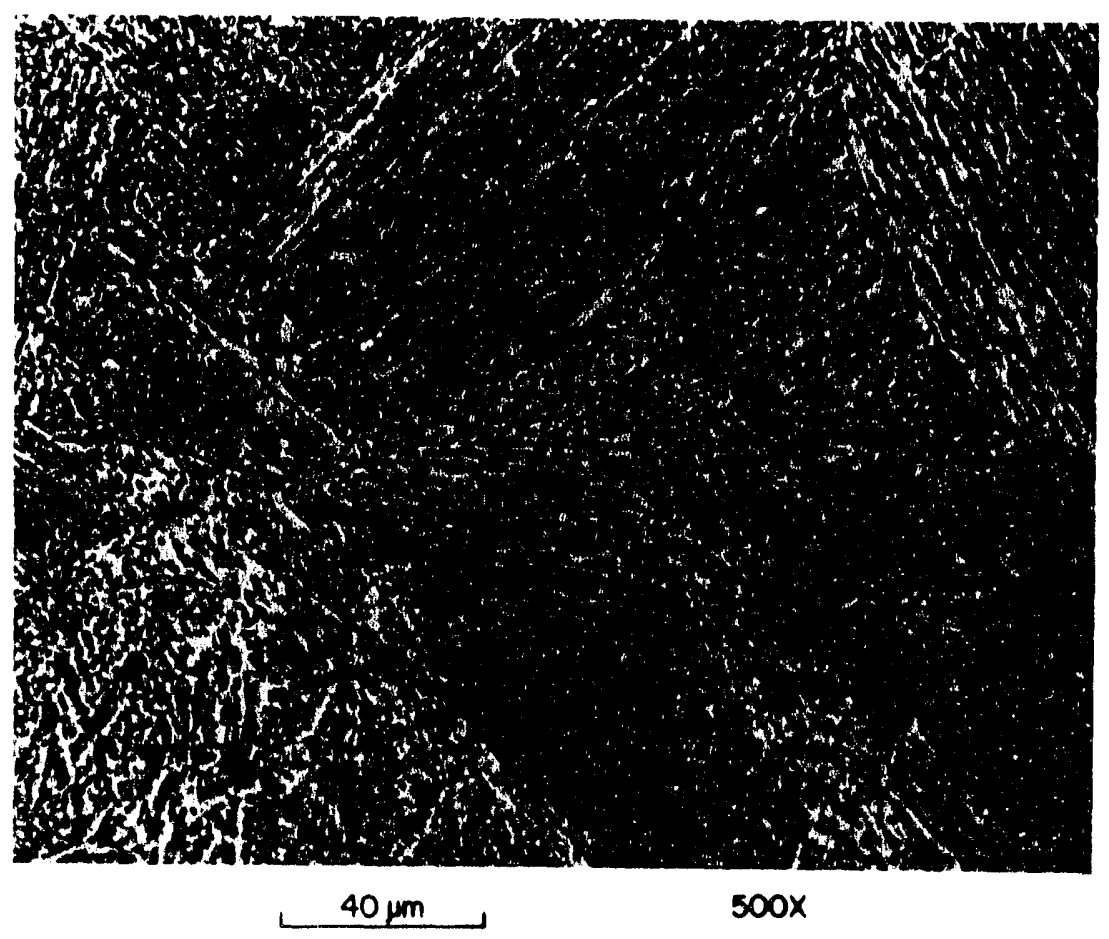

F18. 56. Microstructure of SA-508, class 2, steel corresponding to energy input of $136 \mathrm{~kJ} / \mathrm{in}$., $500^{\circ} \mathrm{F}$ preheat, $2400^{\circ} \mathrm{F}$ peak temperature. HRC 27. Super picral etch. Source: University of Tennessee. 
Superimposing the CCT diagram for the $1650^{\circ} \mathrm{F}$ peak temperature on the CCT diagram for the $2400^{\circ} \mathrm{F}$ peak temperature (Fig. 57) shows that the shift of bainite nose is similar to that observed in SA.533, grade B, class 1 , steel - that is, farther to the right and to lower temperatures. (The cooling time start temperature alters this somewhat.) In this case, the nose has shifted approximately $30 \mathrm{~s}$ on the time scale and decreased in temperature approximately $100^{\circ} \mathrm{F}$. Again, the $M_{S}$ and $M_{f}$ transformation temperatures were unaffected by the different peak temperature exposures.

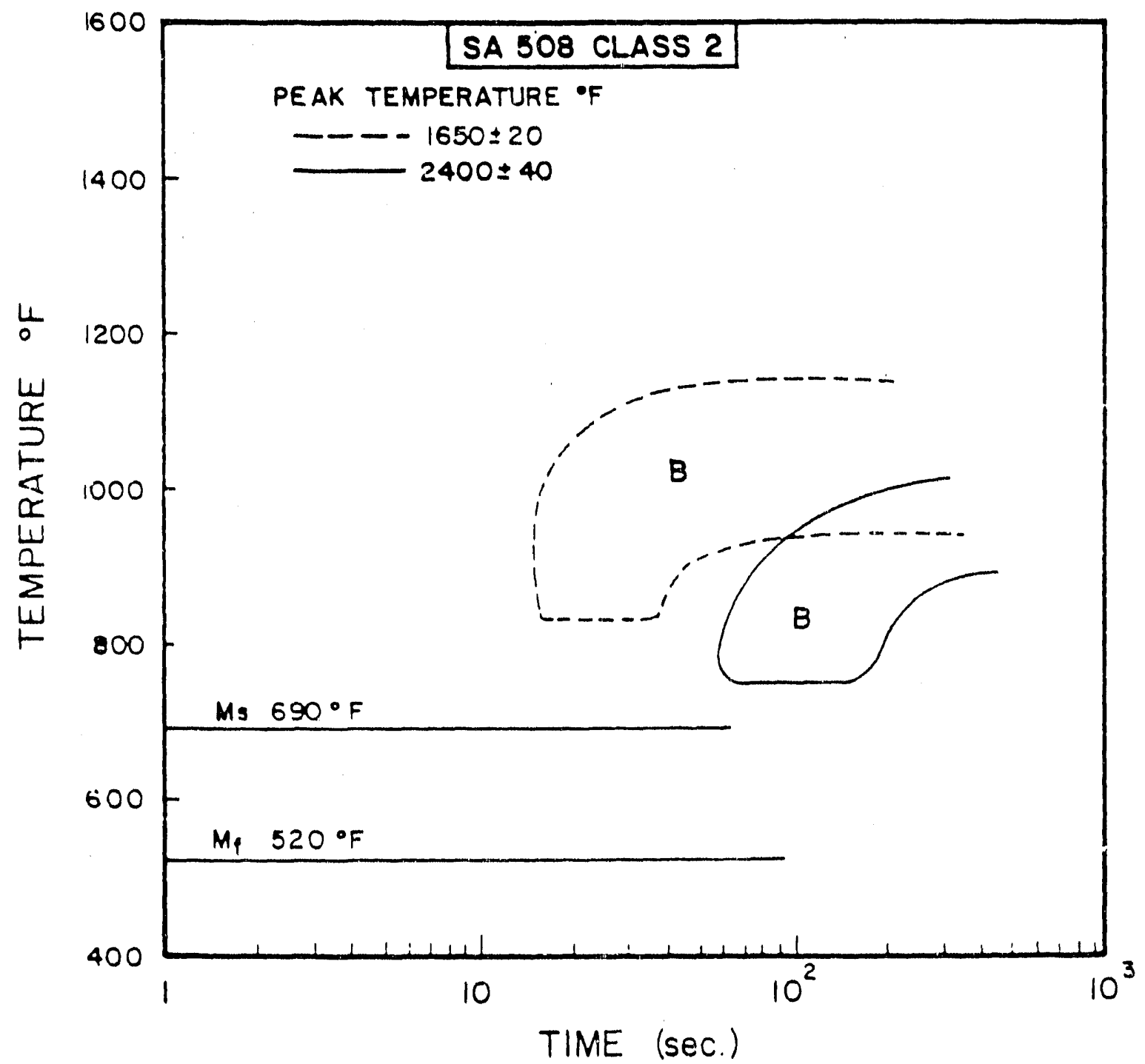

Fig. 57. Effect of peak temperature on continuous-cooling transformacion behavior of SA-508, class 2, steel. Source: University of Tennessee. 
CCT comparisons, The CCT behavior of SA-533, grade B, class 1 , and that of SA-508, class 2 , heated to a peak temperature of $2400^{\circ} \mathrm{F}$, are virtually identical. Both CCT diagrams are shown in Fig. 58. Thus in the actual weld HAZ, both steels have a similar transformation behavior for regions close to the fusion line. Further, both steels have similar. hardenability for higher peak temperatures. This conclusion is verified in the hardenability discussion to follow.

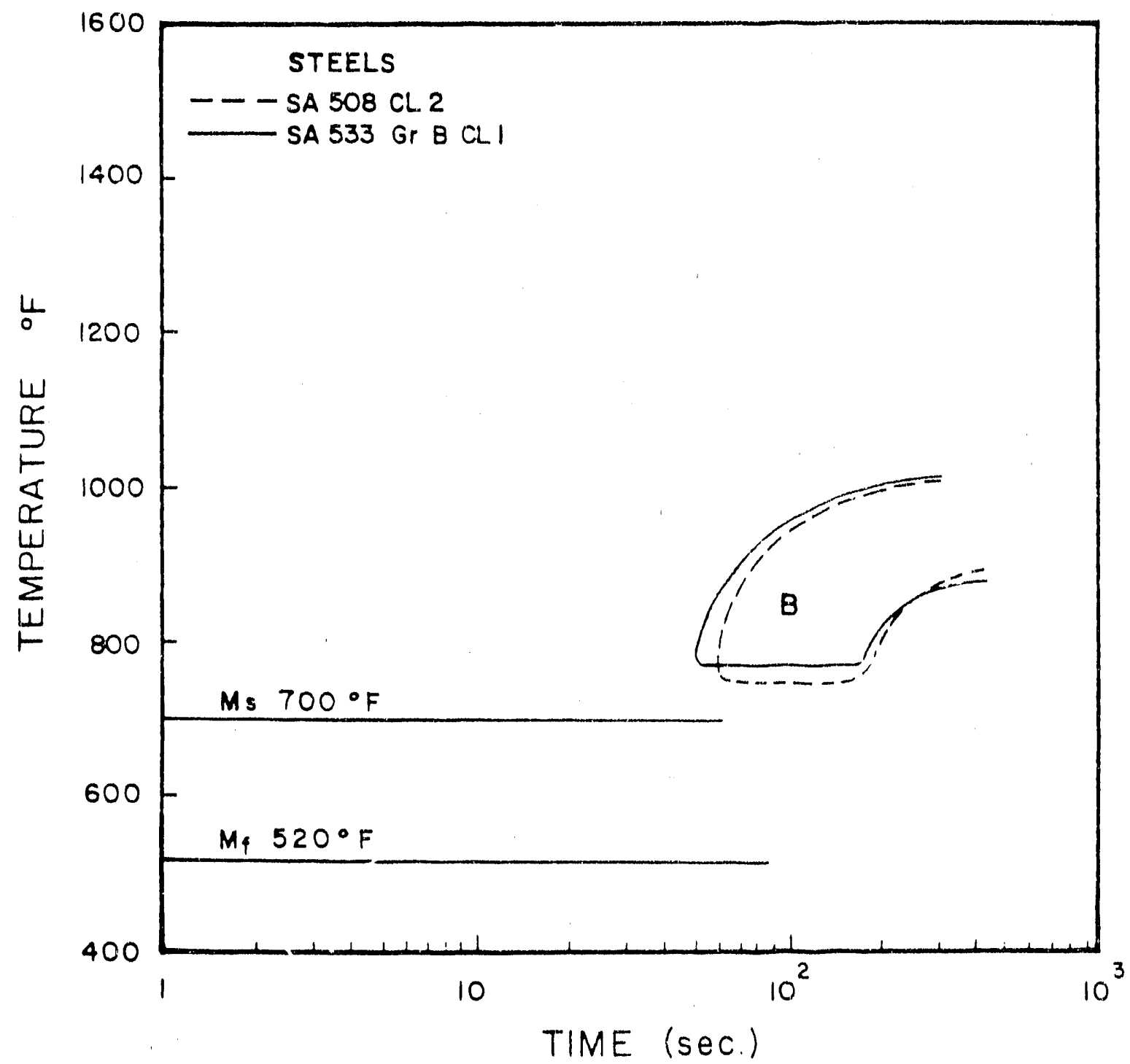

Fig. 58. Comparison of continuous-cooling transformation behavior of SA-533, grade B, class 1, and SA-508, class 2, steels for a peak temperature of $2400^{\circ} \mathrm{F}$. Source: University of Tennessee. 
To note any difference in transformation characteristics on holding at a peak temperature of $2400^{\circ} \mathrm{F}$, specimens of SA-508, class 2, and SA-533, grade B, class 1 , were held for $20 \mathrm{~s}$ and cooled under condition IV [136 kJ/in., $80^{\circ} \mathrm{F}$ (1-in. plate)]. The transformation behavior did not change; the transformation obtained was similar to that observed for "no holding" with thermal cycle IV (136 kJ/in., $80^{\circ} \mathrm{F}$ preheat) for both steels. This indicates that solution of alloy elements is rapid at the high peak temperatures. When a peak temperature of $1900^{\circ} \mathrm{F}$ was used with thermal cycle VI ( $136 \mathrm{~kJ} / \mathrm{in} ., 500^{\circ} \mathrm{F}$ preheat), the transformation characteristics were similar to those obtained by $2400^{\circ} \mathrm{F}$ peak temperature; this indicates that significant grain growth and solution also occur at $1900^{\circ} \mathrm{F}$ peak temperature.

Fuji Maki's ${ }^{19}$ CCT diagram of steel "B" (see literature review), which is similar in composition to SA-508, class 2, steel (except that steel "B" is lower in carbon content), is compared with the CCT diagram of SA-508, class 2, steel in Fig. 59. Because of the lower carbon content, steel "B" has a faster critical cooling rate to avoid bainite transformation than does SA-508, class 2, steel. The critical cooling rate for steel "B" is approximately $133^{\circ} \mathrm{F} / \mathrm{s}$, whereas for $\mathrm{SA}-508$, class 2 , steel it is approximately $50^{\circ} \mathrm{F} / \mathrm{s}$. The ferrite nose in SA-508, class 2, steel is shifted farther to the right than in stee1 "B."

Klumpes ${ }^{20}$ discussed the PTCT diagrams of steels SA-508, class 2, and SA-533, grade B, class 1 , exposed to several thermal cycles with peak temperatures ranging from 1650 to $2460^{\circ} \mathrm{F}$. The PTCT diagrams of steels SA-508, class 2, and SA-533, grade B, class 1 , showed that a cooling rate of $90^{\circ} \mathrm{F} / \mathrm{s}$ gives a fully martensitic structure. This cooling rate seems to be reasonable in comparison with the experimental. results herein for SA-508, class 2, steel, which had a critical cooling rate of $50^{\circ} \mathrm{F} / \mathrm{s}$. How. ever, for SA-533, grade B, class 1, steel, our experimental results show a critical cooling rate of $140^{\circ} \mathrm{F} / \mathrm{s}$, which indicates that Klumpes' cooling rate of $90^{\circ} \mathrm{F} / \mathrm{s}$ would not be fast enough to form martensite. Klumpes menticned that the depth of hardening in the case of SA-533, grade $B$, class 1, steel exceeds that of SA-508, class 2, stee1, which means that, for his steels, the bainite nose for SA-533, grade B, class 1, stee1 occurs at a longer time than the bainite nose for SA-508, class 2 . This result is totally opposite to the one we obtained and is not predictable from chemical composition.

There is an interrelationship between energy input, preheat, and plate thickness and the cooling rates obtained in welds. The thermal cycles calculated for use in this study were for 1 -in. steel plate with different energy inputs and preheats; thus, for direct utility under other conditions, the correlations predicted by other investigators are reviewed here for information. Signes ${ }^{45}$ proposed a simple method for predicting weld metal cooling rates for mild and low-alloy steels. Using Signes' method, different energy inputs were obtained for thicker plates with the same cooling rate as for 1 -in.-thick steel plate. These values have been summarized in Table A4 of Appendix A and are graphically shown in Fig. 60. In plate thickness of more than 3 in., the cooling rate does not change 


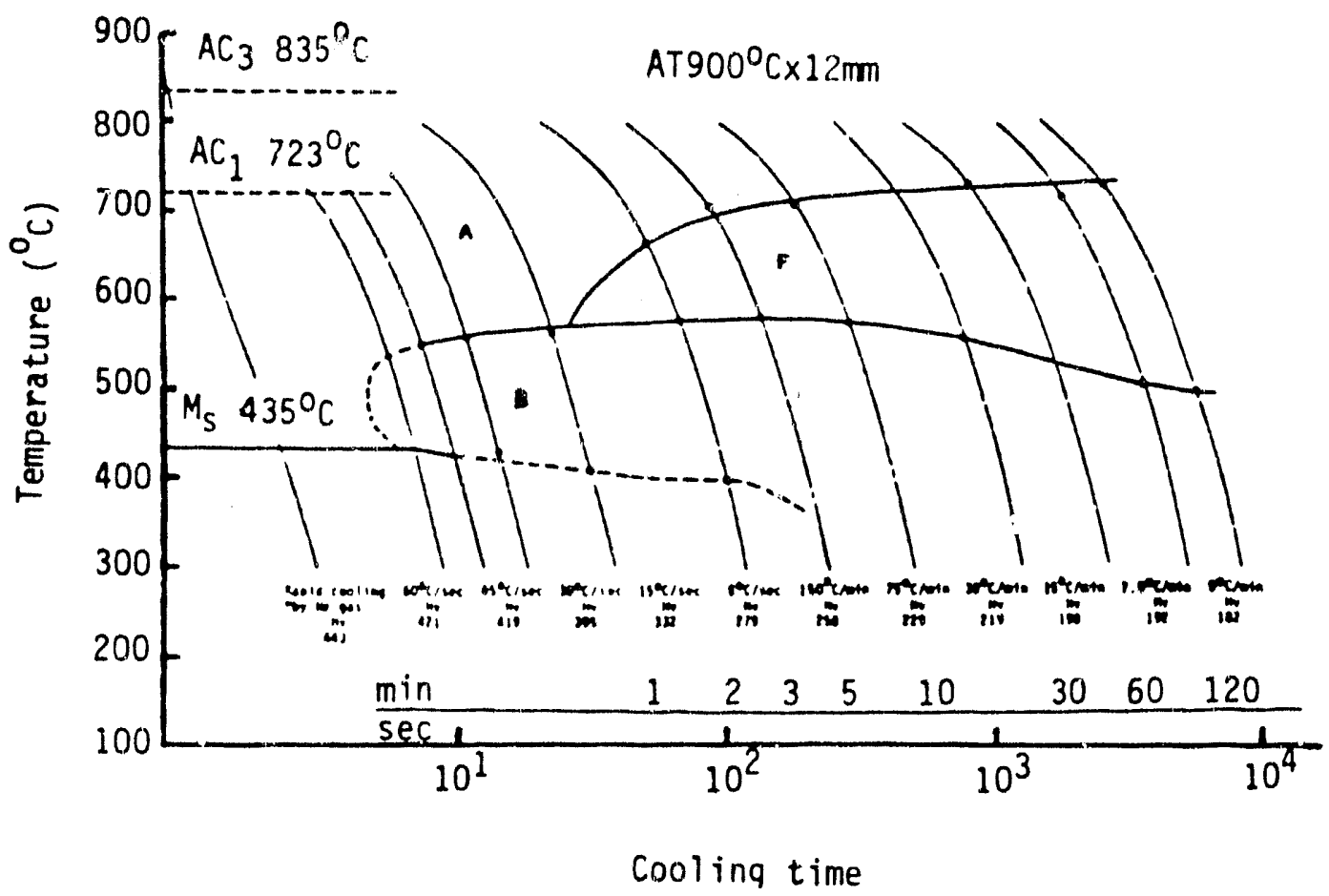

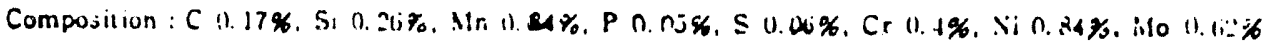
CCT niagram of Sicel $B$

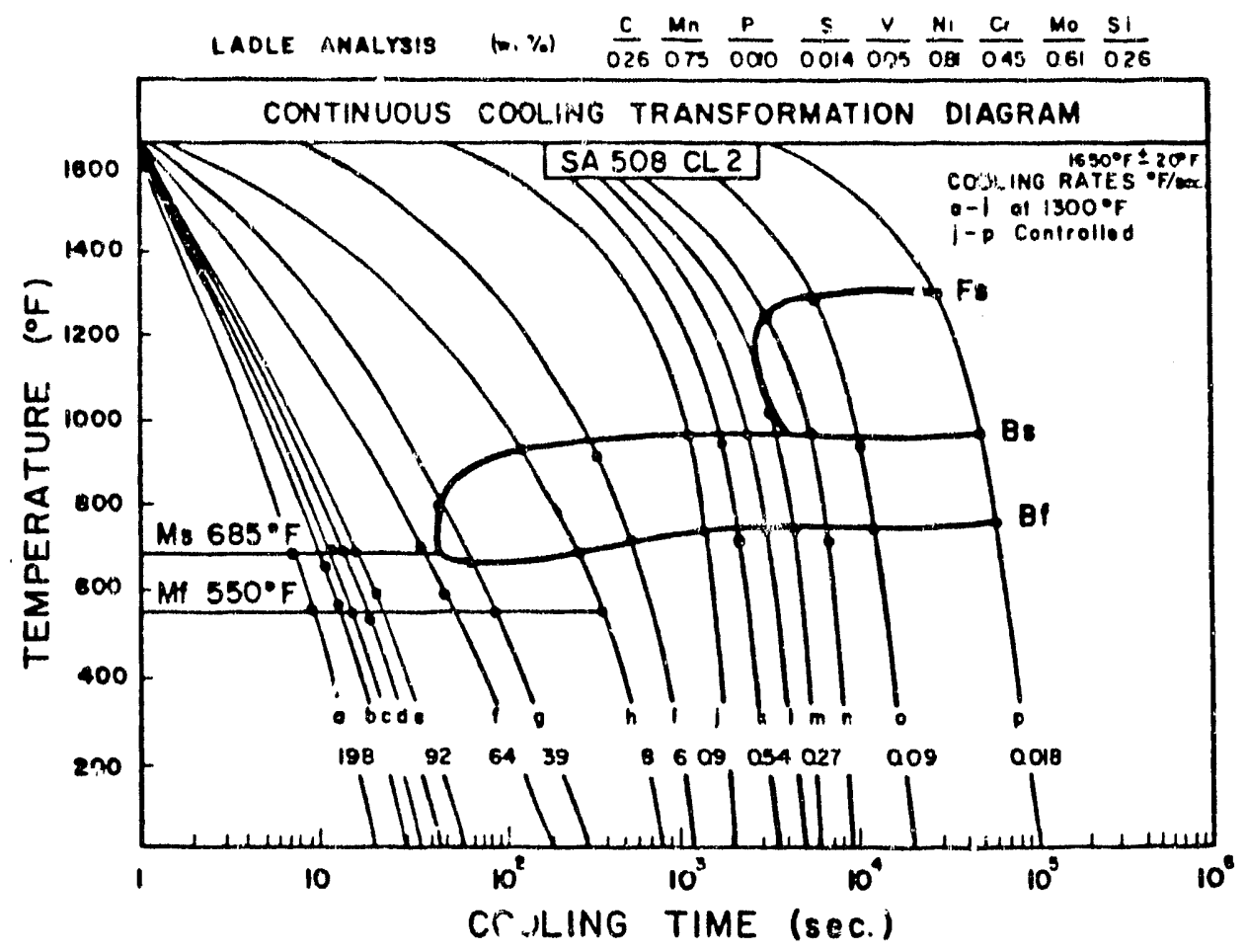

Fig. 59. Comparison of continuous-cooling transformation behavior of steel. "ri" with that of SA-508, class 2, steel. Source: University of Tennessee. 


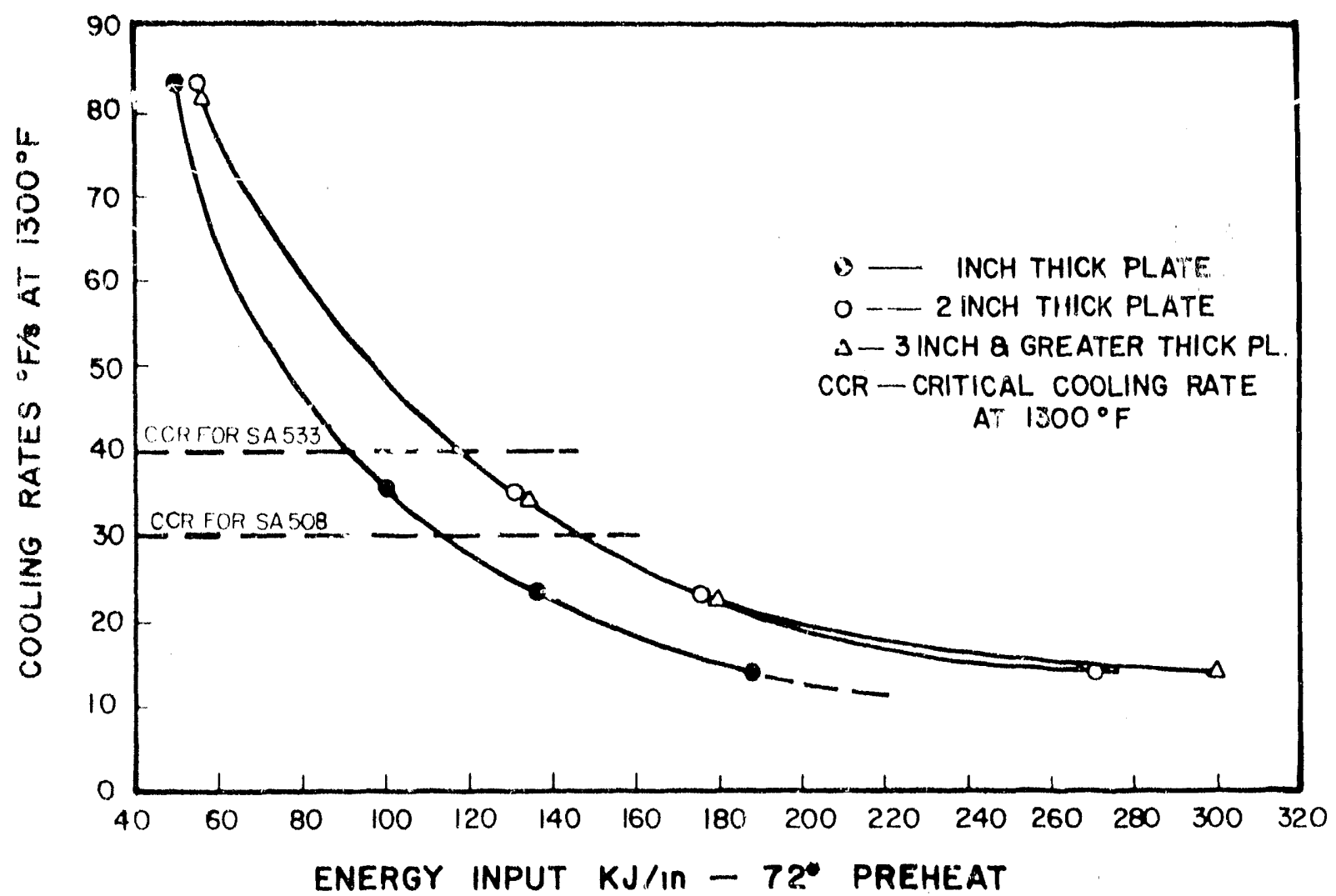

Fig. 60. Energy input vs cooling rates for steel plates welded by the SMAW process. Source: University of Tennessee.

"ignificantly (i.e., increasing the thickness further nas no influence on conling 1.1t(). Signes' nethod gives the cooling rate of weld metals (i.e., (w) orlin of (he wold) and not the HAZ. Jhaveri and his colleagues ${ }^{46}$ muth ioner thit the cooling rate is a maximum on the weld centerline, and that the shape of the cooling rate distribution curve is such that the enterline cooling rate is only 5 to 10 o higher than that in the weld HAZ and is therfore representative of the cooling rate in the entire weld regiom. Figures 61 through 68 snow thermal cycles for 2 - and 3 -in. plate hicknesses.

HARDENABILITY OF SA-533, GRADE B, CLASS 1, AND SA-508, CLASS 2, STEELS

The study of hardeability in oel is the study of the transformation kinetics of austenite. Austenitizing temperatures for hardening heat treatments are usually chosen to be high enough so that all alloy additions are in solution, to maximize their hardenability effect, but not tro high to coarsen the austenite grain size to the point that it detracts from the 


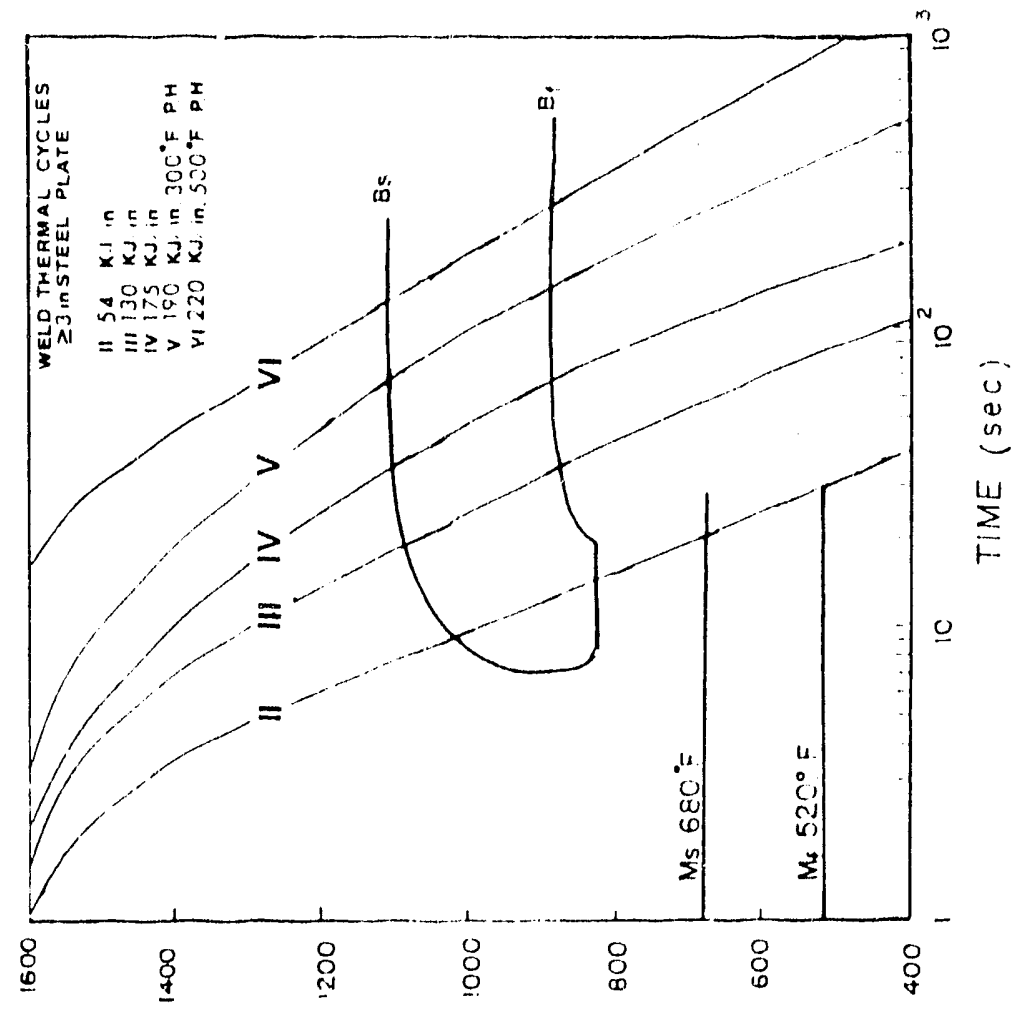

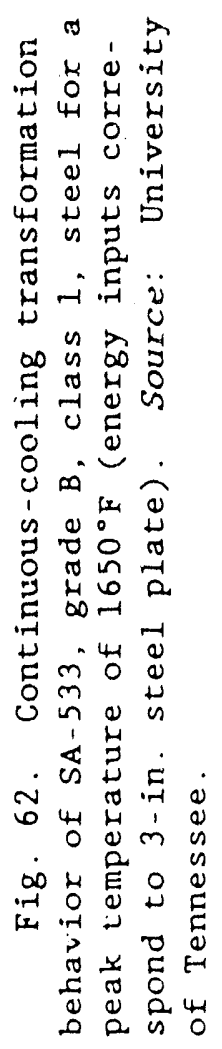

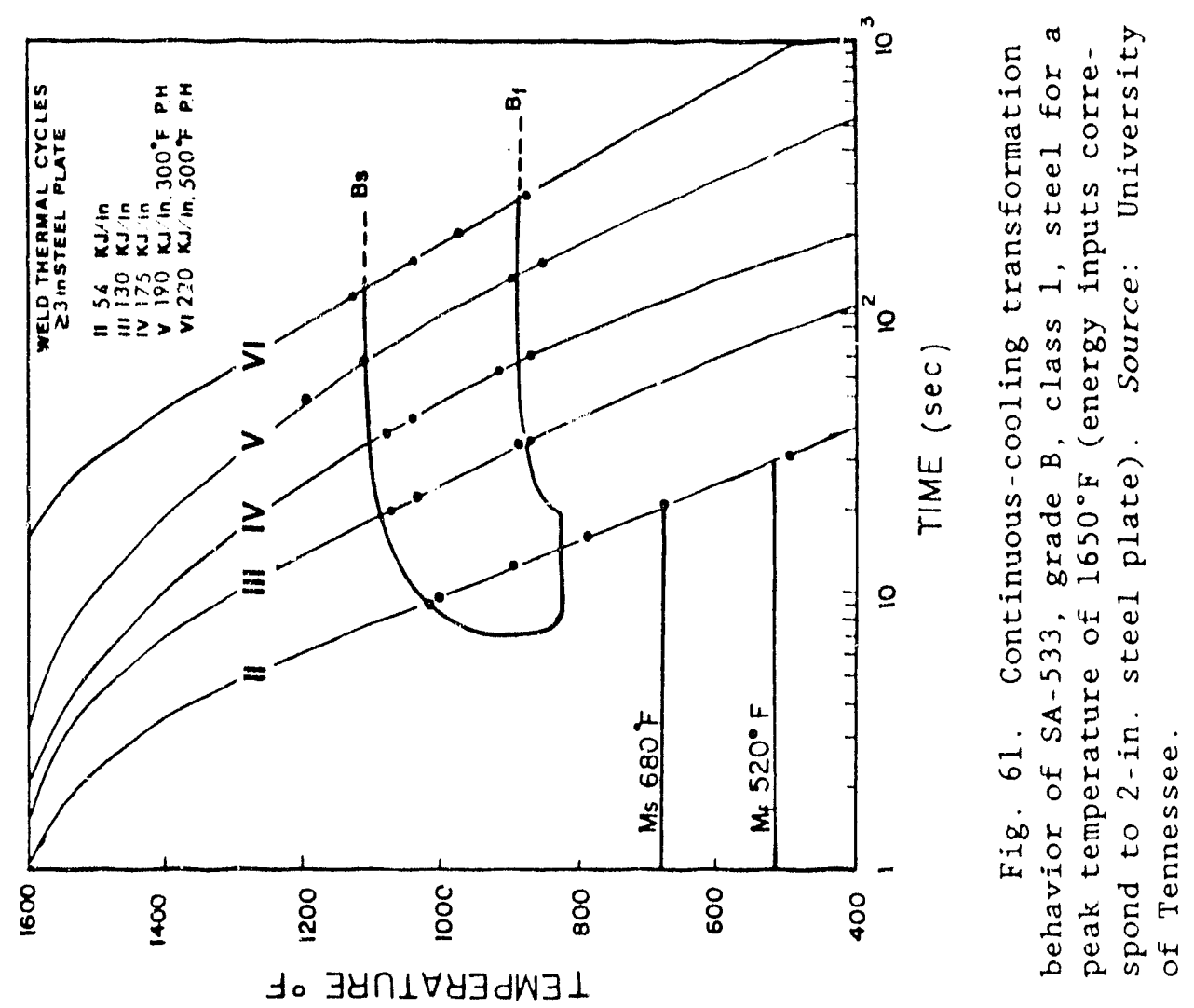




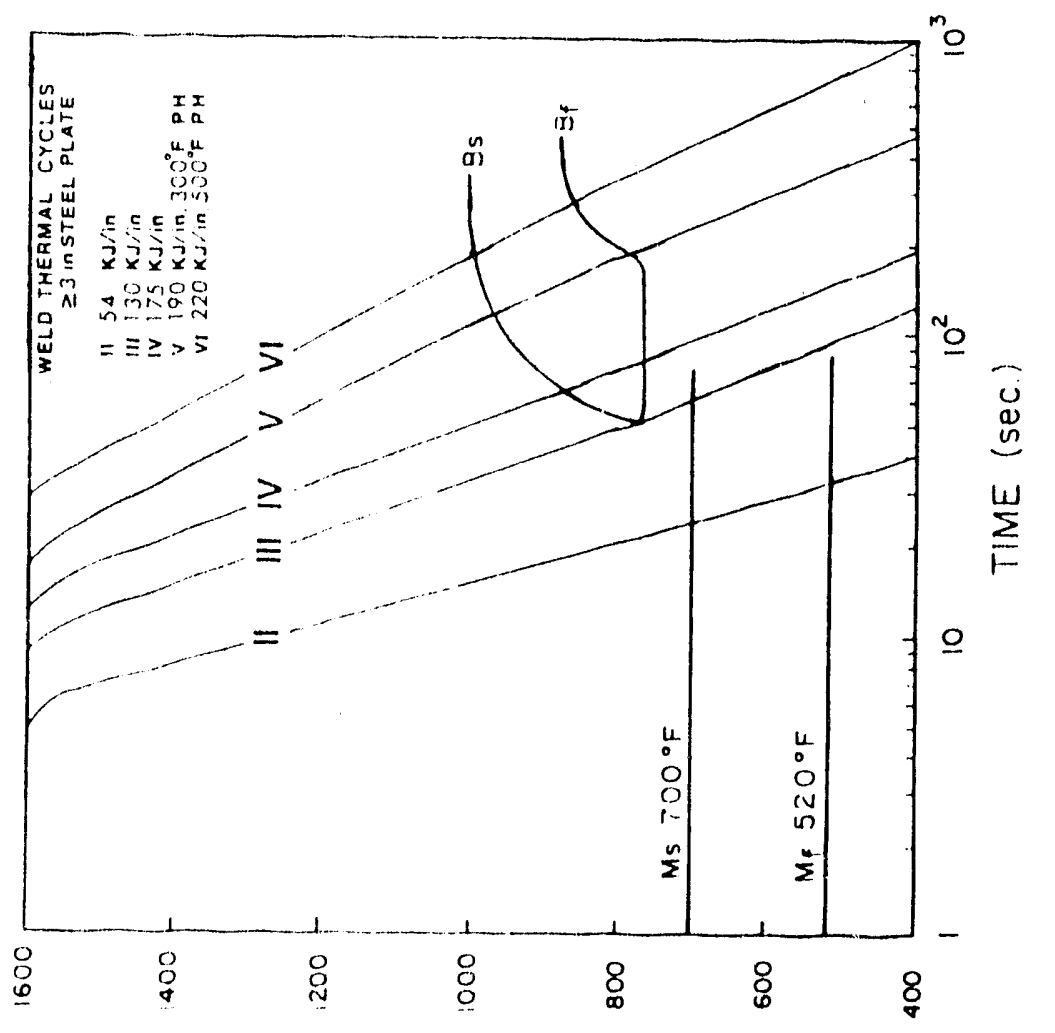

to $\exists$ HII $\triangle 4 \mathrm{H} 3 \mathrm{dW} \exists \perp$
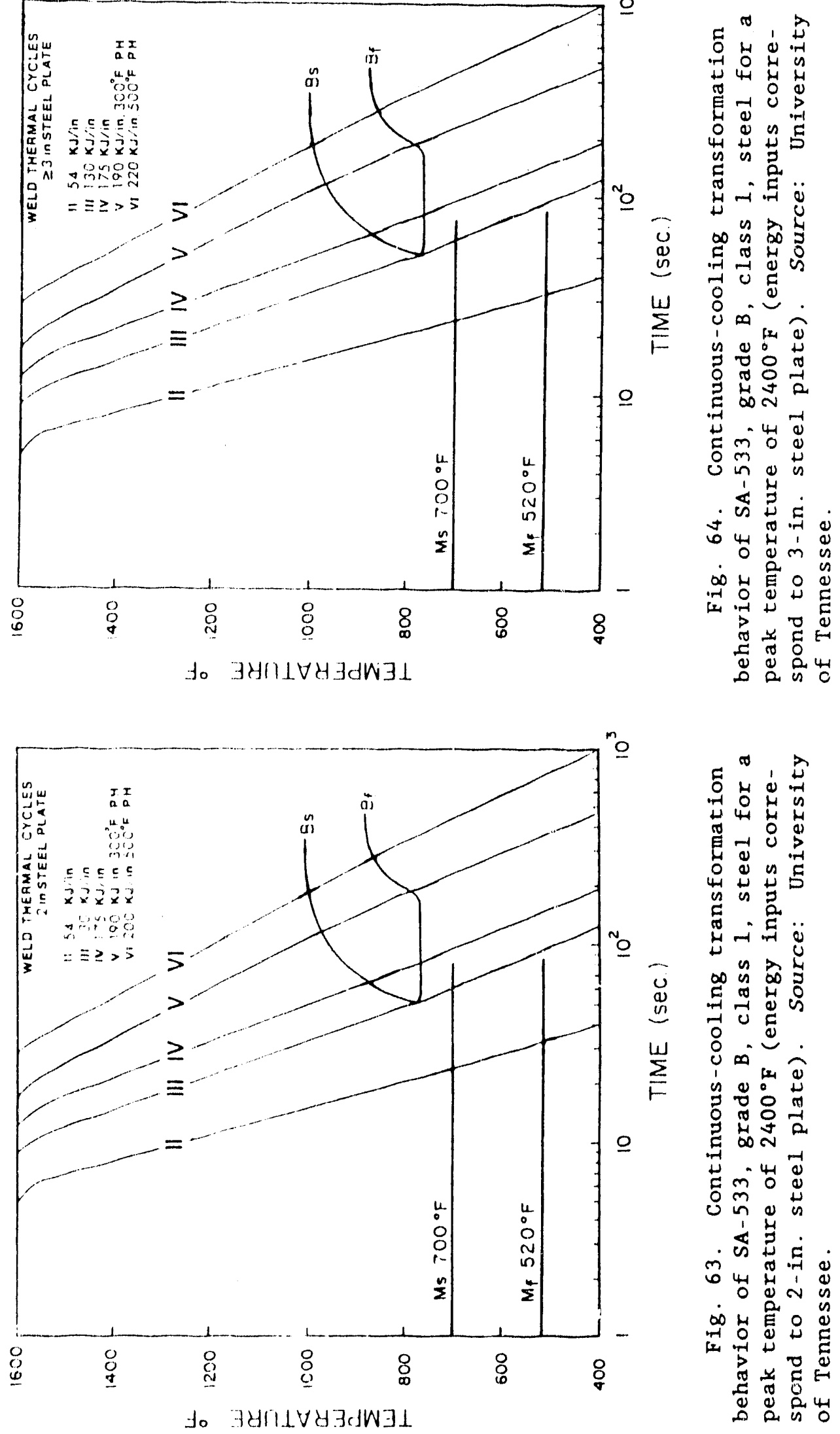

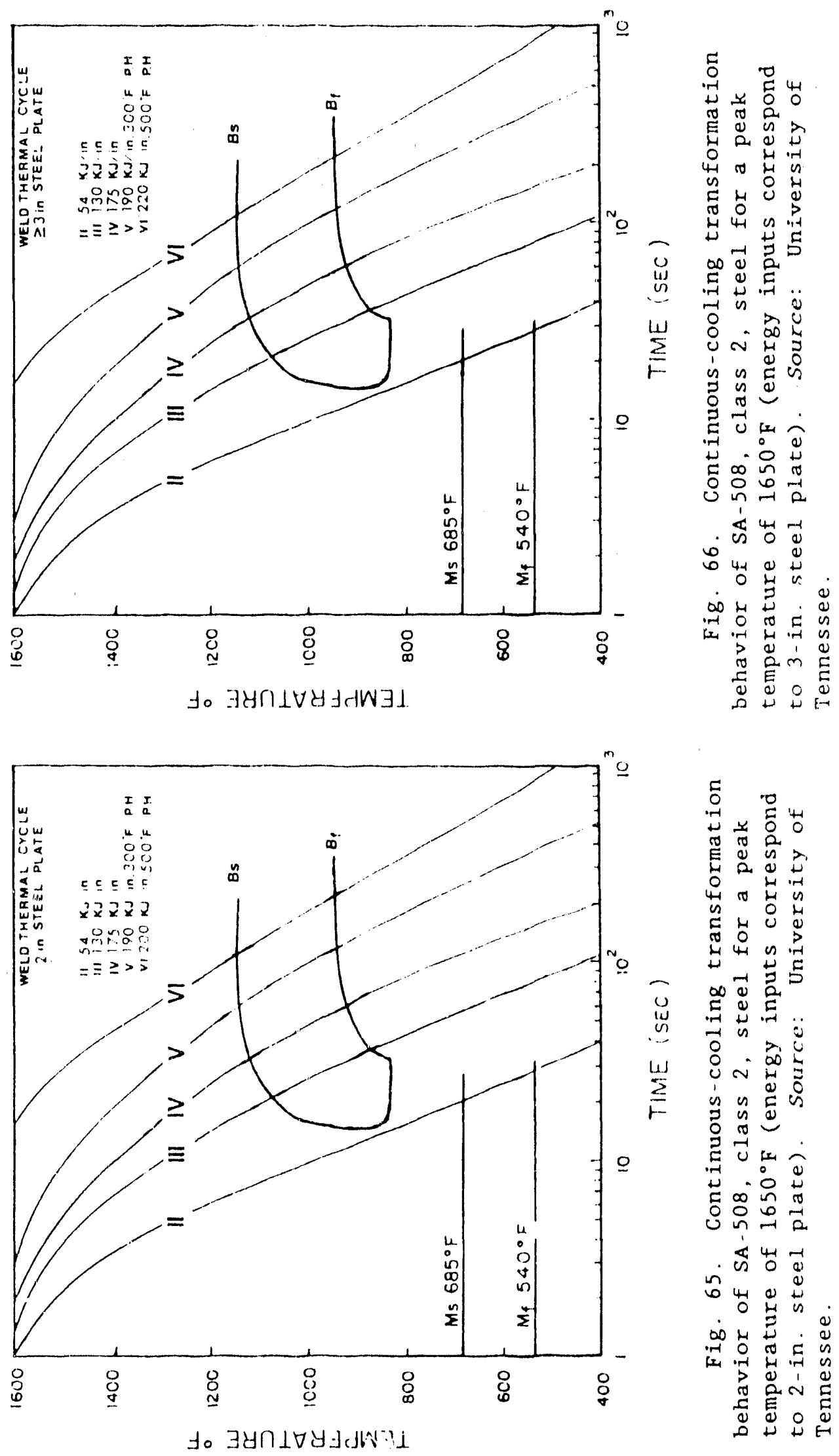

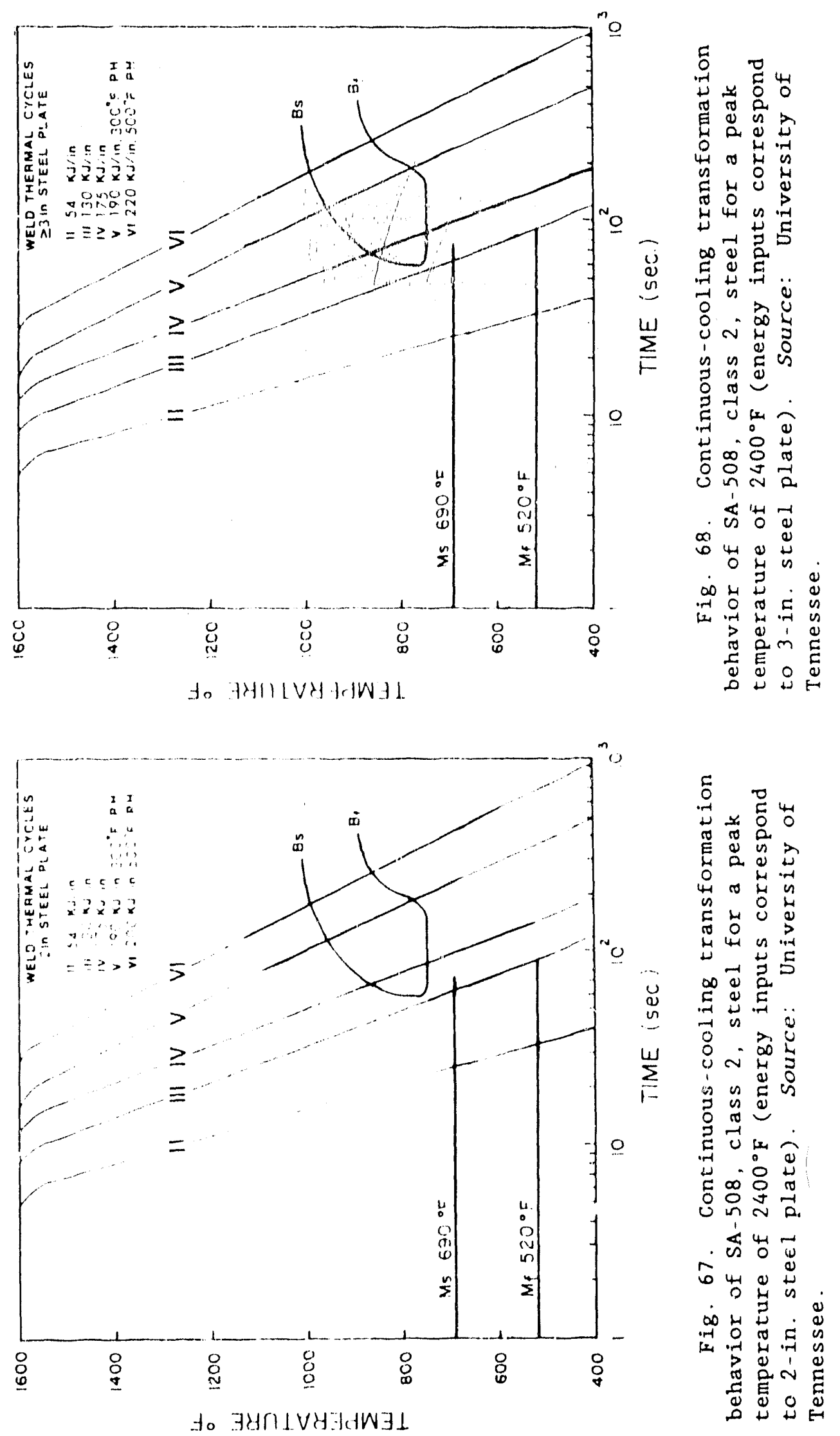
toughness of the hardened steel. At higher austenitizing temperatures, a more homogeneous austenite is achieved, which reduces nucleation sites for high-temperature transformation and thus increases hardenability. 'lime at: the austenitizing temperature also influences hardenability, primarily because time is needed to achieve austenite homogeneity.

Jominy hardenability tests were conducted for SA-533, grade B, class 1, and SA-508, class 2, materials according to the ASTM Standard A 255. The hardenability curves, Fig. 69, show that SA-508, class 2, steel has higher hardenability than SA-533, grade B, class 1. Hardness at the quenched end for SA-533, grade B, class 1, is HRC 38 and for SA-508, class 2, is HRC 46. The hardenability curve for SA-508, class 2, shows a drop in hardness at an approximate cooling rate of $42^{\circ} \mathrm{F} / \mathrm{s}$ at $1300{ }^{\circ} \mathrm{F}$. Similarly, the curve for SA-533, grade B, class 1 , shows a drop in hardness at an approximate cooling rate of $125^{\circ} \mathrm{F} / \mathrm{s}$ at $1300^{\circ} \mathrm{F}$, and the hardness decreases further with slower cooling rates.

The CCT behavior obtained by ERM is correlated with the hardenability curves in Figs. 70 and 71 . The critical cooling rate for SA-533, grade $B$,

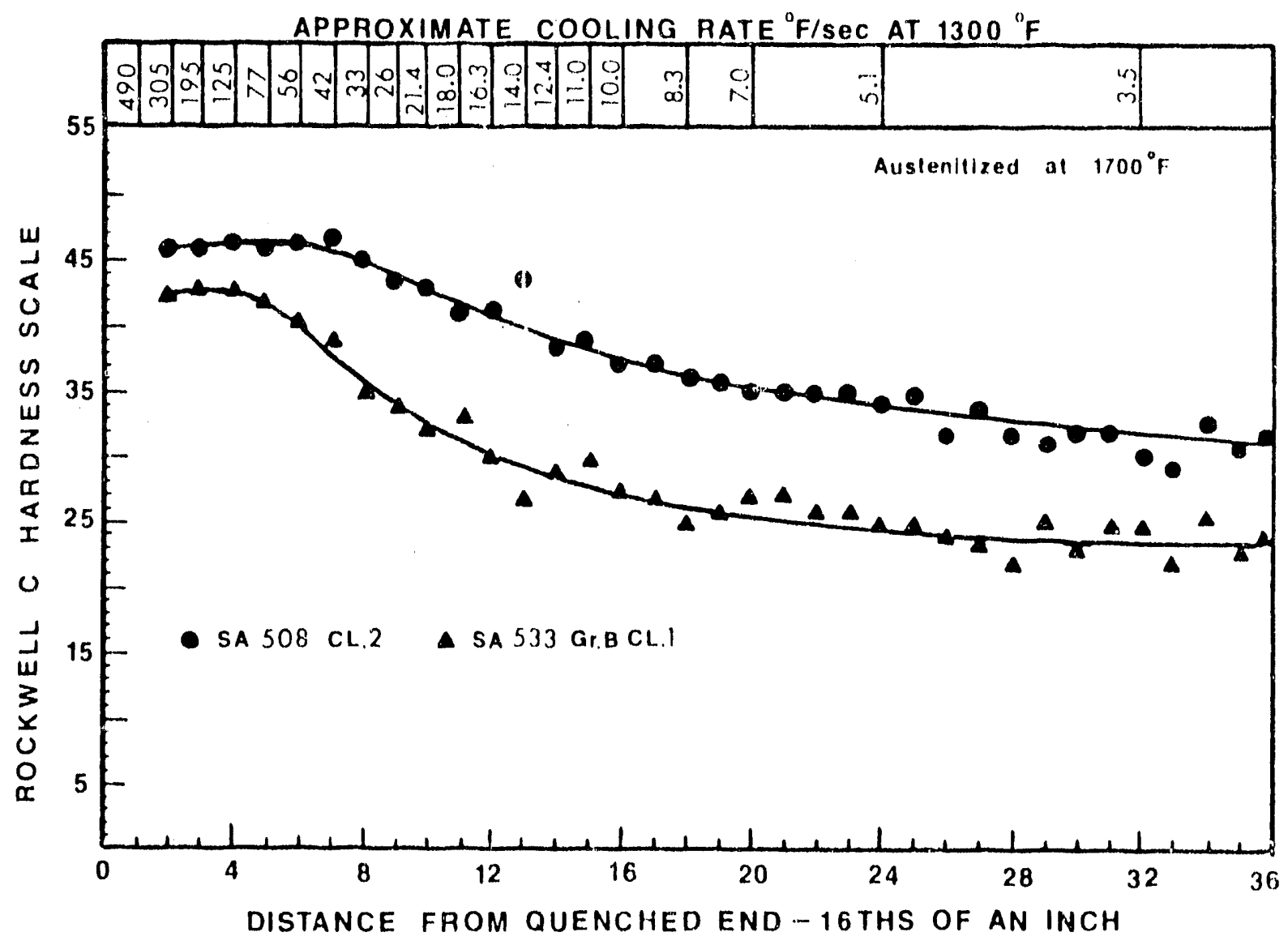

Fig. 69. Hardenability curves for SA-508, class 2, and SA-533, grade B, class 1, steels. Source: University of Tennessee. 

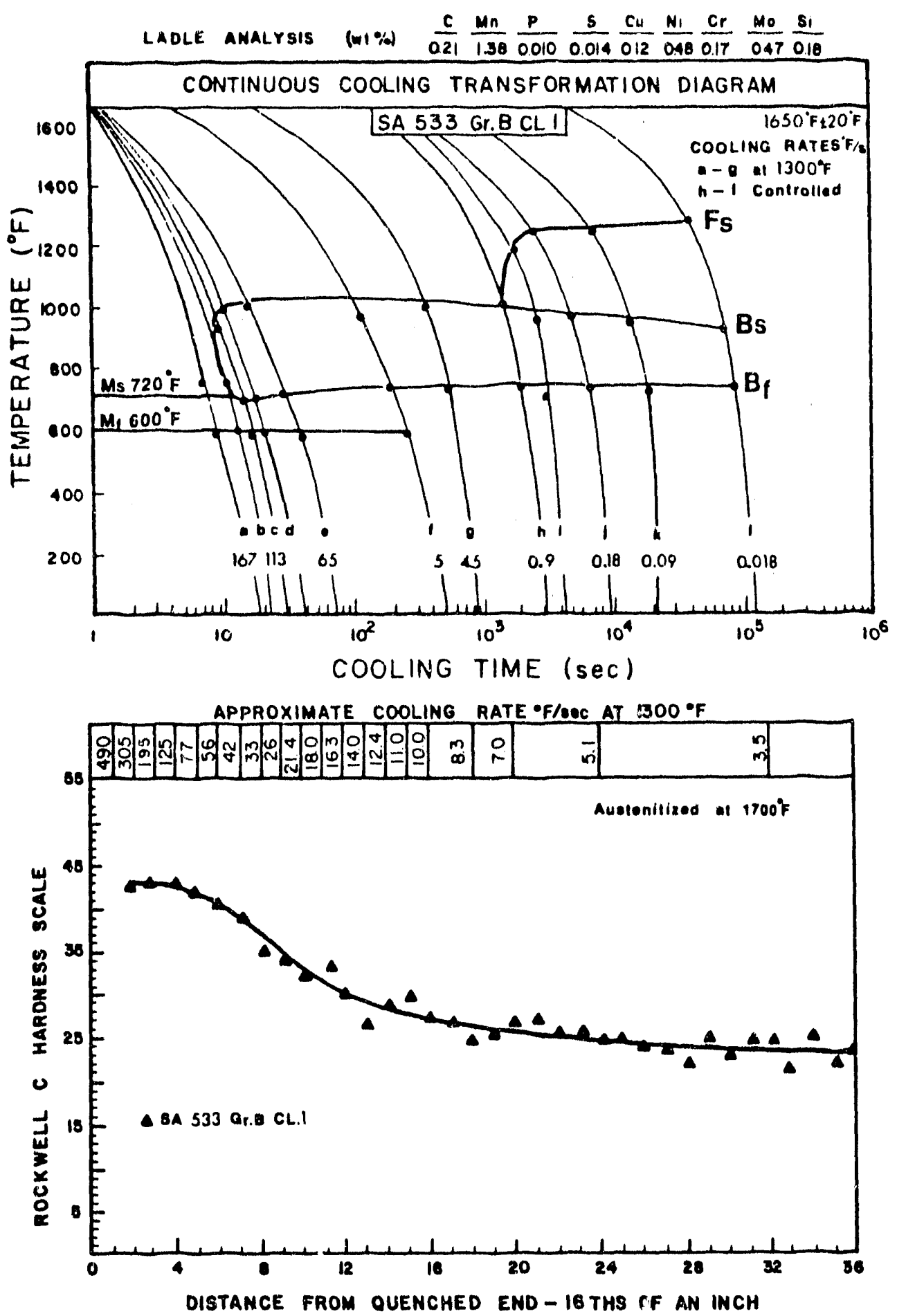

Fig. 70. Correlation of continuous-cooling transformation and hardenability curves of SA-533, gxade B, class 1 , steel. Source: University of Tennessee. 

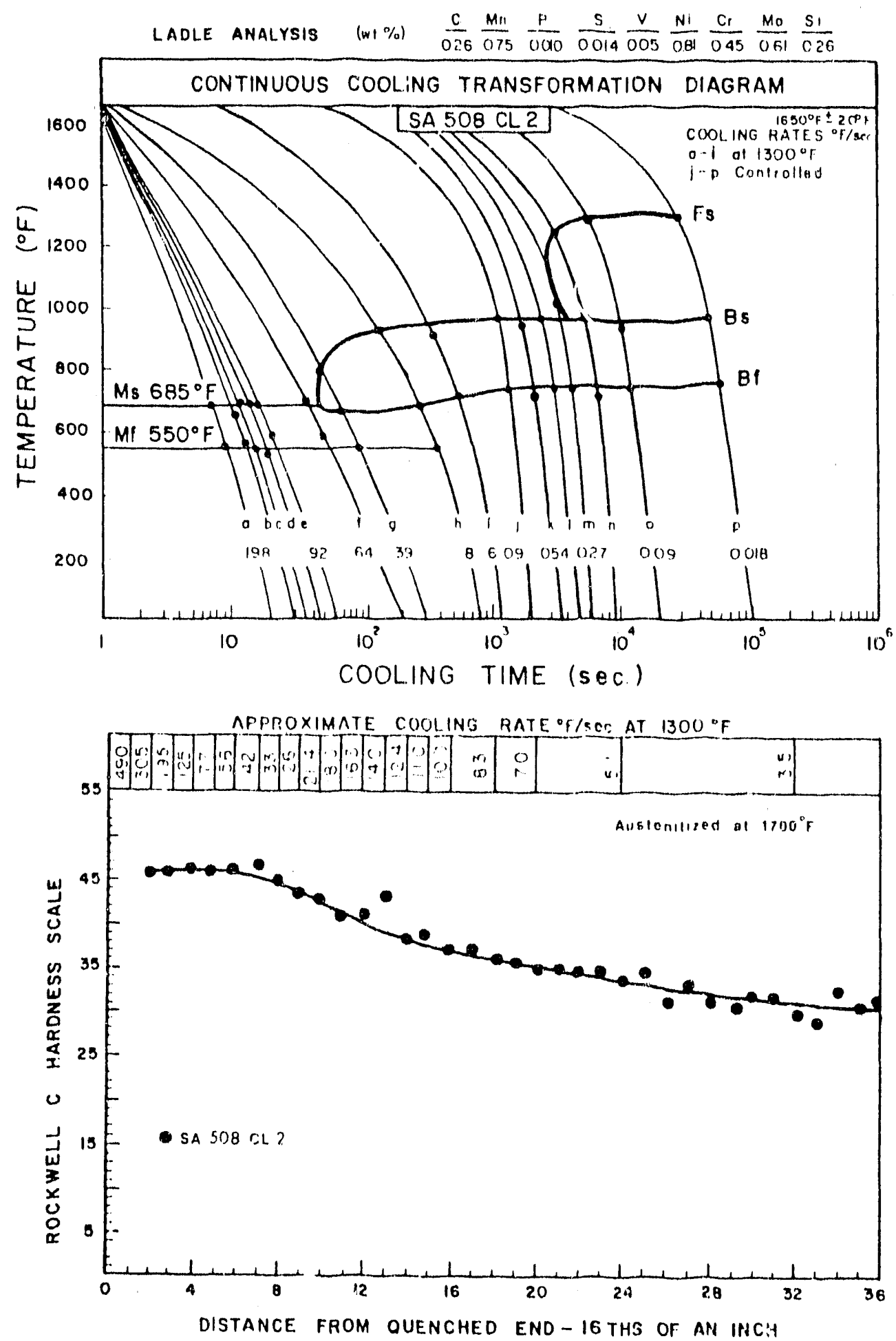

Fig. 71. Correlation of continuous-cooling transformation and hardenability curves of SA-508, class 2, steel. Source: University of Tennessee. 
class 1 , steel is approximately $140^{\circ} \mathrm{F} / \mathrm{s}$ at $1300^{\circ} \mathrm{F}$, whereas with the Jominy curve, a hardness drop is noticed at a cooling rate of $125^{\circ} \mathrm{F} / \mathrm{s}$ at $1300^{\circ} \mathrm{F}$. This hardness drop indicates that bainite has formed. Similarly, in SA-508, class 2, steel, the critical cooling rate is approximately $50^{\circ} \mathrm{F} / \mathrm{s}$ at $1300^{\circ} \mathrm{F}$, and the Jominy curve shows a drop in hardness at an approximate cooling rate of $42^{\circ} \mathrm{F} / \mathrm{s}$ at $1300^{\circ} \mathrm{F}$. This also shows that bainite has formed.

Jominy bars were also austenitized at a higher temperature $\left(2200^{\circ} \mathrm{F}\right)$ in addition to the standard $1700^{\circ} \mathrm{F}$. The main purpose was to achieve a larger grain size. The hardenability curves for $2200^{\circ} \mathrm{F}$ are shown in $\mathrm{Fig} .72$. The higher austenitizing temperature of $2200^{\circ} \mathrm{F}$ increased the hardenability of both steels over that obtained with an austenitizing temperature of $1700^{\circ} \mathrm{F}$. The depth of hardness for both steels is almost identical, which indicates that, at higher temperature, both steels have similar hardenability. This result agrees with the CCT diagrams for SA-533, grade B, class 1, and SA-508, class 2, stee1s as determined dilatometrically for a peak temperature of $2400^{\circ} \mathrm{F}$ (Fig. 58).

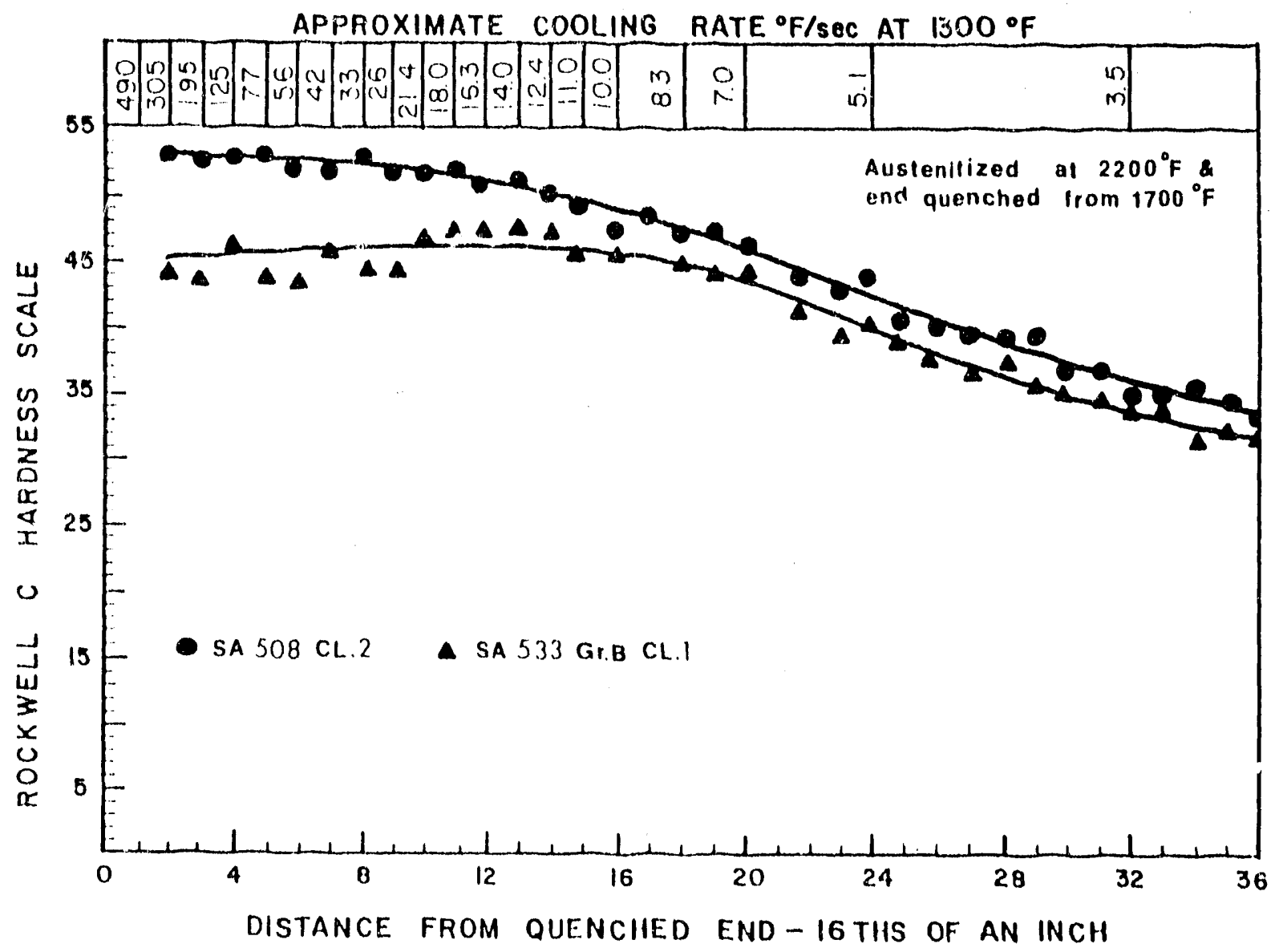

Fig. 72. Hardenability curves for SA-508, class 2, and SA-533, grade B, class 1, steels, austenitized at $2200^{\circ} \mathrm{F}$. Source: University of Tennessee. 
To better define the transformation charucteristics of steels SA-533, grade B, class 1, and SA-508, class 2, the Jominy bars were examined meta1lographically. The microstructure was martensitic at the quenched end and gradually changed to a martensitic-bainitic structure as the distance from the quenched end increased. The Jominy bar with the higher austenitizing temperature had a larger grain size.

COLD CRACKING TESTS

The most intensive research in the field of weldability has been that concerned with "cold cracking." This type of cracking originates primarily in the HAZ of base metals. The cracking is brought about through the embrittlement effects of hydrogen in a predominantly martensitic structure, the dynamic stresses of austenite-martensite transformation, the residual stress rate, or combinations of those factors.

In the welding of certain low-alloy steels, a better understanding of the mechanisms involved in hydrogen-induced cold cracking is required. It is usually assumed that cold cracking is associated with hydrogen embrittlement of martensite or bainite and that it is initiated by high residual stresses developed ir, the weld joint during cooling.

\section{Battelle Underbead Cracking Test}

Underbead cracking is one or the forms of hydrogen-induced cracking. Hydrogen can be introduced into weldments by the dissociation of moisture in organic corif unds in the welding flux, moisture in shielding gas, moisture on the steel surface, and other sources. The greatest problems arise in shielded metal arc welding because the flux coating often contains large amounts of hydrogen-bearing materials.

The Battelle underbead tests, discussed previously in the "Experimental. Procedures" section for steels SA-533, grade B, class 1 , and SA-508, class 2, were conducted at different preheat temperatures ranging from 32 to $300^{\circ} \mathrm{F}$. After the specimen was sectioned longitudinally (along the weld bead), the cross section of weld bead is polished, etched, and examined microscopically. The SA-533, grade B, class 1 , specimens welded ai 32 to $200^{\circ} \mathrm{F}$ showed underbead cracking, whereas specimens welded at $300^{\circ} \mathrm{F}$ showed no cracking. Similarly, for SA-508, class 2, underbead cracks appeared in specimens welded from 32 to $300^{\circ} \mathrm{F}$, and at $400^{\circ} \mathrm{F}$ no cracking was observed. Table 6 sumurizes results for both materials.

Cracking in a susceptible microstructure can be avoided by maintaining the material at a sufficiently high temperature until the microstructure has been softened, by tempering, to render it less susceptible. This principle is employed as postweld hold treatments at the original preheat temperature.

An increase in temperature increases the diffusion rate of hydrogen and hence accelerates its removal from the weld. Any measure that slows 
Table 6. Results of Battelle underbead cracking tests

\begin{tabular}{ccc}
\hline & \multicolumn{2}{c}{ Observations } \\
\cline { 2 - 3 } $\begin{array}{c}\text { Preheat or precooled } \\
\text { temperature }\left({ }^{\circ} \mathrm{F}\right)\end{array}$ & $\begin{array}{c}\text { SA-533, grade B, SA-508, class 2 } \\
\text { class 1 }\end{array}$ & \\
\hline 32 & Crack & Crack \\
85 & Crack & Crack \\
200 & Crack & Crack \\
300 & No crack & Fine crack \\
400 & & No crack \\
\hline
\end{tabular}

the weld cooling rate also is helpful in reducing the hydrogen level and promoting softer microstructures. Thus, preheat, by slowing the cooling rate, not only softens the microstructure but also helps hydrogen to escape. Two micrographs of underbead cracks are shown in Fig. 73. The cracks are formed just below the weld bead and run parallel. to the fusion line; they tend to be transgranular but responsive to the orientation of the martensitic lath structure.

In the Battelle test, the SA-508, class 2, steel was more susceptible to underbead cracking than was SA-533, grade B, class 1.

\section{Results of Hydrogen Susceptibility Testing}

The University of Tennessee Hydrogen Susceptibility Test 43.47 was used to further document the sensitivity to hydrogen cracking using an augmented strain of 48 . The SA-533, grade B, class 1 , steel welded from 32 to $400^{\circ} \mathrm{F}$ cracked, whereas specimens welded at $500^{\circ} \mathrm{F}$ did not crack. Similarly, cracks were observed in SA-508, class 2, specimens welded from 32 to $500^{\circ} \mathrm{F}$, but no cracking was observed in the specimen welded at $600^{\circ} \mathrm{F}$. These results show that, for the most critical situations, a preheat of $500^{\circ} \mathrm{F}$ for $\mathrm{SA}-533$, grade B, class 1 , and a preheat of $600^{\circ} \mathrm{F}$ for SA-5u8, class 2, are sufficient to drive off hydrogen and prevent cracking. The results are summarized in Table 7 . Macrographs of the cracking observed in the University of Tennessee Hydrogen Susceptibility Test are shown in Fig. 74. The cracking is shown as a function of preheat temperature.

We concluded from both cracking tests that SA-508, class 2 , is more susceptible to hydrogen-induced cracking than is SA-533, grade B, class 1. The preheat required to prevent cracking in the University of Tennessee Hydrogen Susceptibility Test is higher than the preheat required to eliminate cracking in the Battelle Underbead Cracking Test. This result is in line with other evaluations on carbon-manganese steels. The pre. heat determined in the Battelle test has been shown to be adequate in fabrication.

For the University of Tennessee Hydrogen Susceptibility Test, the ease of rankirig steels as to hydrogen susceptibility is good. However, 

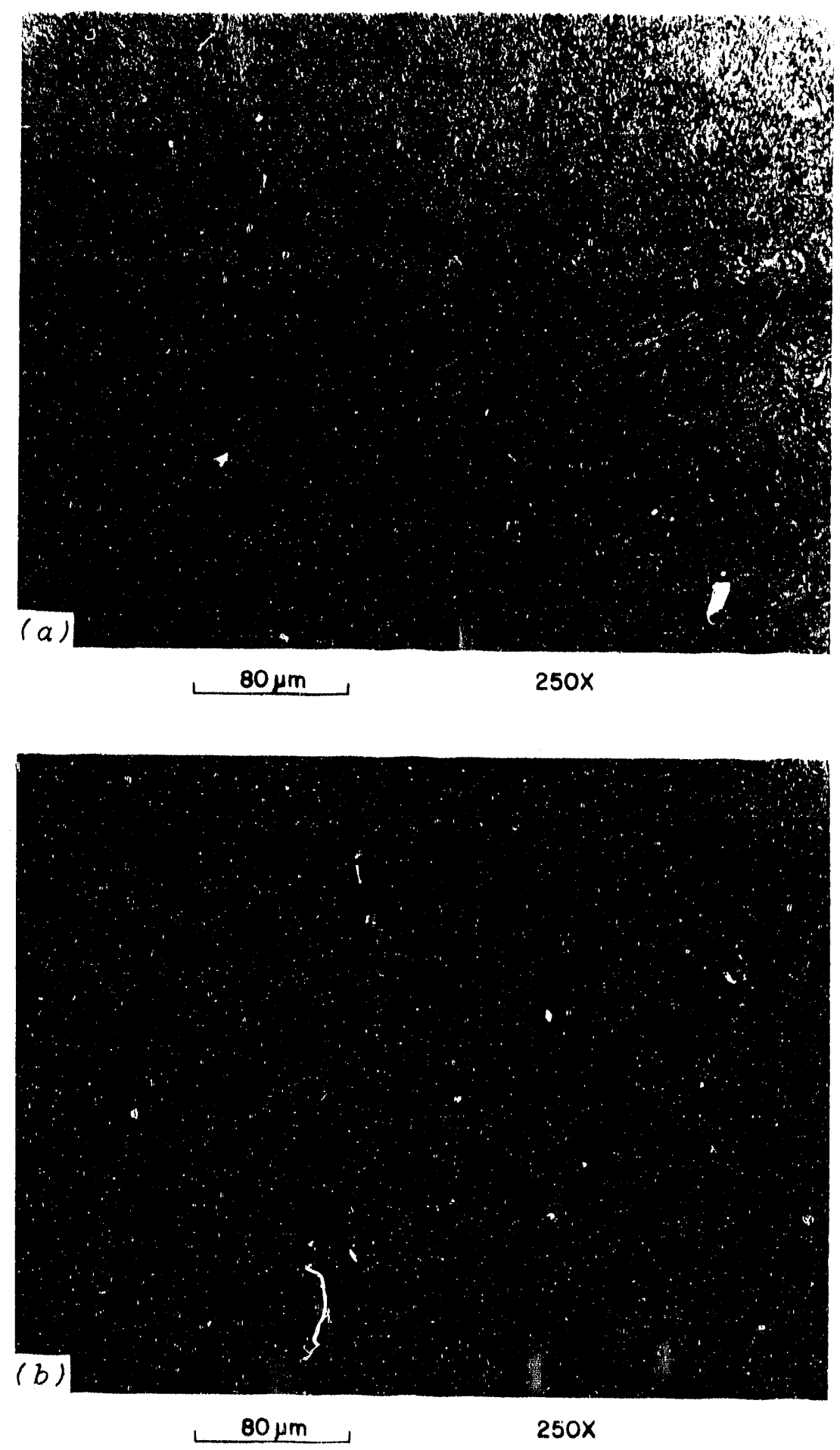

Fig, 73. Microstructures show underbead cracks for specimens welded at $32^{\circ} \mathrm{F}$. The top section of each micrograph is weld metal. Super picral etch. (a) SA-533, grade B, class 1, stee1, (b) SA-508, class 2, steel. Source: Unsversity of Tennessee. 
Table 7. Results of Unlversity of Tennessee hydrogen susceptibility tests

\begin{tabular}{|c|c|c|}
\hline \multirow{2}{*}{$\begin{array}{l}\text { Preheat or precooled } \\
\text { temperature }\left({ }^{\circ} \mathrm{F}\right)\end{array}$} & \multicolumn{2}{|c|}{ Observations } \\
\hline & $\begin{array}{c}\text { SA-533, grade B } \\
\text { class } 1\end{array}$ & SA-508, class 2 \\
\hline 32 & Crack & Crack \\
\hline 90 & Crack & Crack \\
\hline 300 & Crack & Crack \\
\hline 400 & Crack & \\
\hline 500 & No crack & Crack \\
\hline 600 & & No crack \\
\hline
\end{tabular}

the results (preheat temperatures) of the hydrogen susceptibility test are not sufficiently realistic to be used for actual fabrication conditions because the test is quite severe, and the results tend to be conservative. The advantage in this test lies in its ability to quickly rank the weldability of steels with respect to welding conditions, hydrogen levels, and preheat temperatures.

STRESS-RELIEF CRACKING

Stress relief cracking (SRC) (or reheat cracking) may be defined as intergranular cracking in the coarse-grained HAZ occurring during the exposure of welded assemblies to the elevated temperatures used for PWHT or service. The cracks generally occur as a result of the redistribution of residual welding stresses coupled with HAZ metallurgical changes when sound weldments are heated to elevated temperatures.

The HAZ cracks are intergranular, and the material exhibits low ductility, showing little or no evidence of plastic deformation near the cracks. Because the cracks are usually confiried to the coarse-grained region of the $\mathrm{HAZ}$, cracking is directly related to prior high-temperature exposure.

According to the experimental procedure described earlier, SRC tests were conducted for SA-533, grade B, class 1 , and SA-508, class 2. The time to rupture and the reduction of area for each specimen are functions of the stress applied and of the thermal treatment given to the specimen. The results are sumnarized in Table A.5 of Appendix A. The specimen with the bainitic microstructure prociuced by Cycle VI $\left(136 \mathrm{~kJ} / \mathrm{in}\right.$, , $500^{\circ} \mathrm{F}$ preheat) took longer to rupture than the one with the martensitic structure produced by Cycle II $\left(50 \mathrm{~kJ} / \mathrm{in} ., 87^{\circ} \mathrm{F}\right.$ preheat).

For comparing the steeis on the basis of stress-rupture strength and stress-rupture ductility, time to rupture versus percentag reduction of 


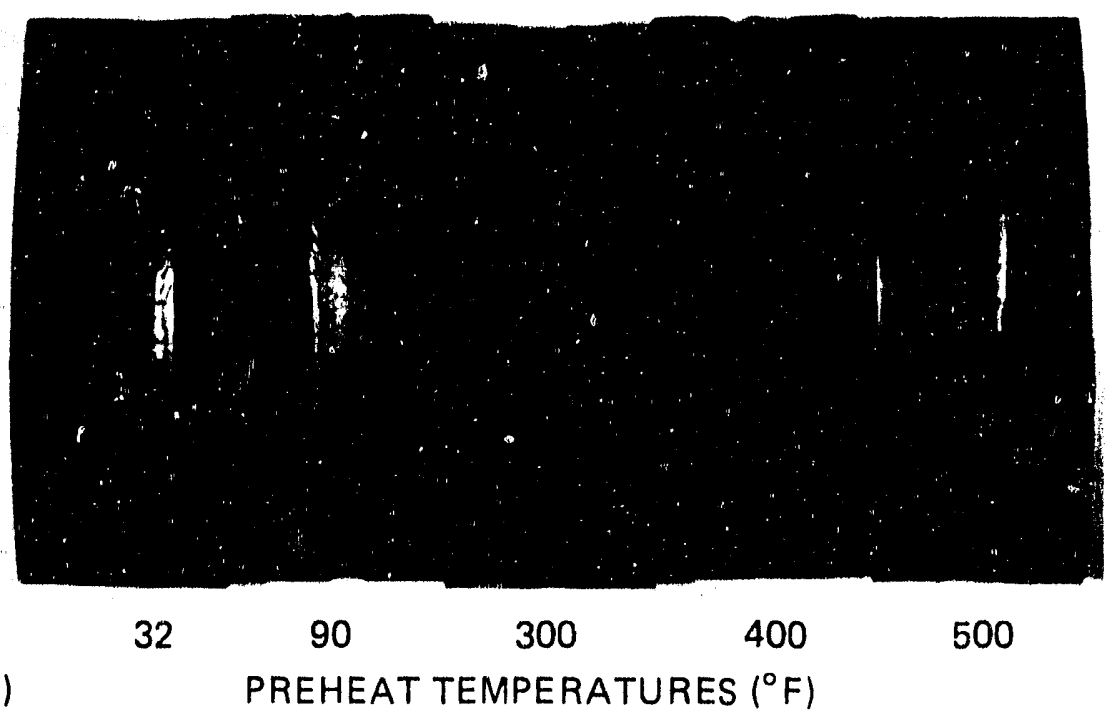

(a) PREHEAT TEMPERATURES $\left({ }^{\circ} \mathrm{F}\right)$

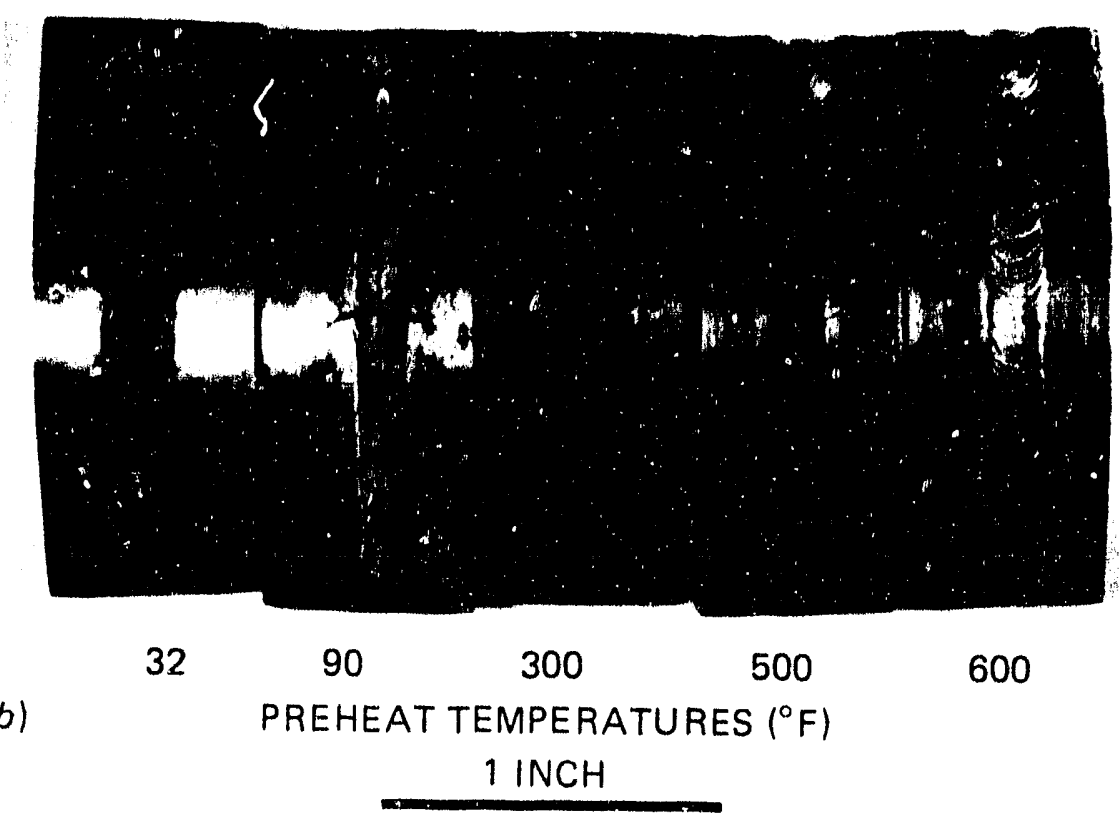

Fig. 74. Macrographs of cracks observed in University of Tennessee hydrogen susceptibility test specimens. (a) SA-533 steel, (b) SA-508 steel. Source: University of Tennessee. 
area and applied stress are plotted in Fig. 75. The SA-508, class 2, steel exhibited a higher stress to rupture (for equivalent times) than did SA-533, grade $B$, class 1, indicating a stronger material at the PWHT temperature, whereas SA-533, grade B, class 1 , exhibited a higher creep rupture ductility than did SA-508, class 2 .

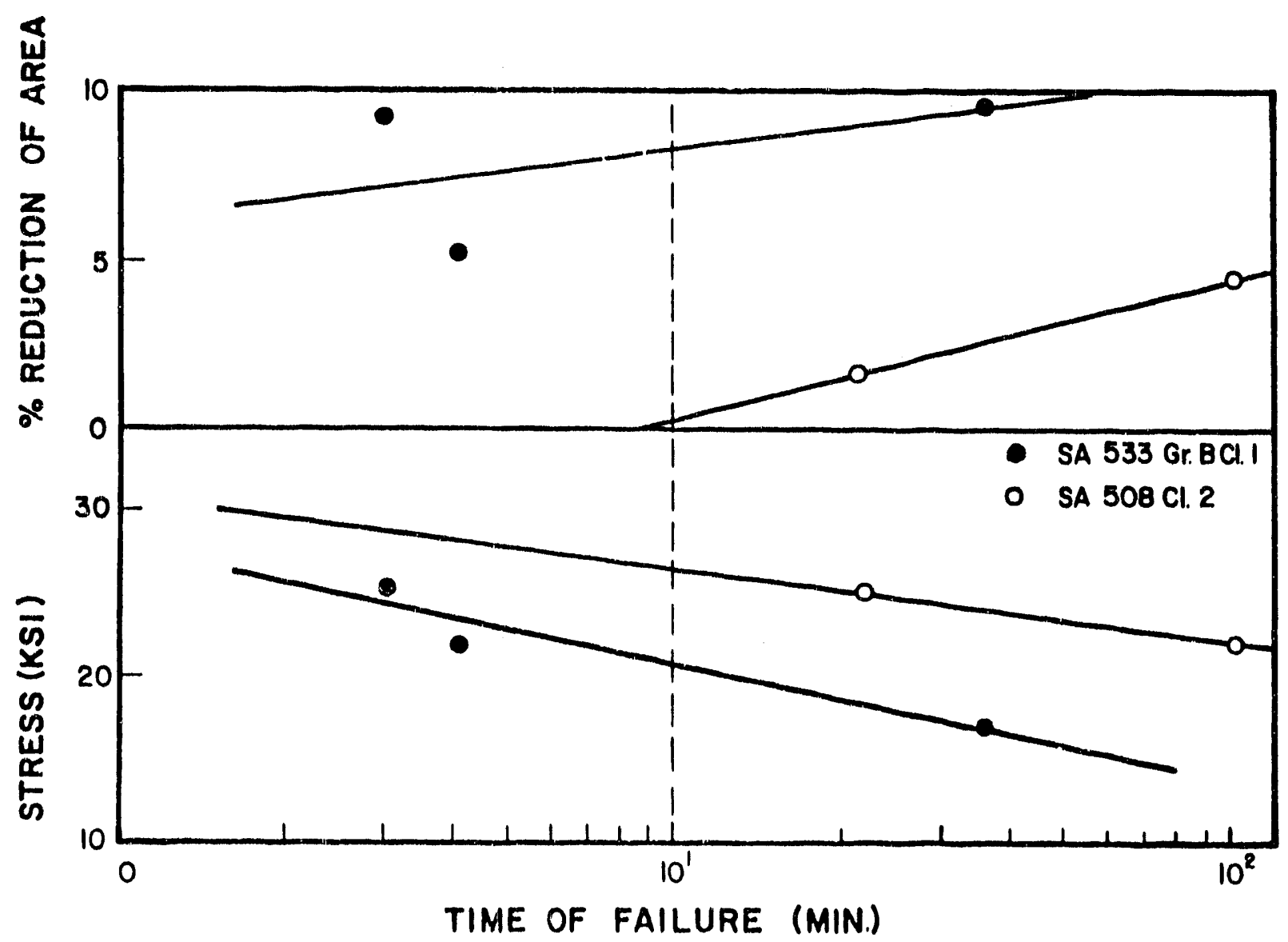

F18. 75. Stress-rupture properties at $1150^{\circ} \mathrm{F}$ of simulated graincoarsened weld heat-affected zone of SA-508, class 2, and SA-533, grade B, class 1, steels. Source: University of Tennessee.

Pense et al. ${ }^{22}$ performed considerable work on SRC in carbon and highstrength steels. The results of tensile and stress relaxation tests on plain carbon and carbon-boron steels indicated that SRC is not a problem in those steels but that A $517-\mathrm{F}$ ( $\mathrm{Ni}-\mathrm{Cr}-\mathrm{Mo}-\mathrm{B}-\mathrm{V}$ ) was highly susceptible to SRC whereas A $517-J$ (Mo-B) was not. Pense also observed that the plain carbon steel, consisting of upper bainitic structure, had a reduction of area of 768 ; on water quenching, the reduction of area reduced to $33 \%$ 
because of massive martensite production. Similar ductility was also observed for carbon-boron steel, but for A $517-J$ the value dropped from 138 for the bainitic structure to 5 f for the martensitic structure because of the precipitation of molybdenum carbide. Our results agree well with Pense et al., in the sense that the creep-rupture ductility after a thermal cycle was quite high for steels not containing $\mathrm{Ni}, \mathrm{Cr}$, and $\mathrm{V}$. In our study, the bainitic microstructure did not produce a higher creep-rupture ductility than did the martensitic structure obtained by Pense.

The SRC susceptibility can be evaluated by a stress-rupture parameter. The stress-rupture parameter is the product of the stress for a rupture life of $10 \mathrm{~min}$ and the corresponding reduction of area. For highstrength steels (martensitic microstructure), ff the value of this parameter is greater than approximately $15 \times 10^{4}$, then the stress-rupture strength and ductility are considered good and, accordingly, a low susceptibility to cracking would be expected. Conversely, if the value is less than $15 \times 10^{4}$, then poor stress-rupture properties and increased crack susceptibility would occur. The stress-rupture parameter obtained for $\mathrm{SA}-533$ is $16.8 \times 10^{4}$ and for SA-508 is $1.3 \times 10^{4}$ (as shown in Table 8). The results of stress-rupture testing, based on the coarse-grained martensitic structure, lead to the conclusions that SA-508, class 2, is more susceptible to SRC than is SA-533, grade B, class 1 .

Table 8. Values obtained in stress-relief cracking test for rupture 11 fe of $10 \mathrm{~min}$

\begin{tabular}{cccc}
\hline Steel & $\begin{array}{c}\text { Stress for a } \\
\text { rupture life of } \\
10 \text { min (psi) }\end{array}$ & $\begin{array}{c}\text { Reduction } \\
\text { of } \\
\text { area }(8)\end{array}$ & $\begin{array}{c}\text { Stress - } \\
\text { rupture } \\
\text { parameter }\end{array}$ \\
\hline $\begin{array}{r}\text { SA-533, grade B, } \\
\text { class } 1\end{array}$ & 21,000 & $8 \mathrm{~s}$ & $16.8 \times 10^{4}$ \\
SA-508, class 2 & 26,500 & 0.5 & $1.3 \times 10^{4}$
\end{tabular}

aThe stress-rupture parameter is the product of the stress for a rupture life of $10 \mathrm{~min}$ and the corresponding reduction of area.

By using the data from the coarse-grained bainitic structure to evaluate the stress-rupture parameter, we predict that a bainitic structure will have lower stress to rupture and creep-rupture ductility for SA-533, grade B, class 1, and SA-508, class 2, steels. Consequently, a lower stress-rupture parameter is ohtained, with SA-508, class 2, being the more susceptible to SRC with a bainitic microstructure.

The nature of the fracture surfaces of the stress-rupture specimens was examined with the scanning electron microscope (SEM). The mode of fracture in the specimens was predominantly intergranular. Hamilton ${ }^{48}$ 
mentioned that precipitation hardening within the grain concentrates the strain on the grain boundaries, which alread; have reduced ductility because of residual element segregation, and intergranular cracking results. The fractographs of the fractured surfaces of both steels are shown in Figs. 76 through 79. Those in Fig. 76 are the result of Cycle II
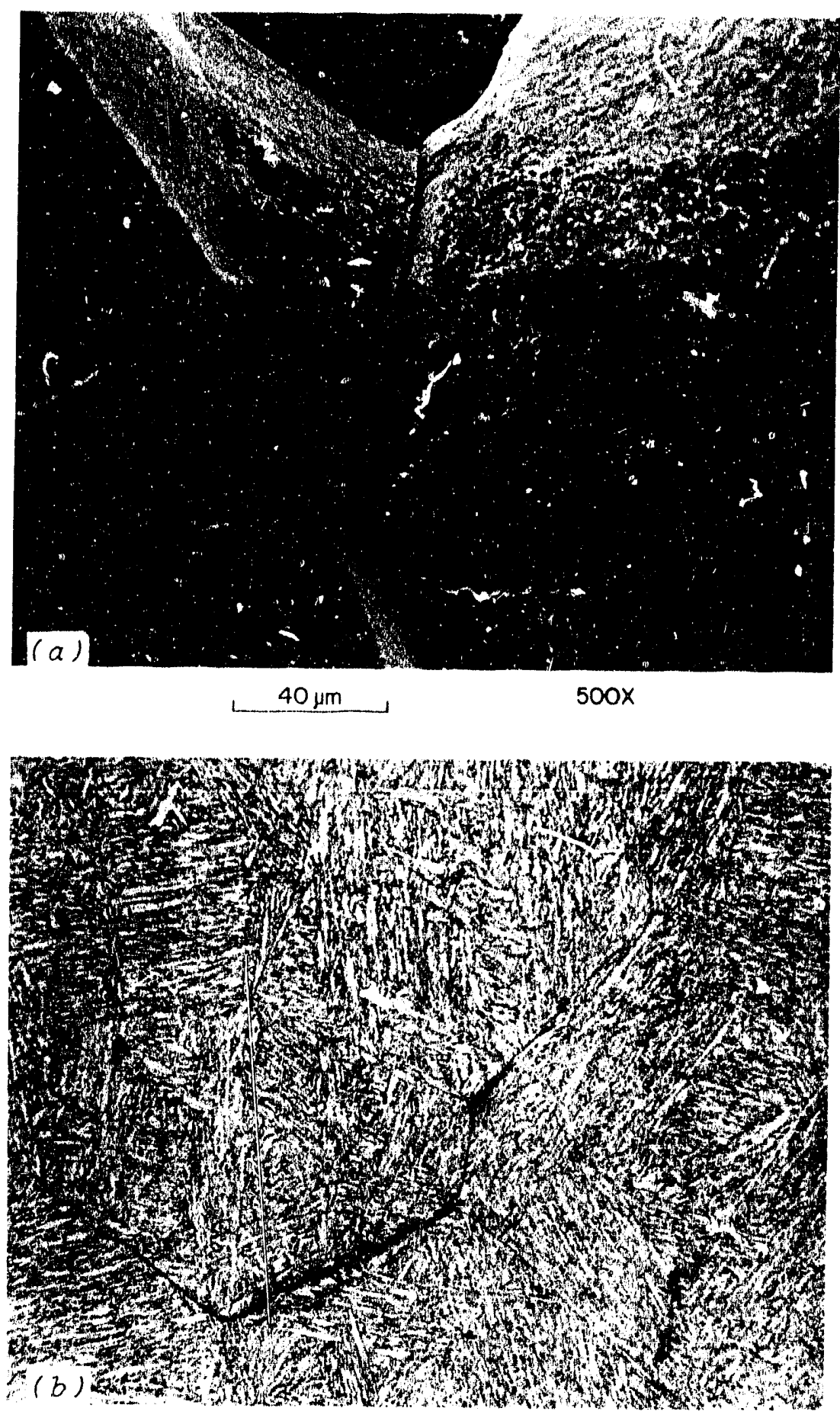
bu $\mu \mathrm{m}$ $250 x$
Fig. 76. Intergranular fracture behavior in stress relief cracking test 3 , of SA-533, grade $B$, class 1 stee1 (martensitic structure). (a) Scanning electron micrograph. (b) Metal lographic section of (a) revealing grain boundary cracks, super picral etch. 

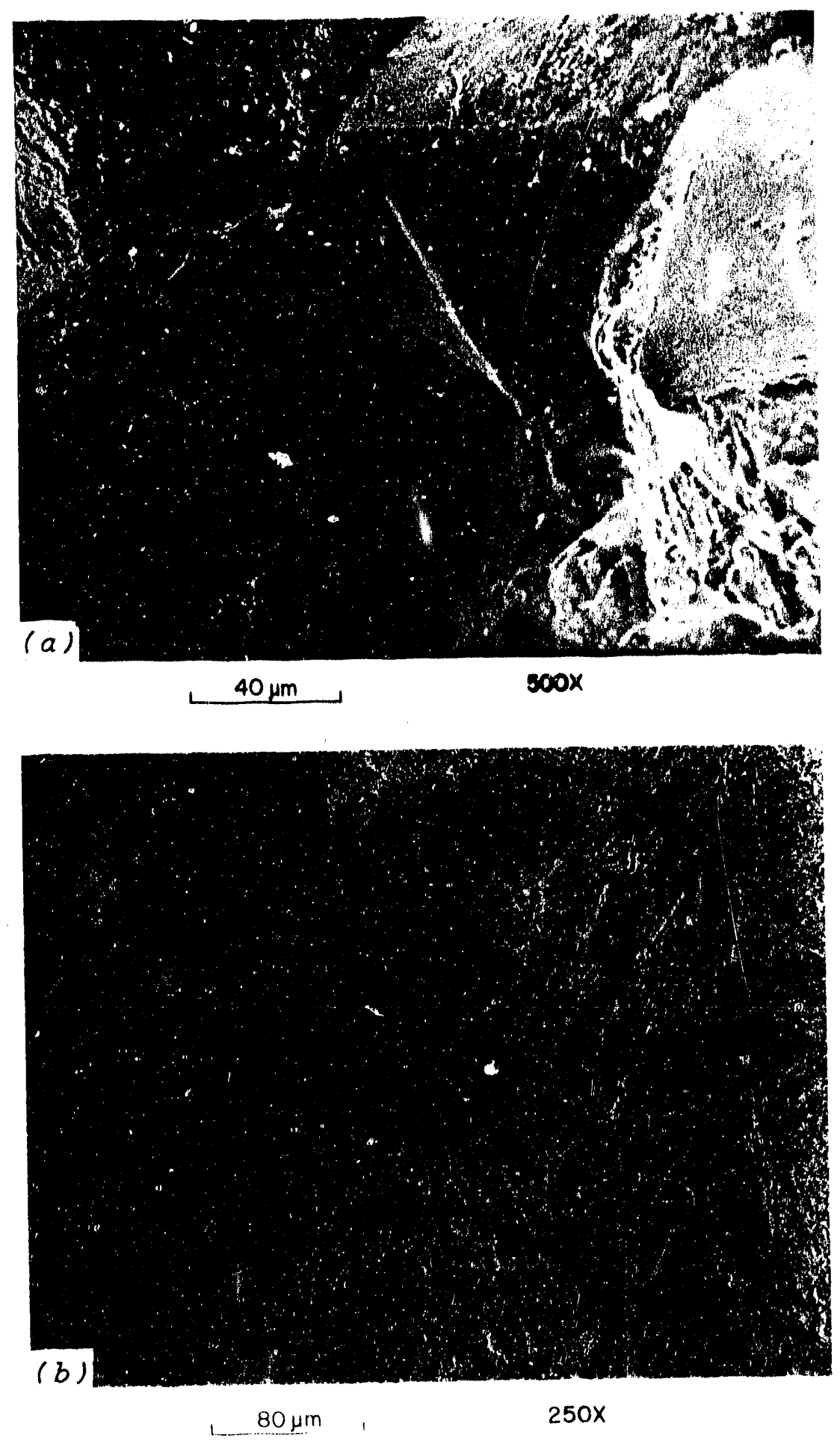

Fig. 77. Intergranular fracture behavior in stress-relief cracking test 7 of SA-533, grade B, class 1, stee1 (bainitic structure). (a) Scanning electron micrograph. (b) Metallographic section revealing grain boundary secondary cracks below the main rupture surface of (a), super picral etch. 

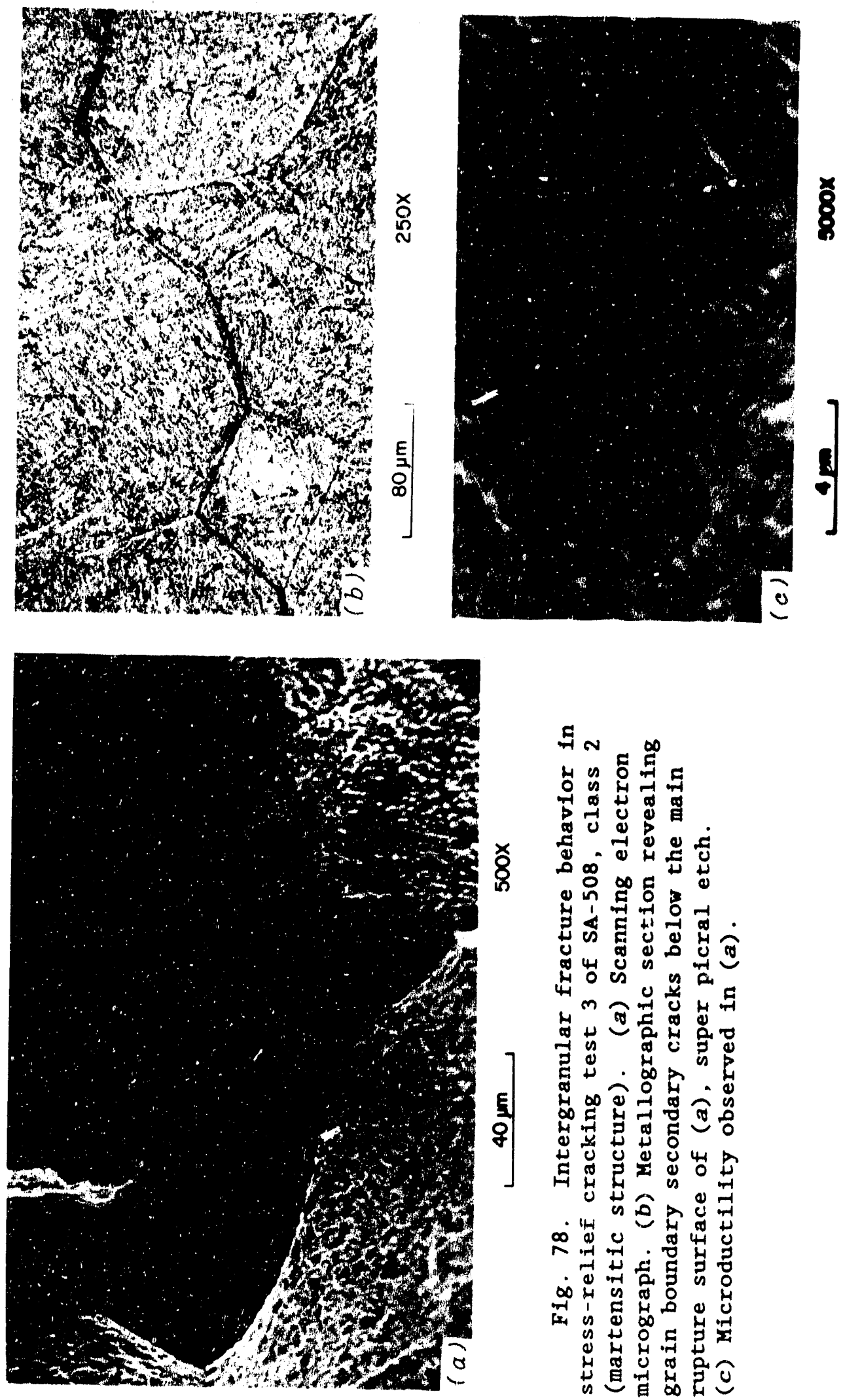

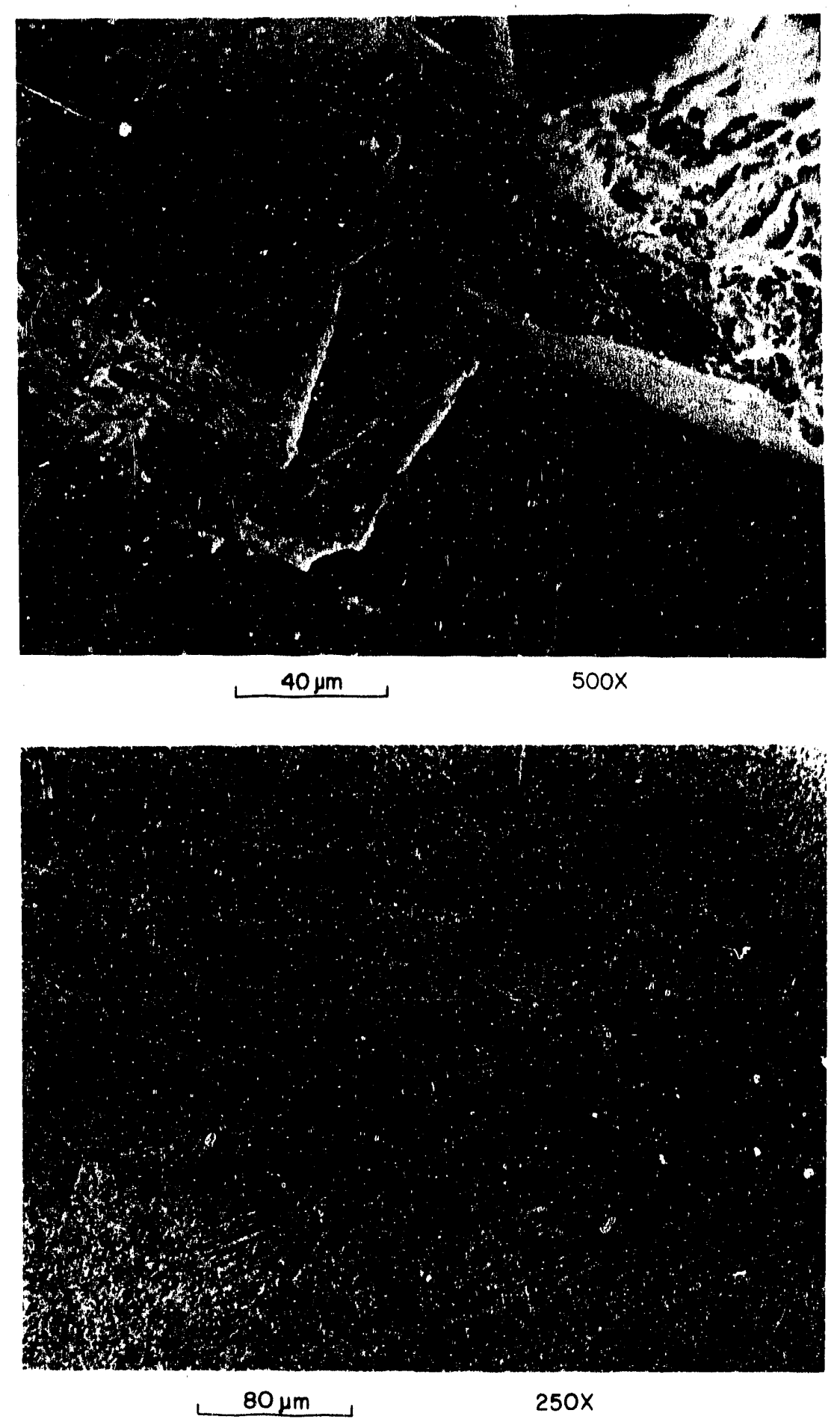

Fig. 79. Intergranular fracture behavior in stress-relief cracking test 7 of SA-508, class 2 (bainitic structure). (a) Scanning electron micrograph. (b) Metallographic section revealing grain boundary secondary cracks below the main rupture surface of (a), super picral etch. 
plus PWHT forming a martensitic structure; the grain size is large and the cracks are intergranular. Similar behavior is noted in Fig. 77, except that the microstructure is bainitic, produced by Cycle VI plus PWHT. A similar trend for cracking and a related microstructure were observed in SA-508, class 2, steel and are shown in Figs. 78 and 79. The SEM fractographs of the martensitic structure [Figs. 76(a) and 78(a)] show traces of microductility on the grain faces; this microductility is shown in Fig. $78(c)$ at a higher magnification. Fractographs for the bainitic structures [Figs. $77(a)$ and $79(a)$ ] show no microductility, but the grain faces show oxides and inclusions. Those defects are not related to the intergranular failure.

The results of the SRC tests show that $\mathrm{SA}-508$, class 2 , steel is more susceptible to reheat cracking than is SA-533, grade B, class 1 . This conclusion is based on the stress-rupture strength and stress-rupture ductility of the specimens.

Careful handling of susceptible materials in terms of weld energy input, weld joint restraint, and choice of PWHT conditions can prevent stress-rupture cracking. However, in general, reheat cracking is best prevented by correct selection of material and PWHT.

CHARPY V-NOTCH TOUGHNESS OF SIMULATED HEAT-AFFECTED ZONE MICROSTRUCTURES

The toughness of any multipass HAZ microstructure is primarily determined by the final thermal cycle experienced at a particular location. Thus, the toughness of a steel subjected to a peak temperature of $2400^{\circ} \mathrm{F}$ would not be expected to be identical with the toughness of the same steel grain coarsened at $2400^{\circ} \mathrm{F}$ and then recycled to $1650^{\circ} \mathrm{F}$. After a material has been exposed to high-peak-temperature thermal cycle it differs from the original base metal in prior austenite grain size and in the amount of carbon and other alloy elements in solution. Thus, the influence of multiple HAZ cycles on properties is of interest.

The energy input conditions were selected for weld thermal cycles with 2400 and $1650^{\circ} \mathrm{F}$ peak temperatures. Cycle II $\left(50 \mathrm{~kJ} / \mathrm{in}, 8^{\circ} \mathrm{F}\right.$ preheat, 1 -in. plate) was chosen to provide a fully martensitic transformation product, and Cycle VI $\left(136 \mathrm{~kJ} / \mathrm{in} ., 500^{\circ} \mathrm{F}\right.$ preheat, $1-\mathrm{in}$. plate $)$ was chosen to provide a fully bainitic structure. A number of thermal treatments were employed for this test, among which was a dual-cycle treatment consisting of exposure to a higher peak temperature of $2400^{\circ} \mathrm{F}$ (sufficient to cause complete austenitization) followed by a lower peak temperature $\left(1650^{\circ} \mathrm{F}\right)$ to obtain a grain-refined structure. This multicycle thermal excursion represents a multipass welding procedure. Another thermal treatment employed consisted of exposure to a $2400^{\circ} \mathrm{F}$ peak temperature followed by postweld hold at 600 or $300^{\circ} \mathrm{F}$ to temper the initial microstructure. A complete schedule of thermal heat treatments is shown in Table A.3, and Charpy V-notch toughness is shown in Tables A.6 and A.7 of Appendix A. These values are presented in bar graph form in the 
following discussion. The lateral expansions associated with these impact toughness values for SA-533, grade B, class 1, and SA-508, class 2, stcels are shown in Figs. B. 1 and B.2 of Appendix B.

\section{SA-533, Grade B, Class 1}

A bar graph of Charpy $V$-notch toughness as related to different HAZ thermal cycles is shown in Fig. 80. The impact test temperature selected was $-25^{\circ} \mathrm{F}$, which corresponds to the transition temperature (50 ft- $1 \mathrm{~b}$ ) of the base metal. A toughness of $60 \mathrm{ft}-1 \mathrm{~b}$ was observed for the base metal.

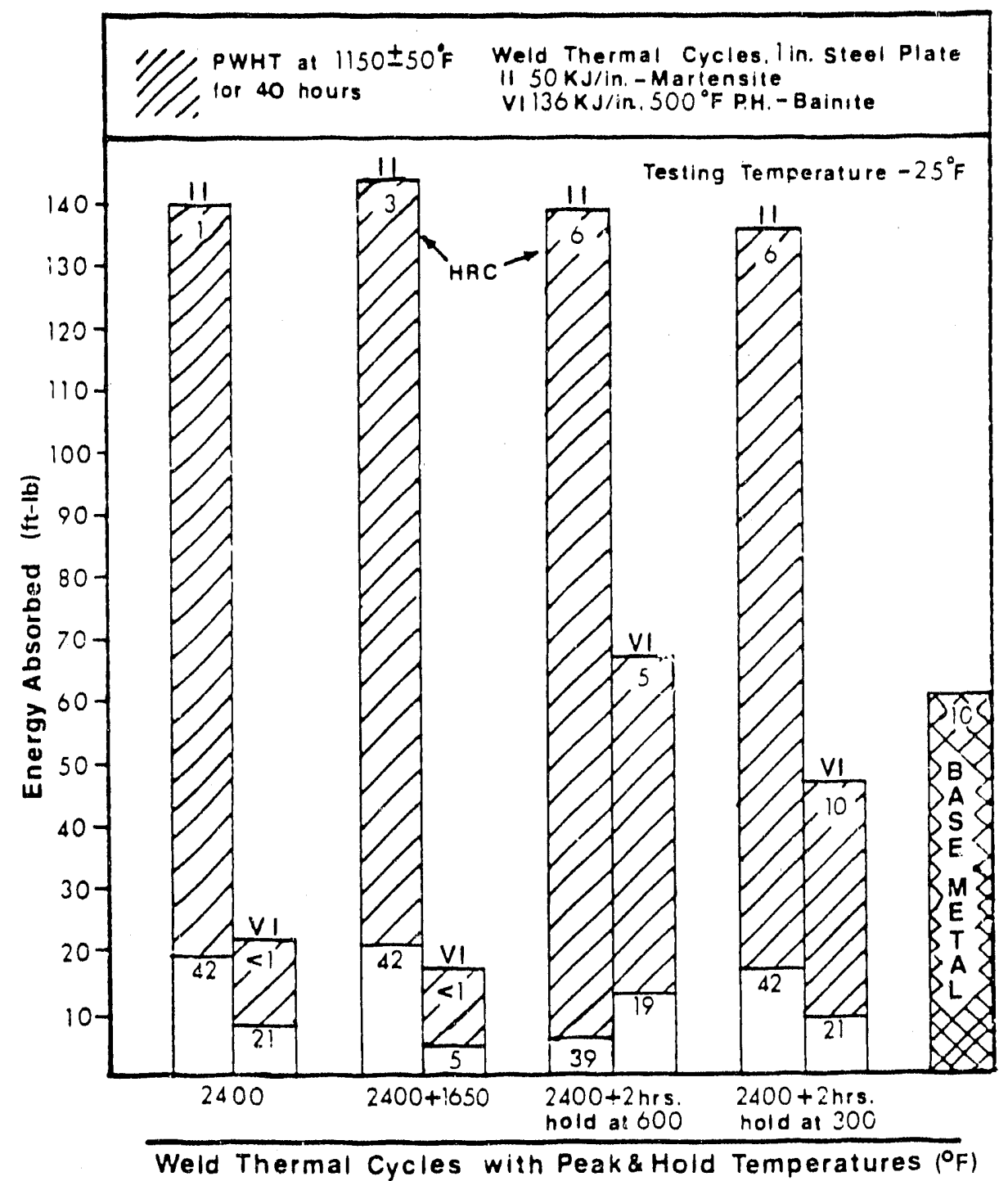

Fig. 80. Charpy $V$-notch toughness as related to different heat-affected zone thermal cycles for SA-533, grade B, class 1, steel. Source: University of Tennessee. 
The coarse-grained martensitic structure (obtained by Cycle II) gave a toughness of about $20 \mathrm{ft}-\mathrm{lb}$, and upon PWHT the toughness increased significantly to $140 \mathrm{ft} . \mathrm{lb}$. The hardness decreased from HRC 42 to HRC 1 (HRB 83). For the coarse-grained bainitic structure (obtained by Cycle VI) an impact toughness of $10 \mathrm{ft}$-lb was recorded, which, upon PWHT, increased to approximately $20 \mathrm{ft}-1 \mathrm{~b}$. The hardness dropped from HRC 21 to HRB 80 . This result shows that the toughness of the bainitic structure is lower than that of the martensitic structure and that PWHT increases the toughness of martensite significantly but does not appear to improve the toughness of bainite to a great extent. The respective microstructures are shown in Figs. 81 and 82 .

For SA-533, grade B, class 1, the optimum toughness of the martensitic structure was obtained by multiple cycles with different peak temperatures $\left(2400^{\circ} \mathrm{F}\right.$ followed by $1650^{\circ} \mathrm{F}$ peak), whereas the toughness for the bainitic structure was deteriorated by a double cycle. The thermal recycling duplicating multiple-pass welding resulted in properties largely determined by the peak temperature and cooling rate of the final cycle. This fact serves as a reminder that the HAZs of multiple-pass welds comprise a complex conglomerate of microstructures produced by a wide range of peak temperatures spatially distributed in a complicated pattern. Hardness measurements cannot be expectec to be related isefully to the notch toughness of such a conglomerate. The microstructures obtained after multiple cycles are shown in Figs. 83 and 84.

Martensite, although very hard and basically strong, lacks toughness; however, tempered martensite can have high strength and good toughness if it is heat treated proper!y, because the brittle martensite is replaced by a fine dispersion of rigid carbide particles within a tough ferrite matrix. The untempered martensitic structure with postweld hold at $600^{\circ} \mathrm{F}$ showed the least toughness of all treatments, that is, "as welded" (this thermal treatment is similar to Martempering), but superior toughness was achieved after PWHT. The bainitic structure showed the best toughness when a postweld hold (at $600^{\circ} \mathrm{F}$ ) and PWHT were employed. The micrographs for those thermal treatments are shown in Figs. 85 ald. 86 . The untempered martensitic and bainitic structure with a postweld nold at $300^{\circ} \mathrm{F}$ showed toughness similar to that obtained without postweld holds, but the bainitic microstructure for this hold showed the second best bainitic toughness. The respective microstructures are shown in Fig. 87. These observations clearly show that tempered martensitic structures are tougher than tempered bainitic structures. Thus, after l'WHT of as-welded HAZs, a significant increase in toughness was observed for martensitic structures as compared with bainitic structures. This indicates that weld HAZ regions containing tempered martensite are tougher than the base metal.

The hardness results showed that higher hardnesses were obtained for martensitic structures than for bainitic structures and that hardness has no direct relation to the toughness. As the cooling rate from the austenitizing temperature is increased, the microstructure shifts from relatively soft aggregates of ferrite and carbide to harder bainitic or martensitic structures with accompanying loss in ductility. The degree of hardening 

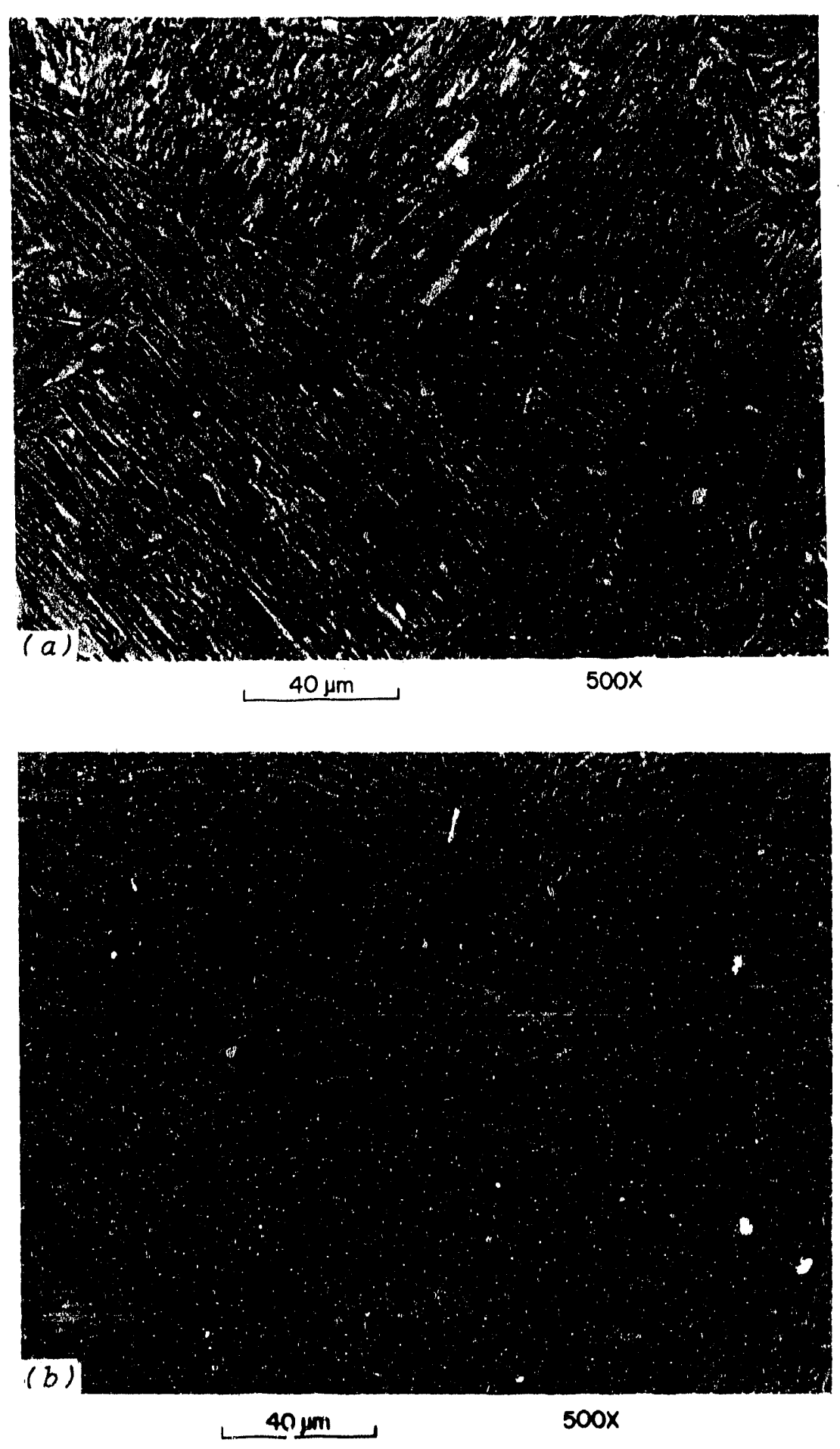

Fig. 81. Microstructural behavior in SA-533, grade B, class 1 , steel for Cycle II, $2400^{\circ} \mathrm{F}$ peak temperature. Super picral etch. (a) Martensitic structure, HRC 42. (b) Postweld heat treated, tempered martensitic structure, HRC 1. Source: University of Tennessee. 

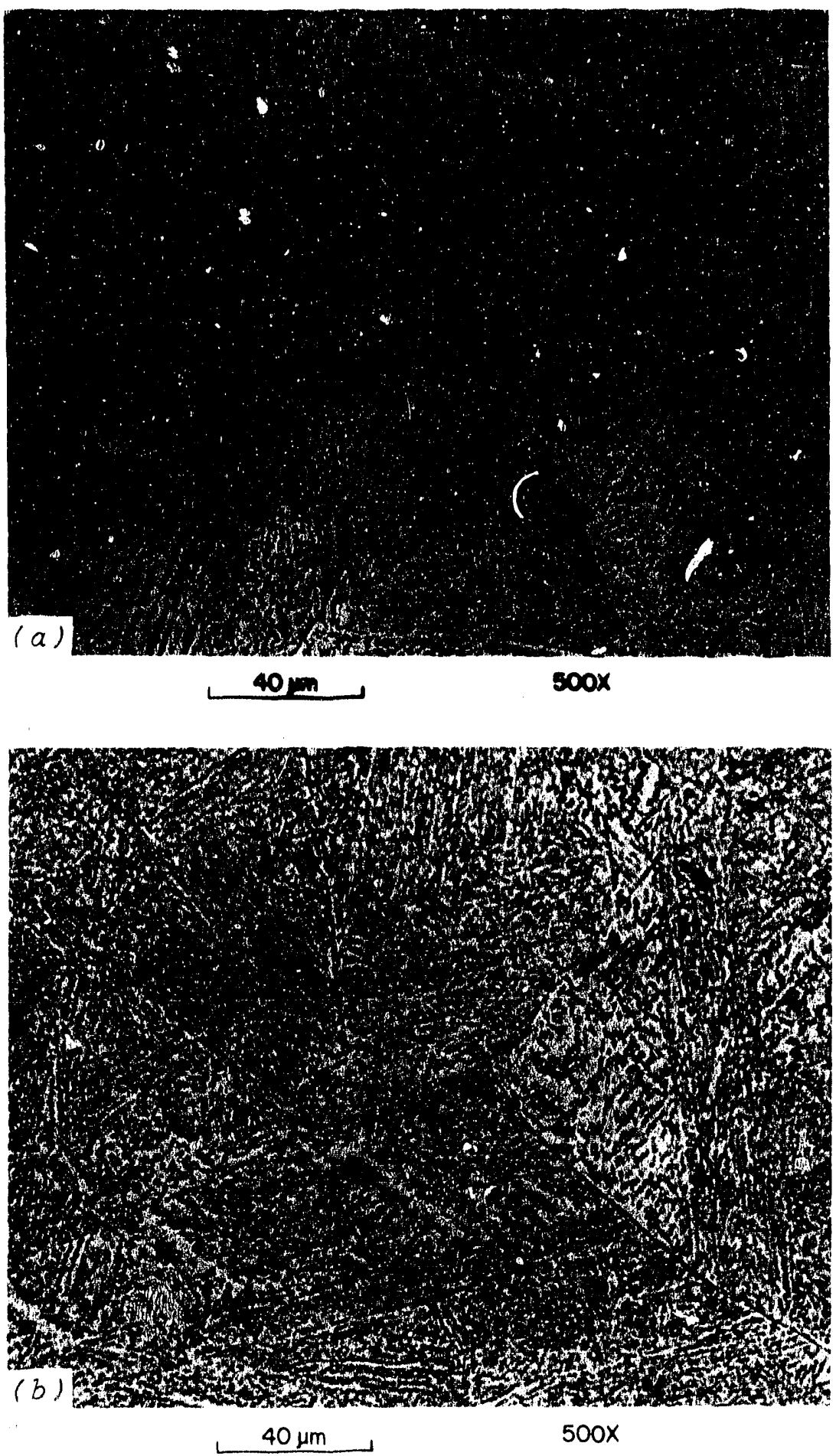

Fig. 82, Microstructural behavior in SA-533, grade B, class 1 , steel for Cycle VI, $2400^{\circ} \mathrm{F}$ peak temperature. Super picral etch. (a) Bainitic structure, HRC 21. (b) Postweld heat treated, tempered bainitic structure, HRB \&2. Source: University of Tennessee. 

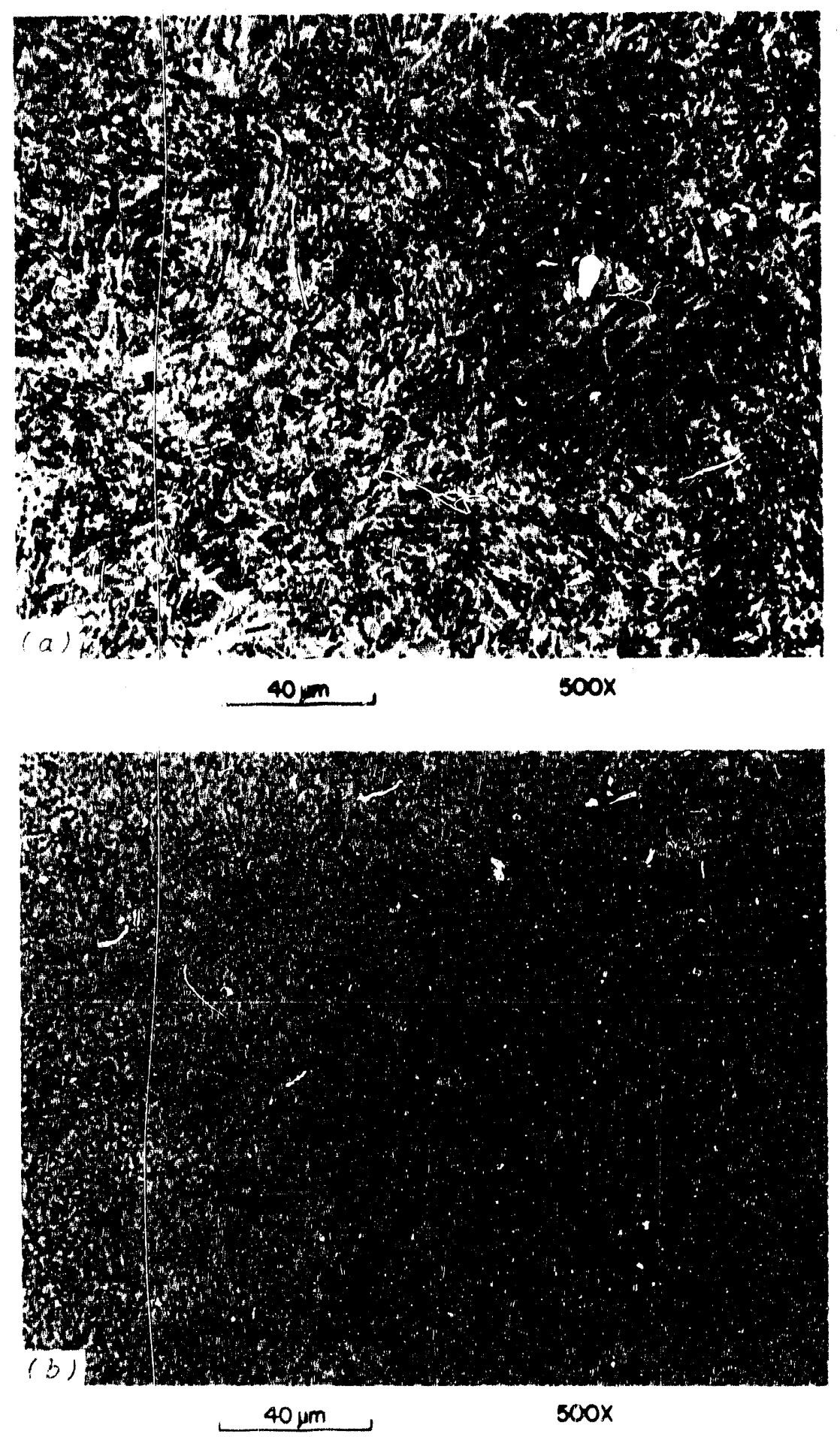

Fig. 83. Microstructural behavior in SA-533, grade $B$, class 1 , steel for multiple cycles: Cycle II with $24000^{\circ} \mathrm{F}$ peak temperature followed by Cycle II with $1650^{\circ} \mathrm{F}$ peak temperature. Super plcral etch. (a) Mixture of coarse and fine martensite, HRC 42 . (b) postweld heat treated, tempered martensite structure, HRC 3. Source: University of Tennessee. 

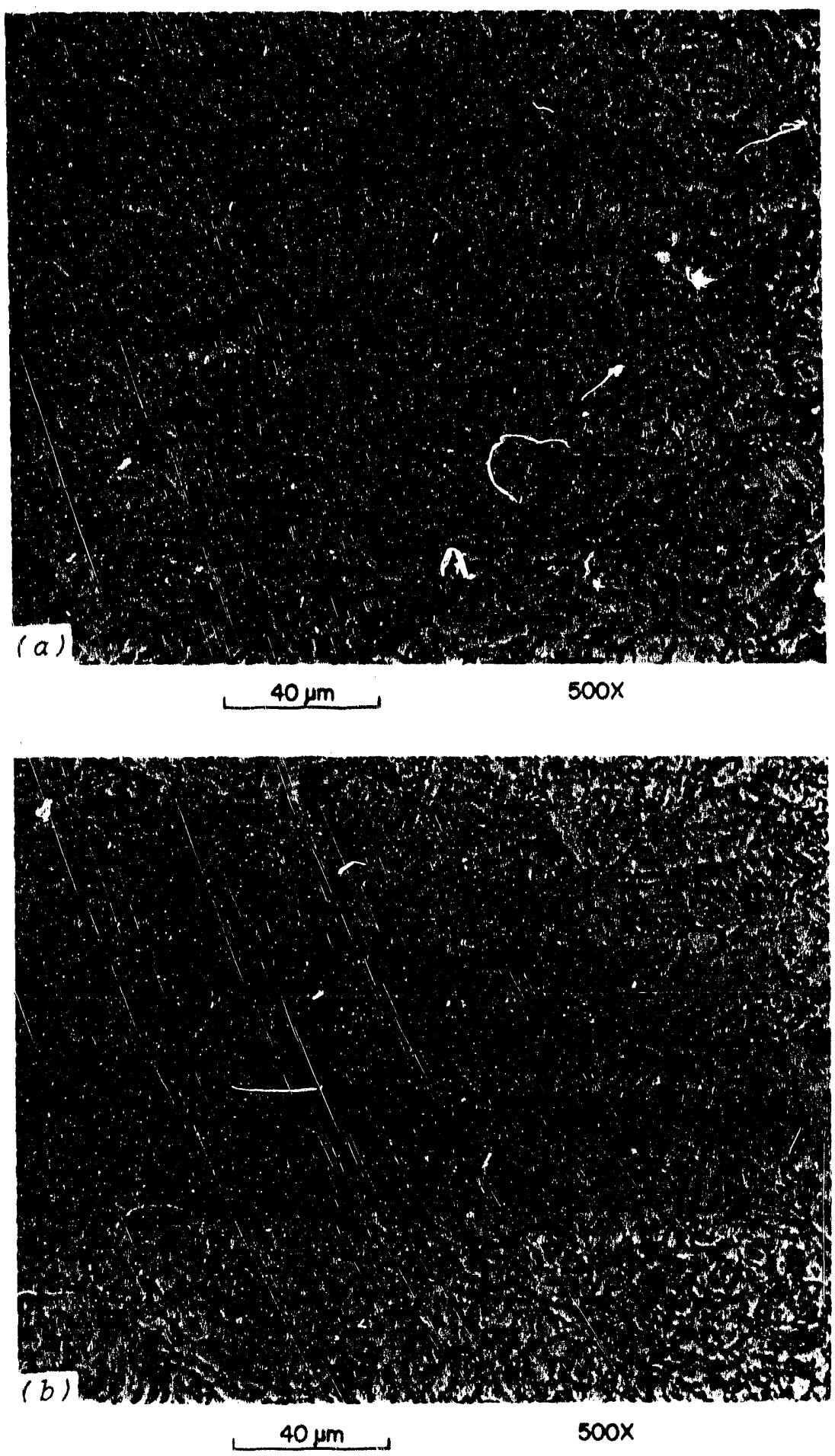

Fig. 84. Microstructural behavior in SA-533, grade $B$, class 1 , steel for multiple cycles: Cycle VI with $2400^{\circ} \mathrm{C}$ peak temperature followed by Cycle VI with $1650^{\circ} \mathrm{F}$ peak temperature. Super picral etch. (a) Fine bainitic structure, HRC 5. (b) Postweld heat treated, tempered bainitic structure, HRB 82. Scurce: University of Tennessee. 

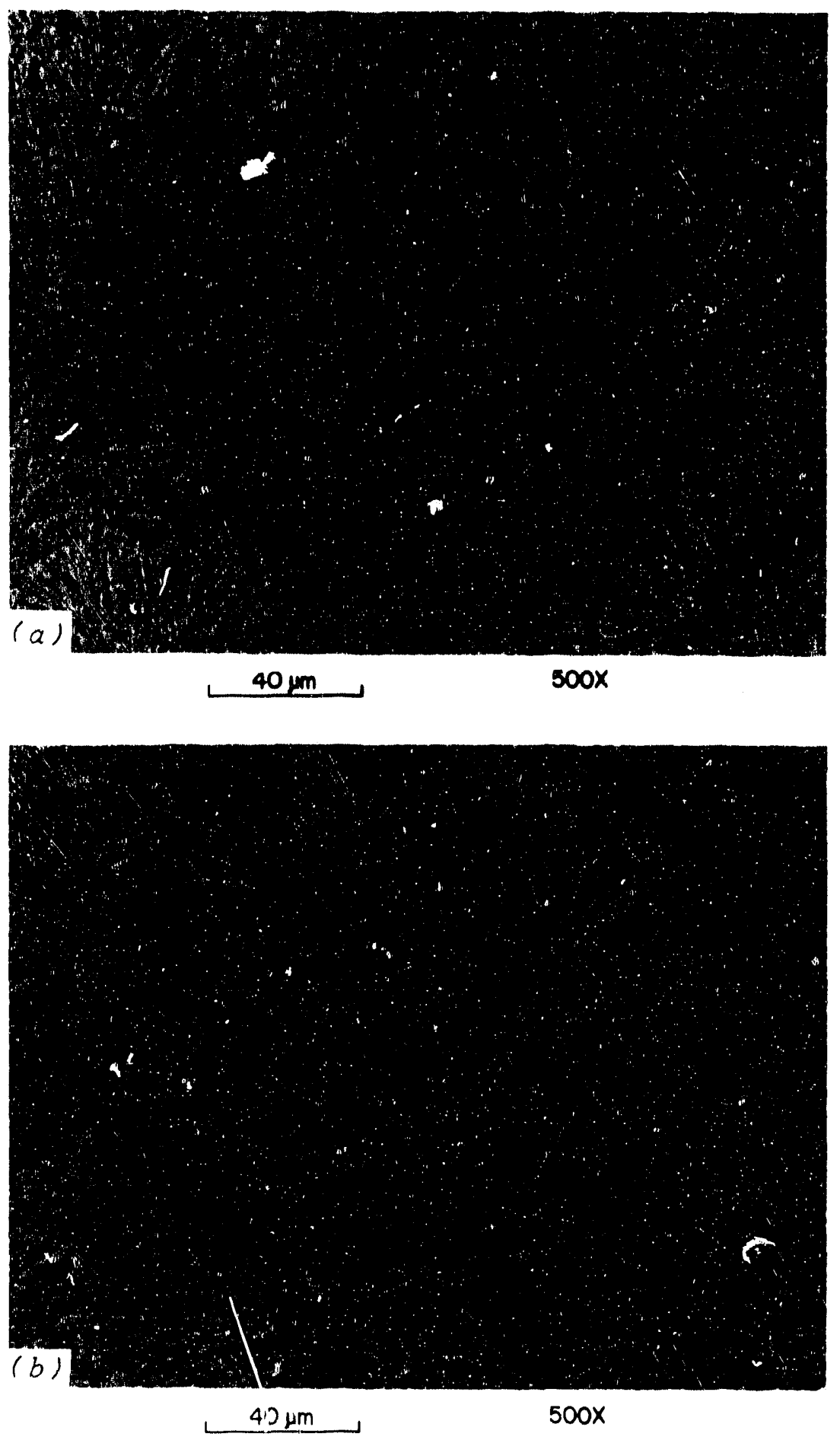

Fig. 85. Microstructural behavior in SA-533, grade $B$, class 1 , steel for Cycle II with $2400^{\circ} \mathrm{F}$ peak temperature and $2-\mathrm{h}$ hold at $600^{\circ} \mathrm{F}$. Super picral etch. (a) Martensitic structure, HRC 39. (b) Postweld heat treated, tempered martensitic structure, HRC 6. Source: Unfversity of Tennessee. 

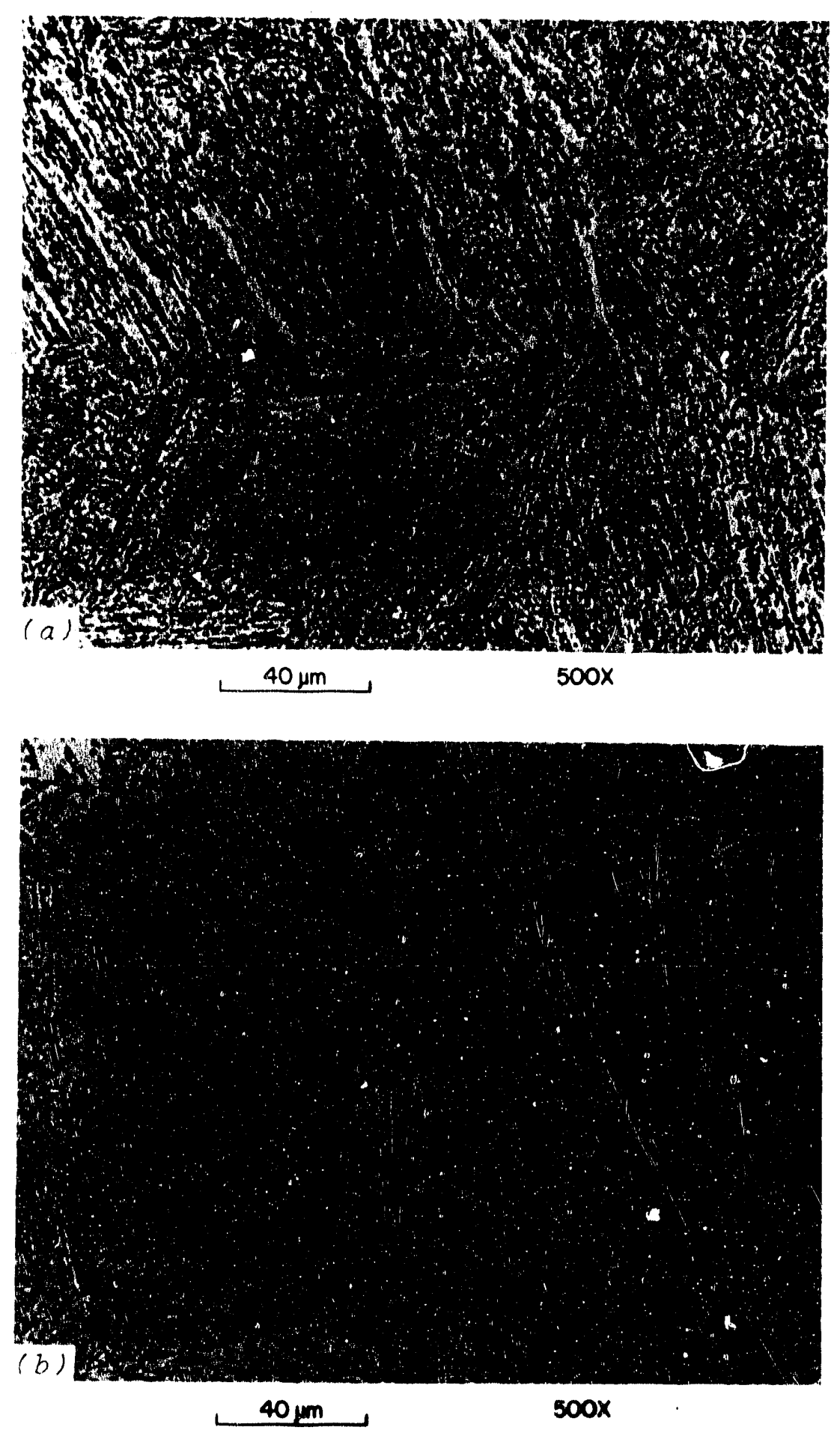

Fig. 86. Microstructural behavior in SA-533, grade B, class 1 , steel for Cycle VI with $2400^{\circ} \mathrm{F}$ peak temperature and $2-\mathrm{h}$ hold at $600^{\circ} \mathrm{F}$. Super picral etch. (a) Tempered bainitic structure, HRC 19. (b) Postweld heat treated, tempered bainitic structure, HRC 5. Source: University of Tennessee. 

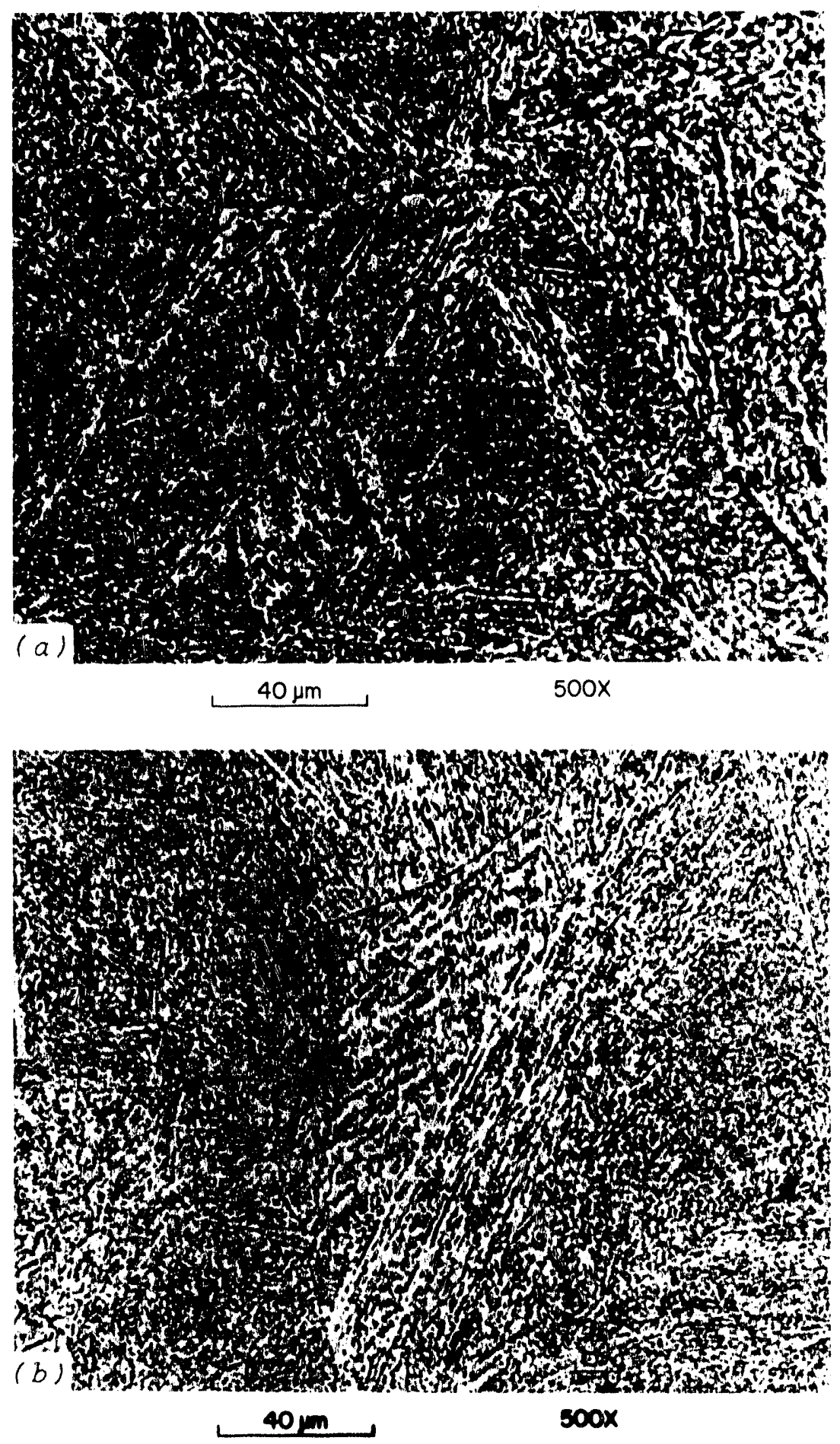

Fig. 87. Microstructural behavior in SA-533, grade $B$, class 1 , steel for Cycle VI with $2400^{\circ} \mathrm{F}$ peak temperature and $2-\mathrm{h}$ hold at $300^{\circ} \mathrm{F}$. Super picral etch. (a) Tempered bainitic structure, HRC 21. (b) Postweld heat treated, tempered bainitic structure, HRC 10. Source: University of Tennessee. 
observed in the HAZ of a welded ste $\$ 1$ will not be useful in judging the toughness of that region without prior knowledge of the response of the steel to cooling rate and resulting microstructure.

SA-308, Class 2

The SA-508, class 2, results are presented (Fig. 88) in a manner similar to those for SA-533, grade B, class 1 . The impact test temperature

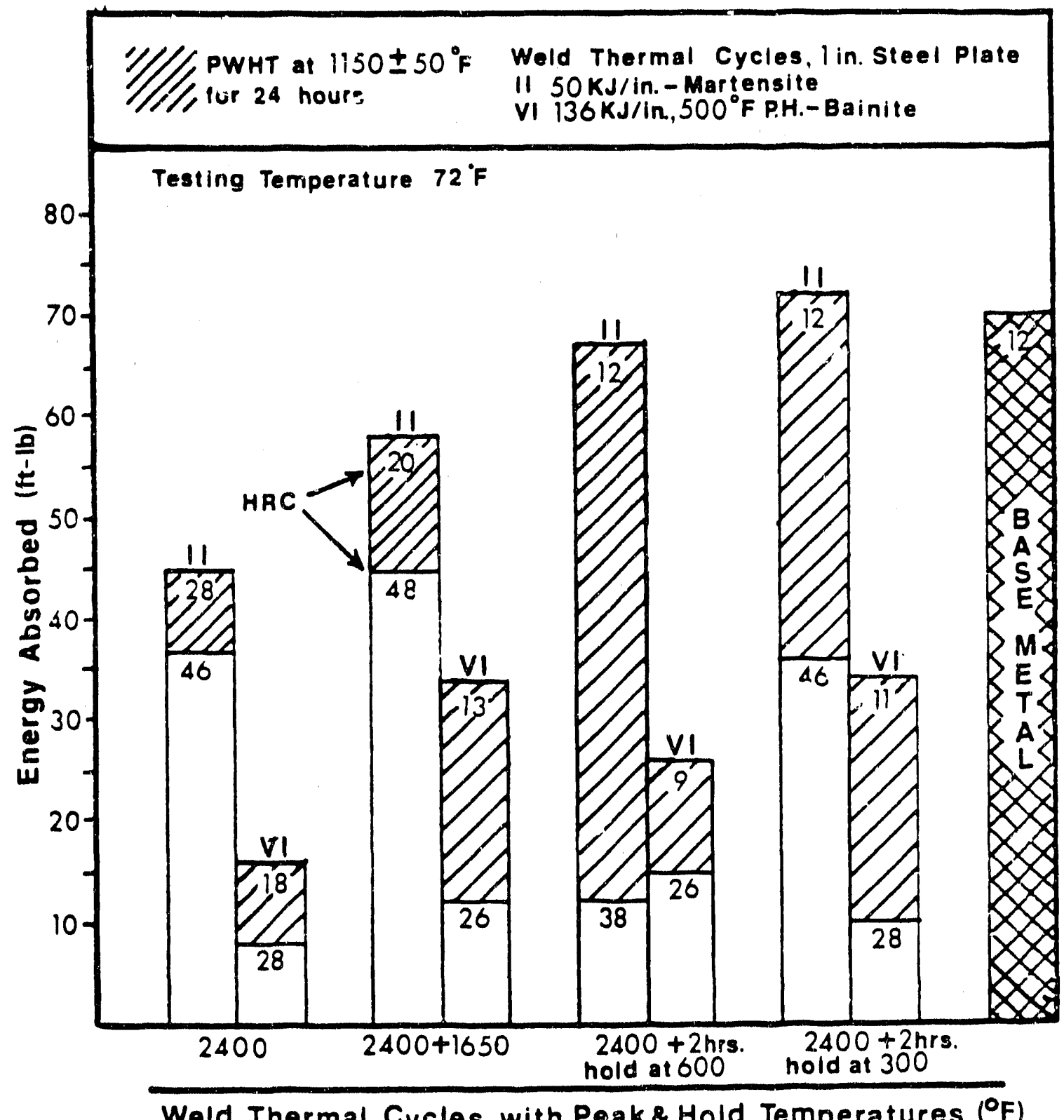

Fig. 88. Charpy V-notch toughness as related to different heataffected zone thermal cycles for SA-508, class 2, steel. Source: University of Tennessee. 
for this steel was selected to be room temperature $\left(72^{\circ} \mathrm{F}\right)$, which corresponds to the transition temperature region of the base metal. The base metal exhibited $70 \mathrm{ft}-1 \mathrm{~b}$ at $72^{\circ} \mathrm{F}$. The HAZ coarse-grained martensitic structure gave a toughness of $37 \mathrm{ft}-1 \mathrm{~b}$ ard, after PWHT, the toughness increased to $45 \mathrm{ft}-1 \mathrm{~b}$. The hardness decreased from HRC 46 to HRC 28 . For the HAZ coarse-grained bainitic structure, a toughness of $8 \mathrm{ft}-\mathrm{lb}$ was rec'srded, which, after PWHT, increased to $16 \mathrm{ft}-\mathrm{lb}$. The hardness dropped from HRC 28 to HRC 18. These results indicate that the toughness of the bainitic structures is lower than that of the martensitic structures. The microstructures are shown in Figs. 89 and 90 . The toughness of both microstructures was increased after multiple cycling with a grain-refining peak temperature cycle $\left(2400^{\circ} \mathrm{F}\right.$ followed by $1650^{\circ} \mathrm{F}$ peak), and, after PWHT, the toughness was further increased. The micrustructures are shown in Figs. 91 and 92. These microstructures are similar to those observed for SA-533, grade B, class 1, steel (Figs. 83 and 84 ).

The toughness of the untempered mirtensitic structure deteriorated when a postweld hold at $600^{\circ} \mathrm{F}$ was applied, but superior toughness was achieved by subsequent PWHT. This is in contrast to the results for the untempered bainitic structure, which showed the best toughness on postweld holding at $600^{\circ} \mathrm{F}$. These results are similar to the ones described for SA-533, grade B, class 1 . The respective microstructures are shown in Figs. 93 and 94 . The untempered ma:tensitic and bainitic structures with a postweld hold at $300^{\circ} \mathrm{F}$ showed todghness similar to that obtained without the postweld hold, but, after PWHT, both microstructures exhibited the best toughness of all thermal treatments (FIgs. 95 and 96).

The hardness results showed that martensitic structure had higher hardness than bainitic structure and that the toughness is not related to hardness per se. The drop in hardness from untempered to tempered structure is greater for SA-533, grade B, class 1, than for SA-508, class 2 . In general, the hardnesses obtained for SA-508, class 2, steel were higher than those for SA-533, grade B, class 1 .

The results of Charpy tests disagree totally with those of Klumpes. ${ }^{20}$ Klumpes mentioned that increasing the amount of martensite in the structure deteriorates the toughness, and PWHT of fully martensitic structure does not benefit the toughness. Our results show just the opposite in that the best toughness is achieved by the PWHT of a martensitic structure, which agrees with Canonico's ${ }^{1}$ statement that untempered martensite is poor in toughness whereas properly tempered martensite has superior properties.

The best toughness of the martensitic structu e is attained when multiple cycles are employed (high peak temperatures followed by a grainrefining cycle). This result agrees with Dolby, ${ }^{6}$ who mentioned that the multipass HAZs show higher toughness because of the increased proportion of grain-refined structure produced in the test specimen, whereas singlepass unreheated HAZ regions show lower toughness. Canonicol noted that HAZs of welds generally possess superior tensile and toughness properties compared with their chemically equivalent base metal. We found that the 

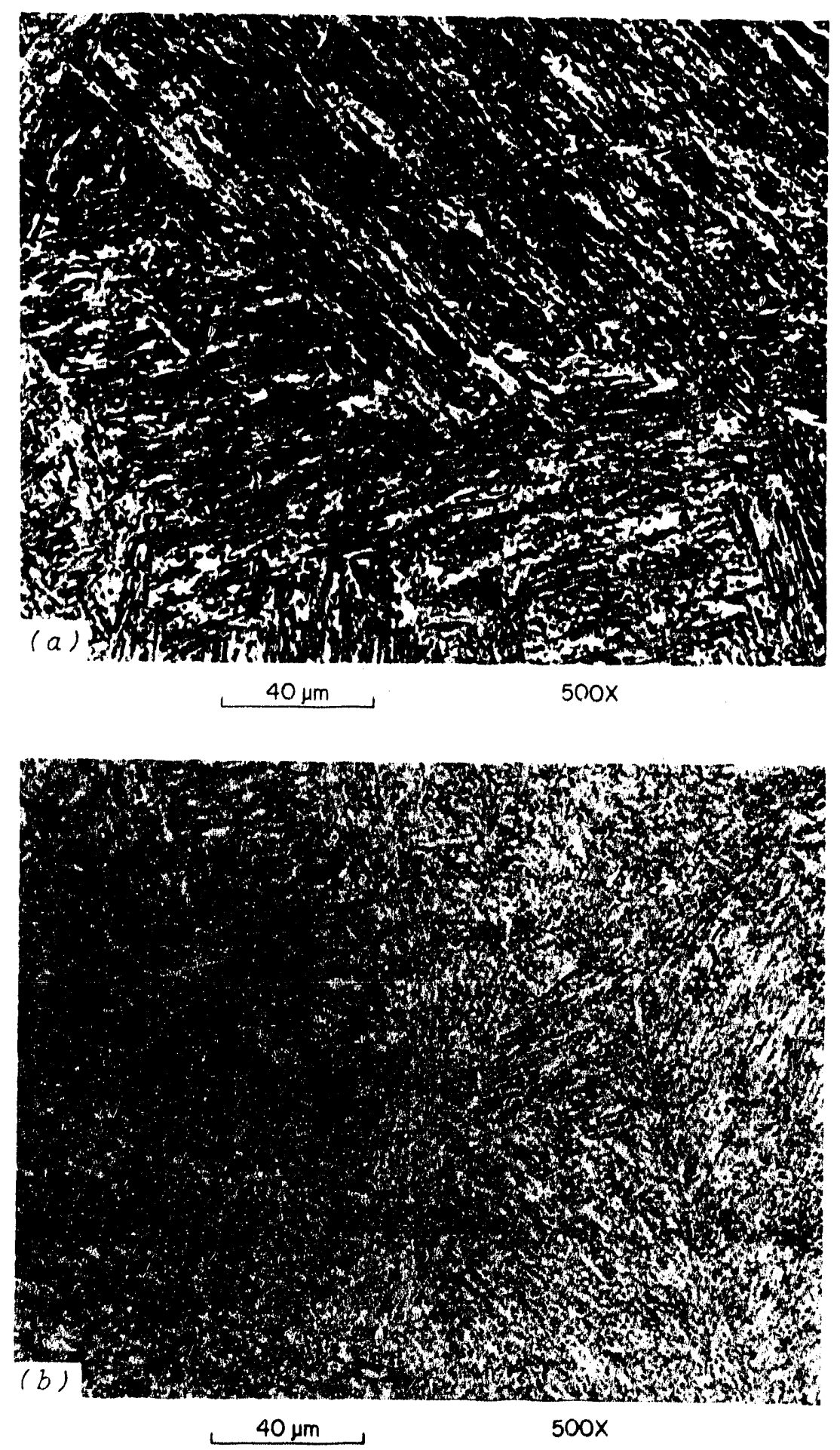

Fig. 89. Microstructural behavior in SA-508, class 2 , steel for Cycle II with $2400^{\circ} \mathrm{C}$ peak temperature. Super picral etch. (a) Martensitic structure, HRC 46. (b) Postweld heat treated, tempered martensitic structure, HRC 28. Source: University of Tennessee. 

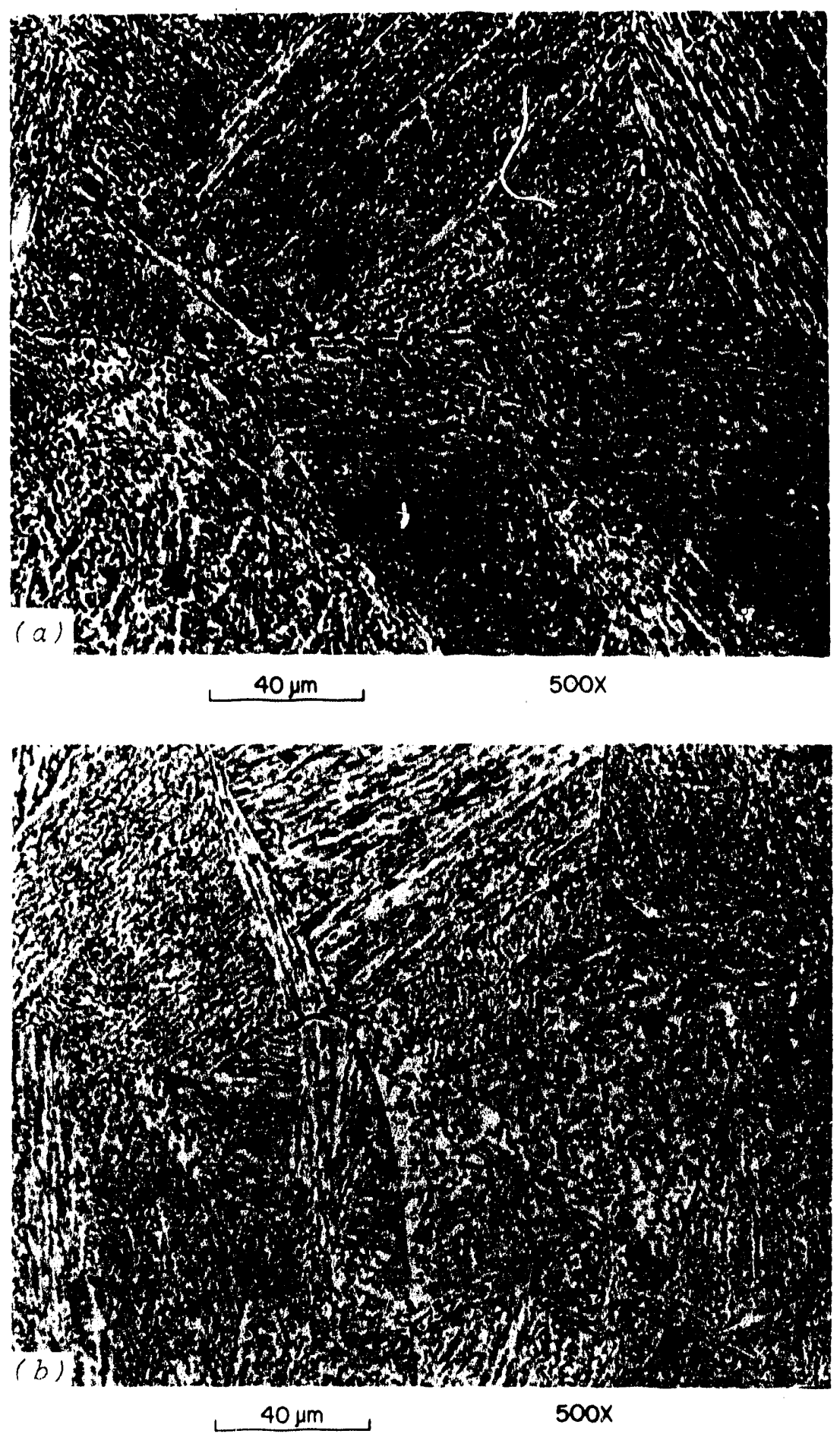

Fig. 90. Microstructural behavior in SA-508, class 2, steel for Cycle VI with $2400^{\circ} \mathrm{F}$ peak temperature. Super picral etch. (a) Bainitic structure, HRC 28. (b) Postweld heat treated, tempered bainitic structure, HRC 18. Source: University of Tennessee. 

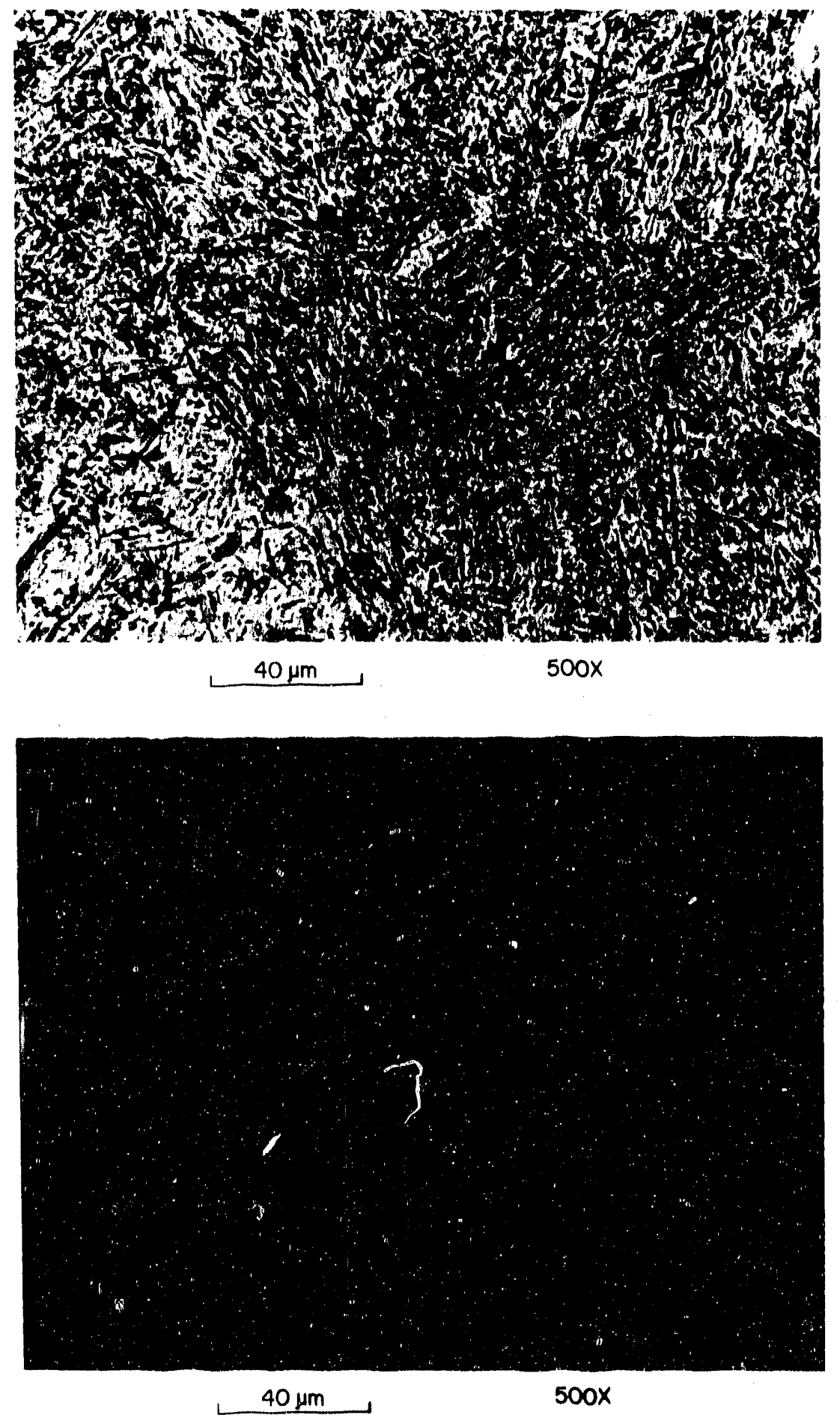

Fig. 91. Microstructure behavior in SA-508, class 2, steel for multiple cycles: Cycle II with $2400^{\circ} \mathrm{F}$ peak temperature and Cycle II with $1650^{\circ} \mathrm{F}$ peak temperature. Super picral etch. (a) Mixture of coarse and fine-grained martensite, HRC 48 .

(b) Postweld heat treated, tempered martensitic structure, HRC 20: Source: University of Tennessee. 

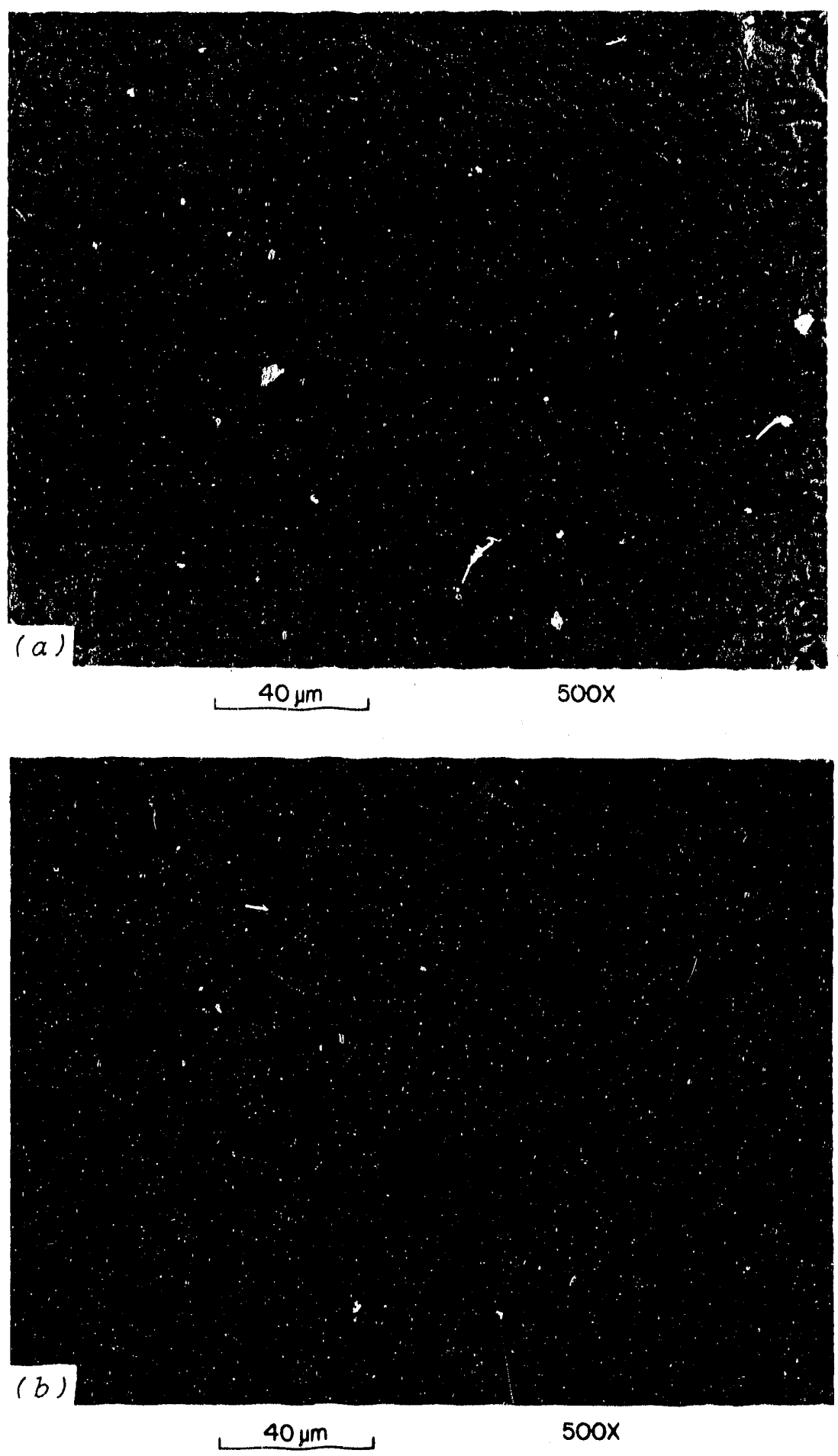

Fig. 92. Microstructural behavior in SA-508, class 2, steel for multiple cycles: Cycle VI with $2400^{\circ} \mathrm{F}$ peak temperature and Cycle VI with $1650^{\circ} \mathrm{F}$ peak tempurature. Super picral etch. (a) Fine bainitic structure, HRC 26. (b) Postweld heat treated, tempered bainitic structure, HRC 13. Source: University of Tennessee. 

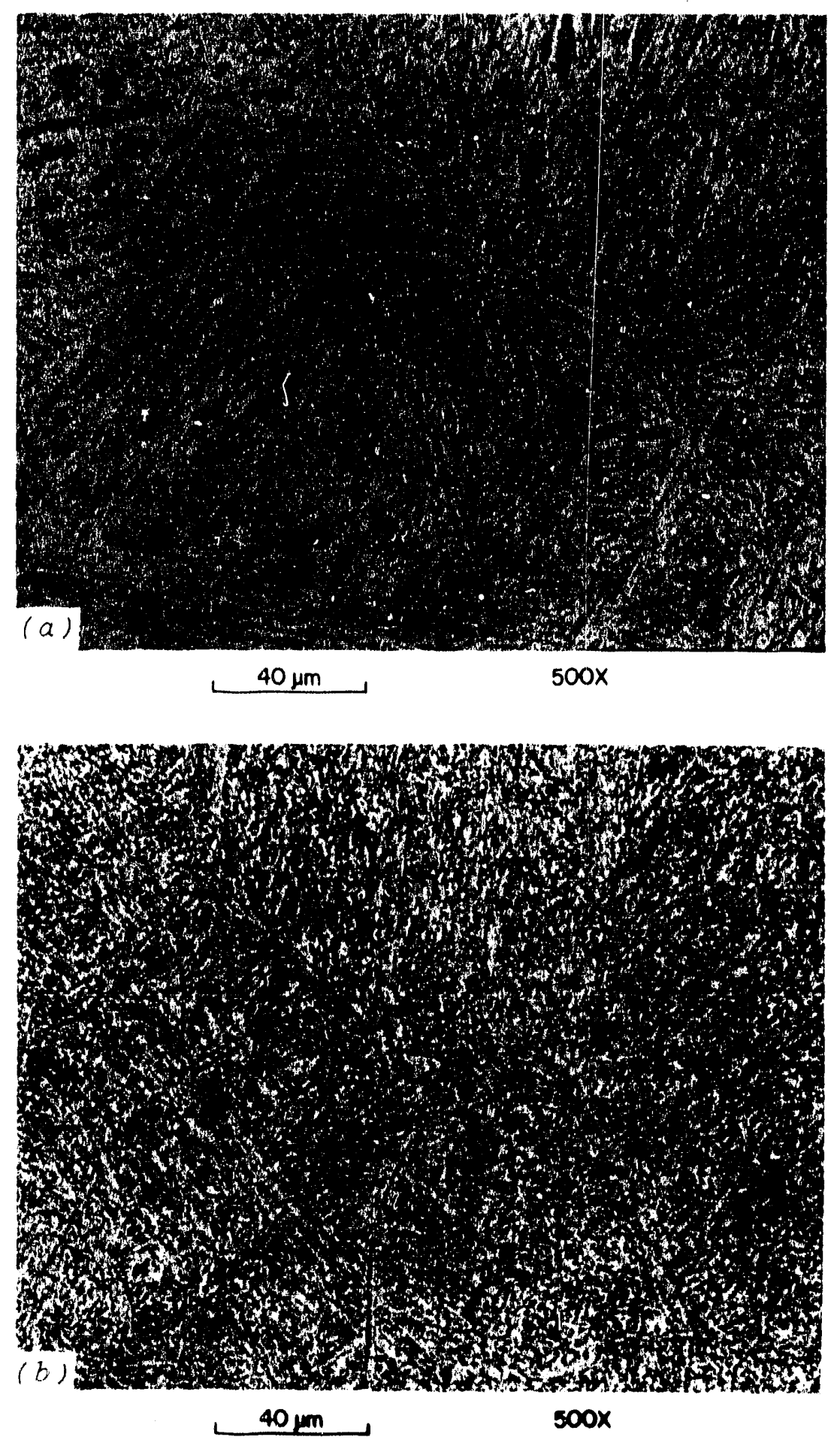

Fig. 93. Microstructural behavior in SA-508, class 2, steel for Cycle II with $2400^{\circ} \mathrm{F}$ peak temperature and 2 -h hold at $600^{\circ} \mathrm{F}$. Super picral etch. (a) Tempered martensitic structure, HRC 38. (b) Postweld heat treated, tempered martensitic structure, HRC 12. Source: University of Tennessee. 

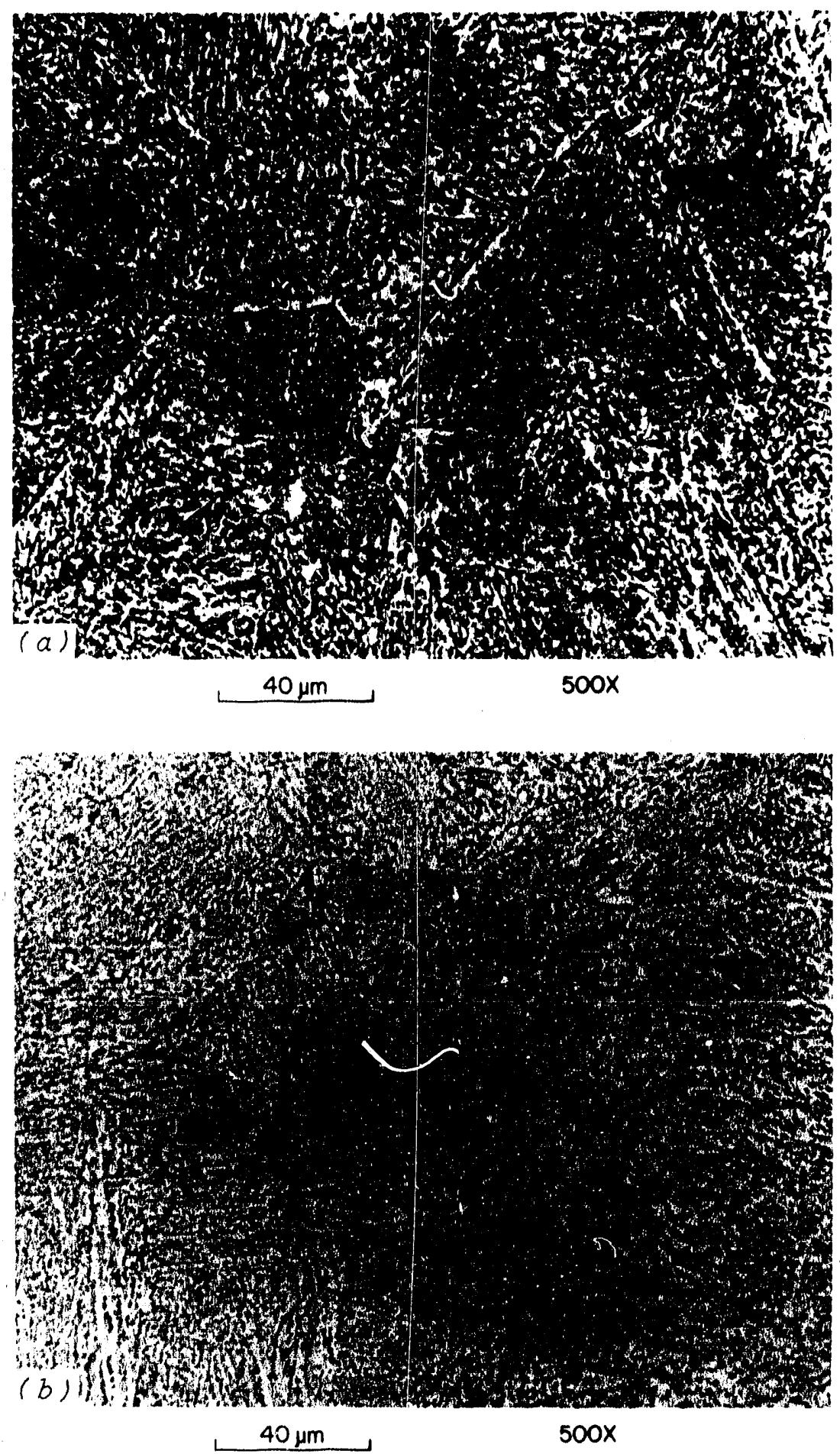

Fig. 94. Microstructural behavior in SA-508, class 2 , steel for Cycle VI with $2400^{\circ} \mathrm{F}$ peak temperature and $2-\mathrm{h}$ hold at $600^{\circ} \mathrm{F}$. Super picral etch. (a) Tempered bainitic structure, HRC 26. (b) Postweld heat treated, tempered bainitic structure, HRC 9. Source: University of Tennessee. 

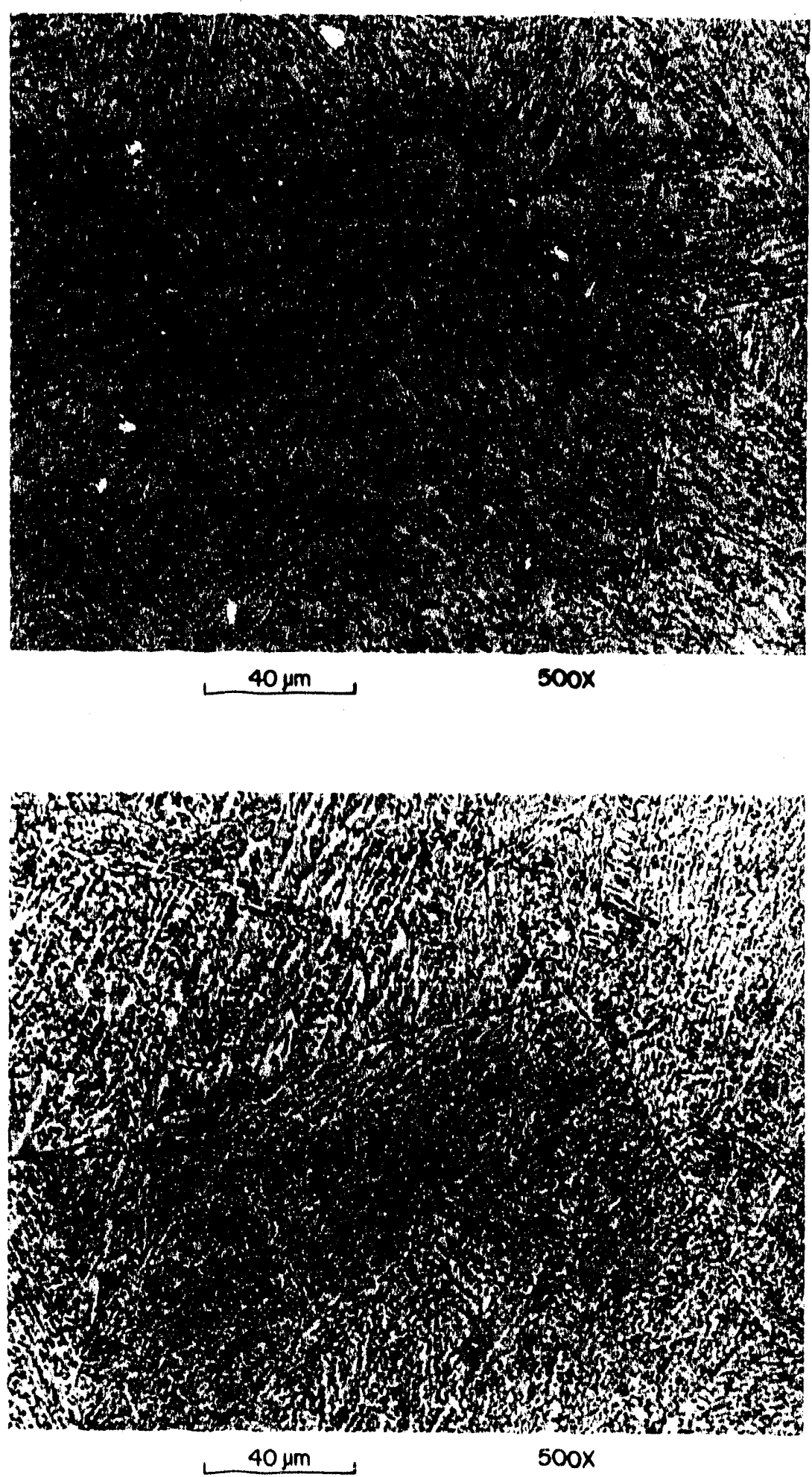

Fig. 95. Microstructural behavior in SA-508, class 2 , steel for Cycle II with $2400^{\circ} \mathrm{F}$ peak temperature and $2-h$ hold at $300^{\circ} \mathrm{F}$. Postweld heat treated. Super picral etch. Tempered martensitic structure, HRC 12. Source: Uni. versity of Tennessee.
Fig. 96. Microstructural behavior in SA-533, grade B, class 1 , steel for Cycle VI with $2400^{\circ} \mathrm{F}$ peak temperature and $2-\mathrm{h}$ hold at $300^{\circ} \mathrm{F}$. Postweld heat treated. Supex picral etch. Tempered bainitic structure, HRC 11. Source: University of Tennessee. 
HAZ of welds may or may not have a toughness superior to that of the base metal because the toughness depends on the transformation products obtained in the HAZ.

We conclude from these tests that SA-533, grade B, class 1 , and SA-508, class 2, behave similarly in the sense that both show a significant increase in toughness by tempering the martensitic structure. The tempered bainite structure showed poorer toughness than the martensitic structures. Therefore, we recommend that bainitic structures be avoided in the HAZ.

It would have been very beneficial to obtain an impact transition curve for each thermal cycle schedule, but the program scope did not allow it. We suggest it for future work.

\section{ENUMERATED RESULTS}

The results of the reported experiments for SA-533, grade B, class 1 , and SA-508, class 2. steels in this program can be enumerated as follows.

1. The isothermal transformation (IT) be avior for SA-533, grade $B$, class 1, and SA-508, class 2, has been documented.

a. The IT behivior shows that the bainite nose for SA-508, class 2, steel lies at longer times than the bainite nose for SA-533, grade B, class 1 , steel.

b. On holding isothermally at $1250^{\circ} \mathrm{F}$ for $10,000 \mathrm{~s}$ some pearlite is formed in SA-508, class 2, steel but not in SA-533, grade B, class 1 , steel.

c. The ferrite nose location in both steels is identical.

d. The bainite start temperature is lower for SA-508, class 2, steel than for $S A-533$, grade $B$, class 1 , steel.

e. The $M_{f}$ temperature for SA-533, grade B, class 1 , is higher than that for SA-508, clas. 2, steel.

2. The continuous-cooling transfi mation (CCT) behavior for SA-533, grade $B$, ciass 1 , and $S A-508$, class 2 , determined by resistivity measurement and dilatometric method, has been documented.

a. The CCT behavior for both steels obtained by resistivity measurements is idencical with the CCT behaviox obtained by the dilatometric method $w^{\prime}$ th a peak temperature of $1650^{\circ} \mathrm{F}$.

b. The CCT diagrams show that the critical cooling rate fo: SA-508, class 2, is less than the critical cooling rate for SA-533, grade $B$, class 1 .

c. In the welding situation the higher peak temperature of $2400^{\circ} \mathrm{F}$ causes grain growth and shifts the bainite nose to longer times for both steels.

d. For heat-affected zones the transformation behavior of both steels with peak temperatures of $2400^{\circ} \mathrm{F}$ is almost identical.

e. Thermal cycle with a hold of $20 \mathrm{~s}$ at $2400^{\circ} \mathrm{F}$ peak temperature does not change the tiansformation behavior of either steel. 
3. The CCTs occur at lower temperature and at longer times (below and to the right) as compared with the correspondirig IT behavior.

4. The CCT behavior of SA-533, grade B, class 1, steel obtained by Klumpes ${ }^{20}$ does not correlate with the $\mathrm{CCI}$ benavior obtained in this study, because the critical conling zate $\left(90^{\circ} \mathrm{F} / \mathrm{s}\right)$ obtained by Klumpes is nuch lower than the cricical cooling rate $\left(140^{\circ} \mathrm{F} / \mathrm{s}\right)$ obtalned in this study.

5. Hardenability results show that SA-508, class 2, has higher hardenability than SA-533, grade B, class 1.

6. In cold cracking tests, SA-508, class 2, was found to be more susceptible to hydrogen-induced cracking than SA-533, grade B, class 1.

7. Stress-relief cracking (SRC) for SA-533, grade B, class 1, and SA-508, class 2, steels has been observed experimentally and metallographically.

a. The cracking behavior in both steels was intergranular.

b. For all the thermal treatments, SA-533, grade B, class 1, showed higher ductility than did SA-508, class 2.

c. The stress-rupture parameter in SRC test was much lower for SA-508, class 2, than for SA-533, grade B, class 1, indicating that SA-508, class $\angle$, steel is more susceptible to reheat cracking than is SA-533, grade $B$, class 1 .

8. The Charpy impact toughness of SA-533, grade $B$, class 1 , and SA-508, class 2, for bainitic and martensitic structures, exposed to different thermal heat treatments, has been documented.

a. Tempered martensite (in the coarse-grained region of the HAZ) shows greater toughness than does tempered bainite.

b. An uritempered, as-welded, coarse-grained, martensitic structure subjected to a postweld hold at $600^{\circ} \mathrm{F}$ provides poor $\mathrm{HAZ}$ toughness.

c. Multiple thermal cycles $\left(2400^{\circ} \mathrm{F}\right.$ peak, followed by $1650^{\circ} \mathrm{F}$ peak temperature) are beneficial to the toughness of the martensitic structures of both stcels.

d. PWHT gives higher toughness of the weld HAZ of SA-533, grade B, class 1 , than that of SA-508, slass 2 .

e. The hardnesses observed for all identical thermal treatments were higher for SA-508, class 2, than for SA-533, grade B, class 1, steel.

f. The hardness drop from an untempered structure to tempered structure was greater for SA-533, grade B, class 1, than for SA-508, class 2 .

9. Postweld heat treatment has a significant effect on HAZ toughness. 10. Hardness cannot be used as a reliable indicator of notch toughness.

\section{CONCLUSIONS}

The cransformation behavior for both SA-508 and SA-533 low-alloy steels has been determined under conditions representing standard heat 
treatment austenitizing $\left(1650^{\circ} \mathrm{F}\right)$ and under the high-temperature austenitizing conditions characteristic of the coarse-grained region of the HAZ $\left(2400^{\circ} \mathrm{F}\right)$. Although the position of the bainite nose was displaced further in time for SA-508 than for SA-533 under $1650^{\circ} \mathrm{F}$ austenitization, the bainitic transformation behavior was virtually identical for the coarsegrained $\mathrm{HAZ}\left(2400^{\circ} \mathrm{F}\right)$. This is due to the strong effect of grain size in swamping the compositional differences between the two materials. These conclusions were confirmed by the Jominy hardenability tests and by microstructural examination.

Under welding conditions (approximately $130 \mathrm{~kJ} / \mathrm{in}$. ) in 2 -in. plate with a room-temperature preheat, the only microconstituent formed in the coarse-grained region of the HAZ is martensite. Slower cooling conditions rep:esented by higher energy inputs and higher preheats produce a mixed martensitic-bainitic structure in the coarse-grained HAZ. (The equivalency of plate thickness preheat and energy input is illustrated in the test.) The CCT diagrams developed by two independent means are the first known reporting of such information for the SA-508 and SA-533 materials.

The SA-508 material was found to be slightly more sensitive to HAZ than SA-533 in the University of Tennessee hydrogen sensitivity tests. A preheat of approximately 400 to $500^{\circ} \mathrm{F}$ would most likely be sufficient for both materials under high-restraint welding conditions. Postweld holds at the preheat temperature could permit the application of lower preheats for both materials.

The stress-rupture cracking potential for SA-508 was greater than that for SA-533. This indicates a need for chemistry control (e.g., use of $\mathrm{SA}_{\mathrm{A}}$-508-C) or control of stresses in complex weldments. The SRC cracking method employed shows great promise for evaluation of other steels.

With limited data available on the toughness of the coarse-grained $\mathrm{HAZ}$, the following conclusions must be considered tentative. However, the trends noted do suggest the need for further studies on the SA.508 and SA-533 materials and on similar steels. These additional studits will permit more definitive choices of welding conditions for optimizing toughness.

The tempered martensite produced in the coarse-grained region of the $\mathrm{HAZ}$ by the welding conditions with more rapid cooling rate was of poor toughness in the as-welded (single-pass) condition. This microstructure responded in an extremely positive manner to PWHT with toughnesses at a nigher level than those of the base material. The bainitic microstructures produced by heat input that causes the cooling curves to pass through the bainite nose also cause poor as-welded toughness. Unfortunately, the data available indicate that the bainitic microstructures respond poorly to PHWT and the toughriess falls short of that of the as-received base metal. A grain-refining $\left(1650^{\circ} \mathrm{F}\right.$, peak cycle subsequent to the grain coarsening did not significantly improve the toughness for the bainitic structure. This tends to indicate that the inicrostructural constituents rather than grain size per se control toughness in these materials. The data further suggest 
that the maximum energy input should be selected on the basis of the CCT diagram and, when possible, welding condjtions resulting in martensite should be used (which, fortunately, is the general case).

\section{ACKNOWLEDGMENTS}

Ttis research was sponsored by the Office of Nuclear Regulatory Research, U.S. Nuclear Regulatory Commission, under Interagency Agreement DOE 1886-8010-3B with the U.S. Department of Energy under contract DE-AC05-840R21400 with Martin Marietta Energy Systems, Inc. The technical guidance and assistance provided by D. A. Canonico and R. K. Nanstad is gratefully acknowledged.

\section{REFERENCES}

1. D. A. Canonico, Significance of Reheat Cracks to the Integrity of Pressure Vesse1s for Light-Water Reactors, ORNL/NUREG-15, July 1977.

2. R. D. Stout and W. D. Doty, "Appendix," Weldability of Steels, $2 \mathrm{~d}$ ed., ed. Samue1 Epstein and R. E. Somers, Welding Research Council, New York, 1971.

3. M. W. F. Cane and R. E. Dolby, "Metallurgical Factors Controlling the HAZ Toughness of Submerged Arc Welded C-Mn Steels," Welding Research Institute, 1.974.

4. R. E. Dolby, "The Effect of $\mathrm{Nb}$ on the HAZ Toughness of High Heat Input Welds in C-Mn Steels," Proceedings of Conference on Welding of HSLA (Microalloyed) Structural Steels, Rome, November 1976, American Society for Metals.

5. N. E. Hannerz, "Effect of Stress Relieving Heat Treatment on the Toughness Properties of Simulated HAZ's in V-Alloyed Steels," Schweissen Schneiden (1976).

6. R. E. Dolby, "HAZ Toughness of Structural and Pressure Vessel Steels Improvement and Prediction," Weld. J. (Miami) 55, 225-38s (August 1979).

7. T. U. Marston and W. Server, "Assessment of Weld Heat Affected Zones in a Reactor Vessel Materials," J. Eng. Mater. Technol. 100(3), 267-71 (July 1978).

8. H. S. Chung, T. Takahashi, and M. Suzuki, "Microstructural Gradient in HAZ and its Influence Upon The HAZ Fracture Toughness," Weld. World 16(11/12), 248-61, 1978.

9. C. E. Childress, Fabrication Procedures and Acceptance Data for ASTM A 533 Welds and a 10-inch Thick ASTM A 543 Plate of the HSST Program, ORNL-4313-3, January 1971.

10. R. D. Stout and W. D. Doty, "The Properties of Steel Related to Weldability," Weldavility of Steels, $2 \mathrm{~d}$ ed., ed. Samuel Epstein and R. E. Somers, Welding Research Council, New York, 1971. 
11. D. A. Canonico, "Heavy Section Steel Technology Program (HSST)," Met. Prog. 116(2), 32-40 (j:11y 1979).

12. D. A. Canonico, "Microstructure Studies of HSST Plate 01," pp. 20, 32 in HSST Program Semiannual Prog. Rep. for Period Ending. August 31, 1968, ORNL-4377, April 1969.

13. J. R. Hester, "Correlation of Microstructure with Mechanical Properties for HSST Program Plate 01," M.S. Thesis, The University of Tennessee, Knoxville, 1970.

14. G. E. Grotke et al, Reheat Cracking and Heat Affected Zone Toughness in SA 508 Class 2 Steel Weldments, Report 76-ID4-Reheat-R1, Westinghouse Research Laboratory, Pittsburgh, Penn., Feb. 20, 1976.

15. A. G. Glover et a1., "The Influence of Cooling Rate and Composition on Weld Metal Microstructures in a C/Mn and a HSLA Steel," Weld. J. (Miami) 56, 267-74-s (September 1977).

16. E. S. Davenport, "Isothermal Transformation in Steels," Trans. Am. Soc. Met. 27, 837 (December 1939).

17. R. A. Grange and J. M. Keifer, "Transformation of Austenite on Continuous Cooling and Its Relation to Transform at Constant Temperature," Transactions, March 1941.

18. K. E. Dorschu, "Control of Cooling Rates in Steel Weld Metal," Supplement to the Weld. J. (Miami) 47, 49-62-s (February 1968).

19. H. Fuji Maki et al., "Development and Manufacturing of Steel Forgings of ASTM-A508 Class 2 for Nuclear-Reactor Pressure Vessels," pp. 21-35 in Nippon Steel Technical Report 7, Nippon, Japan, November 1975.

20. H. Klunpes, "Peak Temperature Cooling Time Diagram of Pressure Vessel Steels ASME SA $508 \mathrm{Cl} 2$ and SA 533 Gr B C1 1," pp. 23-24 in tidVS Berichte No. 32, Proceedings, 2nd International Colloquium on Welding in Nuclear Engineering, Dusseldorf, October 1974.

21. J. D. Murray, "Stress-Relief Cracking in Carbon and Low Alloy Steels," Br. Weld. J. 14(8), 447-56 (1967).

22. C. F. Meitzner and A. W. Pense, "Stress-Relief Cracking in Low Alloy Steel Weldments," Weld. J. (Miami) 48(10), 432-40-s (October 1969).

23. A. W. Pense, E. J. Galda, and G. T. Powell, "Stress-Relief Cracking in Pressure Vessel Steels," Weld. J. (Miami) 50(8), 374-78-s (August 1971).

24. R. W. Nichols, "Reheat Cracking in Welded Structures," Welding Research Abroad, pp. 36-44, March 1970.

25. K. Detert, W. Bertram, and R. Banga, "Stress Relief Cracking in Strip-Weld Cladded Steel Plates," pp. 1269-76 in Federation of Materials Societies, Metals Park, Ohio, 1976.

26. M. Lorenz and P. Lugibuhl, "Stress Relief Cracking in OverlayWelded Components for Nuclear Reactor Pressure Vessels of a Heat-Resistant Structural Steel," Sulzer Tech. Rev. 56, 51-60 (1974).

27. C. J. McMahon, R. J. Dobbs, and D. H. Gentner, "Stress Relief Cracking in Mn, Mo, Ni and Mn, Mo, Ni, Cr Pressure Vessel Steels, "Mater. Sci. Eng. 37, 179-86 (1979).

28. J. M. Brear and B. L. King, "Stress Relief Embrittlement in MnMo-Ni Pressure Vessel Steels (ASME SA 533 B/SA 508)," Grain Boundaries, presented at Institution of Metallurgists conference, 1.976.

29. L. G. Liljestrand et al., Formation of Microcracks during Stress Relief Annealing of a Weldment in Pressure Vessel Steel of Type A 508 C1 2, IX-996-76, Aktiebolaget Atomenargi, Studsvik, Sweden. 
30. S. Yukawa, Evaluation of Periodic Proof Testing and Warm Prestressing Procedures for Nuclear Reactor Vessels, HSSTP-TR-1, General Electric Co., Schenectady, N.Y., July 1, 1969.

31. C. D. Beachem, "A New Model for Hydrogen-Assisted Cracking (Hydrogen 'Embrittlement')," Metal. Trans. 3(2), 437-51 (1972).

32. F. R. Coe, Welding Steels Without Cracking, The Welding Institute, Cambridge, England, 1973.

33. H. E. McGannon, The Making, Shaping, and Treating of Steel, 9th ed., 592, United States Steel Corp., Pittsburgh, Pa., 1971.

34. J. F. Lancaster, Metallurgy of Welding, Chap. 7, Allen and Unwin, London, 1980.

35. I. M. Bernstein, "The Role of Hydrogen in the Embrittlement of Iron and Stee1," Mater. Sci. Eng. 6, 1-19 (1970).

36. C. Zapffe and C. Sims, "Hydrogen Embrittlement, Internal Stress and Defects in Steel," Trans. Am. Inst. Mining Met. Eng. 145, 225-47 (1941).

37. N. O. Petch and P. Staples, "Delayed Fracture of Metals Under Static Load," Nature 169, 842-43 (1952).

38. G. E. Linnert, Welding Metallurgy 2(13), American Welding Society, New York, 1967.

37. A. R. Troiano, "The Role of Hydrogen and Other Interstitials in the Mechanical Behavior of Metals," Trans. Am. Soc. Met. 52, 54-80 (1960).

40. F. R. Coe, The Avoidance of Hydrogen Cracking in Welding, The Welding Institute, Cambridge, England, 1973.

41. W. R. Apblett, R. P. Dumphy, and W. S. Pellini, "Transformation of Cr-Mo Steels During Welding," Weld. J. (N.Y.) 33(1), 57-64-s (1954).

42. C. E. Childress, Fabrication and Mechanical Test Data for Acceptance of the First Six 6-inch Thick Intermediate Test Vessels of the HSST Program, ORNL/TM-4351, October 1973.

43. Tien Shou Lei, "The Effect of 0-8 Wto Iron on Transformations of Alpha Phase Ni-Mo-Fe Alloys with Ni:Mo Ratio," Ph.D. dissertation, The University of Tennessee, August 1979.

44. R. D. Stout and W. D. Doty, Weldability of Steels, Welding Research Counci1, New York, 1978, pp. 252-54.

45. E. G. Signes, "A Simplified Method for Calculating Cooling Rates in Mild and Low Alloy Steel. Weld Metals," Weld. J. (Miami) 51, 473-84-s (Octcher 1972).

46. Pravin Jhaveri, W. G. Moffatt, and C. M. Adams, Jr., "The Effect of Plate Thickness and Radiation on Heat Flow in Welding and Cutting," Weld. J. (Miami) 41, 12-16-s (January 1962).

47. W. F. Savage, E. F. Nippes, and E. S. Szekeres, "Hydrogen Induced Cold Cracking in a Low Alloy Steel," Weld. J. (Miami) 57(9), 276-83-s (1976).

48. I. G. Hanilton, "Ferritic Steel Plates for Pressure Vessels," pp. 1-33 in Developments in Pressure Vessel Technology-3, ed.

R. W. Nichols, Applied Science, London, 1980.

49. H. Nakamura et al., "Fracture in The Process of Stress-Relaxation Under Constant Strain," pp. 863-78 in Proceedings of First International Conference on Fracture, Sendai, Japan, September 1965, Japan Welding Society, 1965. 


\section{SELECTED BIBLIOGRAPHY}

1. K. P. Bentley, "Precipitation During Stress Relief of Welds in Cr-Mo-V Steels," Br. Weld. J., 507-..5 (October 1964).

2. N. C. Binkley and R. W. Herrmann, "An Inservice Reactor Repair Simulation," pp. 289-98 in DVS Berichte 32, Proceedings, 2d International Colloquium, Welding in Nuclear Engineerine, Dusseldorf, October 1974.

3. J. S. Caplan and E. Landerman, Preventing Hydrogen-Induced Cracking After Welding of Pressure Vessel Steels by Use of Low Temperature Postweld Heat Treatments, WRC Bulletin 216, Welding Research Council, New York, June 1976.

4. W. Debray, "Reheat Cracking in Low Alloy Steels," Met. Constr. 8, 74-77 (February 1976).

5. A. Dhooge et a1., "A Review of Work Related to Reheat Cracking in Nuclear Reaccor Pressure Vessel Steels," Int. J. Pressure Vessels Piping 6, 329-409 (1978).

6. D. V. Doane and J. S. Kirkaldy, "Hardenability Concepts with Applications to Steel," Symposium, AIME, Oct. 26, 1977.

7. R. E. Dolby and G, G. Saunders, A Review on the Problem of Reheat Cracking in Nuclear Vessels Steels, Report for the Nuclear Installation Inspectorate, Dept. of Energy, April 1975.

8. R. E. Dolby and G. G. Saunders, "Underclad Cracking in Nuclear Vessel Steels, Part I," Met. Constr. 9, 562-66 (December 1977).

9. R. E. Dolby and G. G. Saunders, "Underclad Cracking in Nuclear Vessel Steels, Part II," Met. Constr. 10, 20-24 (January 1978).

10. W. D. Doty, "Welding of Quenched and Tempered Alloy Stee1s," Met. Eng. Q., ASM, February 1969, pp. 66-78.

11. G. E. Grotke, "Varestraint Weldability Testing of SA 508 Class 2 arid SA 533 Grade B Class 1 Pressure Vessels Steels," 73-1D4-WELST-R1, Westinghouse Research Laboratory, February 1973.

12. J. M. Hodge, Properties of Heavy Section Nuclear Reactor Steels, WRC Bulletin 217, Welding Research Council, New York, pp. 14-22.

13. W. K. C. Jones, "Reheat Cracking Susceptibility of Some 2Cr-Mo Submerged Arc Weld Metals," Weld. J. (Miami) 55, 42-46-s (February 1976).

14. J. Kameda, H. Takahashi, and M. Suzuki, "Residual Stress Relief and Local Embrittlement in a SA 533 B Reactor Pressure Vessel Weldment," Int. J. Pressure Vessels Piping 6, 245-74 (1978).

15. E. H. Kottcamp, D. A. Canonico, and R. D. Stout, "Prediction of the Properties of Heavy Section Pressure Vessel Steels from End-Quench Tests," Weld. J. (N.Y.) 41, 350-54-s (August 1962).

16. J. C. Lochead and A. Speirs, "The Effect of Heat Treatment on Pressure Vessel Steels," Journal of the West of Scotland Iron and Steel Institute 80, paper 623 (1972-73).

17. C. D. Lundin, W. F. Savage, and J. L. Ledman, "Study of the Transformational Characteristics and the Weldability of HY-80 Steel," $R P I$, January 1963.

18. C. F. Meitzner and R. D. Stout, "Microcracking and Delayed Cracking in Welded Quenched and Tempered Steels, "Weld. J. (N.Y.) 45, 393-400 (September 1966).

19. A. A. M Jler, D. G. Howden, and F. B. Simmons, "HAZ Thermocycle and Structure Sirulation," Weld. J. (Miami) 62, 411-16-s (September 1973). 
20. E. F. Nippes, "The Weld Heat-Affected Zone," Weld. J. (N.Y.) 38, 1-18-s (January 1959).

21. E. F. Nippes, W. F. Savage, and J. M. Paez, "Transformational Behavior of Mn-Mo Armor Steels," Weld. J. (N.Y.) 38, 475-81-s (December 1959).

22. E. F. Nippes and E. C. Nelson, "Prediction of Weld HAZ Microstructures from Continuous Cooling Transformation Data, "Weld. J. (N.Y.) 37, 289-94-s (June 1958).

23. E. F. Nippes, W. F. Savage, and R. J. Allio, "Studies of the Weld Heat-Affected Zone of T-1 Steel, "Weld. J. (N.Y.) 36, 531-40-s (December 1957).

24. J. H. Rogerson, "Welding Defects and Their Elimination," pp. 327-55 in Development in Pressure Vessel Technology-3, ed.

R. W. Nichols, Applied Science, London, 1980.

25. W. F. Savage, E. F. Nippes, and E. S. Szekeres, "Hydrogen Induced Cold Cracking in a Low Alloy Steel," Weld. J. (Miami) 55, 276-83-s (September 1976).

26. W. F. Savage, E. F. Nippes, and H. Homma, "Hydrogen Induced Cracking in HY-80 Steel Weldments," Weld. J. (Miami) 55, 368-76-s (November 1976).

27. R. D. Stout, Hardness as an Index of the Weldability and Service Performance of Steel Weldments, WRC Bulletin 189, Welding Research Council, New York, November 1973.

28. M. Suzuki, H. Takahashi, and M. Saito, Assessment of Allowable Maximum Crack Size in Toe HAZ of Welded Low Alloy Steel Components, IIW X-903-78, Tohoku University, Senda1, Japan.

29. J. E. Vanden Boom and J. P. F. Mulder, "Mechanicirl Properties of Strip Clad Weld Heat Affected Zones Determined for Steels ASTM SA 508 Class 2, SA 533 Grade B Class 1, A 302, Grade B and A 387 Grade D, in View of Susceptibility to Stress Relief Cracking," Weld. Res. Int. 2(2), 20-36 (1972).

30. A. Vinckier and A. Dhooge, "Reheat Cracking in Welding Structures During Stress Relief Heat Treatments," J. Heat Treat. 1(1), 72-80 (June 1979).

31. A. G. Vinckier and A. W. Pense, A Review of Underclad Cracking in Pressure Vessel Components, WRC Bulletin 197, Welding Research Council, New York, August 1974. 
Appendix A

HEAT TREATMENT SCHEDULES, CHARPY TOUGHNESS

DATA AND REHEAT CRACKING DATA 
Table A.1. Schedule of salt bath heat treatment of SA-533 (3T) and SA-508 (8M) specimens

\begin{tabular}{|c|c|c|c|c|c|}
\hline \multirow{2}{*}{$\begin{array}{l}\text { Time } \\
\text { (s) }\end{array}$} & \multicolumn{5}{|c|}{ Specimens treated at each temperaturea } \\
\hline & $550^{\circ} \mathrm{F}$ & $800^{\circ} \mathrm{F}$ & $950^{\circ} \mathrm{F}$ & $1150^{\circ} \mathrm{F}$ & $1250^{\circ} \mathrm{Fs}$ \\
\hline $10^{\circ}$ & $\begin{array}{l}3 \mathrm{TOA} \\
8 \mathrm{MOA}\end{array}$ & $\begin{array}{l}3 \text { TTOB } \\
8 \mathrm{MOB}\end{array}$ & $\begin{array}{l}3 \mathrm{TOC} \\
8 \mathrm{MOC}\end{array}$ & $\begin{array}{l}3 \text { TOD } \\
\text { 8MOD }\end{array}$ & $\begin{array}{l}3 \text { TOE } \\
8 M O E\end{array}$ \\
\hline $10^{1}$ & $\begin{array}{l}3 \mathrm{~T} 1 \mathrm{~A} \\
8 \mathrm{M} 1 \mathrm{~A}\end{array}$ & $\begin{array}{l}3 \mathrm{~T} 1 \mathrm{~B} \\
8 \mathrm{M} 1 \mathrm{~B}\end{array}$ & $\begin{array}{l}3 \mathrm{~T} 1 \mathrm{C} \\
8 \mathrm{M} 1 \mathrm{C}\end{array}$ & $\begin{array}{l}3 T 1 D \\
8 M 1 D\end{array}$ & $\begin{array}{l}3 \mathrm{~T} 1 \mathrm{E} \\
8 \mathrm{M} 1 \mathrm{E}\end{array}$ \\
\hline $10^{2}$ & $\begin{array}{l}3 T 2 A \\
8 M 2 A\end{array}$ & 3 Т $2 B$ & $3 \mathrm{~T} 2 \mathrm{C}$ & 3 T2D & $3 \mathrm{~T} 2 \mathrm{E}$ \\
\hline $10^{3}$ & $\begin{array}{l}3 \mathrm{~T} 3 \mathrm{~A} \\
8 \mathrm{MA}\end{array}$ & $\begin{array}{l}3 \mathrm{~T} 3 \mathrm{~B} \\
8 \mathrm{MB}\end{array}$ & $\begin{array}{l}3 \mathrm{~T} 3 \mathrm{C} \\
8 \mathrm{M} 3 \mathrm{C}\end{array}$ & $\begin{array}{l}3 T 3 D \\
8 M 3 D\end{array}$ & $\begin{array}{l}3 T 3 E \\
8 M 3 E\end{array}$ \\
\hline $10^{4}$ & $\begin{array}{l}3 T 4 A \\
8 M 4 A\end{array}$ & $\begin{array}{l}3 \mathrm{~T} 4 \mathrm{~B} \\
8 \mathrm{M} 4 \mathrm{~B}\end{array}$ & $\begin{array}{l}3 \mathrm{~T} 4 \mathrm{C} \\
8 \mathrm{M} 4 \mathrm{C}\end{array}$ & $\begin{array}{l}3 T 4 D \\
8 M 4 D\end{array}$ & $\begin{array}{l}3 \mathrm{~T} 4 \mathrm{E} \\
8 \mathrm{M} 4 \mathrm{ES}\end{array}$ \\
\hline
\end{tabular}

$a_{8}=$ material SA-508, class $2 ; \mathrm{M}=1 / 2 \mathrm{~T}$

section of material; $3=$ material. SA-533, grade $B$, class $1 ; \mathrm{T}=$ surface section of materlal.; $0-4=$ different time periods (i.e., $0=10^{0} \mathrm{~s}, 1=10^{1} \mathrm{~s}$, etc.); $A-E=$ different temperatures (i.e., $A=$ $550^{\circ} \mathrm{F}, \mathrm{B}=800^{\circ} \mathrm{F}$, etc.).

Table A.2. Thermal treatments and stresses employed in stress relief cracking test

\begin{tabular}{cc}
\hline Test & Stress \\
applied \\
(ksi)
\end{tabular}

\begin{tabular}{lll}
\hline 1 & Cycle II + PWHT & 17 \\
2 & Cycle II + PWHT & 22 \\
3 & Cycle II + PWHT & 25 \\
4 & Base metal PWHT & 25 \\
5 & Cycle II + Cycle II & 22 \\
& $\left(1650^{\circ} \mathrm{F}\right.$ peak temp $)$ PWHT & 25 \\
6 & Cycle II + hold at & \\
7 & $\left(600^{\circ} \mathrm{F}\right.$ for 2 h) + PWHT & 25 \\
7 & Cycle VI + PWHT & 25 \\
8 & Cycle VI + hold at & \\
& $\left(600^{\circ} \mathrm{F}\right.$ for 2 h) + PWHT \\
\hline
\end{tabular}

$a_{\text {All }}$ thermal cycles employed $2400^{\circ} \mathrm{F}$ peak temperatures unless otherwise mentioned. Cycles II and VI are simulated $50 \mathrm{~kJ} / \mathrm{in}$. and $136 \mathrm{~kJ} / \mathrm{in}$. ( $500^{\circ} \mathrm{F}$ preheat) heat input on 1-in.-thick steel plate, producing martensitic and bainitic structures. Temperature for PWHT for both materials is $1150^{\circ} \mathrm{F}$. 
Table A.3. Thermal treatments employed in Charpy V-notch testa

\begin{tabular}{|c|c|}
\hline Test & Thermal treatment ${ }^{b}$ \\
\hline 1 & Run Cycle II \\
\hline 2 & Run Cycle VI \\
\hline 3 & Run Cycle II + PWHT \\
\hline 4 & Run Cycle VI + PWHT \\
\hline 5 & Run Cycle II + Cycle II at peak temperature of $1650^{\circ} \mathrm{F}$ \\
\hline 6 & Run Cycle VI + Cycle VI at peak temperature of $1650^{\circ} \mathrm{F}$ \\
\hline 7 & Run Cycle II + Cycle II at peak temperature of $1650^{\circ} \mathrm{F}+$ PWHT \\
\hline 8 & Run Cycle VI + Cycle VI at peak temperature of $1650^{\circ} \mathrm{F}+1 \mathrm{NHT}$ \\
\hline 9 & Run Cycle II and hold at $600^{\circ} \mathrm{F}$ for $2 \mathrm{~h}$ \\
\hline 10 & Run Cycle VI and hold at $600^{\circ} \mathrm{F}$ for $2 \mathrm{~h}$ \\
\hline 11 & Run Cycle II and hold at $600^{\circ} \mathrm{F}$ for $2 \mathrm{~h}+\mathrm{PWHT}$ \\
\hline 12 & Run Cycle VI and hold at $600^{\circ} \mathrm{F}$ for $2 \mathrm{~h}+$ PWHT \\
\hline 13 & Run Cycle II and hold at $300^{\circ} \mathrm{F}$ for $2 \mathrm{~h}$ \\
\hline 14 & Run Cycle VI and hold at $300^{\circ} \mathrm{F}$ for $2 \mathrm{~h}$ \\
\hline 15 & Run Cycle II and hold at $300^{\circ} \mathrm{F}$ for $2 \mathrm{~h}+$ PWHT \\
\hline 16 & Run Cycle VI and hold at $300^{\circ} \mathrm{F}$ for $2 \mathrm{~h}+\mathrm{PWHT}$ \\
\hline
\end{tabular}

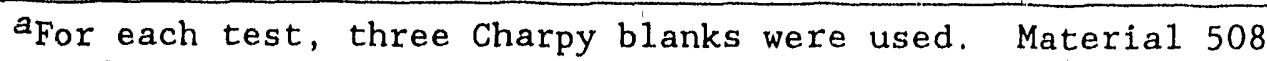
was PWHT for $24 \mathrm{~h}$ and 533 for $40 \mathrm{~h}$, both at $1150 \pm 50^{\circ} \mathrm{F}$.

$b_{\text {All }}$ thermal cycles were run with $2400^{\circ} \mathrm{F}$ peak temperature unless otherwise indicated. Cycle II and VI are simulated $50 \mathrm{~kJ} / \mathrm{in}$. and $136 \mathrm{~kJ} / \mathrm{in}$. ( $500^{\circ} \mathrm{F}$ preheat) heat input on 1 -in.-thick steel plate, producing martensitic and bainitic structures.

Table A.4. Energy inputs as a function of plate thickness for SMAW process

\begin{tabular}{|c|c|c|c|c|c|}
\hline \multirow{2}{*}{$\begin{array}{l}\text { Plate } \\
\text { thickness } \\
\text { (in.) }\end{array}$} & \multicolumn{5}{|c|}{$\begin{array}{l}\text { Energy inputs (kJ/in.), preheat }\left({ }^{\circ} \mathrm{F}\right) \text { for } \\
\quad \text { each cooling rate in }{ }^{\circ} \mathrm{F} / \mathrm{s} \text { at } 1300^{\circ} \mathrm{F}\end{array}$} \\
\hline & 84 & 35 & 23 & 14 & 8 \\
\hline 1 & 50,84 & 100,72 & 136,72 & 136,300 & 136,500 \\
\hline 2 & 54,72 & 130,72 & 175,72 & 190,300 & 200,500 \\
\hline 3 & 54,72 & 130,72 & 175,72 & 190,300 & 220,500 \\
\hline 4 & 54,72 & 130,72 & 175,72 & 190,300 & 220,500 \\
\hline
\end{tabular}


Table A.5. Data obtained by stress-relief cracking test

\begin{tabular}{|c|c|c|c|c|c|c|}
\hline \multirow[b]{2}{*}{ Test } & \multirow[b]{2}{*}{ Thermal treatment ${ }^{a}$} & \multirow{2}{*}{$\begin{array}{l}\text { Applied } \\
\text { stress } \\
\text { (ksi) }\end{array}$} & \multicolumn{2}{|c|}{$\begin{array}{c}\mathrm{SA}-533, \text { grade } \mathrm{B} \\
\text { class } 1\end{array}$} & \multicolumn{2}{|c|}{ SA-508, class 2} \\
\hline & & & $\begin{array}{l}\text { Time to } \\
\text { fallure } \\
\text { (min) }\end{array}$ & $\begin{array}{l}\text { Reduction } \\
\text { of area } \\
(z)\end{array}$ & $\begin{array}{l}\text { Time to } \\
\text { failure } \\
\text { (min) }\end{array}$ & $\begin{array}{l}\text { Reduction } \\
\text { of area } \\
(z)\end{array}$ \\
\hline 1 & Cycle II + PWHT & $1 \%$ & 36 & 9.8 & $>120^{b}$ & \\
\hline 2 & Cycle II + PWHT & 22 & 5 & 5.4 & 104 & 4.6 \\
\hline 3 & Cycle II + PWHT & 25 & 3 & 9.2 & 22 & 1.1 \\
\hline 4 & Base metal PWHT & 25 & 4 & 75.6 & 17 & 64.0 \\
\hline 5 & $\begin{array}{l}\text { Cycle II + Cycle II } \\
\left(1650^{\circ} \mathrm{F} \text { peak tem- }\right. \\
\text { perature })+ \text { PWHT }\end{array}$ & 22 & $>120^{b}$ & & & \\
\hline 6 & $\begin{array}{c}\text { Cycle II }+2-\mathrm{h} \text { hold } \\
\text { at } 600^{\circ} \mathrm{F}+\mathrm{PWHT}\end{array}$ & 25 & 8 & 6.8 & 61 & 1.6 \\
\hline 7 & Cycle VI + PWHT & 25 & 37 & 4.5 & 69 & 4.0 \\
\hline 8 & $\begin{array}{c}\text { Cycle VI }+2-\mathrm{h} \text { hold } \\
\text { at } 600^{\circ} \mathrm{F}+\mathrm{PWHT}\end{array}$ & 25 & $>120^{b}$ & & $>120^{b}$ & \\
\hline
\end{tabular}

${ }^{a}$ All thermal cycles employed $2400^{\circ} \mathrm{F}$ peak temperature unless indicated otherwise. Cycles II and VI produce martensitic and bainitic structures. PWHT was done at $1150^{\circ} \mathrm{F}$.

$b_{\text {No }}$ failure.

Table A.6. Charpy test data for SA-533 steel

tested at $-25^{\circ} \mathrm{F}$

\begin{tabular}{ccccr}
\hline Test & $\begin{array}{c}\text { Energy } \\
(\mathrm{ft}-\mathrm{lb})\end{array}$ & $\begin{array}{c}\text { Hardness } \\
(\mathrm{HRC})\end{array}$ & $\begin{array}{c}\text { Lateral expansion } \\
(\mathrm{mils})\end{array}$ & $\begin{array}{c}\text { Shear } \\
(8)\end{array}$ \\
\hline 1 & 19 & 42 & 2 & 30 \\
2 & 8 & 21 & 3 & 0 \\
3 & 140 & 1 & 55 & 100 \\
4 & 22 & $<1$ & 13 & 0 \\
5 & 21 & 42 & 2 & 30 \\
6 & 5 & 21 & 1 & 0 \\
7 & 144 & 3.3 & 62 & 100 \\
8 & 17 & $<1$ & 8 & 30 \\
9 & 6 & 39 & 1 & 0 \\
10 & 13 & 19 & 5 & 0 \\
11 & 139 & 6 & 67 & 100 \\
12 & 67 & 5 & 44 & 30 \\
13 & 17 & 42 & 1 & 0 \\
14 & 9 & 21 & 3 & 100 \\
15 & 136 & 6 & 29 & 10 \\
16 & 47 & 10 & 41 & 60 \\
Base & 60 & 10 & & \\
metal & & & & \\
\hline
\end{tabular}


Table A.7. Charpy test data for SA-508 steel tested at $72^{\circ} \mathrm{F}$

\begin{tabular}{ccccr}
\hline Test & $\begin{array}{c}\text { Energy } \\
(\mathrm{ft}-1 \mathrm{~b})\end{array}$ & $\begin{array}{c}\text { Hardness } \\
(\text { HRC })\end{array}$ & $\begin{array}{c}\text { Lateral expansion } \\
\text { (mils) }\end{array}$ & $\begin{array}{c}\text { Shear } \\
(\mathrm{z})\end{array}$ \\
\hline 1 & 37 & 46 & 5 & 40 \\
2 & 8 & 28 & 4 & 0 \\
3 & 47 & 28 & 24 & 50 \\
4 & 16 & 18 & 8 & 0 \\
5 & 45 & 48 & 4 & 40 \\
6 & 12 & 26 & 6 & 5 \\
7 & 58 & 20 & 31 & 100 \\
8 & 34 & 13 & 23 & 30 \\
9 & 12 & 38 & 2 & 5 \\
10 & 15 & 26 & 8 & 5 \\
11 & 67 & 12 & 39 & 100 \\
12 & 26 & 9 & 17 & 15 \\
13 & 36 & 46 & 6 & 30 \\
14 & 10 & 28 & 44 & 100 \\
15 & 72 & 12 & 20 & 15 \\
16 & 34 & 11 & 47 & 60 \\
Base & 70 & 12 & & \\
metal & & & & \\
\hline
\end{tabular}


Appendix B

COMPARISON OF LATERAL EXPANSIONS

IN CHARPY TESTS 


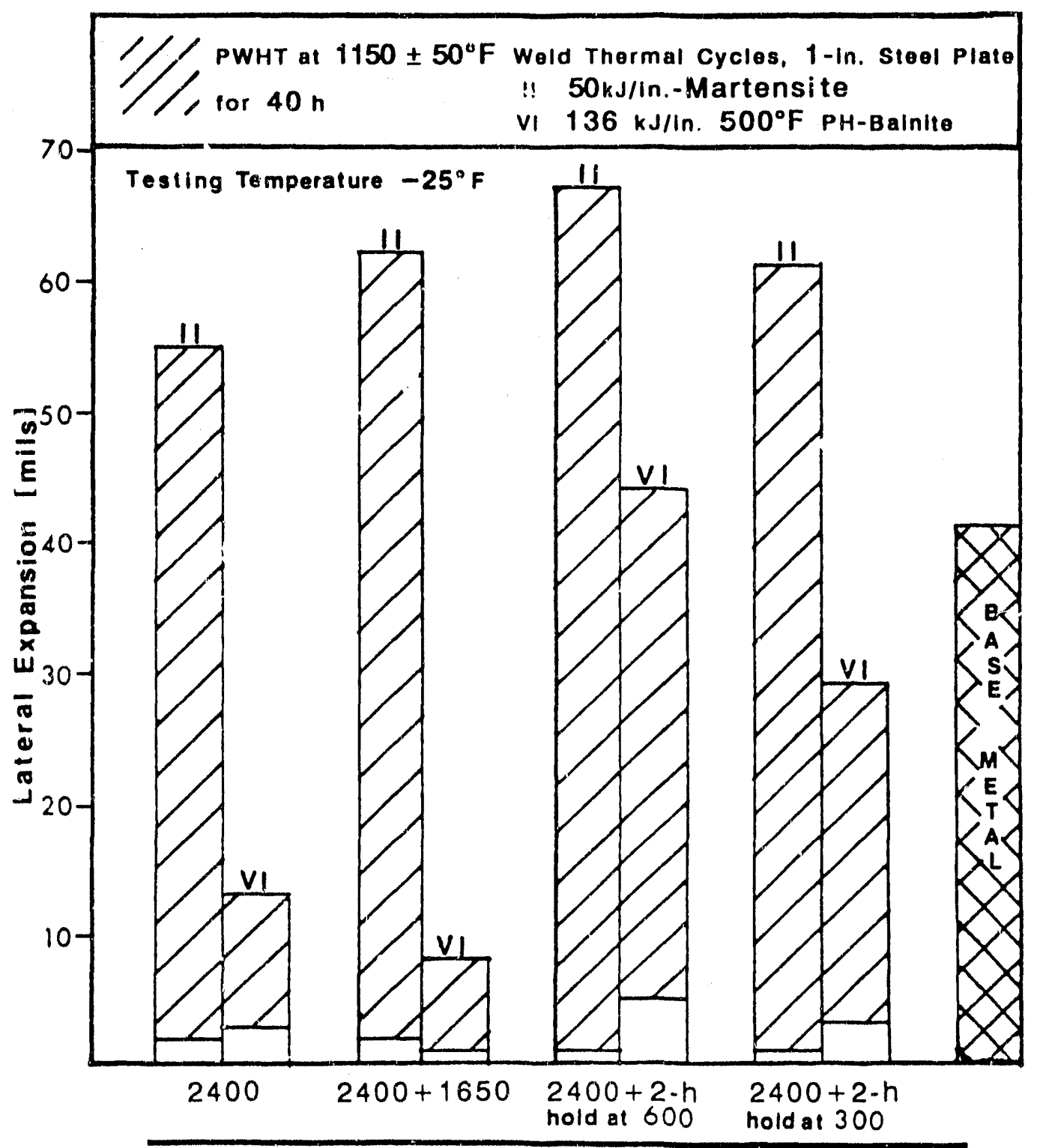

Weld Thermal Cycles with Peak and Hold Temperatures ( $\left.{ }^{\circ} \mathrm{F}\right)$

Fig. B.1. Lateral expansion values for Charpy specimens of SA-533, grade B, class 1 , exposed to different heat-affected zone thermal cycles. Source: Univirsity of Tennessee. 


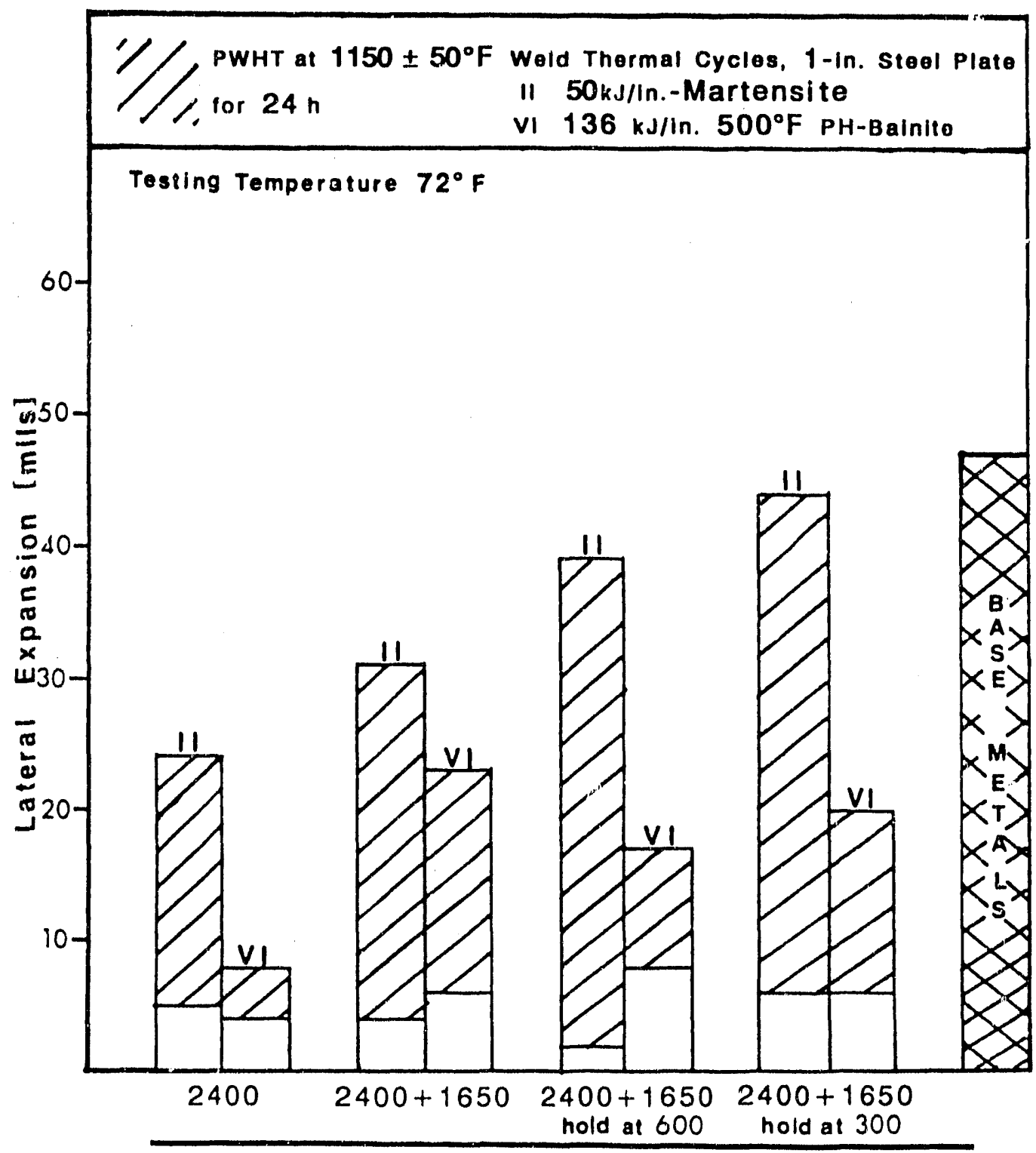

Weld Thermal Cycles with Peak and Hold Temperatures ( $\left.{ }^{\circ} \mathrm{F}\right)$

Fig. B.2, Lateral expansion values for iharpy specimens of SA-508, class 2, exposed to different heat-affected zone thermal cycles. Source: University of Tennessee. 
Appendix C

SI EQUIVAI,ENTS OF UNITS USED IN THIS REPORT 
Property

Dimension

Temperature

Stress

Energy Input

Stress

Toughness
Unit

in.

${ }^{\circ} \mathrm{F}$

ksi

$\mathrm{kJ} / \mathrm{in}$

psi.

$1 b$
SI equivalent

$25.4 \mathrm{~mm}$

${ }^{\circ} \mathrm{C}=(5 / 9)\left({ }^{\circ} \mathrm{F}-32\right)$

$6.89 \mathrm{MPa}$

$0.039 \mathrm{~kJ} / \mathrm{mm}$

$6.89 \times 10^{3} \mathrm{MPa}$

$1.4 \mathrm{~J}$ 

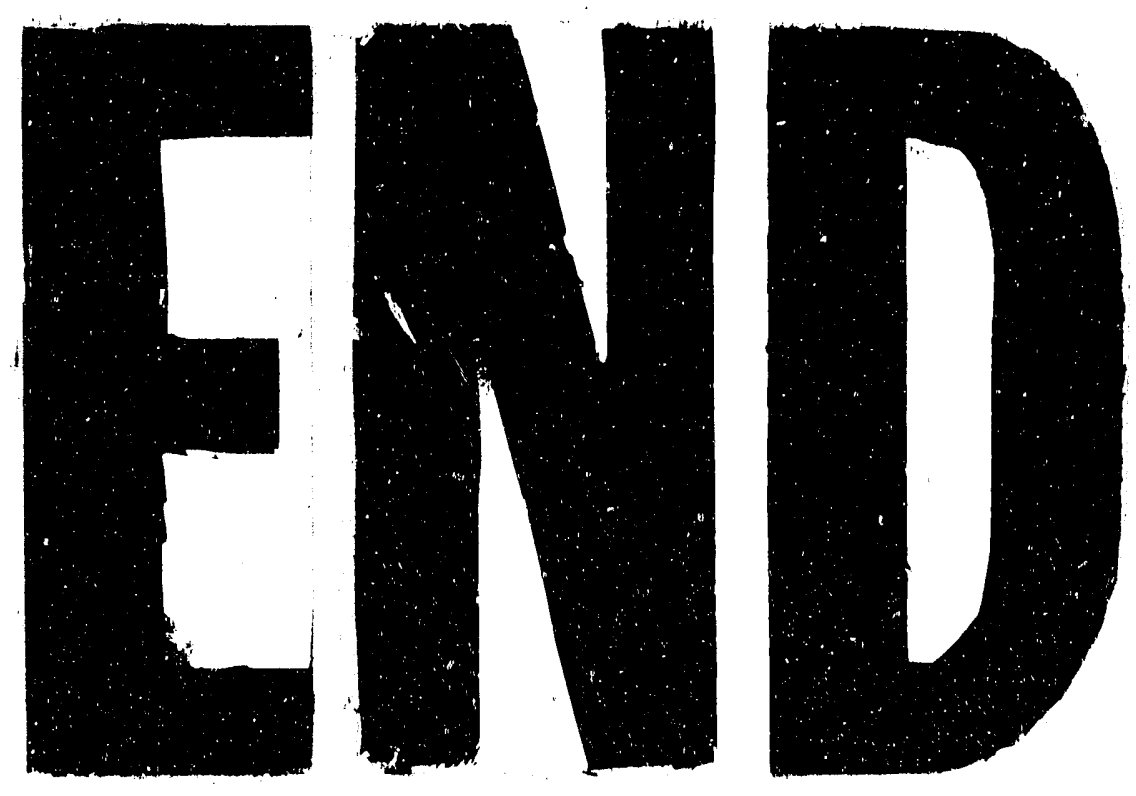

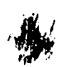
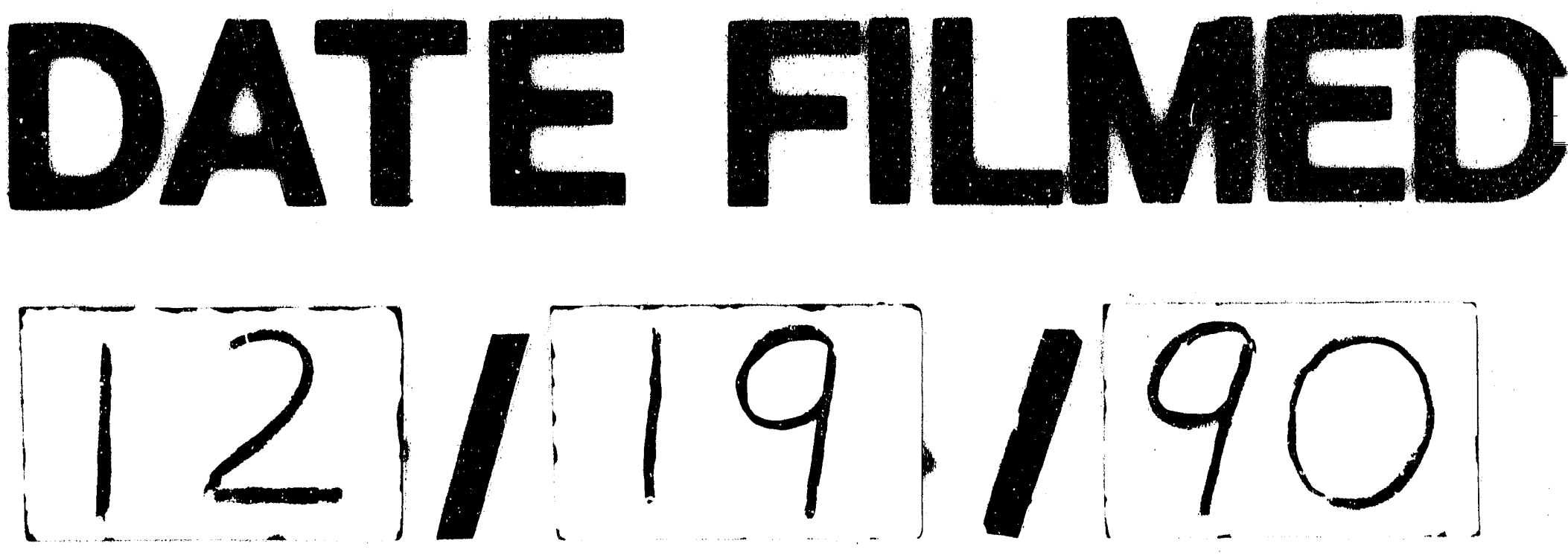
